

\section{To the Student}

Knowledge, like anything else, is valuable or valueless just in proportion as it is userul or useless. The main thing for you, as a student, to decide is what kind of knowledgo you need the mist. Then sturly to get that kind.

There are two ways in which knowledye may be of use to you: First, as a souree of pleasurable exercise of faculty; and spcond, as a tool of trade to attain success in life.

Language is man's most useful instrument, and skill in its use brings both the greatest pleasure and the greatest success.

Literature is merely good talk written out. The book which can teach you the most about the things that you need most to know is the book which you need most to read and to study.

This is exactly such a book-"The Science of Poetry and the Philosophy of Language." No other book contains sn much that is new and useful upon the subjects with which it deals, as does "The science of Poetry and the Philosophy of Language."

If you want to know how to write well, read well, speak well-if you want to know how to be a logical, convincing, powertul speaker, you can learn how in this book, and can also learn the why, so that you will understand the how.

If you want to know how to write poetry, this book will teach you, and it is the only book in the world that can teach you. Furthermore, it is the only book in the world that pretends either to tell you what poetry is, or to teach you how to write it. If you have a creative imagination, you can, by stuaiying this book, write good poetry, just as you can do anything else with the necessary creative imaginatiou and information; but without the necessary creative imagination, you can neither write poetry nor learn to write it, any more than you can do any other creative act.

After you have read this book and have found out that it is the most interesting and the most useful of all the hooks you have ever read, then remember that there are others who would, if they only knew about it, be as glad to get it as you bave been, and who would be benefited by it as you have been benefited. You can easily judge how much a good word about this book may benefit a friend, by asking your. self what you would take in money to sell out what you have learned from it.

Therefore, spread the glad tidings. Tell your friends about this book. You wil! do them a great kindness and one which will be appreciated.

This is the first really scientific treatise that has ever veen written upon the subjects with which it deals. This is the first work to show that the function of language is twofold-to express thought and to impress thought, and to stimulate and qualify the mind of the hearer for perception.

it is the first treatise that has ever explained the specific functions in language of the four properties of sound-loudness, duration, pitch and tone color. It is the first work to show that the forty so-called elementary sounds of our language are different tone color blends-that the difference between "a" and "o," for example, is merely in tone color blending; also, that non-em!otional tone blends are used to stimulate thought and to energize the hearer; and tlat we manifest our emotions and induce similar emotions in others by super-imposing emotional tone blends upon the arbitrary symbolic blends of meaning.

This book is the first to show that it was analogical speech and not mere articulate speech that intellectually differentiated man from brute.

This book is the first to show what poetry really is-that it is the expression of insensuous thought in sensuous terms by artistic trope, and that mere versification without artistic figure does not constitute poetry.

In this book you will find the principles of versification for the first time scientiflcally elucidated. You will also find a new discovery in verse construction, namely, that iambic, narrative verse, not intended for song, may ofter better be written with a continuous primary rhythm throughout, and without pentametric or other line rhythm. You will find this form of verse construction exemplified.

You wi!l also find the principles of oratory for the first time scientifically elucidated.

The book has introduced seven new words into the language, three of which are

in the New Standard Dictionary.

Lastly, this book is the first to supply a scientific standard of judgment for the estimation of literary productions.

The book will be sent to any one, postage paid, on receipt by the publiskers of \$2.50. Address Funk and Wagnalls Company, 354 Fourth Aienue, New York. 


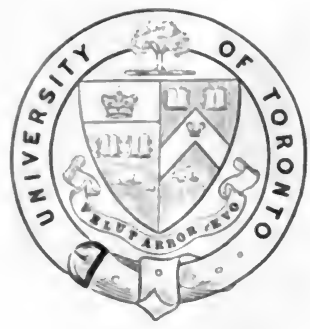

The 3. $\mathbb{c}$. Wanl collection of

irineteentb Century Englisb Titerature

Trurcbased in part througb a contribution to the Library ffunos made by the Department of Englisb in Uninersity College. 
Digitized by the Internet Archive in 2007 with funding from Microsoft Corporation 

$\hat{f}$

.

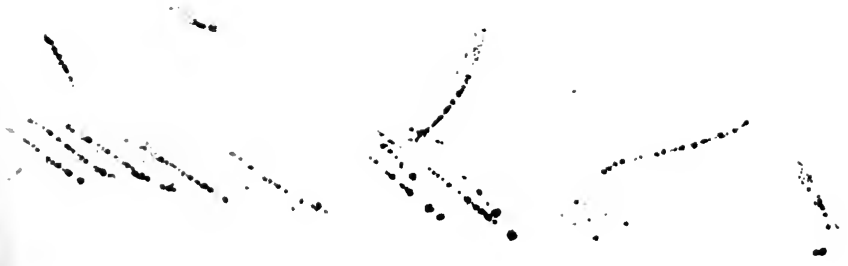

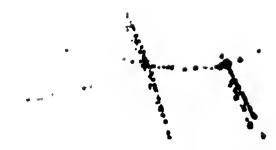

$\ddots$
$\ddots$

;

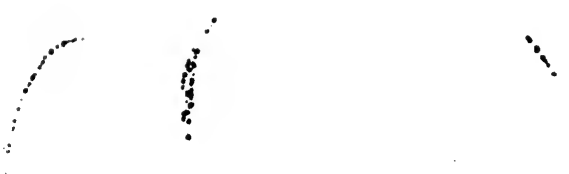




\section{THE SCIENCE OF POETRY}

AND

THE PHILOSOPHY OF LANGUAGE 


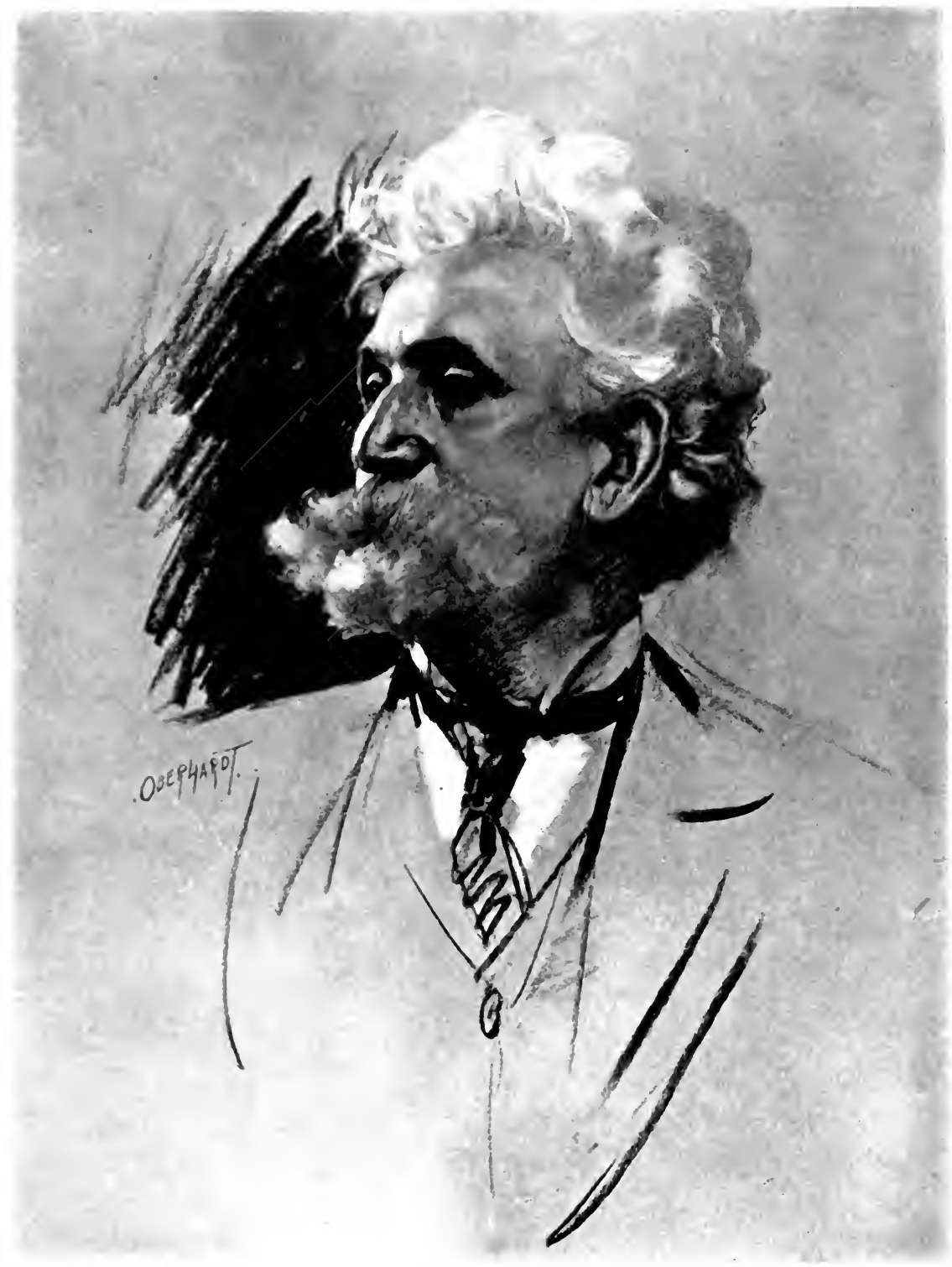

\section{Mclusicinelyfuation} of imerisaowe thought mi finilsonflegton 


\title{
The Science of Poetry
}

and

\section{The Philosophy of Language}

\author{
By HUDSON MAXIM
}

ILLUSTRATIONS BY

WILLIAM OBERHARDT
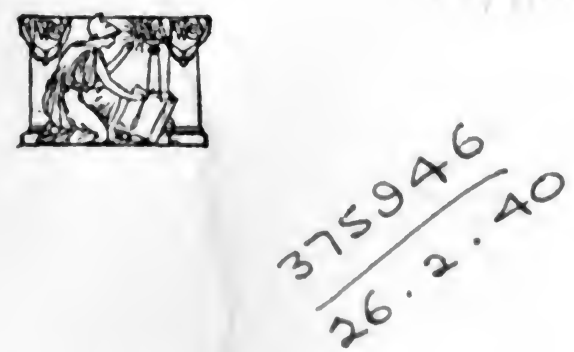

FUNK \& WAGNALLS COMPANY

NEW YORK AND LONDON

1910 


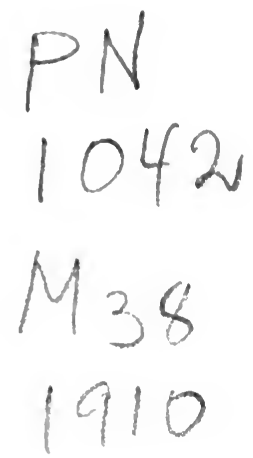

Copyright 1910

BY

FUNK \& WAGNALLS COMPANY

[Printed in the United States of America]

Published August, 1910

All Rights Reserved 


\section{CONTENTS}

PAGR

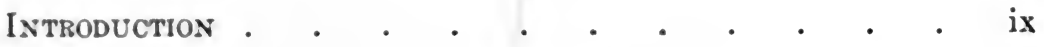

CHAPTER I

Foundation Principles . . . . . . . . . . . 1

\section{CHAPTER II}

The Evolution of Axalogical Speech-The Crossing of the Rubicon of Trope Separating MaN from the Brute

CHAP'TER III

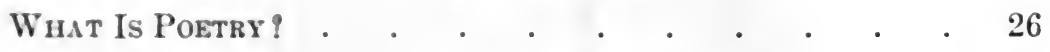

\section{CHAP'TER IV}

What Poftry Is Not . . . . . . . . . 45

\section{CHAPTER V}

Potentry . . . . . . . . . . . 75

\section{CHAPTER VI}

Application of the Fundamenta, Principles of Composition AND Rhetoric-Potentry, Tropetry, Literitry, Tro-POTENTRY, TEM-POTENTRY, AND Tro-TEM-POTENTRY . 93

CHAP'TER VII

The DYNamics of Human Speech . . . . . . 111

\section{CHAP'TER VIII}

The Puhosophy of Englan Verse ('Tem-Potentry) . . 133 


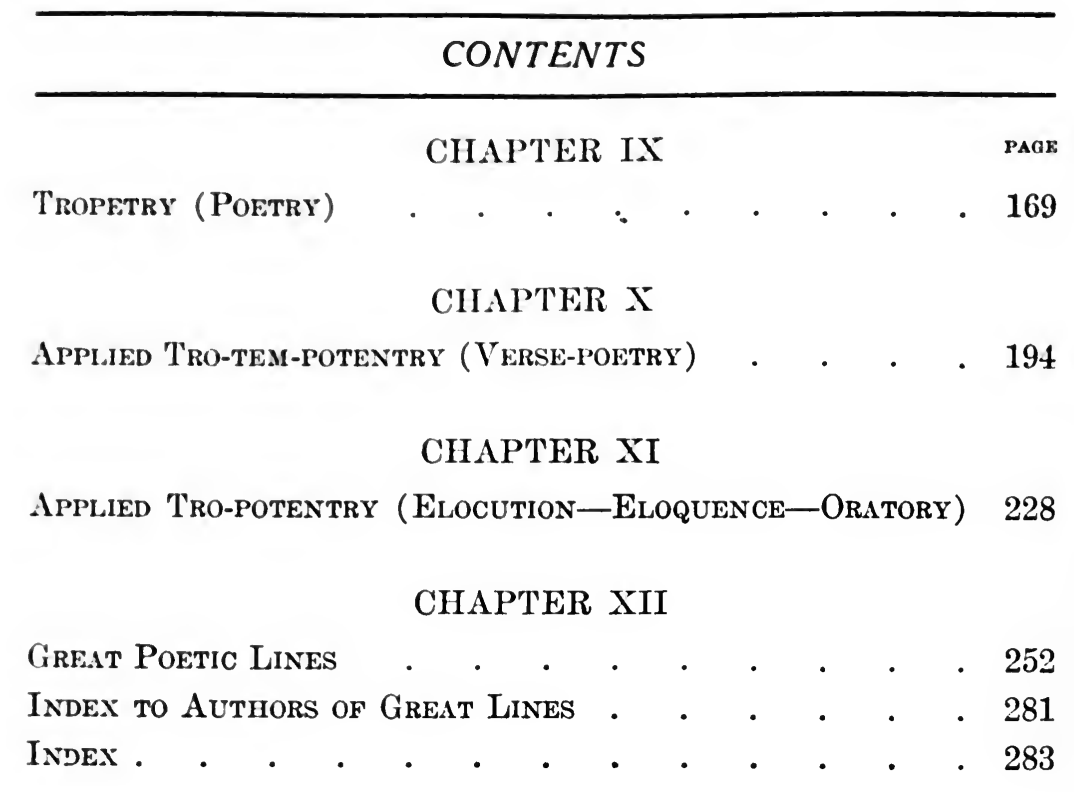




\section{LIST OF ILLUSTRATIONS}

EACING

PAGE

Hudson Maxim . . . . . . . . Frontispiece

Brenking Pegasus . . . . . . . . . . . 26

Pegasus Broken . . . . . . . . . . . . 44

Sin Frincisco Doomed . . . . . . . . . . 56

San Francisco FalleN . . . . . . . . . . 72

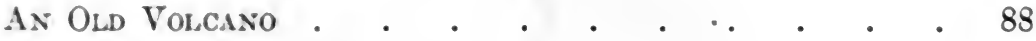

The Flight of Satan . . . . . . . . . . . 104

A Veiled Illusion . . . . . . . . . . . . . 120

The Dance of Shadows . . . . . . . . . . 136

$\left.\begin{array}{l}\text { Some SHadows of Toll } \\ \text { Some SHudows of Toll }\end{array}\right\} \quad$. . Between pages 148 and 149

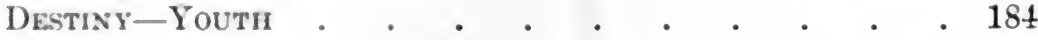

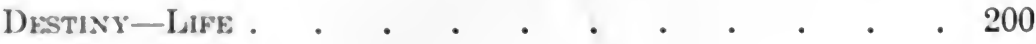

DESTINY-Drath . . . . . . . . . . 208

D.IRKFST BEFOR: DAWN . . . . . . . . . 216

L'APACHE . . . • • • • • • • . . 227 



\section{NTRODUCTION}

TнE main object of this book is to provide a practical 1 method for literary criticism and analysis, and a standard of uniform judgment for determining the relative merits of literary productions, and further, to supply a more practical and efficient means than we have had heretofore for the standardization of poetry, whereby any poem may be assayed and the amount of its poetic gold determined and separated from the slag and dross.

Whatever the subject of any investigation may be, whether poetry, biology, ethics or torpedo warfare, the same scientific method of procedure must be followed. We must first unravel the complex and heterogeneous back to first principles, and then reason forward from the simple to the complex, from the homogeneous to the heterogeneous, from what we know to what we would learn. Such are the methods pursued by all successful inventors, scientific investigators and discoverers.

Poetry must necessarily be a natural phenomenon, for there can be no such things as supernatural phenomena. Like all effects, poetry must be a natural effect, subject to laws which may be investigated and formulated.

Any true Sherlock Holmes of science, possest of an adequate knowledge of first principles, may unravel a very tangled web of mystery. The great naturalist requires but a few pieces of bone from any prehistoric monster in order to ascertain whether it was herbivorous or carnivorous, reptile or mammal, or even to construct a counterpart of its entire skeleton.

Nothing of human production can be beyond human investigation; and, despite the assumptions and declarations of those sentimentalists who hold the principle of 
poetry to be something transcendental, inscrutable and incomprehensible, it requires only simple scientific method for its elucidation.

Most professional litterateurs and critics make reverential apologies when they approach the subject of poetry, as tho the temple of the Muses were so sacred a place as to make it a profanation to enter there in search of truth. Others, like John Bunyan's Apollyon, "straddle" themselves "over the whole breadth of the way," and say to the truth-searehing pilgrim, "thou shalt go no farther."

The more I have studied, the stronger has grown my conviction that no other subject of equal interest and importance to mankind has been so neglected by science, so abandoned to the chaos of misunderstanding. There is, indeed, no general agreement as to what constitutes poetry. There are as many opinions as there are critics. Often the worst poetry is pronouneed the best, and often the best the worst, by some who are considered leading authorities.

Naturally, there is always a great diversity of opinion about a popular subject when it is not well understood. We all know how true this is of social, ethical and religious subjects, upon which no two persons ever really agree. The exact sciences, however, admit of no differences of opinion. We know that the whole is greater than any of its parts. We know that a straight line is the shortest path between two points. We know that ten times a number is more than twice the number. These truths are selfevident. Truth self-evident to one mind may not, however, be self-evident to another mind. The greater the mind, the greater are the truths self-evident to it, and the greater also is its power to induce complex from simple truths-complex truths of which we may be as certain as we are of the primary self-evident truths themselves. It is evident to every one that the whole is greater than any of its parts. But every one is not capable of perceiving with equal certainty that chaos and disorder, 
except in the eyes of our confusion, are in all nature impossible; that order is universal; that everything is controlled by immutable mathematical laws, from which there is, and can be, no deviation whatsoever. We learn the complex from the simple. We arrive at the abstract by way of the concrete. During the last hundred years, problem after problem hitherto believed to be inscrutable has been solved by science, and man is constantly pushing the frontiers of knowledge farther and farther into the realri of what has been deemed the unknowable.

We are certain that a straight line is the shortest path between two points. We are equally certain that two added to two makes four, because we can see this simple truth in all its relations by a single view. But it is not equally easy to see at a glance that two multiplied by two, plus eight multiplied by eight divided by two, equals thirty-six $(2 \times 2+8 \times 8 \div 2=36)$. Yet the perfect certainty of every step makes us as sure of the final result as we are certain of the fact that two and two make four.

Similarly, we may proceed with the less exact sciences, feeling sure of our conclusions as long as we are sure of our premises. In other words, we may, if we proceed with due caution, be practically as certain of the truth of our conclusions as of the premises from which they are deduced. It is indispensable, therefore, that we should be reasonably sure of our premises. We must be able to perceive the difference between fact and fancy, knowledge and belief.

It is my conviction that we are in possession of suffcient incontrovertible facts to unravel the Gordianknotted tangle of poesy and discover the elemental constants. Possest of these, we may judge poetry by scientific method and so render extravagant differences of opinion impossible. We shall then be able to dispel the fog of befuddling, mystifying definitions through which every student attempting the study of poetry is obliged to steer. 
'T'o many persons it will appear an audacity to crossquestion the Muses, a sacrilege to enter the temple of their worship with the lamp of science. Galileo startled the orthodoxy of his age, religious and scientific alike, by his declaration that the earth revolves around the sun. Darwin shocked the world with his announcement that man and monkey are descendants of a common ancestoran arboreal creature with tail and pointed ears. The thought of such lowly origin was most repugnant to many, who had been taught to believe in man's divine origin; but Darwin's evidence staggered the world, made it pause and investigate. Investigation was followed by conviction.

It is a trait of human nature that in our thinking and in our judgments we, like other natural agencies, follow the law of inertia. There are few indeed whose intellectual faculties are so strong as to compel them to recognize and stand for the right even at the cost of going counter to, rather than in accordance with, the general consensus of opinion. Hence, few persons form their own conclusions on subjects requiring much thought; it is easier and pleasanter for them to let others do the pioneer thinking. They ascertain what those authorities think who are supposed to know, and with whom it will be the most creditable to agree, and then think their way.

Every one's experience affords many illustrations of this human weakness that makes the voice of the gods the voice of the people. For nearly two thousand years the Christian world was controlled chiefly by faith, fear and fire. Until quite recently, few have dared to use their reason. Not many, even now, give reason full rein. The monument erected to genius in the not remote past has frequently been one of fagots. The subversion of the fittest, through clerical selection and educational bias during the dark ages, has ensmalled modern thought. Born leaders, men guided by their own understanding, are few. The majority are born to follow. They move on the 
lines of least resistance, and these lines do not always lie through the understanding.

There is an intermediate class of men who, not having the ability to lead, and lacking either the faith or the courage to follow, hang on to the coat-tails of progress and cry out "Whoa!" under the delusion that they are meritorious conservatives.

The ability to perceive, appreciate and judge, without bias, true distinctions of merit, is one of the rarest of intellectual endowments. 


\section{CHAPTER I}

\section{FOUNDATION PRINCIPLES}

$A^{\mathrm{T}}$ the outset, I shall, for expediency, state certain A truths, many of which may not at first be evident to all, neither will their relevancy to poetry and the principles of expression be always apparent in advance of the reasons and demonstrations that follow. To many persons, however, these truths will, $\grave{a}$ priori, be obvious. Others will see their force and accept them on reading the rest of the book, while there will doubtless be still others lacking the mental grasp to understand them at all. These will either accept of reject them on the authority of those in whom they have confidence, and who do their pioneer thinking for them.

A living being is a body of matter organized to utilize the forces and properties of surrounding matter for its functions of life and reproduction.

Life is the functional response of an organized body to the forces of surrounding matter, termed the environment.

All environing forces to which a living body is adapted to react or to give functional response are stimuli to functional response. All sensations are functional responses to environing forces. More specifically stated, all forces of the environment to which an organized body is adapted to respond are stimuli of sense. All things that we see, feel, hear, smell or taste, are stimuli of those nerves constituting the faculties of sense.

All nerve stimuli are in constant competition with one another in their appeal to the consciousness. The successful appeal results in perception.

All senses of living bodies, whether of touch, smell, taste, sight or hearing, are modifications and specializations of the sense of touch.

Consciousness is the sense of awareness of all the other senses. It is the sensorium of the senses. 
All five of our branches of sense are auxiliary to the general sense of consciousness. These branches, known as the five senses, are feelers by which the consciousness becomes acquainted with the external world. We have, therefore, but a single sense, that of feeling, whose center is the consciousness; and consciousness itself is but the introspective sense of the general sense of feeling-the sense through which we know all the other senses. It is the introspective eye of the mind.

The consciousness can receive only what comes to it by way of the five senses-through its five feelers. All impressions, all ideas, all knowledge-all conceptions of every name and nature-are resolvable into elements of acquaintance with the environment of the individual. Memory is only a record of impressions from experience.

This view as to the external origin of mental impressions is in accord with the views of the leading psychologists. The following two paragraphs are quoted from Prof. William James' "Psychology," Vol. II, Chap. XVIII:

"Sensations, once experienced, modify the nervous organism, so that copies of them arise again in the mind after the original outward stimulus is gone. No mental copy, however, can arise in the mind of any kind of sensation which has never been directly excited from without.

"The blind may dream of sights, the deaf of sounds, for years after they have lost their vision or hearing; but the man BORN deaf can never be made to imagine what sound is like, nor can the man BORN blind ever have a mental vision. In Locke's words, already quoted, 'the mind can frame unto itself no one new simple idea. The originals of them all must have been given from without. Fantasy, or Imagination, are the names given to the faculty of reproducing copies of originals once felt. The imagination is called 'reproductive' when the copies are literal; 'productive' when elements from different originals are recombined so as to make new wholes." 
All mental, as well as physical, processes are physiological processes, the brain being the organ of the mind.

All normal physiological processes are pleasure-giving. This makes the sense of life an enjoyable one, and makes living things tend to live instead of tending to die, and wish to live instead of wishing to die. It puts a premium on life, growth and well-being through exercise of faculty.

Pleasure, happiness, the delights of love and all the felicities of complete living depend upon the normal exercise of faculty. Formative exercise of faculty alone is the source of all human enjoyment.

All pain is consciousness of impeded function-consciousness of discord between the individual and the environment. Pleasure and happiness are Nature's bounty to the individual-Nature's reward for services; and pain is Nature's demand for debt.

\section{SOUND}

All sounds are nerve stimuli and are, consequently, emotional stimuli. All vocal sounds, then, used as signs of ideas in all languages, are nerve stimuli, and emotional stimuli, independently of the thought exprest.

Sound, such as concerns us here, is the sensation produced through the organs of hearing by alternate waves of condensation and rarefaction passing through the elastic atmosphere.

A musical sound is produced by sonorous shocks following one another at regular intervals with a sufficient rapidity of succession.

Noise is produced by an irregular succession of sonorous shocks.

The sounds of the speaking voice used as signs of ideas, and all sets of relations between sounds used to express thought, serve the double purpose of symbolizing thought and stimulating its perception. 
THE FOUR PROPERTIES OF SOUND

There are four, and only four, properties of sound available in speech. They are loudness, duration, pitch and tone-color, or timbre. Loudness and duration are quantitative properties, while pitch and tone-color are qualitative properties.

All oratorical and elocutionary powers of the voice in giving and varying force of expression depend upon the utterance of the oral sounds with respect to loudness, duration, pitch and the timbre or quality, suited to induce moods in the mind of the hearer in harmony with the thoughts exprest.

Different phases of the emotions are exprest by different properties of the oral sounds uttered, and each of the four sound properties represents a corresponding phase of the emotions and is incapable of representing any other phase.

\section{LOUDNESS - FIRST PROPERTY OF SOUND}

The loudness, usually improperly called stress, tells the force of the disturbing or stimulating cause that leads to the utterance, and as the importance of the utterance in the mind of the speaker is proportionate to the forcefulness of the cause, loudness of utterance indicates the importance of what is said, and gives emphasis to utterance.

Loudness of utterance indicates that a large quantity of sound is being emitted within a given time; and, naturally, the total quantity produced depends upon two things: the volume of the sound stream and the time during which it is produced; and as a correspondingly greater energy is required to produce a large than a small quantity, great loudness indicates that great energy is aroused. Loudness relates to sound quantity just as amperage in electricity relates to electrical quantity; hence, to emotional quantity rather than to emotional stress. 


\section{DURATION - SECOND PROPERTY OF SOUND}

Duration, the other quantitative property of sound, depending upon the endurance of the disturbing or stimulating force and on the endurance of the vital energies of the speaker, indicates importance from the aspect of endurance, and indirectly signifies importance by standing as a measure of importance.

Duration is the time during which a sound is being produced, and as the energy consumed in producing the sound is for a given loudness exactly proportionate to the duration, duration is naturally associated with, and suggests, endurance of the energy producing the sound.

Now, as larger and more powerful animals are able to produce louder sounds and for a longer period, and as animals of whatever strength or endurance, when uttering a sound for a purpose, naturally tend to give it such loudness and duration as the importance of the occasion demands, we have come to associate loudness and duration with the vital energy of the speaker and with the importance of what he utters.

\section{PITCH-THIRD PROPERTY OF SOUND}

The pitch at which a word is uttered indicates the stress of the emotions, because it indicates the muscular tension set up by the nerve stimulus.

We associate the baser sounds with largeness and power. Most massive objects when struck produce sounds low in pitch; and light and fragile objects sounds high in pitch. The reason for this is that massive objects do not vibrate so rapidly as small and fragile objects, and consequently a correspondingly greater energy is required to set a massive body vibrating than for a small body. Hence, we have come to associate strength and largeness with sounds low in pitch, and to associate weakness and lightness with sounds high in pitch. 
The powerful command and warn, while the weak must ask and plead. The higher pitch of interrogation was born of this. All supplications, therefore, whether of men or of animals-the whine of child or dog, the plaintive appeals of song-are pitched above the middle register; while declarative, assertive and warning ideas are usually imparted by the use of sounds below the middle register, or if higher in pitch, with correspondingly greater loudness.

When, however, there is no warning or command, and no plaint or interrogation contained in the utterance, as when the numerals are repeated from one to a hundred, the utterance is in the middle register, and is neither high nor low in pitch.

\section{TONE-COLOR-FOURTH PROPERTY OF SOUND}

Tone, known also as timbre and tone-color, indicates the character of the instrument producing the sound; and as instruments change with conditions, it also indicates the condition of the instrument producing the sound, and hence the character and condition of the vocal organs, the speaking instruments of the human voice.

Most of the colors that we see around us are composite. For example, violet is a mixture of blue and red. Similarly, the utterances of the speaking voice are mixtures of different sounds. Because of this analogy between sound and color, we speak of the emotional quality in sound as tone-color.

We know sound to be a wave motion. When a body is struck, its vibration sets up a series of waves of alternate compression and rarefaction in the air, which move outward from it in all directions in a constantly enlarging sphere. With every such wave there always go large numbers of small waves riding on the larger wave; and these impinge upon the ear, along with the larger wave. 
The larger wave is called the fundamental tone or note, and the smaller waves give it tone-color.

The schoolboy knows in a general way that all sounds are produced by the vibrations of bodies which, when struck or otherwise agitated, transmit their tremblings to the surrounding air by setting up in it alternate waves of compression and rarefaction. Yet few persons are familiar with the full particulars of the problem.

For the sake of illustration, let us take the string of a musical instrument. If the string be plucked to one side and released, it is set in vibration with a loudness proportionate to the force exerted in plucking it and the distance to which it is pulled. In other words, the loudness is proportionate to the length of the string's vibrations. The longer vibrations compress more air into each sound-wave, making bigger waves, so that the loudness is proportionate to the quantity of air set going in each wave, while this quantity is itself proportionate to the amount of energy expended on setting the vibrating body in motion. Necessarily, then, the different degrees of loudness indicate corresponding increments of energy expended upon the body producing the sound.

If we now tighten our string and pluck it again with the same force as before, it will vibrate with greater rapidity, producing a sound of a higher pitch. Pitch, therefore, indicates the rapidity with which the vibrations succeed one another, and as the vibrations are the more rapid the more tightly drawn or tense the vibrating body, and as nerve stimuli are muscular stimuli increasing muscular tension, which tension is manifested in the voices of both men and animals, we have come to associate elevation of pitch with increase of nerve and muscular tension. Hence the degree of intensity of the emotions is shown by the pitch of the voice.

The tension of both a catgut string and a steel wire may be adjusted to give sounds of the same pitch, loudness and duration, but the tones will not be the same, and 
they can not be made to sound alike. The reason for this is that the sounds have a different timbre or tonecolor. When the string or wire is plucked, it not only vibrates or swings back and forth as a whole, but the string vibrates in segments upon itself; it trembles. The main vibration-that of the string as a whole-gives the fundamental tone, while the segmental vibrations set up smaller, independent sound-waves, known as harmonics, which mingle with the fundamental tone to modify or color it. Hence the term tone-color. As the catgut string and the steel wire can not both be made to give the same segmental vibrations, the resulting wave-mixtures are different-the timbres are different. They are practically independent instruments of sound.

Here is another graphic illustration of tone-color: If a large stone be dropt into a smooth sheet of water, it will set up a series of waves, which will move outward from it in enlarging circles. But there will be observed a great number of smaller waves upon the larger waves. In sound, these smaller waves are what give tone-color to the larger.

No two objects give out sounds of the same wavemixture; that is to say, of the same tone-color. It is by means of tone-color that we are enabled to distinguish whether it be a fiddle or a piano or the human voice that produces a given sound.

It is a physiological phenomenon, which Herbert Spencer has made very clear, that the vocal organs in man and animals are greatly affected by strong emotions, because all emotions act as muscular stimuli. We know then that the vocal organs are altered under the influence of powerful emotions, and from long experience we have come to recognize the character of these emotions by means of the tone-colors in the speaking voice.

All sounds produced as the results of emotions act as stimuli to arouse similar emotions in the mind of the hearer. Just as it is impossible to hear certain tunes 
played by a good band-“The Marseillaise," for example -without being affected, similarly it is impossible not to be affected by the tunes of expression in the human speaking-voice.

It becomes evident, then, that the tone-color of spoken words indicates the state of the speaker's emotions, and also that the speaker is thereby provided with a means of arousing in the hearer similar emotions, which qualify him for the perception of what the speaker desires to express, by establishing a sympathetic contact between the two. This is why a beggar presents his plea in a high-pitched, whining tone. This is why a lover puts the cooing tones into his voice. This is why a dog, whining at the door, utters a sympathy-stirring note. The growl of a dog over a bone indicates that he has no sympathy with the intruder.

It has long been recognized that the timbre or quality of the voice has much to do with the expression of the emotions; but, so far as I know, this is the first time that the true significance of each of the four properties of sound has been explained, and the first time that each property of sound has been shown to have one, and only one, emotional significance; and, too, the first time that timbre alone has been shown to tell the kind of emotion, thus enabling us by means of it, to distinguish between painful and pleasurable emotions.

Never heretofore, to my knowledge, has the truth been discovered that our ability to distinguish the quality of a speaker's emotions depends entirely upon this tone-color or quality of the voice. Nevertheless, others have made discoveries that have helped me immensely in finding out this truth and some have come very near its discovery, perceiving that timbre gives color to the expression of emotions. Two sounds may be uttered, identical in pitch, duration and loudness, but one may be made to mean grief, and the other pleasure, according to the tone-color. For example, repeat: O-0-0-oh! O-o-o-oh! as you would do if in great pain; then, in the same pitch and with the 
same loudness and duration, repeat the exclamation as you would if greatly pleased, and you will very easily prove for yourself the truth of the above statement; for pitch, duration and loudness being the same in both cases, the only difference in the sound uttered is due to change in its tone-color.

There are two kinds of oral tone-colors-the emotional and the non-emotional, the non-emotional being employed in sounds used arbitrarily as signs of ideas and, the emotional to give those sounds emotional significance.

We must not confound pitch with tone-color. We must constantly bear in mind that pitch relates solely to stress of utterance in the sense of tenseness and not in the sense of loudness. When a dog whines at the door, he pitches his voice high because it is a plaint, and he needs to indicate the stress of his emotions; while the peculiar tone, or tone-color, indicates the character of those emotions. When, however, he growls over a bone, his utterance is of low pitch, asserting a power behind the growl wherewith to back up his demand that he be let alone. If you persist in annoying him, his tone will rise in pitch until it reaches a fierce snarl, which shows a greater intensity of emotion; but he utters his snarl with such increase of loudness as partly to compensate for the loss in dignity of power arising from a higher pitch. Thus we see that, when higher pitch is accompanied with greater loudness, the loudness tends to compensate for the loss in power indicated by the higher pitch. When speaking at a distance or in the midst of noise, a higher pitch as well as greater loudness is required. In the roar of battle an officer speaks with a loud voice, but at the same time in a high pitch, to make himself heard.

Plaintive tones, whinings, the murmurings of love, and the like, are not only relatively high in pitch, but are small in volume. The beggar invariably lessens his voice to utter his whine for a coin. We speak of the whispers of love. 
The strong are in a position to demand, command and thrust away; while the weak plead, interrogate and ask sympathy. The strong have plenty of reserve power for loudness of utterance, while the weak use the opposite of loudness to symbolize their needs.

Ponderous bodies, as I have said, give bass tones when struck, while light bodies give tones of higher pitch. As a rule, strong and large men and animals have heavier voices than do the weak and small.

It is the tone-color that enables us to recognize the voices of different persons, and to tell a woman's voice from a man's voice, and a child's voice from either.

As nerve stimuli are muscular stimuli and as the buccal cavity alters its shape under the tension of varying emotions, and as each particular kind of emotion tends to produce a corresponding adjustment of the vocal organs, let us give an illustration of how readily we are enabled to distinguish the kind of emotions by the quality of the speaker's voice.

Let us suppose that your little daughter calls to you from an adjoining room, "Oh, papa, papa, come, come here! Come quickly!" If the child has found some lost trinket, or calls you to see some gorgeous parade passing in the street, there is an expression given to her voice vastly other than if she has chanced upon a terrifying mouse, or her dolly has toppled from the window-ledge, to be dashed in pieces on the pavement below. Yet, in both cases, the loudness and pitch of her voice might be the same, and she might give equal duration to the periods.

You would recognize by the loudness and duration of the periods the importance of what she was saying. You would recognize from the pitch of her voice the intensity of her emotions, but from neither of these properties of sound would you be able to tell the kind of emotions agitating her, whether they were of pain or pleasure, for the reason that all of these properties might be the same in both cases. There is only one property that could not 
be the same in both cases: the tone-color of the sounds. The sounds of her voice would have a different quality in the one case from that in the other, and by this quality, and this alone, would you be able to know whether her emotions were painful or pleasurable. 


\section{CHAPTER II}

\section{THE EVOLUTION OF ANALOGICAL SPEECH-THE CROSSING OF THE RUBICON OF TROPE SEPA- RATING MAN FROM THE BRUTE}

The opinion appears to be general among the most 1 eminent authorities that articulate speech is an endowment of which man has a monopoly, and that the lower animals have no power of talking with one another. Max Müller, in his "Science of Language," says :

"Speech, so far as we know, is a specific faculty of man. . . . Where, then, is the difference between brute and man? What is it that man can do, and of which we find no signs, no rudiments, in the whole brute world? I answer uithout hesitation: the one great barrier between the brute and man is LANGuage. Man speaks, and no brute has ever uttered a word."

Frederick Pincott, in "The Laws of Language," declares that language "marks in an indelible way the line of demarcation between man and beast-the rubicon which no other animal has ever crossed."

Ernst Haeckel has made articulate speech the attainment that elevated man from brutehood to manhood. He has given the name Alalus to the man-ape who immediately preceded the ape-like man-the one a dumb brute, the other the primitive human being endowed with a simple articulate speech. He says in his "Evolution of Man"':

"I have applied this name (Alalus) to the speechless Primitive Men (Alali) who made their appearance in what is usually called the human form; that is, having the general structure of Men (especially in the differentiation of the limbs) -but yet being destitute of one of the most important qualities of Man, namely, articulate 
speech, as well as of the higher mental development connected with speech. The higher differentiation of the larynx and of the brain occasioned by the latter, first gave rise to the true 'Man.',

If we take this to be the distinction between man and the lower animals, we shall have arrayed on our side all of the greatest authorities, living and dead, with whom it is certainly highly creditable to agree. But if, on the other hand, we are able to show that, in spite of their wisdom and their eminence, these great authorities are radically wrong in setting articulate speech as the line of demarcation between man and brute, we shall, in a measure, have found justification for our temerity in differing from them.

What is articulate speech? The following, which I quote from the Century Dictionary, is a generally accepted definition:

"Jointed by syllabic division; divided into distinct successive parts, like joints, by the alternation of opener and closer sounds, or the intervention of consonantal utterances (sometimes also of pause or hiatus) between vowel sounds: said of human speech-utterance, as distinguished from other sounds made by human organs, and from the sounds made by the lower animals."

Is articulate utterance the main characteristic of human speech, which distinguishes it from that of the lower animals? I contend that it is not the property of articulation that makes human speech preeminent above that of the lower animals, for we shall, I think, be able to show that animals have articulate speech in common with man. But there is another property of language, common to the speech of all men, whether civilized or savage, which is entirely absent from the talk of the brute creation, and it is this property that really differentiates man's language from the speech of the lower animals, a property based upon what man makes articulate oral 
sounds stand for or symbolize, in order to express thoughts peculiar to him and far above the capacity of any member of the brute creation.

When an animal ntters a sound consciously for a purpose, it is said to be an onomatope, as distinguished from an interjectional sound not uttered for a definite purpose. The howl of a kicked dog is typical of interjectional animal utterance. When he whines at the door to be let in, he utters onomatopes.

Altho Frederick Pincott starts out with exactly opposite views-as witness his statement first quoted-in pursuing the subject he begins to see the truth:

"Why, then, do not all creatures talk, since they can and do utter the sounds from which language is elaborated? The reply may take the form of a question-How do we know that they do not talk in a way sufficient for their needs? When a hen finds a sprinkle of corn, she clucks with a peculiar sound that brings her chickens rapidly from every direction in the farmyard; but should a cat appear instead of corn, she lifts up her head and utters a sudden noise that puts all her brood on guard. This is certainly effective language."'

Max Müller admits that certain animals possess all the physical requirements for articulate speech.

A trained parrot will distinctly utter a sentence of well-articulated speech. But does he ever know the meaning of what he says? When a parrot has come to associate the words, "Polly wants a cracker," or merely the word "cracker" with the coming of food, and uses the expression for the definite purpose of obtaining food, it can be nothing else than articulate speech, and the sounds are furthermore arbitrarily used as symbols or signs of ideas. Many other birds are provided with articulate speech organs. The lyre-bird talks and can perfectly imitate any sound it hears in the forest. 
Certain birds admittedly have all the physical requirements of speech much more elaborately developed than were those of man until he had advanced far into the human stage.

We know that talking organs could not have been developed in birds without a demand for their use. Talking organs could never have been evolved except for the specific purpose of talking. Necessity leads to adaptation; not adaptation to necessity. Witness the physical and mental adaptation of all animals to the exigencies of the struggle for existence.

The assumption is absurd that the need of animals for intercommunication-the need for speech-has been without result. Where there has been such an urgent need through the ages, it is absurd to claim that animals have not met this need in their evolution, for there is almost nothing else capable of so much service to animals as some practical means of communication through language. In view of the fact that birds do possess speaking organs in a highly developed state, and the fact that they are constantly making all sorts of sounds to one another with them, it certainly appears reasonable to believe that they have some form of articulate speech sufficient for their needs-speech whereby they communicate ideas. If birds do this, if by the sounds they utter they do convey ideas, then they unquestionably possess articulate speech.

When a hawk appears in the sky and the mother-hen makes a peculiar sound to her chickens, telling them to hide, which they understand and obey, is not that sound used as the sign of an idea? When a rooster picks up a chip and makes the food-call, deliberately practising deception, is not the sound used as the sign of an idea? He understands that if he makes the food-call, some of the hens will flock round him, but he knows, too, that he has no food, and that he is making the call for an entirely different purpose. If this be not speech, what is it?

A bird, frightened from its nest, will often run along 
the ground, pretending, with gestures and cries, that it has a broken wing, thereby offering the attractive bait of a wounded bird, with the object of leading the enemy from the vicinity of the nest.

We understand these gestures. Is it not reasonable to believe that the utterances of the bird, if we could but understand them, would be found to be equally intelligent?

We call this action of the bird in defense of its young, instinct. Instinct is a handy word, and stands for much, without explaining anything. Call it instinct or what not, the fact remains the same, that animals, with thought and purpose, by means of speech and gesture, convey definite ideas. Furthermore, they are capable of both understanding and conveying thought by sounds and gestures used as arbitrary symbols; their speech does not rest alone upon the emotional significance of the sounds uttered. Chickens may be as easily ealled to their food by rapping with a stick on a post as by any other means. After they have been fed a few times, they come to associate that sound with their food, and readily understand its meaning.

We have seen that certain lower animals do have all the requisite organs for articulate speech; that they are capable of uttering articulate speech; that they do and must use their articulate speech for conveying ideas, in many cases using sounds as arbitrary symbols of ideas, the same as does man.

It is probable that the anthropoid ape, the progenitor of man, in common with certain other contemporary animals, employed a limited number of oral sounds as arbitrary signs of ideas, without regard to tonal and onomatopic significance.

The evolutionists and naturalists have taught us that the animals are our kin and that they are more intelligent than we used to think. We are beginning to find out that we are quite as much brutes as they in very many ways. We are beginning to have more respect for the lower animals and a feeling of comradeship for them. 
Man, therefore, .can not be distinguished from the lower animals merely on the ground of being endowed with articulate speech. Neither is a high degree of intelligence a necessary concomitant of articulate speech. There is, however, another property of human speech which the greater intelligence necessary to its use places above the capacity of the brute. In order to explain what this property is, let us return to the Alalus, follow him up from the brute, and see what he found or invented that made him a man.

When the Alalus crept from his warren, threw the long, tousled hair from his eyes and stood in the sunlight, the world wore a vastly different meaning for him from what it wears for enlightened man to-day as he steps from his home into the bustle and business of life.

The understanding of the Alalus was probably about equal to that of a human infant a year old. To the Alalus, everything that moved was alive, and all sounds were voices. He recognized vital energy alone, conceiving it to be behind all forces.

He thought this, not as an act of understanding or reason, but because he lacked understanding and reason to enable him to trace effects to their causes. To the Alalus appearances were realities. The flaring fire, the rush and the surge of water, the whistling and the howling of the wind, the moaning of the trees, were all manifestations of life. He understood nothing of the nature of heat and cold except as conditions associated with comfort or discomfort. He cowered at the tongues of fire that spoke with thunder voice in the storm. The brooklet that sang to him, and the torrential river that foamed across his path in its descent to the sea, were endowed with life. He understood nothing of the source of those waters-how the sun lifted them from earth and ocean to fall again in rain, giving the sap of life to all the bloom and green of forest and field.

It required long ages for the dull brain and the un- 
accustomed hand to shape the simple stone hatchet and arrow-head of flint or bone. The first man to build a fire was a great discoverer; the first to hollow a log and launch it in the stream was a great inventor; and the first to build a simple habitation of logs and boughs was a mighty architect of his time.

Nothing in his environment had any but sensuous meaning for the Alalus. He learned the habits of the animals he sought for food, and became skilled in their pursuit. He likewise learned the ways of those animals that hunted him for food, and became expert in the avoidance of them. He learned to discern the healthful from the noxious roots, nuts and fruits. Heat, cold, hunger and bodily injury had acquainted him with their immediate sources. He knew pain and fear as common experiences. He was attracted to his mate and his offspring, and they in turn to him. He enjoyed their companionship, the pleasures of eating and the comforts of warmth and shelter. Such constituted nearly all the phases of his experience. His appetites and passions were strong, but his tastes were very simple. and his needs few.

Necessity being the prime mover in every step of evolution, we may judge fairly well what the main needs of the Alalus must have been, what were the springs that prompted him to create an improved oral instrument for communication with his companions. He already possest a way of expressing his emotions of pain or pleasure. $\mathrm{He}$ was able to call his companions to him and could warn them against danger. He was able to voice his erotic emotions for his mate and his affection for his offspring, and to express contentment. He could tell his enemies to depart and could let them know that it was dangerous to come near. These were about the only uses he had for language, and as these uses were very simple indeed, and related mostly to the expression of emotional states, we know that the sounds he employed and their significance were correspondingly simple and primitive. He doubtless 
possest articulate speech in a rudimentary form, tho possibly much inferior to that of many birds and other animals of his time.

The emotions of the Alalus were divided into two main classes-those of pain and those of pleasure, and to express his pain or pleasure he uttered pain-sounds or pleasure-sounds. The sounds he used for giving warning belonged to the class of pain-sounds. The sounds he used to eall his companions to join him in a repast, his grunts of contentment over a choice morsel, or when curled up in some position of comfort, and the sounds uttered in expressing his erotic emotions, belonged to the class of pleasure-sounds.

As the life of the individual typifies the life of the race, the human infant should, at some stage of its development, in a measure typify by its speech the language of the Alalus, and doubtless it does. It is a rational assumption that the Alalus was in certain respects the intellectual and physical inferior of some other members of the brute creation, just as the year-old infant is inferior in various ways to many adult animals.

Let us consider the ways and speech of the human infant-that interesting little fellow about a year old. His language is very expressive as far as it goes, and is not misunderstood by any mother; but it is limited, as was that of the Alalus, to the expression of pleasurable and painful emotions, to the rejection of what he does not want, to calls for what he does want, and to expressions of comfort and affection-exactly the language of the Alalus. The infant needs are simple and few and all entirely sensuous, as were also those of the Alalus.

That the infant speaks a real language no one can deny. His mother understands his every want perfectly. His language is also a universal one. Every mother in the world, of whatever race, can understand the babytalk of any child of any race. The infant, in turn, can understand the language of every mother, for the mother, 
too, reverts to the Alalus in her talk to the infant. It is baby-talk. It is nonsense talk as far as the symbolic significance of the words go, but is not by any means nonsense talk in what the sounds in their nature signify.

There are five ways, and only five ways, that ideas can be conveyed by oral sounds, and they are: first, by the quantitative properties of sounds, loudness and duration, indicative of the importance of the utterance; second, by the qualitative property of sounds, known as pitch, indicative of the tenseness of the feelings; third, by the qualitative property of sounds, known as tone-color, expressive of the emotions; fourth, by non-emotive tonecolor blends used arbitrarily as symbols or signs of ideas; and fifth, by imitation, either direct or analogical.

There are two main divisions of symbolism-the directly imitative and the arbitrary. Directly imitative symbolism embraces onomatopy, in which words are uttered whose sounds are directly imitative of those made by the objects or animals they are intended to indicate. The words sneeze, snore, bang, smash, roar, clatter, whiz, are words of this class.

In arbitrary symbolism, sounds are arbitrarily used as the signs of ideas wholly independently of any tonal or imitative quality in the sounds. The words liberty, eternity, time, space, good, bad, evil, finite, table, ground, floor, uater, air, fire, earth, are words of this character. Many such words are as free from any tonal significance as the ticks of a telegraphic instrument sounding out the letters of the alphabet.

Gestures, as well as sounds, are used by both men and animals as signs of ideas. Gesture language is as universal as sound language, and, like sound language, is divided into directly imitative symbols and arbitrary symbols.

Up to this point in the development of speech, man stands on common ground with the lower animals, which not only express their emotions by the sounds they utter 
and by gestures, both quantitatively and qualitatively, but also employ the same means to symbolize concrete ideas, arbitrarily as well as imitatively, exactly as does man.

Where, then, did man part company with the brute? It was where man began to have ideas and to think thoughts that could not be exprest by the qualitative and quantitative properties of sound, or by the imitative use of sounds, or merely by the use of sounds as arbitrary symbols of concrete ideas. It was when man entered the abstract that he parted company intellectually with the lower animals and evolved improvements in language that have nothing in common with the brute. This was when man first used metaphor-when he first employed the expedient of expressing insensuous thought by sensuous terms.

The claim is false that instinct is the mentor of the lower animals, and reason man's mentor. Man, too, has his instincts, while the inferior animals learn from experience and reason even as does man, differing from man in these respects only in degree. Instinct is but inherited experience. Human experiences work changes in the brain-structure to make them remembered. It is necessary only for these experiences to be repeated times enough with succeeding generations to make the cerebral structural changes hereditary. This is why some of us have so much greater aptitude than others in mathematics, in philosophy, in music, in poetry, in painting, and the like. This is why habit is so refractory.

Not only does the knowledge we acquire in life and remember by means of structural changes made in the brain by experience tend to the acquirement of the same knowledge in the offspring, but also the knowledge itself tends to be hereditary. Then this knowledge becomes instinct, whether in man or brute. That is why certain animals can walk at birth without learning; can voice their emotions and their needs without being taught to do so; and later on, 
in their business of living, perform evolutions requiring a certain amount of reason-and all without being taught.

Animals are born with certain endowments or structural requirements for physical and mental functions, and as nerve stimuli are muscular stimuli, the animal is impelled not only to act automatically, but also to know and to think automatically. Because certain animals do things instinctively, it is none the less true that they do them understandingly. To think is but a physiological function, and to a certain extent the function of thinking and reasoning may as well be instinctive as are physical functions. The sense of the eternal fitness of things in the mind of the great physicist and philosopher is in a way instinctive. Music in others is practically instinctive. The ability to make astounding arithmetical calculations was instinctive with Zerah Colburn. The only view we can rationally take of man is that he is simply a more highly specialized animal than is the brute, more nearly perfected.

Even brutes reason inductively that because of certain sensuous experiences other sensuous experiences necessarily follow; but man alone is capable of reasoning inductively that because of certain sensuous experiences and relations certain abstract and abstruse truths must follow as necessary corollaries. A brute, sitting under an appletree, would not be led to discover the law of gravitation by the falling of an apple upon his head, but the brute might easily reason that, as one apple had fallen, more would follow, and he might sit and wait for them to come down. A carnivorous animal will reason that he must keep to the leeward when stalking game, and he tells the direction of the wind by the cold produced from the evaporation of the moisture on the windward side of his nose, but the brute would never conclude that this was why nature had given him a moist nose. A brute might naturally suggest a smooth state of the emotions by smoothness of his uttered sounds, but no lower animal has the ability to suggest smoothness of temper metaphorically by means of a 
smooth surface; and no lower animal would utter a smooth sound to suggest a smooth surface, or would utter a rough or rugged sound to suggest a rough or rugged surface.

Man's vastly superior powers of imagination form the greatest gulf between him and the brute. Man alone is capable of expressing insensuous thought, and man alone has such thoughts to express. Man alone is capable of expressing in terms of experience thoughts lying beyond experience, and this is the only way that thoughts lying beyond experience are capable of expression. To this end trope, chiefly metaphor, has become the master instrument of human speech.

Max Müller says:

"Metaphor is one of the most powerful engines in the construction of human speech, and without it we can hardly imagine how any language could have progrest beyond the simplest rudiments."

And he adds :

"But let us now consider for a moment that what philosophers, and particularly Locke, have pointed out as a peculiarity of certain words, such as TO APPREHEND, TO COMPREHEND, TO UNDERSTAND, TO FATHOM, TO IMAGINE, SPIRIT, and ANGEL, must have been, in reality, a peculiarity of a WHOLE PERIOD in the early history of speech. No advance was possible in the intellectual life of man without metaphor. Most roots that have yet been discovered, had originally a material meaning."

He continues further on:

"Let us consider, then, that there was, necessarily and really, a period in the history of our race when all the thoughts that went beyond the narrow horizon of our every-day life had to be exprest by means of metaphors, and that these metaphors had not yet become what they are to 
$u s$, mere conventional and traditional expressions, but were felt and understood half in their original and half in their modified character."

What is the function of metaphor? It is simply an attempt to express in terms of experience thoughts lying beyond experience. It is an attempt to express the abstract in terms of the concrete, to express insensuous thought by sensuous terms.

Metaphor-trope-is concrete symbolism. It is the employment of sense images of concrete, tangible things to symbolize abstract, intangible things through association by similarity of the concrete with the abstract, the tangible with the intangible.

Arbitrary symbolism is the metaphoric employment of one thing to symbolize another where there is no similarity, as the word $\operatorname{dog}$ is a sign that stands arbitrarily for that animal, and as the letter $a$ symbolizes or stands for certain elementary oral sounds. This is abstract symbolism -arbitrary symbolism.

All thought-expressing properties of oral language depend upon symbolism, the directly metaphorical, the analogical, or the arbitrary. No thought whatever beyond simple ideas of emotional states in the speaker can be conveyed by oral sounds merely as sounds, for the reason that the four properties of sound have only sensuous and emotive significance. Even sounds used in imitation of other sounds, altho but indirectly imitative (onomatopy), come under the general head of symbolism. Conversely, metaphor comes indirectly under the general head of imitation. 


\section{CHAPTER III}

\section{WHAT IS POETRY?}

"It is not riming and versing that maketh a Poet, no more than a long gowne maketh an Advocate."-Sir Philip Sidney.

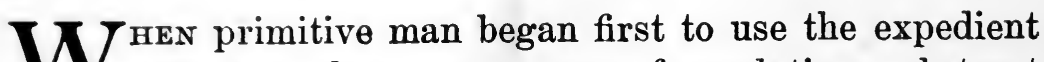
of metaphor, or trope-formulating abstract thoughts in concrete terms, interpreting thoughts lying outside experience in terms of experience, expressing insensuous thoughts in sensuous symbols through some analogy between the insensuous and the sensuous-he also naturally employed every other artifice of expression at his command.

Already proficient in expressing his emotional states through the loudness, duration, pitch and tone-color of the sounds he uttered, he united these emotive properties of sound with trope to emphasize his meaning, in order that he might arouse his auditor's emotions, thereby stimulating and qualifying the mind of the hearer for perception and inducing a mood in harmony with the thought exprest.

With his first use of trope man naturally made the most of the quantitative and qualitative properties of sound. He gave quantitative expression to his emotions, and emphasized their importance by the loudness and duration of his periods; while by the pitch and tone-color-the qualitative properties of sound-he told how intensely he was strung up by those emotions and revealed their nature, whether of pleasure or of pain.

As his powers of expression by single utterance were necessarily limited, he naturally resorted to the expedient of numerous repetitions. Repetition became a natural concomitant of expressive utterance, and the awakened attention of the hearer grew to be always expectant of repetitions in strongly emotional utterance. 


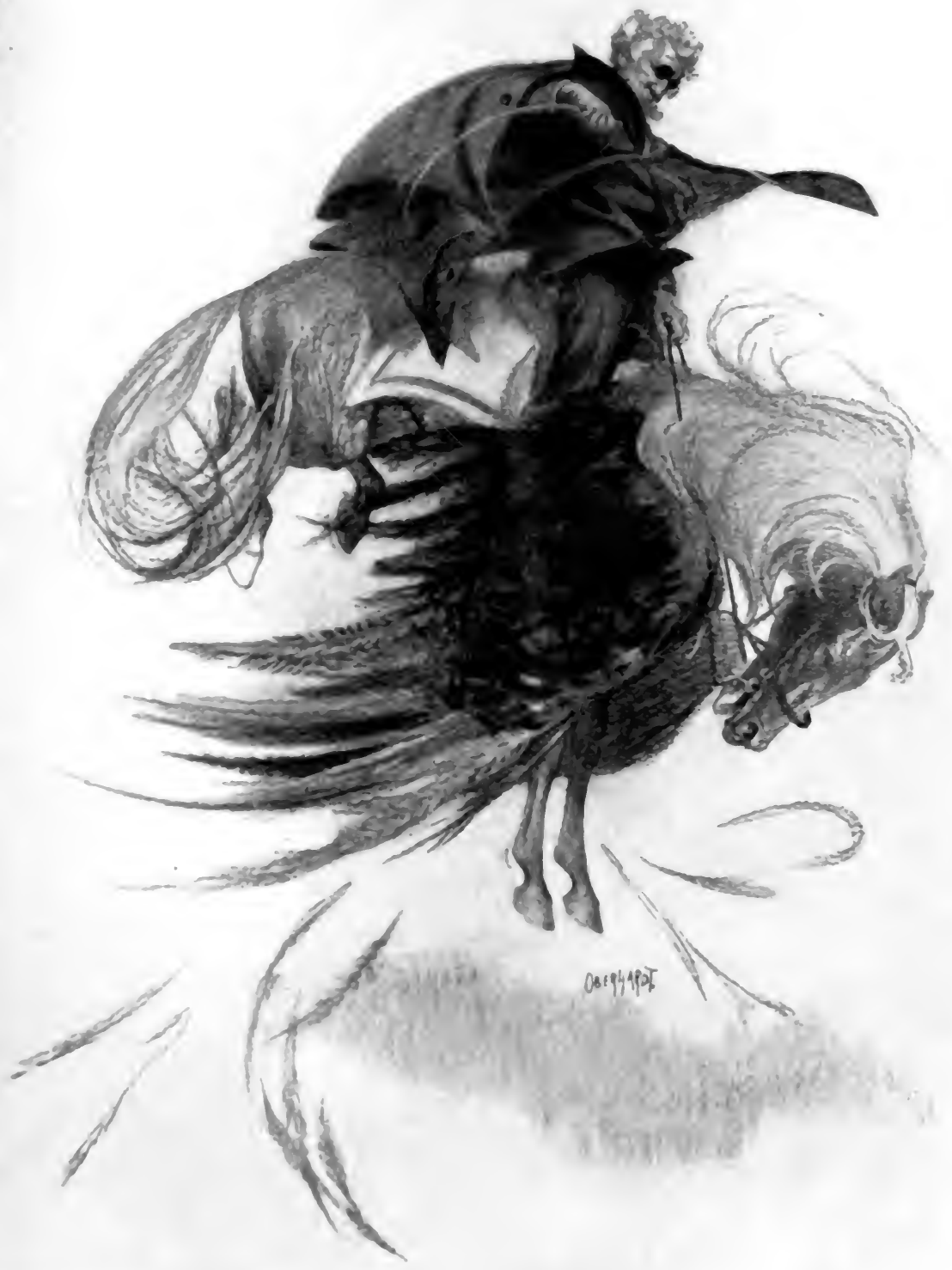



Herbert Spencer says :

"Among tribes in the earliest stages . . . a few words uttered in tones expressive of joy or grief recur over and over again; showing a natural tendency which even among ourselves may often be witnessed under sudden disasters: 'Oh, dear me,' 'Oh, dear me,' 'Oh, dear me,' being uttered time after time in the same tones."

When a thought had been thus exprest by primitive man, and a new thought required expression by a new trope, the new thought would be more expressive if uttered with the repetition of as nearly as practicable the same sounds, with the same loudness and duration and the same repetitions as those with which the preceding thought had been uttered, and to which the mind of the hearer had been adjusted and attuned. Thus the thought would be more readily pereeived than if exprest in any other way. Furthermore, a relevant idea and a thought not too foreign to the thought already exprest usually followed the first expression. This was the birth of verse.

In primitive verse, either the same thought was repeated in slightly different words, or a relevant or new idea was given as nearly as possible the same manner of expression. Time, the basic principle of verse, is based on rhythm, and rhythm, in turn, is based on repetition. Primitive verse consisted mainly of what may be called parallelisms, rimes of idea and accentuations by contrast. There was then no systematic riming of words. Rime, as we know it, is a comparatively modern invention.

Much of the Bible was written in such primitive verse, as witness :

\section{PARALLELISMS AND RIMES OF IDEA}

Psalm CXIV. back.

3. The sea saw it and fled: Jordan was driven 
4. The mountains skipped like rams, and the little hills like lambs.

5. What ailed thee, $O$ thou sea, that thou fleddest? thou Jordan, that thou wast driven back?

6. Ye mountains, that ye skipped like rams; and ye little hills, like lambs?

7. Tremble, thou earth, at the presence of the Lord, at the presence of the God of Jacob;

8. Which turned the rock into a standing water, the flint into a fountain of waters.

\section{Genesis I.}

27. So God created man in his own image, in the image of God created he him; male and female created he them.

Proverbs III.

24. When thou liest down, thou shalt not be afraid: yea, thou shalt lie down, and thy sleep shall be sweet.

Proverbs IV.

11. I have taught thee in the way of wisdom; I have led thee in right paths.

14. Enter not into the path of the wicked, and go not in the way of evil men.

25. Let thine eyes look right on, and let thine eyelids look straight before thee.

Proverbs V.

1. My son, attend unto my wisdom, and bow thine ear to my understanding.

5. Her feet go down to death; her steps take hold on hell.

\section{Proverbs XVI.}

18. Pride goeth before destruction, and an haughty spirit before a fall. 


\section{ACCENTUATION BY CONTRAST:}

Proverbs XIII.

7. There is that maketh himself rich, yet hath nothing: there is that maketh himself poor, yet hath great riches.

24. He that spareth his rod hateth his son: but he that loveth him chasteneth him betimes.

\section{Proverbs XII.}

19. The lip of truth shall be established forever: but a lying tongue is but for a moment.

\section{Proverbs XIV.}

29. He that is slow to wrath is of great understanding: but he that is hasty of spirit exalteth folly.

Onomatopy was largely used in early verse. Sounds not only directly imitative of other sounds, but indirectly imitative, as the use of a rough sound to give an idea of a rough object, or a smooth sound of a smooth object; moreover, words used arbitrarily as the signs of ideas, which had come into use prior to the advent of trope, were combined with emotive sounds in conjunction with trope, for the expression of thought. Naturally, then, the emotive, the imitative and the arbitrarily symbolic uses of sound, together with phonetic repetitions and rimesin short, the sets of especially related sounds constituting verse-have always been more or less closely associated with trope for emotional expression.

All figures of speech are born of analogy, and for this reason they are all intimately related. The expression figure of speech and the word trope, are, in general usage, the broadest terms and they are applicable in all instances. Altho the word metaphor is not generally used in an equally comprehensive sense, still, since it is the chief figure of speech, all others being either directly or indirectly branches of it, metaphor may be justly used in a broad sense, including every form of the figurative in language. 
Nevertheless, trope, being the shorter word and having the like broad applicability, is preferable, and I shall therefore employ it for all figures of speech. Trope is any deviation from literal statement to facilitate the expression of thought.

The principal divisions of trope are known as Metaphor, Simile, Metonymy, Personification, Synecdoche, Allegory, Hyperbole and Irony.

If we examine into the nature of any figure of speech, it becomes apparent that it is based on analogy, upon some resemblance that one thing bears to another.

We call a tool dull because of the resemblance that a dull edge bears to a dull boy, a dull student or dull mind. Likewise, we speak of a color as dull, because of its resemblance to a dull-edged tool. This form of trope is known as Metaphor. Dull mind and dull color are simple metaphors, but dull boy and dull student are complex figures, for it is not the boy or the student to which we refer, but a property or attribute of the boy and the student: dulness of mind. This particular figure, where a part is spoken of as the whole, or the whole as a part, or where a property or attribute of an object is spoken of as that object, is called Synecdoche; but synecdoche is in reality a branch of metaphor.

Closely allied to synecdoche is Metonymy, also a kind of metaphor, where the name of one thing is substituted for that of another to which it bears an analogy. Thus, we speak of Heaven for God, or of head and heart for intellect and affection.

Perhaps the most common metaphor is where one object is spoken of as another to which it bears a certain resemblance; as, "He was a lion in the fight." If we say, "He fought like a lion," it is Simile.

Personification is a species of metaphor which consists in representing inanimate and insensuous things as endowed with the properties and attributes of living, thinking and speaking things. 
Allegory is simply an extended metaphor, the main difference being that true metaphor asserts that one thing is another, while allegory simply infers and never affirms.

Hyperbole is exaggeration. It consists in representing things to be either greater or less, better or worse, than they really are, with the object of making the thought more effective by overstating it. When we say, "The waves ran mountain high," or, "The sound echoed in the stars," we know that waves never reach the height of mountains, and that no sound could reach the stars.

Irony consists in ridiculing an object under a pretense of praising it. Irony often renders argument very effective, for it presents a false belief in its true light, by giving to the idea or principle an analogous application where its absurdities become strongly evident.

It must be borne firmly in mind that all sounds are nerve stimuli and that all stimuli are exercisers of faculty; that the normal exercise of faculty is pleasurable; and further, that the greatest pleasure is experienced by the exercise of those faculties most vital to us and most instinctive, which have come down to us from remotest antiquity, of which the exercise is necessary to the maintenance of the life of the individual and the race. These faculties are the seats of sensuous passion, which, when stimulated into activity, give the most exquisite pleasure. Naturally, then, the emotive properties of sounds, which enter so largely into the expression of versified speech, are pleasing; but they have nothing whatever to do with thought except to stimulate it as mood-inducers and as qualifiers for perception.

Thought must necessarily be exprest by some sort of symbolism, by sounds used as arbitrary symbols, or by analogical imitative symbols, or by gestures. Sounds, whether directly or indirectly imitative, are nevertheless used symbolically; for if we pronounce the word bang in imitation of the sound, or the word sneeze or snore in 
imitation of those sounds, our words are still symbols of those sounds, and onomatopy must be considered as a branch of symbolism.

Trope is analogical symbolism. For example, if we say, "He was a lion in the fight," we have used the resemblance of the lion to emphasize a leonine character in the man. In the expression, "I spear'd him with a jest," the analogy between a jest and spear is made very effective. The same is true with all forms of figure or trope.

Blair, in speaking of metaphor, says:

"Of all the figures of speech, none comes so near to painting as metaphor. Its peculiar effect is to give light and strength to description; to make intellectual ideas, in some sort, visible to the eye, by giving them color, and substance, and sensible qualities."

John S. Hart, in his "Rhetoric," speaks of metaphor in much the same way:

"Metaphor, indeed, of all the figures, comes nearest to painting, enabling us to clothe at will the most abstract ideas with life, form, color, and motion, and to 'give to airy nothing a local habitation and a name.",

In "The Philosophy of Style," Herbert Spencer says :

"Metaphors, similes, hyperboles, and personifications, are the poet's colors."

We shall see further on that metaphor in the broad sense, embracing all forms of trope, is the soul of poetry, and that verse-forms are simply tonal expedients of potential expression. We are then forced to consider poetry as either a compound product, constituted of tonal verseforms and trope, or we must consider verse and trope as distinct properties of speech, and give the name poetry to the one of these that in our opinion best deserves it. 
Most of the authorities confound poetry with verse, thinking them to be synonymous terms; others see that they are entirely different. But let us closely examine the facts for ourselves, that we may see and know how and why they are wholly unlike.

It is certain that a composition may have perfect verseconstruction and contain no poetry whatever, as witness the following two lines, which have good verse-construction, but are without poetry:

\section{"Thirty days hath September, April, June, and November."}

The following quotations are examples of good simple verse, but they are certainly not poetic:

"Old King Cole was a jolly old soul, And a jolly old soul was he;

He called for his pipe, And he called for his bowl, And he called for his fiddlers three."

"Mary had a little lamb, Its fleece was white as snow, And everywhere that Mary went The lamb was sure to go."

"The King of France, with twenty thousand men, Marched up a hill and then marched down again."

The multiplication-table could be written in aceurate verse-form, but it would not be poetry. The insidious jingle that enslaved Mark Twain is not poetry:

"Punch, brothers, punch; punch with care; Punch in the presence of the passenjare."

Even Poe's "Raven," which is a marvelous mixture of poetry with excellent verse, is quite devoid of poetry in 
some stanzas; for example, the first stanza contains no poetry :

"Once upon a midnight dreary, while I pondered, weak and weary,

Over many a quaint and curious volume of forgotten lore,

While I nodded, nearly napping, suddenly there came a tapping,

As of some one gently rapping, rapping at my chamber door.

' 'Tis some visitor,' I muttered, 'tapping at my chamber door,

Only this and nothing more." ",

Now, if verse may be written without containing any poetry, and if good verse-construction is possible without poetry, then we are led to the conclusion that verse and poetry can not be the same thing, and that poetry must depend upon something other than these properties of sound-rhythm, meter, rime, reading flow, or pitch, duration, loudness and tone-color-altho in the expression of poetic thought these properties of sound may be used just as they are used in the expression of any other thought. And they aid in the expression of poetic thought just as they aid in the expression of ordinary thought.

The emotions find expression in the character of the sounds uttered; therefore, verse, and not poetry, is emotional.

We may proclaim or define our emotions through the arbitrary symbolic meanings of words; but we can express our emotions-that is, make our utterance itself emotional -only through the sounds of the words. We emphasize emotion by loudness and dwell, tell its stress by the pitch, and express the kind of emotion by the tone-color of the voice.

What, then, is poetry? If the basic principle of poetry be not one of sound, such as we know that of verse to be, then what is it? Thus, by elimination, we are forced to 
conclude that poetry relates in some way to the thought exprest, because it can not depend upon the character of the sounds used in its expression-that poetry depends upon the kinds of words and how they are marshaled in a sentence with respect to meaning to express thouglit. Poetry is based on the meanings of words, while verse is based on the sounds of words and upon the way those sounds are marshaled in a sentence to stimulate and qualify the mind of the hearer for the perception of thought, by inducing a mood in harmony with the thought exprest.

Let us cite some examples of real poetry, which are recognized even by the acknowledged authorities as being poetry of the highest class, and assay them for poetic gold, to help us discover what constitutes poetry.

Take these lines of Shakespeare:

\section{"Jocund day}

Stands tiptoe on the misty mountain tops.'

"Let not our looks put on our purposes."

"Your wisdom is consumed in confidence."

"All pity choked with custom of fell deeds."

"A curse shall light upon the limbs of men."

"Thou art the ruins of the noblest man

That ever livè in the tide of times."

"O judgment! thou art fled to brutish beasts."

Take the following lines from Edwin Markham's "Man with the Hoe"':

"How will you ever straighten up this shape;

'Touch it again with immortality;

Give back the upward looking and the light;

Rebuild in it the music and the dream?" 
Take the lines of Marlowe:

"The horse that guide the golden eye of Heaven, And blow the morning from their nostrils,"

or the lines by Marlowe, speaking of Helen of Troy:

"Was this the face that launched a thousand ships And burnt the topless towers of Ilium?"

The foregoing lines would be equally poetic in prose or verse. They touch us otherwise, and with more force, than do the following lines of Wordsworth:

\section{"I met a little cottage girl:}

She was eight years old, she said;

Her hair was thick with many a curl

That clustered round her head."

In what does this difference consist? It lies in the fact that the first examples are verse, with great poetry, while the last example is good verse, without poetry.

The foregoing lines from Shakespeare, Marlowe and Markham would still be great poetry if found in prose.

What is the quality in the above poetic lines that we find "soul-lifting," as Edgar Allan Poe would put it? What is that quality possest by them which fascinates us? What is that quality or force which compels clear perception of thought? What is that quality which distinguishes great poetry from mere verse, and the great poet from the mere rimester? Let us explain. Poetry obeys the law of conservation of energy. By poetry a thought is presented with the utmost economy of word symbols. Frequently one line of poetry will convey as much meaning as is usually exprest in a dozen lines of plain prose:

"The brute despair of trampled centuries

Leapt up with one hoarse yell and snapt its bands,

Groped for its right with horny, callous hands, And stared around for God with bloodshot eyes."

-LOWELL. 


\section{WHAT IS POETRY?}

To beckon with the hand is more potent than the words, "Please come here," because the words, which are mere arbitrary signs of ideas, can enter consciousness only by the roundabout process of interpretation, while a beck of the hand expresses the thought without word symbols. The beck of the hand presents the idea whole at a stroke, by a single symbolic motion. This is what poetry tends to do, and it thereby economizes in the use of word symbols by selecting only those most pregnant with meaning; and this conserved energy is utilized by the hearer in perceiving the thought with unusual force and vividness. Any surplusage of word symbols in a line weakens the line by diluting it. The mere act of perceiving and interpreting to the mind the word symbols consumes energy, diverts the attention and detracts from the vividness of thought-perception.

We find this universal property in all true poetry: It metamorphoses that which lies outside tangible, concrete experience and expresses it in concrete guise and in terms within the intimate acquaintance of experience.

Let us start out with a new definition of poetry, one based upon trope and the office performed by trope in giving us a clearer perception of thought, by expressing the unfamiliar, the abstract, the intangible, and the insensuous, in terms of the familiar, the concrete, the tangible and the sensuous, which are analogous to, or in some way resemble or suggest, the things they are made to symbolize, thereby expressing in terms of experience thoughts lying outside experience: Poetry is the expression of insensuous thought in sensuous terms by artistic trope and the dignification of thought by analogically articulated imagery.

Poetry transforms the abstract to the concrete, the intangible to the tangible; it exalts the inanimate to the animate, the impersonal to the personal, and gives to each all the properties and attributes common to those things to which they have been dignified-things familiar to our 
experience, with whose properties and attributes we are well acquainted.

We may easily ascertain the difference between verse and poetry by breaking up the rhythmical structure of a stanza, and arranging the sentences in the form of prose in such a way as to maintain the integrity of the thought exprest, robbing the lines only of the musical or emotional and mood-inducing quality of verse.

Then, if the poetry still remains undiminished, or even very manifest, we know that it is versified poetry with which we are dealing. If, however, we have simply common prose, with nothing but prosy thought, and with nothing unordinary or surprizing or especially beautiful in the manner of its presentation, then we know that this is not poetry, but merely verse.

Let us take, for example, the first stanza of Longfellow's "Excelsior":

"The shades of night were falling fast, As through an Alpine village pass'd

$A$ youth, who bore, 'mid snow and ice,

$A$ banner, with the strange device'Excelsior!',

This is good verse, but it contains no figure. Now, if we paraphrase it, so as to spoil the rime and break up the verse-measure, it becomes plain prose statement, as witness :

The shades of night were fast falling, as a youth bore a banner through the ice and snow of an Alpine village with the strange word "Excelsior" upon it.

It is easy to see that this is now not poetry.

Let us paraphrase it into prose with still less change. For example:

The shades of night were falling fast, as a youth, who bore 'mid snow and ice a banner with the strange motto, "Excelsior," passed through an Alpine village. 
In the last paragraph $I$ have used the exact words of Longfellow, except that I have simply changed the one word "device" to "motto," spoiling the rime.

Let us now paraphrase the lines already quoted from Markham's "Man with the Hoe":

How will you ever straighten up this shape, give back to it the light and the upward looking and touch it again with immortality? How will you rebuild in it the dream and the music?

The above sentence is plainly prose. In other words, its verse-structure has been broken up, but the poetry is still there. Hence, we conclude that it is poetry we have to deal with in these lines.

But instead of paraphrasing poetic verse into prose to show that the poetry is still there, let us quote some good examples of poetic prose, and we shall readily see that verse has no essential advantage over prose as a matrix of poetic gems.

Napoleon, speaking to his troops in Egypt, just before the battle of the Pyramids, said:

"From the summit of yonder Pyramids forty centuries look down upon you."

The following lines occur in the prose of Edward Everett:

"Faint streaks of purple soon blushed along the sky; the whole celestial concave was filled with the inflowing tides of the morning light."

That great prose poet, Robert G. Ingersoll, in speaking of Voltaire, says:

"Through the shadows of faith and fable, through the darkness of myth and miracle, through the midnight of superstition, through the blackness of bigotry, past cathedral and dungeon, past rack and stake, past altar and throne, he carried with chivalric hands the sacred torch of reason. . . 
"The seeds of the French Revolution were watered by the tears of agony. Blows began to bear interest."

Elsewhere, he says :

"And every life, no matter if its every hour is rich with love and every moment jeweled with a joy, will, at its close, become a tragedy as sad and deep and dark as can be woven of the warp and woof of mystery and death.

"Life is a narrow vale between the cold and barren peaks of two eternities. . . But in the night of death hope sees a star and listening love can hear the rustle of a wing."

\section{Again :}

"The complex, tangled web of thought and dream . . . has never yet been raveled back to simple threads."

Literature has quite as many noteworthy examples of great poetry in its prose as in its verse-as witness the prose writings of Carlyle, Ruskin, Robert G. Ingersoll, and many others. Ingersoll's prose was replete with poetry, and his poetry gave him crowded houses.

Most of the good old verses known to us by heart are but slightly alloyed with true poetry; and many of them, as Longfellow's "Excelsior," contain no poetry whatever, altho the poem as a whole is an allegory of the aspiration of youth, and as such is a true poem. This shows, not that verse should be valued little, but that poetry should be valued as something different.

Poetry is pregnancy of meaning-the pregnancy of meaning in words, their pregnancy of the thought exprest; while verse is pregnancy of the words in sounds suited to stimulate and qualify the mind of the hearer for perception and to induce a mood in harmony with the thought exprest. 
Poetry-making is an act of metamorphosis or transfiguration, an act of creating comprehensible tangibility from chaotic intangibility. Poetry incarnates the abstract in the concrete. Poetry-making is always an act of creation and dignification. It is always an act of invention.

Consequently, hackneyed phrases, didactics and explicit moral inculcations must be avoided in poetry. The best words are those that have been lavendered by time, use and association, now employed in some new way where they convey a fresh or surprizing meaning. Every word must be made to do utmost duty as a vehicle of meaning by enlisting the imagination in the amplification of its meaning.

Poetry is no haphazard art. It is neither lawless nor beyond law. On the contrary, it is the child of law, and conforms to law-there is no otherwise of poetry.

Select any number of the finest lines from great poems and assay them for poetic gold, and we find that the distinguishing features of the lines are that the intangible assumes tangibility, the abstract becomes concrete, the inanimate is made animate, the impersonal is personified, and the dumb speaks. Always that which seems to be is treated as an actual existence.

Poetry is largely an act of visualization. The unsubstantial is given substance that it may be realized in consciousness, which can be done only by metamorphosis into the sensuous. Poetry does this by artistic trope.

We know things through their acts, properties and attributes; and unsubstantialities are made realizable in consciousness by giving them through metaphor the acts, properties and attributes of substantialities.

The imagination is the power by which we recall into consciousness the impressions of experience, and construct new ideas from them, thereby creating new impressions in the mind, which take their places beside the impressions received directly from the environment. Each 
of our five senses has its own specific imagination. There is the imagination of sight, of smell, of taste, of hearing and of touch.

Imagination enables us, while standing upon experience, to reach out beyond experience. Imagination acts as a vidette of the mind in the van of thought, to give us intelligence from the frontiers of knowledge. Imagination is the parent of all poetry.

Poetry is the most imaginative form of expression. It is a creation of the imagination. The poet sees analogies between entities, and speaks of a thing less capable of being clearly perceived in terms of something it resembles, which is more readily and distinctly perceptible. Poetry speaks of one thing as being another, and gives to it properties and attributes not literally belonging to it, but rather to its analogical counterpart. Sir Francis Bacon, the Shakespeare of liars, evidently understood this, for he said: "Poetry is the mixture of a lie that doth ever add pleasure." The poet, taken literally, speaks in riddles. Taken literally, poetry is meaningless.

It is a good test for poetry that, taken literally, it makes nonsense; but with the aid of the imagination it is far more expressive than any literal wording could possibly be. The imagination must be enlisted in the understanding of poetry, as well as in its production.

Take the line:

$$
\text { "I spear'd him with a jest." }
$$

How could one use a jest as a spear? Or the line:

"The face that launched a thousand ships."

How could a face launch a ship?

$$
\text { "As if the new reality of death }
$$

This, taken literally, is the merest nonsense.

$$
\text { "That fatal and perfidious bark, }
$$
Built in the eclipse, and rigg'd with curses darle." 
How could a bark be perfidious? It would be impossible to build it in the eclipse; and how could a ship be rigged with curses?

" My heart is in the coffin there with Casar."

Nothing could be more absurd than this statement of Mark Antony, unless by means of the imagination we understand that he did not mean his physical heart of flesh and blood, but that he was greatly afflicted at the death of Casar; that he had a great affection for Casar, and that his hopes were shattered by this assassination. Shakespeare was enabled by the enlistment of the imagination to state all this very clearly and effectively in one poetic line.

Now, with this understanding of poetry, let us frame a definition more elaborate than the one previously given, but one with essentially the same meaning: Poetry is the expression of imaginative thought by means only of the essentials to the thought, conserving energy for thought-perception, to which end all animate, inanimate and intangible things may assume the properties and attributes of tangible, living, thinking and speaking things, possessing the power of becoming what they seem, or of transfiguration into what they suggest.

It is the function of poetry to make the children of the imagination our real friends and intimates, to lead us into a fairy world of "pretend," an Elysium of "makebelieve." Poetry gives to the commonplace a touch of magic and mystery; and there is no mystery that is not commonplace to poetry. It fathoms all mysteries and solves for itself the riddle of the universe. It transforms the metaphysical into the physical, or the physical into the metaphysical, thus doing for all non-quantitative knowledge what the one-to-one transformations of mathematics do for the finite and the infinite respectively.

We may grant the claim of Coleridge that poetry is the antithesis of science. Nevertheless, there is the science 
of this antithesis-there is the science of poetry. Altho apparently paradoxical, it is still true that poetry is the antithesis of science, for science is based upon actual existences-upon facts, upon things as they really arewhile poetry is based upon what seems to be actual. Science is knowledge of things as they are, reduced to a system; while poetry is the art of expressing abstract thought and imparting knowledge of intangible properties of things by the expedient of metamorphosing them into what they seem to be or into what they suggest. By this means, the abstract thought is presented in the guise of tangible things or things more intimate to the senses and more within the range of experience. Consequently, the thought is offered in more pleasing form, while at the same time it is more clearly presented.

Before man through science came to understand the phenomena that surrounded him, his environment was a maze of mystery, and magic was his system of evolution. The possible then was bounded only by the imagination. Magic and mystery and the seemings of the imagination are the soul of poetry. This is why the dawn of civilization was filled with poetry. For the reason that poetry came before science, it has a stronger hold upon us than science has, and for the same reason man's love for poetry is innate, and poetry is a necessity.

The advance of cold, calculating science need not make us fearful of losing, as a playground for the imagination, that old wonder-world from which we are emerging; for even to-day the magic wand of the intangible halts grayhaired Science confounded on the brink of the unknowable, and he reaches to take hands with his mystic brother, while together they peer into the depths.

The wonder-science, which we inherit from the long ages, is stronger in us than the new-born science of reason. Poetry has its foundation upon our inheritance from the wonder-world of the remote past, while science is a parvenu. Fact falls, weary-winged, in its flight with fancy. 


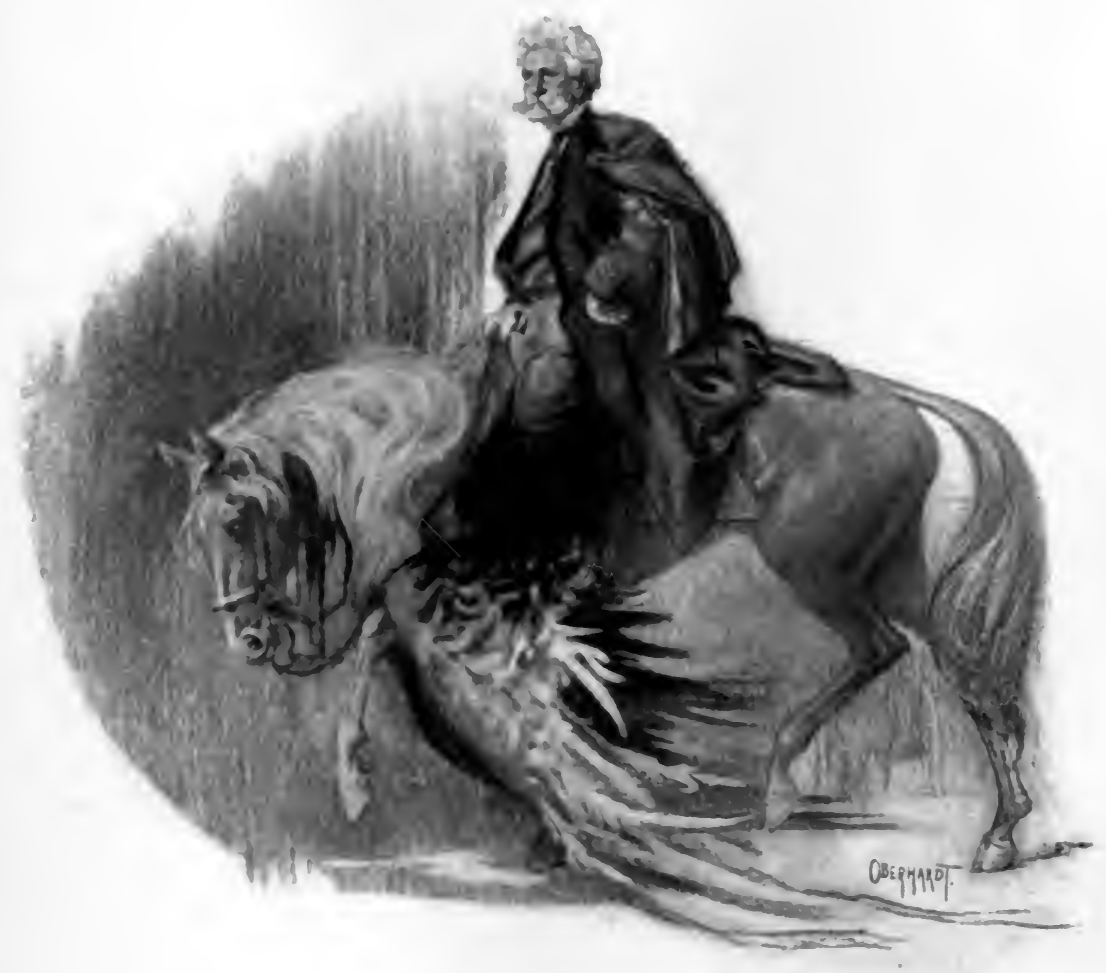





\section{CHAPTER IV}

\section{WHAT POETRY IS NOT}

\section{REMARKABLE DEFINITIONS BY THE AUTHORITIES}

T $x$ Aristotle's time, inductive philosophy and exper1 imental science were unknown; but in all states of society experience teaches much, and every mind possesses a more or less dependable sense of the eternal fitness of things, derived not only from individual experience but also from the accumulated ancestral experience of the entire species.

Experimental science, on which is based most modern inductive reasoning, is only a methodical appeal to experience.

Aristotle was the master mind of all antiquity. $\mathrm{He}$ for his time was not only what Herbert Spencer was in a later age, but he was also unique, as Spencer would have been had there not appeared a Darwin, a Haeckel, a Huxley, a Mill, a Tyndall. Aristotle found literature and art, poetry, tragedy and eloquence, all in a chaotic state of misapprehension and misjudgment-indeed, in much the same position as that in which we find them today. Then, they were in the hands of the sophists; to-day, they are again in the hands of the sophists, and sophistry pervades nearly all that is written or said of them at the present time.

Blair says of eloquence-and all good writing, even poetry, as well as public speaking, may be considered a species of eloquence:

"Aristotle laid the foundation for all that was afterwards written on the subject (rhetoric). . . . Aristotle appears to have been the first who took rhetoric out of the hands of sophists, and introduced reasoning and good sense into the art. Some of the profoundest things which have been written on the passions and manners of men are to be found in his Treatise on Rhetoric." 
In Aristotle's time, the possibilities of experience were so limited and the horizon of human knowledge so circumscribed, that even genius such as his could not be expected to frame a philosophy capable of remaining unimproved and unenlarged through the ages; but considering what his environment afforded, Aristotle evidently made as good use of his opportunities as did ever any man.

Since Aristotle there have been but few able to improve his philosophy or even to enlarge upon it. Herbert Spencer, however, was another Aristotle, and he enlarged our intellectual horizon mightily. But in the far greater world of Spencer, the task which he undertook-the unification of knowledge-was a labor of Hercules compared with what Aristotle did or with what Spencer could have done had he lived in Aristotle's time. Had Herbert Spencer been able to devote the time and attention to literature and the fine arts that he devoted to the other profound problems with which he labored, he would, like Aristotle, have taken those subjects entirely out of the hands of the sophists and have given them an indestructible scientific basis. We may surmise what he might have done from what he did accomplish in his little treatise, "The Philosophy of Style," for there he did more than all mankind beside to place literary composition on the secure foundation of science.

As Ernst Haeckel says, "Nothing is constant but change," and nothing in human affairs remains at a standstill. Everything is changing either for the better or for the worse, either improving or degenerating. In literature and the fine arts, along with the formative processes have been going on others powerfully degenerative.

Wisdomless egotists, ambitious of place and of favor, have polluted with sophistry all the fountains of human judgment on the subject of poetry, painting and literature. The religious bigot of the Middle Ages, in order to protect his dungeon of ignorant superstition from the torch 
of reason and the lamp of science, pronounced blind faith the most eminent of virtues; made heresy the most hated word in the world, inquiry the most heinous felony. Similarly the sophists, with respect to poetry, seek to inhibit reason and to thwart investigation by claiming that poetry transcends understanding; that it is a thing of God; that it would be a sacrilege to place it upon the dissecting table as a subject for scientific investigation.

Since the time of Aristotle, so little advancement has been made in the understanding of poetry that it is as tho there had been a universal agreement on the part of mankind to strive for knowledge of everything except this single subject; to reason and to be reasonable about everything else, but to leave poetry forever as in the dark ages of thought.

Herbert Spencer said that, as he grew older, he came to realize more and more how little the great mass of mankind is governed by rationality.

The reason why there has never heretofore been framed a rational and adequate definition of poetry is the crass ignorance of the accepted authorities concerning the fundamental principles. Such a definition is needed by every student of poetry at the very start.

Voltaire said, "Let us first define our terms, then proceed." Often, however, it is more difficult to interpret a current definition of poetry than to understand the thing itself without the definition. This is especially true when the framer of the definition does not himself understand what he is defining, and seeks to appear profound by using an array of words of striking sound and obscure meaning, covering his ignorance in a fog of meaningless phrases, as the cuttlefish throws out an inky cloud to conceal its presence.

No other subject has been made the victim of more definitions that do not define than has poetry. There is no other topic about which the multitude knows so little, while assuming to know so much. 
Guided by the bookish definitions of the critics, we are forced to conclude that poetry is something transcending comprehension, something outside the province of human understanding. Small wonder, then, that scarcely any one seems to know what poetry really is, or exactly where the poet belongs among human phenomena.

In most lay minds, and even in the minds of many esteemed as authorities, there is no well-defined idea as to what constitutes the poet. They know not whether he should be regarded as a person differentiated from others by virtue of a superior literary genius and attainment, a person possessing greater wisdom, better philosophy or a happier faculty of expression, and therefore deserving of homage and reverence; or whether he should be deemed a species of freak, a human curiosity, a sort of neurotic degenerate, a Caliban afflicted with a kind of periodic hysteria or frenzy, the cacoëthes scribendi, under the influence of which he is impelled to write poetry.

It is possibly this uncertainty about the genus poet that has evolved the hermaphroditical, long-haired, Pegasean equestrian, who seems to imagine that flowing locks have something to do with the over-soul. Joaquin Miller once wrote Edwin Markham, "Let your hair grow and be a poet."

Those spirituelle persons of both sexes who imagine themselves poets and prate about the Pierian spring, and wear a calf-like cast of countenance, deeming the sweet and mellowed look indispensable to the poetic atmosphere, are others of the fungi germinated and grown in the same cavern of ignorance.

Ambition moves on lines of least resistance, and when phantasmagorial eccentricity is confounded with merit the path is made kinder for the halt and the blind.

Mankind has long been looking for correct definitions of love, happiness, duty, and of that form of expression which best voices them-poetry-but without success. Why? Because every one either has looked too high- 
over the head of fact, beyond the truth and among the stars, or has looked into the fog for light. Even the unthinkable and the unknowable have been made the pillars of numerous philosophies. We have been told that we must look to the universal for the true interpretation, or to the soul as a manifestation of the universal-things more vague, unfamiliar and remote than those we seek to define. We have been told that what we seek has its source in God. Now, as we can have no conception of God except through the very attributes on which we want light; and as God is infinite and can not be compassed by human understanding, we feel that we are all at sea and that the ship is dragging anchor, that we can not get a good hold in all this mud of definition and that we are drifting farther and farther into the fog.

Let us now review a few of the multitudinous indefinite definitions that the authorities have given us for a compass with which to steer our course, whose sole effect is, nevertheless, to lead us deeper and deeper into the haze of obscurity.

Let us first quote from a little book entitled "What is Poetry?" by Edmond Holmes, author of "The Silence of Love," a volume of love sonnets, and other works of muddle, mist and moonshine. Mr. Holmes is a very good type of the professional definition-maker-a fine specimen of the most common warden of ignorance. There are many like him, and they have succeeded in binding poetry to ignorance with a Gordian knot. I therefore quote Mr. Holmes at considerable length, and what I say of his views will apply to a very large class.

\section{"What is poetry? There are as many answers} to this question as there are minds that take an interest in it. . . . When I ask myself, What is Poetry? I am setting myself a task which far ' $e x$ ceeds man's might.'

There can be but one true answer to this question. There can be but one true answer to any question. Tho 
a question may be answered in innumerable ways, still only one answer can be the true one.

What Mr. Holmes meant is, doubtless, that, whatever answer one gives, he is sure to hit poetry somewhere, as one would the broadside of a barn used as a targetfor he says :

"Each answer in turn is as real and true as the individual life which it summarizes and the personality which it expresses and reflects."

If one can not tell what poetry is, how can he recognize it? How can he judge it? How could a man born blind know the beauties of the rainbow? How could he define those beauties? If there be as many answers to the question, What is Poetry? as persons, there is then no certainty that any such thing as poetry exists at all. Differences of opinion on a subject disappear as the subject becomes understood, and in exact proportion as it is understood.

But let us continue our quotation from Mr. Holmes, repeating a couple of lines, which are well worth it:

"When I ask myself, What is Poetry? I am setting myself a task which far 'exceeds man's might.' I am inviting myself to solve, by implication, all the master problems of human thought. And if I take my own answer seriously, I do so not because I think that the question can be answered, but because I know well that it can not; not because I flatter myself that I have succeeded where others have failed, but because I see in the failure which awaits us all, convincing proof that the problem is worthy of our highest endeavors, and that each answer in turn is as real and true as the individual life which it summarizes and the personality which it expresses and reflects. . . .

"I am about to set out on one of the most desperate of all enterprises; and in order to pro- 
vide myself with a base, I must ask to be allowed to make two initial assumptions:

"(1) That poetry is the expression of strong and deep feeling;

"(2) That wherever there is feeling, there is something to be felt."

Altho Mr. Holmes is wrong in most things, I am inclined to believe him right in this last assumption of histhat when we feel anything, it is an indication at least that there is something to be felt. A toothache, for example, indicates that there is a tooth to be felt.

Mr. Edmond Holmes reminds me of the man who was asked by a young lady if he could play the violin, since she wished some one to accompany her with that instrument, and who answered, "I don't know, as I never tried; but I will do the best I can." Mr. Holmes confesses that he knows nothing of poetry, yet he volunteers a definition of it. In fact, he claims that it can not be defined, that it belongs to the unknowable, that to define it is "a task which far exceeds man's might." In justice to Mr. Holmes, we must admit that he is no more culpable for taking a try at a definition of poetry than are equally ignorant predecessors and contemporaries.

The first definition he ventures is: "Poetry is the expression of strong and deep feeling." He continues: "True poetry is the language which feeling finds for itself."

We have frequently heard cab-drivers and truckdrivers, when coming into collision, give expression to strong and deep feeling. How few of us have realized that the volleys of expletives and epithets hurled back and forth on those occasions constituted true poetry!

Edgar Allan Poe, in his admirable essay on "The Poetic Principle," tells us that "a poem deserves its title only inasmuch as it excites by elevating the soul." Some cab-driver poetry then, in the light of Mr. Holmes' definition and Poe's interpretation, ought to give a tremendous bounce to the soul! 
Mr. Holmes further tells us something about the nature of passion that is unique:

"Passion means suffering. The passionate heart is one that suffers much." And he adds, "What the poet suffers is not trouble or sorrow, tho even to these he is perhaps more than ordinarily sensitive, but the stress of Nature's influence, the despotic might of his own inborn genius."

And Mr. Holmes is himself the author of a volume of poems!

I am glad to know that the poet, too, has to suffer for it. I have sometimes been inclined to think poetry intended only to make others suffer. A poem, according to Mr. Holmes, is a sort of wail, a rhythmic sigh, voicing an agony in the soul of the poet, under "the despotic might of his own inborn genius." What an affliction such a genius must be! Putting such a genius as that into a man is like putting a thousand horse-power motor into a tenfoot boat, or a locomotive engine into an automobile runabout, where the vehicle would be shaken to pieces by its own machinery.

Robert G. Ingersoll has the following to say about passion. I quote from his article on "Art and Morality":

"It has been the object of thousands of reformers to destroy the passions, to do away with desires; and could this object be accomplished, life would become a burden, with but one desirethat is to say, the desire for extinction. Art in its highest form increases passion, gives tone and color and zest to life. But while it increases passion, it refines. It extends the horizon. The bare necessities of life constitute a prison, a dungeon. Under the influence of art the walls expand, the roof rises, and it becomes a temple."

How plain it is that Ingersoll is right, and that Mr. Holmes is wrong, about passion! Passion is nerve po- 
tential, which makes us tend to let strong faculties have free rein in their exercise, because that exercise gives strongly gratifying sensations.

Let us refer again to the literature of Mr. Holmes:

"Now, if it be true that poetry is the interpretation and expression of man's deeper life, and that his deeper life is the seat of his personality, then it is certain that poetry, true poetry, is personal in the fullest sense of the word, and in the highest possible degree. But just because it is personal, and just so far as it is personal, it is free from the taint of individuality. For the deeper we go into the buried life, and the nearer we get to the springs of poetry, the nearer also do we get to those dormant passions and unformulated thoughts which seem to be potentially common to all men, and which constitute a secret bond of sympathy between man and man. And so it comes to pass that universality, not individuality, is of the essence of the poet's genius; that he belongs to mankind even more than to himself; that he is in secret sympathy with the hidden lives of his fellow men; and that his poetry, the voice of his personality, wakes a response in the hearts of others, not only in his own time, but also in far distant ages."

I have quoted the above paragraph from Mr. Holmes for the purpose of illustrating the difficulty one has in describing something about which he knows nothing. Such definitions require to be lengthy and replete with abstractions of abstruse meaning, in order to give the reader a desired impression of the great size of the author-the impression that the author is profound-and to give the reader the conviction that he is getting a masterful definition when he is not getting a definition at all. This sort of literary conjuring requires a certain kind of art-an art of which I shall treat further on.

Mr. Holmes has a vivid imagination, excellent musical faculty, much veneration, great self-esteem, large powers 
of observation, but his bump of causality is small. He is a poor reasoner and a poor natural philosopher. He is blind to the interpretation of natural phenomena.

Mr. Holmes says at the start that he is "about to set out on one of the most desperate of all enterprises." Let us, as Voltaire directs, first define our terms. Let us turn to the definition of the word desperate. According to the Standard Dictionary, it means:

"Without care for danger or safety; reckless, as from despair or rage; as, continued misfortune had rendered him DESPERATE; something resorted to in a last extremity, or as if prompted by utter despair; most hazardous; hence, marked by recklessness ; furious."

Looking at the matter from the viewpoint of $\mathrm{Mr}$. Holmes himself, and realizing that his language is that of a desperate man, uttered under the influence of rage, despair, or fury, uttered without care for danger or safety, language resorted to in a last extremity, we may pardon him.

What should we think of an engineer who, in applying for a job to run a locomotive, recommended himself by declaring that he knew nothing about the steam-engine; that the steam-engine is something transcending human understanding; that it involves principles far beyond man's ability ever to solve or comprehend?

And what should we think of a railroad official who employed such an engineer to run an express train? Yet, it is customary for poetic engineers to recommend themselves in exactly this manner, by proclaiming their profound ignorance of the subject.

It may be argued that Edmond Holmes is only a literary lightweight. This will hardly do, for not only is he considered a great authority by many, but his bumptious logic also is typical of the great majority of the most venerated authorities.

Charles F. Johnson, professor of English literature 
in Trinity College, Hartford, makes the following statement in his "Elements of Literary Criticism":

"We say that these qualities-unity, music, wit, etc.-are referable to certain powers of the author's mind, altho we have no right to say that the mind possesses powers or parts at all. When we speak of the different mental powers-imagination, argumentative powers, etc.-altho, as far as we know, no such powers exist-we mean merely the unknown and entirely inscrutable differences which make some men's writings argumentative and others imaginative. Possibly we might say that we are conscious that these qualities of the writings address different elements in our own minds, tho we should be very apt to mislead ourselves if we did so, and there is certainly no reason that we should run any such risk. Indeed, there is good reason to say that the most important of the mental operations which result in the production of something artistic do not take place in the realm of consciousness at all, but in some deeper, inscrutable region, and are taken up into the similar hidden region in our own minds. Thus, some of the literary features of folk-lore and mythology can be explained only by saying that they are unexplainable."

If a wild Comanche Indian chief were to make an excursion of investigation through the United States, to see the workings of the scientific apparatus, the mechanical and electrical appliances and devices of modern civilization; and if, on his return to his people, he were interrogated for an explanation of what he had witnessed, he would probably first assert that these things all transcend human understanding-that it is utterly impossible for them to be understood by the human mind; but this much he could tell them: that all electrical apparatus are simply the works of the devil; that the telephone belongs to the black art, and its voices are those of spirits; that the steam-engine is actuated by power borrowed from the infernal regions; and that the trolley-car is propelled by 
the mysterious hand of some demon of the earth and air. His people would then marvel at his wisdom, and would be glad that they had been made to understand these things.

Professor Johnson admits very frankly that he knows as little of his subject as the Comanche chief could know of the arts and sciences and civilized appliances. Not only this, but, like the Comanche Indian, he proclaims unknowable whatever transcends his own understanding, simply for the purpose of magnifying the subject, to give the reader the impression that, in view of its size and the difficulties in its treatment, the task of the author resembles the labors of Hercules, for no one but a giant can do a giant's work. It does not do to let the subject appear simple and the task of treating it an easy one. It would rob the author of that reverence and admiration with which he desires to be haloed.

The main trouble with Professor Johnson is that his generalizations are not good, and that he makes the mistake of magnifying the subject by claiming for it inscrutability in order to focus upon himself the enlarging glass of wonder. Still, when Professor Johnson gets down out of wonderland and to the definite treatment of his subject, we find many good things; and he succeeds at last in throwing light on much that in the beginning he pronounces inscrutable and unexplainable. His book is a valuable one, in spite of his bid for the halo of wonder.

According to the Standard Dictionary, poetry is :

"The form of literature that embodies beautiful thought, feeling, or action, in melodious, rhythmical and (usually) metrical language, in imaginative and artistic constructions."

Then foilow brief definitions by leading authorities:

"Poetry is rhythmical, imaginative language, expressing the invention, taste, thought, passion, and insight of the human soul."

-E. C. Stedman, "Nature of Poetry." 


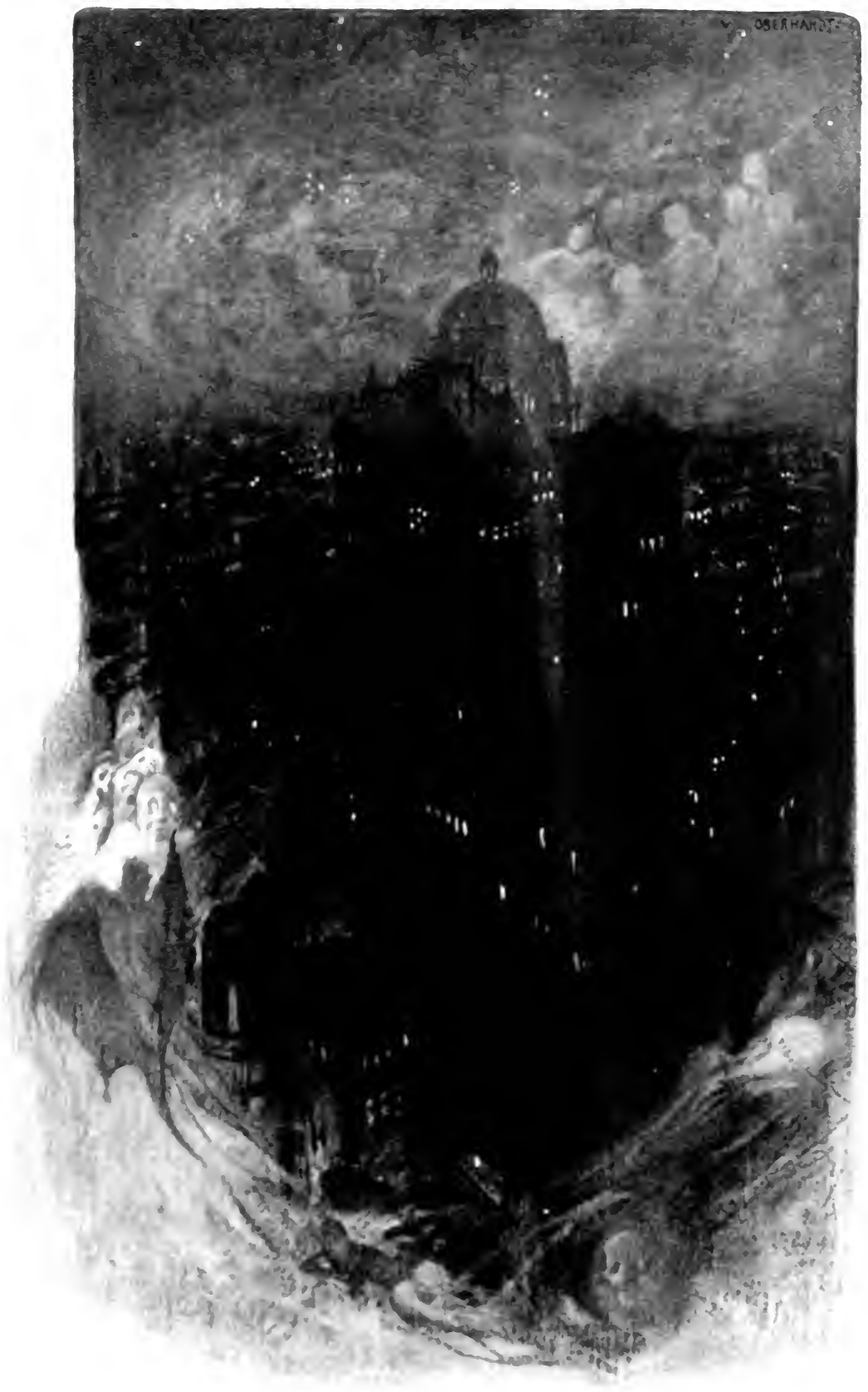

Sill fromerisen flenmed

There. maylue. goris rommunad with somls of men

(1) anf ful themes bereund all merlal h, 1 .

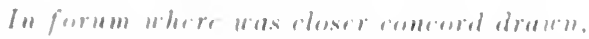

Hid in the hours before the gnerpling deann. 
.

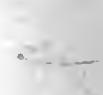


"Absolute poetry is the concrete and artistic expression of the human mind in emotional and rhythmical language."

-Theodore Watts, in Encyclopedia Britannica.

"We must accede to the opinion that only rhythm, and not meter, is essential to poetry. But even this is an indulgent construction. In the full development of its nature what we call poetry unquestionably demands meter."

-Bernard Bosanquet, "History of the Esthetic."

Each of these dictionary definitions confounds poetry with verse, and holds that poetry must be melodious, rhythmical and emotional, while, as a matter of fact, none of these qualities is essential to it.

These dictionary definitions, despite their air of wisdom, appear funny in the face of our newly discovered facts.

Leigh Hunt, in his "Imagination and Fancy," has written a very elaborate definition, under the title, "What is Poetry?" He does not undertake to magnify his subject by classing it with things inserutable, unthinkable and inexplicable, yet he does magnify it in another way. Leigh Hunt's way is to make his definition a long one and to elaborate it with abstractions having obscure meanings, and to create such a maze of winding and twisting sentences that, by the time the reader has waded through the definition and emerged at the other end, he gets the impression that the size of the fire must be in some proportion to the volume of smoke-that it surely must be a ponderous subject which requires a definition so immense and so mysterious.

Leigh Hunt was the friend and patron of the poets. He was a great and good man, and withal, a literary genius; but the heart led him into hyperbole, as it has many great men big enough in other respects to ornament human nature.

Leigh Hunt's definition was written, not to define, but 


\section{THE SCIENCE OF POETRY}

to throw a haze over the subject and make it loom up like a woodchuck in a fog.

Altho Leigh Hunt does not pronounce poetry inscrutable, he gives us a definition that is inscrutable, to wit :

"Poetry, strictly and artistically so-called, that is to say, considered not merely as poetic fecling, which is more or less shared by all the world, but as the operation of that feeling, such as we see it in the poet's book, is the utterance of a passion for truth, beauty, and power, embodying and illustrating its conceptions by imagination and fancy, and modulating its language on the principle of variety in uniformity. Its means are whatever the universe contains; and its ends, pleasure and exaltation. Poetry stands between nature and convention, keeping alive among us the enjoyment of the external and the spiritual world: it has constituted the most enduring fame of nations; and, next to Love and Beauty, which are its parents, is the greatest proof to man of the pleasure to be found in all things, and of the probable riches of infinitude.

"Poetry is a passion*-[Author's foot-note: Passio, suffering in a good sense,-ardent subjection of one's self to emotion]-because it seeks the deepest impressions; and because it must undergo, in order to convey them.

"It is a passion for truth, because without truth the impression would be false or defective.

"It is a passion for beauty, because its office is to exalt and refine by means of pleasure, and because beauty is nothing but the loveliest form of pleasure.

"It is a passion for power, because power is impression triumphant, whether over the poet, as desired by himself, or over the reader, as affected by the poet.

"It embodies and illustrates its impressions by imagination, or images of the objects of which it treats, and other images brought in to throw 
light on those objects, in order that it may enjoy and impart the feeling of their truth in its utmost conviction and affluence.

"It illustrates them by fancy, which is a lighter play of imagination, or the feeling of analogy coming short of seriousness, in order that it may laugh with what it loves, and show how it can decorate it with fairy ornament.

"It modulates what it utters, because in running the whole round of beauty it must needs include beauty of sound; and because, in the height of its enjoyment, it must show the perfection of its triumph, and make difficulty itself become part of its facility and joy.

"And lastly, poetry shapes this modulation into uniformity for its outline, and variety for its parts, because it thus realizes the last idea of beauty itself, which includes the charm of diversity within the flowing round of habit and ease.

"Poetry is imaginative passion. The quickest and subtlest test of the possession of its essence is in expression; the variety of things to be exprest shous the amount of its resources; and the continuity of the song completes the evidence of its strength and greatness. He who has thought, feeling, expression, imagination, action, character, and continuity, all in the largest amount and highest degree, is the greatest poet.

"Poetry includes whatsoever of painting can be made visible to the mind's eye, and whatsoever of music can be conveyed by sound and proportion without singing or instrumentation. But it far surpasses those divine arts in suggestiveness, range, and intellectual wealth; - the first, in expression of thought, combination of images, and the triumph over space and time; the second, in all that can be done by speech, apart from the tones and modulations of pure sound."

According to Hunt's definition, poetry runs through the whole gamut of entities, without leaving a spot in the universe big enough for a croquet-ground not covered a foot deep with it. 
The Fourth Commandment says:

"Thou shalt not make unto thee any graven image, or any likeness of anything that is in the heaven above, or that is in the earth beneath, or that is in the water under the earth."

How Moses might have simplified this, by saying: "Thou shalt not make unto thee any graven image of poetry"! For Hunt makes poetry embrace everything recited in the Fourth Commandment.

In spite of all his flowers of rhetoric-and Leigh Hunt's definition is a bouquet of them-we should never be able to find out what poetry really is from all he has told us. Poetry may be written on any subject whatsoever; and it is not the subject itself, as Leigh Hunt thinks, but is a manner of expression. Nevertheless, a very good word is due Leigh Hunt. In a poetic competition, he once beat both Keats and Shelley at writing a sonnet. He was generous, good and great. He was Keats' patron saint. He was the first to indicate in poems the lines of greatest excellence and to recommend them for emulation.

Artifice such as Leigh Hunt employed in his definition of poetry has been made use of from time immemorial, and not by the critic alone. It has been used by the huckster and the peddler; by the soul-stirring revivalist and the political stump-speaker. The promoter also has made great use of it in raising capital for the exploitation of innumerable schemes. But standing head and shoulders above all as the king of kings in this sort of thing, the very Napoleon of befoggers, was John W. Keely, the deviser and promoter of the Keely motor. I am sorry that Keely did not write about poetry or attempt to define it. His style of defining things worked so well as to transfer more than a million dollars from the pockets of other people into his, for his own use and behoof. His definition of electricity, copied from Mrs. 
Bloomfield Moore's book on Keely and his discoveries, will illustrate his useful method:

"Electricity is the result of three differentiated sympathetic flows, combining the celestial and terrestrial flows by an order of assimilation negatively attractive in its character. It is one of Nature's efforts to restore attractive differentiation. In analyzing this triple union in its vibratory philosophy, I find the highest order of perfection in this assimilative action of Nature. The whole condition is atomic, and is the introductory one which has an affinity for terrestrial centers, uniting magnetically with the Polar stream; in other words, uniting with the Polar stream by neutral affinity. The magnetic or electric forces of the earth are thus kept in stable equilibrium by this triune force, and the chords of this force may be exprest as, first, the dominant; second, the harmonic; and third, the enharmonic. The value of each is, one to the other, in the rates of figures, true thirds. E flat-transmissive chord or dominant; $\boldsymbol{A}$ flat-harmonic; $\boldsymbol{A}$ double flat-enharmonic. The unition of the two prime thirds is so rapid, when the negative and the positive conditions reach a certain range of vibratory motion, as to be compared to an explosion. During this action the positive electric stream is liberated and immediately seeks its neutral terrestrial center, or center of highest attraction.

"The power of attractive vibration of the solar forces is the great coincident toward which the terrestrial-magnetic-sympathetic flow is diverted. This force is the celestial current that makes up the prime third of the triple association. It also induces aqueous disintegration and thermal concentration, the two prime conductors toward this coincident chord of sympathy with itself. Without this aqueous disintegration there would be no connective link between the celestial and terrestrial. There would exist nothing but a condition of luminous radiation on the order of the aurora-a reaching out for the concordant 
without any sympathetic diversion to create unstable equilibrium of terrestrial magnetism."

When Keely got a quorum of capitalists about him to investigate his motor, with a view to making investments, he did not care how many scientific experts they brought with them-the more experts, and the higher their standing, the better for Keely. He knew how to take care of the experts. He had only to spring upon them one of the explanations of his system-one of these chaotic definitions, and it made them conscious of their littleness. Lost in his literary maze, and not knowing the meaning of his high-sounding scientific phrases, the experts felt as helpless as boys lost in windy Saharas. They knew that the words were scientific; for they had heard them before; but for their lives they could make no headway against Keely's terminological hurricane. The experts could not understand, and they would not confess. So they were ready to capitulate to save their reputations. They were ready to make Keely an ally-and Keely had won!

Among the few authors who have seen through the sham and shadow of the multitudinous high-flown definitions of poetry in current literature is Mark H. Liddell, recently professor of English in the University of Texas. His book is entitled, "An Introduction to the Scientific Study of English Poetry." He says:

"The word 'poetry' covers a multitude of careless generalizations. . . But not only is the popular usage of the word bewildering and confusing; the formal definitions of poetry as a part of literature are equally misleading. Metaphysical notions of supernatural inspiration are used to explain its origins; ethical notions of moral perfection are used to describe its influence wpon human life; esthetic generalizations proceeding from vague ideas of a mysterious beauty are used to classify its peculiarities; literary notions of absolute power and perfect fitness of expression are used to guide our appreciation 
of it into proper channels. In fact, all the vaguenesses and bewildering confusions which attend popular conceptions and descriptions of ethical, intellectual, moral, esthetic, and literary phenomena at some time or other enter singly or together into the discussion of this subject of poetry.

"We are told that 'poetry is a thing of God'; that it is 'the finer spirit of knowledge'; that it is 'something divine'; that it is 'the opposition of science'; that it is 'the inner thought of things'; that it is 'the completest expression of humanity'; that it is 'the language of ideality'; that it is 'the expression of the inner motions of the soul.'

"These are but a few of the vague and meaningless forms of literary expression that so-called definitions of poetry take."

While Mr. Liddell sees very clearly the sham in the definitions of poetry that have been perpetrated by its numerous expounders, he does not perceive the basic principle without which no just understanding of poetry can be had, no true definition framed. Like most other authorities, he confounds poetry with verse, and therefore deems the emotional concomitants of verse essential to poetry. He says :

"But there is emotion in poetry; emotion goes into the making of it and into the understanding of it-it is written in a 'fine frenzy' and is likewise to be read in a 'fine frenzy'-that is almost self-evident. That poetry's chief interests are emotional interests, therefore, is scarcely open to question."

What a pity it is that Shakespeare ever used that phrase, "fine frenzy"! It has become a fuddlesome factor in the framing of foolish fancies. It is to the honor of Shakespeare, however, that he came nearer to giving the world the true definition of poetry than has any other man, for he did explain what constitutes the true art of poetry-making, and from this we are enabled to know what 


\section{THE SCIENCE OF POETRY}

Shakespeare considered poetry. Curiously enough, it is in the very passage where Shakespeare uses that unfortunate phrase, "fine frenzy." Let us quote:

"The poet's eye, in a fine frenzy rolling,

Doth glance from heaven to earth, from earth

to heaven;

And as imagination bodies forth

The forms of things unknown, the poet's pen

Turns them to shapes, and gives to airy nothing

A local habitation, and a name."

-Midsummer Night's Dream, Act. V., Sc. I.

Granting that a poet may roll his eyes in a fine frenzy when turning out poetry, this does not necessarily indicate that the poetry produced must be frenzied. All of us feel a fine frenzy whenever we take an intense interest in our work, no matter what it is. We have all witnessed the fine frenzy of an enthusiastic inventor. Emotion is a necessary concomitant of every act of the mind, and the intensity of the emotion is directly proportionate to the interest taken in the act. There is no reason why the poet should have any finer frenzies over his work than an inventor has over his. In fact, the act of inventing and the act of making poetry are similar, both being essentially creative acts. We should not, however, think of defining an invention as an emotional production of the human mind. We should not think of calling a new steam-plow an embodiment of crystallized emotion-a term frequently applied to poetry. Why, then, should the poet have a monopoly of fine frenzy to the exclusion of the inventor, the mechanical engineer and the chemist, to say nothing of the geologist, naturalist, astronomer, philosopher and mathematician?

Come, poets and critics, let us be honest about this fine-frenzy business. Let us make mutual concessions in the sacred cause of science and truth. I have done some inventing, and altho I do not claim to be a poet, nevertheless, in writing this book, I have been obliged for pur- 
poses of illustration to take up the poet's pen and to frame some phrases by the poetic chalk-line, just as in building a powder-mill I have sometimes been obliged to take up the trowel and lay a brick wall by the mason's chalk-line. Perhaps my brick wall was not "pointed up" so well as that of the skilled mason, and perhaps, similarly, my poetry may not be "pointed up" so well as that of the professional; yet it has served me to find out the true inwardness of this fine-frenzy nonsense and to see that it is a hollow mockery. For I have certainly felt just as fine a frenzy, just as keen a delight, when working on some mechanical or chemical problem as did ever any poet at his lucubrations.

I am, therefore, forced to the conclusion that the frenzy we experience is always proportionate to the interest we take in a thing, and that the discoverer, inventor, philosopher and scientist at times thrill with this same fine frenzy in equal degree with the poet, when he feels like:

". . . some watcher of the skies

When a new planet swims into his ken; Or like stout Cortez when with eagle eyes

He stared at the Pacific-and all his men Look'd at each other with a wild surmiseSilent, upon a peak in Darien."

Keats indirectly confesses here that both the astronomer and the discoverer occasionally experience a fine frenzy.

We must strongly bear in mind the psychological truth that, altho the emotions accompany intellectual activities, they are not themselves intellectual activities. The emotions are sensorial phenomena, while poetry is a production of the intellect-an intellectual phenomenon. The wild beasts are quite as emotional as we are. We have the advantage of them in that our emotions are accompanied with more highly intellectual activities, and in that the sense of our emotions and the sense of our intellectual activities mingle together in the consciousness and color 
each other, and in that we are conscious of a blend of emotions with thought. Shakespeare must have meant by his phrase, "fine frenzy," this mental alloy of emotion and thought.

We who are blest with a good appetite must honestly admit that we feel a much more intense frenzy when a good dinner "swims into our ken" than we could feel when reading any poem ever written. But the dinner frenzy is of a lower order, for the very reason that it has more emotion in it and less thought than has the poetic frenzy. This indicates that as we go away from the emotions and in the direction of thought, at the expense of emotion, the less frenzy we have, and the more poetry we get.

I do not expect that the poets and day-dreamers will accept the above pronouncement without protest. They have always been in the habit of esteeming the emotional accompaniments of poetic thought as of a much higher and more spiritual order than those of other intellectual activities. Not only this, but they have confused emotional quantity with emotional quality, and depth with altitude, and have, therefore, sincerely believed that their emotional accompaniments of poetic thought have actually been more powerful and dominating than those that accompany other intellectual activities, and more powerful and dominating than the strong animal emotions, which are not necessary accompaniments of thought, but are often dominators of thought instead of being dominated by it.

The emotions accompanying high intellectual flight do not take so deep a hold upon us as do those aroused by the exercise of our purely animal propensities, for the reason that the emotions underlying and accompanying the exercise of animal passions underlie all other emotions. Man had his animal emotions long ages before he had any flights of intellect, and they are by consequence more vital. Herbert Spencer recognized that the human will 
generally bends in the direction of feeling, and that feeling generally wins.

Pope said:

" 'All this is madness,' cries a sober sage:

But who, my friend, has reason in his rage?

'The ruling passion, be it what it will,

The ruling passion conquers reason still.' ",

I grant freely that the emotional accompaniments of high intellectuality are of an accordant eminent order; but such emotions are not by any means so dominating and powerful as those of lower orders. The first requisite to great intellectuality in a man is to be a good animal. We can not have a powerful steam-engine without a powerful boiler to drive it. That a sound mind requires a sound body is a well-recognized truism.

What does Shakespeare mean by this expression?

"And as imagination bodies forth

The forms of things unknown, the poet's pen

Turns them to shapes, and gives to airy nothing A local habitation, and a name."

He means that abstract and intangible things lying outside experience are embodied by the imagination in the forms of concrete, tangible things lying within experience and endowed with their properties and attributes.

Had Shakespeare written a formal definition of poetry, it would, therefore, have been substantially the same as my own, as follows:

Poetry is the expression of insensuous thought in sensuous terms by artistic trope.

Shakespeare was a great philosopher, and he understood better than any other poet the nature of poetry, just as he understood better than others how to write great poetry.

Shakespeare was not only an intimate of men, but he introduced himself to, and made himself an intimate of, every creature and thing in his environment. Shake- 
speare was a naturalist of men-men were his subjects, his studies; and his poems are a human natural history.

We have seen in the first chapter that all pleasurehappiness, all enjoyment of every description-is derived from the exercise of faculty-consists in our consciousness of exercise of faculty. Therefore, we know that when we derive pleasure from poetry it is due entirely to the way in which it exercises our faculties. Even the pleasure in contemplation or appreciation of the beautiful and the sublime is due entirely to the exercise of faculty. Now, as poetry is substantially the art of giving sensuous expression to insensuous thought; that is to say, consists in using a language whose terms are familiar to the senses-terms of experience-we are naturally more stirred, more exercised, we feel the thought more, and we receive a clearer perception of it than were it exprest in a less sense-touching way.

Let us compare the mind to a lake of water, upon which a vessel is sailed. The vessel, in passing over its surface, sets up a rhythm of waves in motional response to the act of displacing the water by the moving vessel. Similarly, when a thought sails through the mind, it sets up waves of emotion, which have an intensity and amplitude proportionate to the mental effort or mental displacement produced in the act of perceiving it, just as the waves on the surface of a lake have an amplitude and intensity of movement proportionate to the displacement of the water by vessels of different sizes passing at different speeds. We should not think of defining the art of navigation as that of setting up waves upon the surface of water in motional and rhythmical response to the size and speed of vessels. It is equally stupid to define poetry as the act of setting up rhythmical waves of emotion in the mind, or as the rhythmical expression of the emotions.

So strong is the tendency of men in the shaping of thought to follow the lead of those haloed with reputation, 
and so strong is the tendency to think in the fashion, that we frequently find many minds, great in other respects, embracing, amplifying and passing on the most extraordinary breaches of logic, without in the least suspecting incongruities obvious to an unbiased reasoner. The subject of poetry has suffered more than any other from variation and distortion due to the authorities following a blind lead.

In the Encyclopedia Britannica, we find the following by Theodore Watts:

"What is Pontry?-Definitions are for the most part alike unsatisfactory and treacherous; but definitions of poetry are proverbially so. Is it possible to lay down invariable principles of poetry? . . Is it possible for a critic to say of any metrical phrase, stanza, or verse, 'This is poetry,' or 'This is not poetry'? Can he, with anything like the authority with which the man of science pronounces upon the natural objects brought before him, pronounce upon the qualities of a poem? These are questions that have engaged the attention of critics ever since the time of Aristotle. . . . Yet some definition, for the purpose of this essay, must be here attempted; and, using the phrase 'absolute poetry' as the musical critics use the phrase 'absolute music,' we may, perhaps, without too great presumption submit the following:

"Absolute poetry is the concrete AND ARTISTIC EXPRESSION OF THE HUMAN MIND IN EMOTIONAL AND BHYTHMICAL ILANGUAGE.

"This at least will be granted, that no literary expression can, properly speaking, be called poetry that is not in a certain deep sense emotional, whatever may be its subject-matter, concrete in its method and its diction, rhythmical in movement, and artistic in form."

It is too bad to be obliged to shatter our beloved idols, but the reader can not help now seeing that the great Theodore Watts was wrong in the second half of his 
definition. The first part of it, however, comes pretty close to the truth.

How do the other professional definers of poetry agree with the above definition?

"Poetry is the attempt which man makes to render his existence harmonious."-CARLYLE.

"Poetry is the record of the best and happiest moments of the happiest and best minds."

-Shelley.

" $A$ drainless shower

Of light is poesy; 'tis the supreme of power; 'Tis might half-slumbering on its own right arm." -Keats.

"Poetry is the breath and finer spirit of all knowledge; it is the impassioned expression which is the countenance of all science."

-WORDSWORTH.

"Poetry uses the rainbow tints for special effects, but always keeps its essential object in the purest white light of truth."-0. W. Holmes.

"Poetry is not the proper antithesis to prose, but to science. Poetry is opposed to science, and prose to meter. . . . The proper and immediate object of science is the acquirement or communication of truth; the proper immediate object of poetry is the communication of immediate pleasure."-CoLERIDGE.

"The true poem is the poet's mind. . . . The finest poetry was first experience-it does not need that a poem should be long, every word was once a poem. . . . For it is not meters but a meter-making argument that makes a poem."-EMERson.

"Poetry is word-painting."-J. R. Trumbuld.
"Poetry is the eloquence of truth." -T. Campbell. 
"Poetry is a lie to realize reality."

- Van Noppen.

"Poetry is the art of lying beautifully." - Hamerton.

"Poetry is the mixture of a lie that doth ever add pleasure."

- Sir Francis Bacon.

"Poetry is the morning dream of great minds."

-Lamartine.

"Poetry is the expression of the beautiful by words."

一J. Brown.

"Poetry is the frolic of invention, the dance of words, and the harmony of sounds."

-F. REYNolds.

W. J. Dawson, in his book entitled, "The Makers of Modern Poetry," speaking of the poetic art of Robert Browning, says :

"Art is not to be praised for what it achieves, but for what it aspires to. It is the yearning of the spirit not the skill of the hand, which gives it its real value."

He then defines art as follows:

"Art is simply an aspiration.",

The art of writing poetry, then, according to Mr. Dawson, consists simply in yearning and aspiring to write poetry, and has nothing whatever to do with the character of the stuff produced. Judging from much of the poetry in current periodicals, many editors evidently take the same view of poetry that $\mathrm{Mr}$. Dawson does.

According to Mr. Dawson, the art of making money does not consist in the actual acquisition of wealth, but 
the rich man is he who yearns for money. The shabby hobo is no longer to be despised, for according to Mr. Dawson he is the only true millionaire.

Among the very few besides Shakespeare who have approached near to the truth in defining poetry are Aristotle, Moir, Milton, Burke, Samuel Johnson, Theodore Watts and Herbert Spencer.

According to Aristotle, poetry is an imitative art. The word poet being derived from the Greek word maker, we may conceive the Aristotelian definition to be that poetry is a creative art of imitating nature. In the wider meaning of the word imitation in Aristotle's time, especially in the sense that all trope is a species of imitation, we may perhaps justly assume his definition to have been a creative art of expression by imitation-trope-which, as far as it goes, is true of poetry.

Edgar Allan Poe defines poetry as "the rhythmical creation of beauty," whose purpose is to "elevate the soul." The same is true of music. The same is true of a handsome flight of stairs. His definition, however, defines as far as it applies, except that rhythm is not an essential element of poetry. Poe was one of the few who claimed that poetry is not necessarily passionate or emotional. Still, as he confounded poetry with verse, he must have been wrong as far as verse is concerned, because verse is emotional.

What Samuel Johnson said of poetry is perfectly true, but it may be equally true of other things besides poetry:

"The essence of poetry is invention; such invention as, by producing something unexpected, surprizes and delights."

Herbert Spencer did not give us a formal definition of poetry, but in his "Philosophy of Style," he has told us that poetry conforms to the laws of effective expression, and for this reason it becomes poetry; that by the energy conserved, the metaphoric language of poetry enables the 


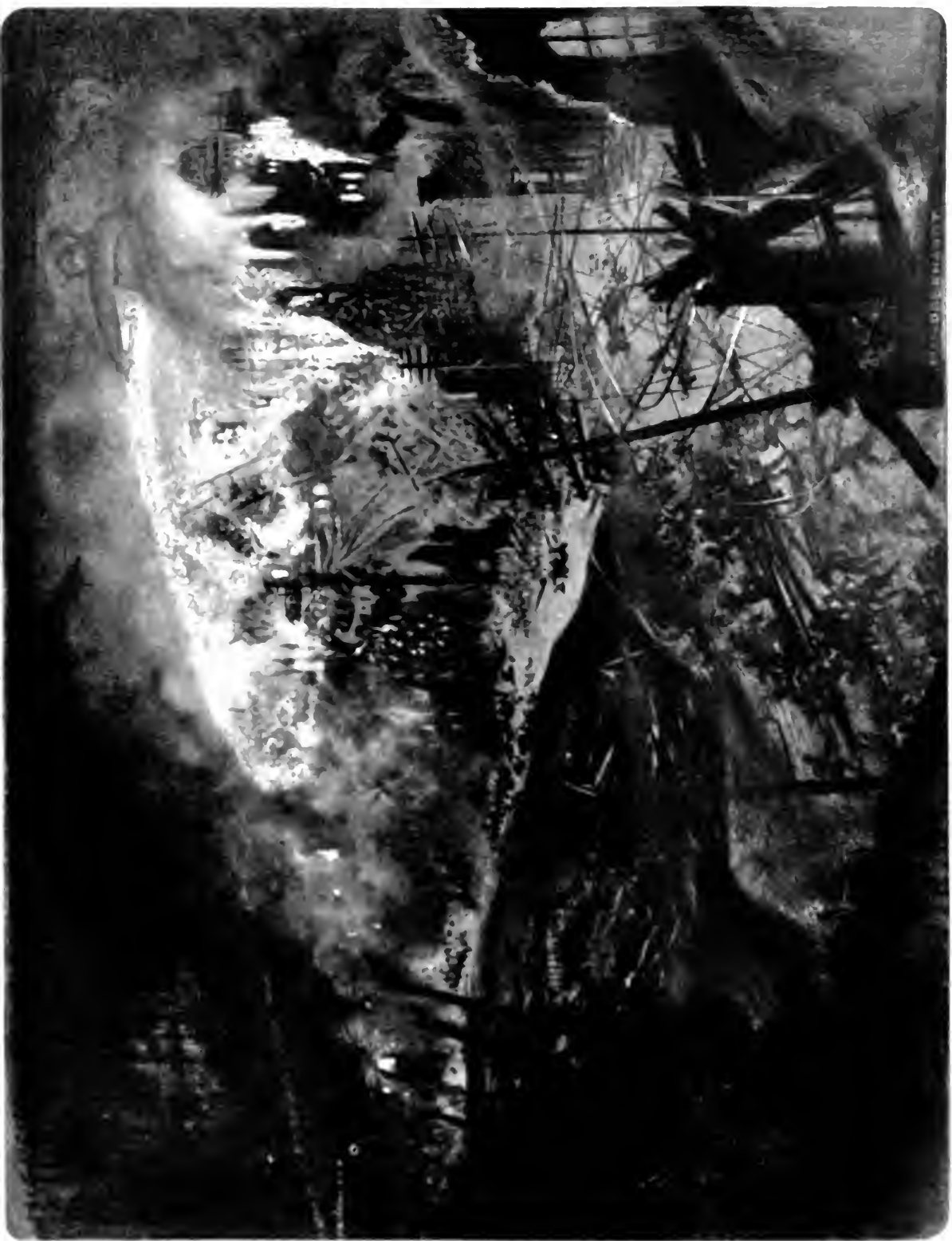



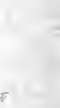

$=1$ 
idea to be perceived with greater clearness. But even Spencer erred by confounding poetry with verse:

"There is one peculiarity of poetry conducing much to its effect-the peculiarity which is indeed usually thought its characteristic one- . . . we mean its rhythmical structure."

I have one old book in my library, which I picked up for fifteen cents, second-hand, where I find the following words of wisdom. It is by George Moir, professor of rhetoric in the University of Edinburgh:

"In all high poetry a certain transforming and beautifying power of imagination is excited, which in some measure transmutes the forms of things from their actual prosaic aspect.

" 'Clothing the palpable and the familiar

With golden exhalations of the dawn.'

"Still less can verse or metrical form be regarded as constituting the essence, or even one of the essentials, of poetry. It no doubt heightens its effect; it increases its charm and power of pleasing, by enlisting the aid of musical sound and cadence on the side of imaginative language or touching sentiment; but it must yet be regarded as amongst the externals of poetry,-something which will never make poetry of itself, and without which poetry is not only conceivable, but has in fact existed, and that in very striking and impressive forms.

"Poetry may perhaps be defined to be an art which has creation of intellectual pleasure for its object, which attains its end by the use of language natural in an excited state of the imagination and the feelings, and generally, tho not necessarily, formed into regular numbers. The proper antithesis, therefore, to poetry, as $\mathrm{Mr}$. Coleridge has remarked, is not prose, but science. The proper antithesis to prose is verse. Science seeks to instruct, to discover and to communicate truth; "the proper and immediate object of poetry is the communication of immediate pleasure.' Poetry may indeed incidentally instruct, as science 
may indirectly communicate pleasure; but the object of each must be gathered from its main direction and bearing, and in this sense the production of INTELLECTUAL enjoyment is unquestionably the aim and the proper province of poetry."

Even if we knew nothing of first principles upon which to base our reasoning, we should be certain, from the great diversity of opinions among the authorities, that most of them must be wrong. Some of the pronouncements, indeed, are so utterly absurd that we wonder they could ever have been offered with seriousness. Take the definition of art, for example, by Dawson. How could any sane man write a definition like that, especially a man of Dawson's great ability?

To close the chapter, I append my own definition:

Poetry is the expression of insensuous thought in sensuous terms by artistic trope. 


\section{CHAPTER V}

\section{POTENTRY}

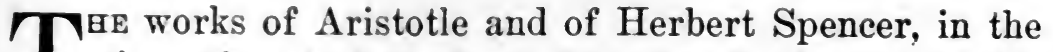
time of each, have been the great landmarks of advanced thought. Like Aristotle, Herbert Spencer took literary composition and rhetoric out of the hands of the sophists, and did more than any other writer since Aristotle to place them on a scientific foundation.

Spencer was an intellectual giant, who gave a new horizon to human knowledge, while his work serves as a touchstone of doctrinal soundness, and as a landmark of intellectual advancement. What he did is very suggestive of what still lies in the unexplored region beyond the Spencerian frontiers, and serves as a guide to enable others, starting where he left off, to penetrate the unknown even farther than he did. I shall, therefore, begin this chapter by quoting at considerable length from Spencer's "Philosophy of Style":

"Carrying out the metaphor that language is the vehicle of thought, there seems reason to think that in all cases the friction and inertia of the vehicle deduct from its efficiency; and that in composition, the chief, if not the sole thing to be done, is, to reduce this friction and inertia to the smallest possible amount. Let us then inquire whether economy of the recipient's attention is not the secret of effect, alike in the right choice and collocation of words, in the best arrangement of clauses in a sentence, in the proper order of its principal and subordinate propositions, in the judicious use of simile, metaphor, and other figures of speech, and even in the rhythmical sequence of syllables.

“. . A certain effort, tho commonly an inappreciable one, must be required to recognize every vowel and consonant. If, as all know, it 
is tiresome to listen to an indistinct speaker, or read a badly-written manuscript; and if, as we can not doubt, the fatigue is a cumulative result of the attention needed to catch successive syllables; it follows that attention is in such cases absorbed by each syllable. And if this be true when the syllables are difficult of recognition, it will also be true, tho in a less degree, when the recognition of them is easy. Hence, the shortness of Saxon words becomes a reason for their greater force. One qualification, however, must not be overlooked. A word which in itself embodies the most important part of the idea to be conveyed, especially when that idea is an emotional one, may often with advantage be a polysyllabic word. Thus it seems more forcible to say, 'IT Is MAGNIFICENT,' than 'IT Is GRAND.' The word VAST is not so powerful a one as stupendous. Calling a thing NASTY is not so effective as calling it DISGUSTING."'

Language is generally considered as an apparatus for the mere conveyance of thought, but it is much more than that. It is as much an apparatus for the thinking as for the conveying of thought. No human thought, beyond the simplest sensuous impressions, can have existence except in a methodical arrangement of symbols constituting language, by which thoughts are both formulated and conveyed. Not only do we think in terms of the arbitrary symbols of language, but through the imagination we feel as well the tonal potentiality of the sounds mentally uttered in the thinking. A spoken thought is but the repetition aloud of the thought already uttered in the mind.

Spoken language is also an apparatus that utilizes the properties of oral sounds to give emotive impress to thought. In other words, oral sounds, used as the signs of ideas, are also emotional stimuli, varying in effect proportionately to their loudness, duration, pitch and timbre; inducing in the mind of the hearer moods in harmony 
with the thoughts exprest, thereby attracting his attention and energizing and qualifying his mind for perception. This is a discovery that has not, so far as I know, been heretofore promulgated. Nevertheless, its truth, I think, must be granted.

Consciousness is constantly being appealed to for attention, and unless especially attracted the attention does not rest for long upon a given idea or chain of thought, but wanders to other ideas and other chains of thought. I quote the following from William James' "Psychology":

"There IS No SUCH THING as voluntary atTENTION SUSTAINED FOR MORE THAN a FEW SECONDS Aт A тIME. What is called sustained voluntary attention is a repetition of successive efforts which bring back the topic to the mind. The topic once brought back, if a congenial one, DEvELOPS; and if its development is interesting it engages the attention passively for a time. . . . This passive interest may be short or long. As soon as it flags, the attention is diverted by some irrelevant thing, and then a voluntary effort may bring it back to the topic again; and so on, under favorable conditions, for hours together. During all this time, however, note that it is not an identical OBJECT in the psychological sense, but a succession of mutually related objects forming an identical TOPIC only, upon which the attention is fixt. No ONE CaN POSSIBLy atTend Continuously TO AN OBJECT THAT DOES NOT CHANGE."

Biologists have found that when there is a very strong demand for the development of a property or attribute in living organisms, it is only a question of time when evolution will meet the need.

Owing to the tendency of the hearer's mind to wander from the speaker, it is a rational assumption that nature has provided the speaker with some means of attracting and retaining the hearer's attention. The mind of the hearer, like any other natural agency, moves on the lines 
of least resistance; and as attraction is the negation of resistance; and as any source of pleasure is always attractive; and as the emotive properties of the sounds uttered by the speaker are pleasure-yielding, the speaker is able to attract and largely control the attention of the hearer. We have all frequently seen a speaker seize a person's arm, to hold his attention while telling him something. Similarly do the tonal powers of utterance serve to tether the hearer to the speaker.

According to Herbert Spencer, language, considered as an apparatus for conveying thought, like any other apparatus, is most nearly perfect when it is of the simplest construction and does its work with the least expenditure of energy. He claims that "the chief, if not the sole thing to be done (in composition) is to reduce the friction and inertia (of the language apparatus) to the smallest possible amount."

If the expression of thought were the sole purpose of language, if the energy consumed in the expression and in the apprehension of the thought represented equivalent loss by speaker and hearer, if the expenditure of a greater amount of energy by the hearer in the apprehension of a given thought were always at the expense of vividness of apprehension, then Spencer's dictum of economy would be true. But, in addition to serving as a vehicle of thought, language utilizes oral sounds to give pleasurable exercise to the emotive faculties and to stimulate and increase the powers of perception, by endowing the hearer with greater energy for his use.

Spencer's dictum, altho exactly true as far as it goes, falls short of stating the whole truth. It is true in a restricted sense-true in certain applications, and not true in others. Frequently, that language is best which consumes the largest amount of energy in the expression of a given thought. It would be better, therefore, to say that that language is best which utilizes the powers of utterance to the best advantage. 
Spencer founded his "Philosophy of Style" upon the principle of conservation of energy as applied in physics and mechanies; and his pronouncement has been generally accepted by literary men the world over as a truism broadly applicable to language, instead of what it is-a truism applicable to language in a restricted sense.

Besides being a vehicle of thought, an apparatus for conveying ideas, language is also an instrument for the conversion of energy into pleasurable emotions, which serve to energize perception; so that in the expression of thought the faculties of both speaker and hearer are exercised to the highest degree consistent with the production of the emotive states desired. Hence, altho language should utilize energy with economy, still that language apparatus is best which, while consuming energy with economy for a given purpose, converts the most energy into useful work-effective expression. One may travel by horse and wagon with far less expenditure of energy than by automobile, but the pleasure may be immeasurably less and the distance covered also far less.

The following statement is quite contrary to that of Spencer, but it is equally true: Considered as a vehicle of thought, that language is best which utilizes, with the greatest economy, the maximum of energy of both hearer and speaker in the production of pleasurable emotions as concomitants of the thought conveyed.

Every normal action of man is pleasure-yielding, and Spencer himself tells us, in his "Origin of Music," that the emotions find their most natural expression through the oral apparatus. And further, he tells us, in effect, that as pleasurable emotions are far more common than painful ones, it naturally follows that a larger number of pleasurable emotions find oral expression than of those that are painful. Spencer thus accounts for the pleasurable effect of music upon us. It is unquestionably true that much of the pleasurable effect is due to this fact.

Practically all human utterance is accompanied by 
sensations of pleasure in both speaker and hearer. The main purpose of a very large proportion of literature, including all the works of the poets and of the composers of music, is the production of pleasure. Other aims, such as didactic inculcations and the pointing of morals, are only secondary. A song sung in an unknown tongue may be pleasing, altho it does not convey a single thought.

The use of oral sounds to convey thought was not their original use. The indication and stimulation of emotions were the original use, and their application as a vehicle of thought came later. Arbitrary word-symbolism is an interloper. But as thought-conveyance increased opportunity for the utterance of pleasure-giving sounds, and as the expression of thought by those pleasure-giving sounds could not be dissociated from the giving of pleasure to both speaker and hearer, the oral apparatus of primitive man most willingly lent itself to the new use; and oral sounds used as arbitrary signs of ideas in the expression of thought have been joined with emotional sounds for the delight of both speaker and hearer.

All language, whether prose or poetry, is of necessity more or less emotional, because the very perception of words and sentences has some emotional concomitants, for some emotion is a necessary concomitant of every mental process. The mere act of being conscious is more or less emotive, because all of which we can be conscious, whether objective or subjective-external things or mental impressions and mental states-are stimuli of the general sense of feeling, of which consciousness is the sense of awareness. But the term emotional, in its generally accepted sense, is applicable only to supermedial states of the mind, for we speak of sounds as emotional only when their expressiveness is supermedial-when they are pitched either above or below the middle register, or when uttered with unusual loudness or unusual lowness or with unusual duration upon the periods, requiring unusual oral effort. 
All language is, broadly, either suggestive or reflective. That is to say, the thought either is directly suggested to the mind by declaration, exclamation or commanc; or is presented unassertively or interrogatively, inviting examination and reflection preparatory to its acceptance.

Reflective language appeals to the understanding, and suggestive language to faith. Reflective language seeks to impress the mind through the powers of reflection, to convince by reason and analysis; and suggestive language through the emotions.

While the language of logic, or non-suggestive language, aims to awaken the understanding, and thereby to establish the thought in the mind on a sounder foundation than that of belief, suggestive language tends to inhibit the critical powers of the mind and to cause the thought to be accepted on faith without examination or analysis. Hence, suggestive language is most effective when the understanding is not awakened.

Suggestive speech is best served by monotone, and by declarative sentences, by rhythm, by musical cadences, and by sonorous, potential and mouth-filling words, because of the tonal impressiveness in the sounds uttered, which enlist the sympathies entirely aside from the symbolic significance of the sounds.

The study of physies, mechanies, arithmetic, geometry and the higher mathematics requires alertness and a wakeful, questioning state of the mind; while the inculcation of creeds requires an unquestioning and somnolent state of the critical faculties of the mind. Suggestive speech impresses belief upon the hearer. It intrudes conviction without examination, while reflective speech appeals to the intellect. The one appeals to the emotions, the other to the understanding. The hypnotist makes use of the suggestive tonal properties of speech. The power of oratory depends upon the tonal potentiality of oral sounds, combined with figures of speech.

Those men who have swayed the multitude have done 
so by telling the people things in an authoritative and declarative way, and by working upon their sentiments and passions, their fears and desires. Those who have reasoned with the multitude and appealed to its understanding have never made any fanatical followers, for fanaticism does not rest upon the understanding. The great revivalists have always been suggestive talkers. Reason has played small part in their exhortations. They have painted with an artist's skill a fearful picture of hellfire and the condition of the lost soul, using hell for a hedge fence of thorns and briers, and the devil for a dog to drive sinners into heaven, through fear on the one hand and the prospect of great reward on the other. The mother's "By-low, Baby By," is void of idea; it is the monotonous cadence that induces slumber. The usual speech of the street-preacher or the demagog is a step higher, but it is similar in nature; it is not burdened with ideas.

Sir Isaac Newton, Herbert Spencer, Darwin, Huxley, Tyndall, Haeckel, and such men, could not sway the multitude by faith. Their task has usually been to educate and lift the multitude by slow degrees, first appealing to an intelligent few, and through them instructing the many. Tyndall was admittedly a very successful lecturer, and aroused intense interest in his audiences, but it was not that fanatical enthusiasm of the typical religious revival. Tyndall appealed to the understanding in such a simple, direct, lucid and concrete way that he delighted his hearers while he instructed them. Herbert Spencer's style is a splendid example of the lucid speech of reason, while that of Tyndall is a remarkable example of Spencerian speech specially adapted to reach the understanding of the common mind. Spencer speaks to the educated mind, to the scholar; while Tyndall appeals to the understanding of the less educated, the less proficient. Spencer's speech presupposes a knowledge of terms current among scientific men. Tyndall's speech presupposes a knowledge of only elementary scientific speech and familiar expressions. 
When the main purpose of language is to convey ideas, then, whatever the style, it must be judged by its efficiency as a vehicle of thought. Considered as a vehicle of thought, that language is best which, by the simplest form of construction and the least expenditure of energy on the part of both speaker and hearer, conveys a given thought with the greatest distinctness and fixes it in the hearer's mind. But it is still necessary that, while presenting the thought clearly and lucidly, it shall also, by its tonal form, attract the attention and energize the perceptive faculties of the hearer to facilitate a full apprehension of the thought.

The above broad view of language is consistent with the following, in spite of the seeming paradox: Considered as a vehicle of thought, that language is best which utilizes with the greatest economy the greatest amount of energy of both speaker and hearer.

There is no English word, and I know of no word in any language, to cover that property of speech which renders it more than usually powerful, sonorous, impressive or sublime, a property not dependent for its power on trope, the basic principle of poetry; a property which, tho including rhythm, may be entirely independent of it; something, therefore, independent of both poetry and verse, yet constituting one of the most important elements in effective expression at our command, which, when coupled with poetic figures in verse, adds greatly to the strength and vigor of language. Such a word is needed, and I have, therefore, taken the liberty of coining one. I have chosen the word potentry, derived from the Latin word potens, meaning powerful, from which root our words potent, potential, potentiality, and the like, are derived.

The dynamics of spoken words depend upon two things: first, upon what the sounds symbolize as arbitrary signs of ideas; and, second, upon the significance of their loudness, duration, pitch, tone-color and imitation, 
summed up in the kinds of sounds and the effort of their utterance by the speaker.

I have given the name potentry to the tonal or potential properties of speech, and have used the term arbitrary symbolism for that property of speech based upon the meanings of words, independently of their tonal significance.

It must be borne firmly in mind that the function of language is twofold: the expression of the thought, and the energizing and qualifying of the hearer for thoughtreception. Such are the dynamics of spoken words. The energizing property of speech depends upon the tonal potentiality of the sounds uttered, and this potentiality depends upon the significance of the quantitative properties of sounds-loudness and duration; upon the qualitative properties of sounds-pitch and tone-color; and upon the directly imitative and analogically imitative character of the sounds. We are exhilarated by a bugle-call. We are naturally impelled to step to a march played by a fife-and-drum corps. The Marseillaise played by a brass band stimulates and exalts us. Similarly do the tones and tunes of the speaking voice arouse in the hearer emotions corresponding with those of the speaker, and in this way the extra effort necessary to apprehend a more potential form of utterance finds ample compensation in the added energies with which the hearer is endowed.

Herbert Spencer made the mistake of taking the available energy of both speaker and hearer as a constant, while it is by no means a constant; for it is capable of being increased or diminished very greatly according to the emotive properties of the sounds uttered. On these emotive properties of sounds potentry is based, and it is independent of any symbolic significance. All imitative or analogically imitative significance of words, and all powers of awakening associated ideas by words or tones, and all properties of words that tend to stimulate or impress the hearer by virtue of any sound-effects whatsoever, belong 
to potentry. It will be seen, then, that potentry overlaps and embraces that part of symbolism where words are either directly or analogically imitative of the idea exprest. But arbitrary word-symbolism is wholly independent of potentry.

In potentry, the sounds mean something as sounds, while in the case of arbitrary symbols the sounds are without meaning as sounds, but are used arbitrarily as signs, like the ticks of a telegraphic instrument. The numerals, $1,2,3,4,5,6,7,8,9,10$, are good examples of arbitrary symbols.

Spencer modified the broadness of his assertion by admitting that a word embodying the most important part of the idea to be conveyed, especially when the idea is an emotional one, may often with advantage be a polysyllabic word. He explained that words with mouth-filling properties, by their very size, are suggestive of largeness and strength, because they admit of more emphatic articulation; and that, as emphatic articulation is a sign of emotion, the unusual impressiveness of the thing named is implied by it; and further, that mouth-filling words allow the hearer's consciousuess a longer time to dwell upon the quality predicated.

Spencer came very near to the discovery of the great fundamental truth, that the function of language is twofold, namely, to convey thought, and to energize the mind of the hearer by means of the emotive properties of the oral sounds uttered.

To illustrate that phase of tonal impressiveness due to increased dwell upon the predication of a thought: If in speaking of a certain event, we say that it was the saddest event in history, the statement is simply plain, literal prose. But if we say, it was the most calamitous event in all the history of the human race, we express practically the same thought, but do it with very much greater vigor, and the property that constitutes this vigor is what I term potentry. 
We have but to compare the simple prepositional phrase, in history, with the amplified prepositional phrase, in all the history of the human race, in order to be fully convinced that there is such a thing as potential amplification-potentry. The short, simple phrase carries the same meaning as the amplified one; but the amplified phrase does something more than present the actual meaning, for, to use a homely expression, it rubs the meaning in. The energies of both hearer and speaker would be the more conserved by the shorter phrase, but the longer and more mouth-filling phrase, by its very size and the length of the periods and the natural elevation and greater loudness of the voice to correspond, gives the meaning greater impressiveness and renders the expression more effective, for the reason that not only are certain thoughts more strongly indicated and symbolized to the hearer, but his mind is more strongly stimulated and qualified for perception.

Length or brevity, ease or difficulty, of utterance, ruggedness or smoothness of oral sounds, symbolize to the mind of the hearer qualities of size or power, which indicate that a requisite effort on his part must be made for the perception of the thought. This is potentry.

Potentry, then, is the art of amplifying the impressiveness of thought-expression by correspondingly differentiating and amplifying the sounds symbolizing the thought. This will do as a broad definition of potentry. Potentry, like verse, is a phenomenon of sound, and verse itself is but a branch of potentry. Potentry, being concerned only with impressiveness of sounds, consists in the art of making language more vigorous, sonorous, impressive or sublime, by effectively disposing and amplifying the number and volume of sounds, and the periods of dwell upon sounds, used as symbols of the thought. To this end, potentry is replete with modifying and qualifying words and with repetitions far beyond the manner of ordinary prose. 
Potentry is a broad term, embracing intonation, modulation, repetition, and all expedients for arranging, prolonging and amplifying sounds and the effects of sounds in language. Whenever a long, mouth-filling and sonorous word or phrase is used in place of a shorter synonym, as a stupendous edifice, for a big house, that is potentry. When the same word or words of similar sounds are repeated, as in all forms of rime, or as in the following lines, it is potentry:

\section{"Alone, alone, all, all alone, Alone on a wide, wide sea!"}

We look at a big house, but we contemplate a stupendous structure. The word vast, tho a strong one, is not so impressive as the word stupendous. "It is more forcible to say, 'It is magnificent,' than, 'It is grand.' Calling a thing nasty is not so effective as calling it disgusting."

In explanation, Herbert Spencer says :

"There seem to be several causes for this exceptional superiority of certain long words. We may ascribe it partly to the fact that a voluminous, mouth-filling epithet is, by its very size, suggestive of largeness or strength; witness the immense pomposity of sesquipedalian verbiage: and when great power or intensity has to be suggested, this association of ideas aids the effect. A further cause may be that a word of several syllables admits of more emphatic articulation; and as emphatic articulation is a sign of emotion, the unusual impressiveness of the thing named is implied by it. Yet another cause is that a long word (of which the latter syllables are generally inferred as soon as the first are spoken) allows the hearer's consciousness a longer time to dwell upon the quality predicated; and where, as in the above cases, it is to this predicated quality that the entire attention is called, an advantage results from keeping it before the mind for an appreciable time." 
Again, Spencer's explanation does not go far enough. He had not discovered the primary reason for the greater impressiveness of sonorous polysyllabic words: that greater loudness and longer dwell upon sounds signify the arousal of greater energy in the speaker, due to a correspondingly greater prompting cause, and indicate equivalent effort of utterance, and tend to arouse the hearer to corresponding effort of perception and to energize him for the extra effort.

We emphasize words by increasing the pitch, loudness, and duration of utterance, and it is just as impossible for the hearer to prevent hearing the sounds as to prevent being roused, stimulated, and imprest by them. Stimulation and impression are as much parts of the apprehension of sounds as is the actual act of hearing. When we see another person gape, catching the mood, we, too, gape. We can not see a picture of some one gaping, or even think of gaping, without feeling like gaping also. This is because the act of apprehending the orgasm stimulates us to a like orgasm.

The thought of vinegar causes a sensation at the articulation of the jaw. The catching of moods is as much a part of the apprehension of speech as are the catching of sounds and the catching of thought, for we just as involuntarily and surely are affected by the nervestimulating and mood-inducing, energizing properties of sounds uttered as we are by what those sounds symbolize.

The following, from Milton's "Paradise Lost," is both good potentry and good poetry:

". . . Him the Almighty Power

Hurled headlong flaming from the ethereal sky, With hideous ruin and combustion, down To bottomless perdition."

The potential words of Milton are very impressive of the thought exprest. The same thought may be exprest in the following lines, but the thought is not so forcibly 


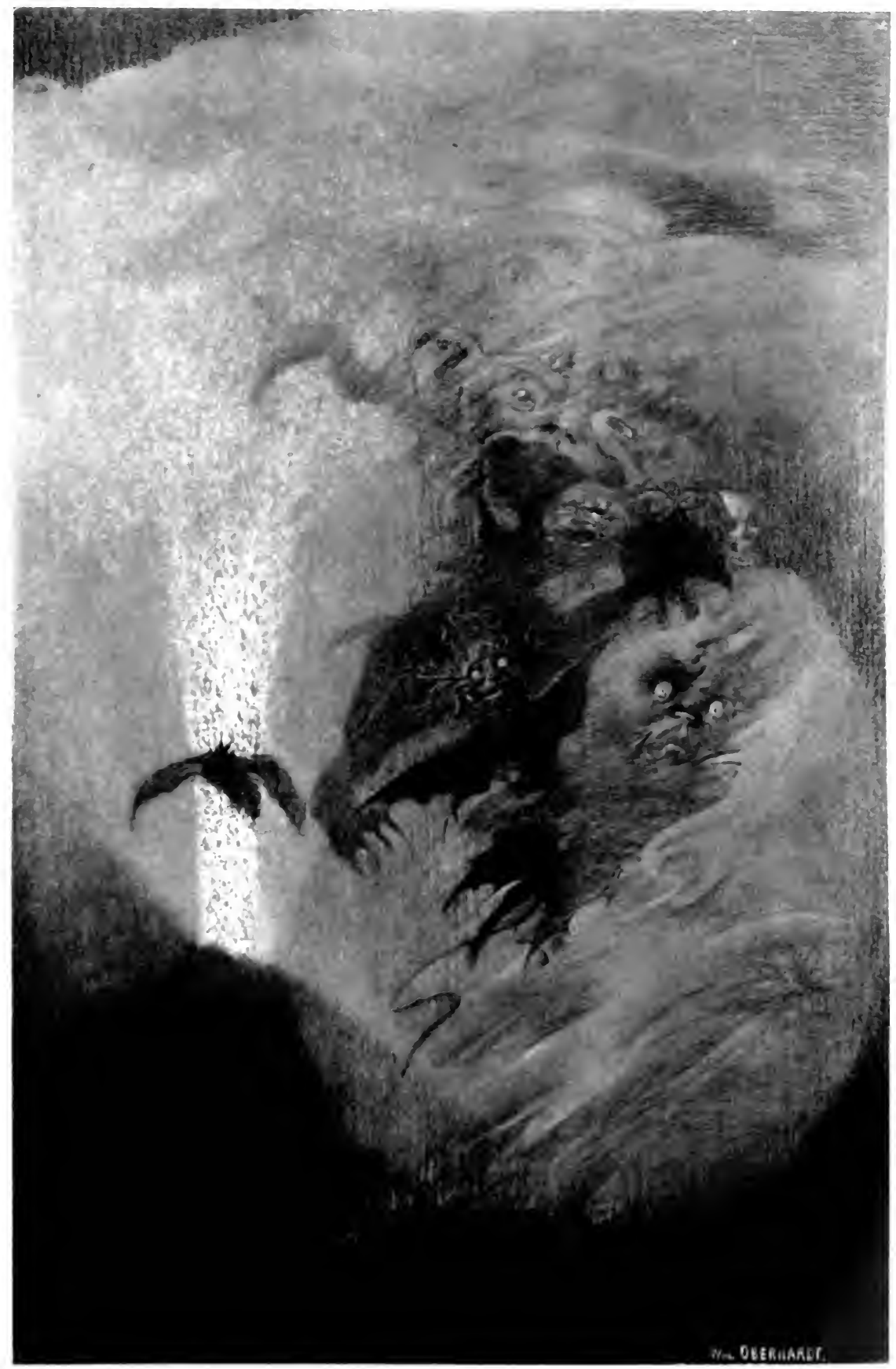

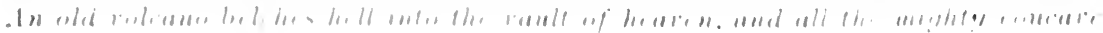

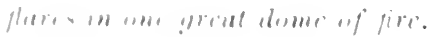



imprest. We have the expression but not the impression of the thought. The impressive form of expression is potentry; the other is not.

Him the God-force sent head-first on fire from the sky, with very great hurt and burning, down to deepest ruin.

The vigorous and sonorous character of Milton's words is lacking in the substituted lines.

Let us also translate Milton's words into French-a language far less potential than English-and note the loss of power:

"Le Tout-Puissant le lança flamboyant de la voute éthérée; ruine hideuse, il tomba brûlant dans des profondeurs sans fin de perdition."

The English words Almighty Power are stronger than the French words Tout-Puissant, and the word hurled than the French lança.

The words hurled headlong, besides being alliterative, are otherwise peculiarly impressive, much more so than would have been the words cast downward. The expression cast flying would have been even weaker than cast downward, and sent flying weaker still than cast flying. But there is room for still further descent. Had Milton used the words sent head-first, he would have exprest himself even more weakly than had he used the words sent flying. What an enormous difference there is in the potentiality of the expression Him the Almighty Power hurled headlong, and the expression Him the God-force sent head-first! It is obvious, therefore, that, altho words may be of equal length and have equal mouth-filling properties, they may possess vastly different potential properties. The reason for this is that they fill different parts of the mouth, parts that utter less potential sounds 
and sounds of less duration. Of course, the associated ideas that different words arouse somewhat modify the significance of their actual tonal properties.

In connection with the foregoing, the following lines of Pope are interesting, for the reason that they combine words used as arbitrary symbols with words and measures both directly imitative of sounds symbolized, and analogically imitative of the properties or qualities of objects and actions symbolized; while their tonal properties are very impressive of the thoughts exprest.

"'Tis not enough no harshness gives offense, The sound must seem an echo to the sense. Soft is the strain when Zephyr gently blows, And the smooth stream in smoother numbers flows;

But when loud surges lash the sounding shore, The hoarse, rough verse should like the torrent roar:

When Ajax strives some rock's vast weight to throw,

The line too labors, and the words move slow:

Not so, when swift Camilla scours the plain, Flies o'er the unbending corn, and skims along the main."

It requires more conscious effort to perceive Ajax striving some rock's vast weight to throw, than to see Ajax throw a stone; and when "swift Camilla scours the plain, flies o'er the unbending corn and skims along the main," the words, by the ease and rapidity of their utterance, symbolize the ease and rapidity with which the perceptive faculties are required to follow her in her flight. Words uttered slowly and with throat-notes are indicative of slow movement and of power; words uttered with rapidity and in a higher pitch and with lip and teeth sounds are indicative of swift motion and lightness of movement; and words replete with liquid sounds indicate 
smoothness, whether slow or rapid of movement. There is liquid smoothness in the lines:

"When swift Camilla scours the plain," etc.,

and still more in the line:

"Lulls with Amelia's liquid name the nine."

Time and effort of utterance are always indicative of the time and effort required by the consciousness for perception, and the tonal properties of words stimulate and qualify the mind for perception. Speed of utterance of words, the pitch and the tone of the voice, are all manifestations of muscular stimuli, and consequently represent effort. It is easier, naturally, to utter sounds in the middle of the vocal register than at either extreme. It takes greater effort to make very low or bass notes than to make middle notes; and it takes greater effort to utter notes of high pitch than for middle notes. It takes also greater effort to utter words rapidly than slowly; that is to say, with medium slowness. But it takes unusual effort to utter words with extreme slowness. Great loudness and long dwell upon sounds are indicative of greater expenditure of energy on the part of the speaker than when the words are short and spoken in a low voice. The more unusual the effort, the more difficult.

We have seen in the preceding chapters that poetry is a phenomenon of thought and depends upon the use of words with respect to their meanings, and that the basic principle of this use is trope. Poetry relates to expressiveness of thought, and potentry to impressiveness of thought. One expresses, the other impresses thought. This truth must beeome a mental fixture.

I am aware that some crities will challenge my right arbitrarily to restrict the definition of absolute poetry to trope, to the exclusion of verse, and will hold that the term poetry has been used by the many for centuries in such a broad sense as to include both figurative language 
and verse; and they will balk at any innovation which to their minds tends to limit the scope of poetry. Altho such a position would be untenable, still for the nonce we shall let the critics have their way. Let them do as they please with the venerated word poetry. Let them continue to embrace and worship it. Let the enthusiasts still go to the limit, and, like Leigh Hunt, define poetry as embracing everything under the sun-yea, more, even the universe itself. We shall make a word of our own for our purposes. We are hunting for truth, and a new word will suit our purpose better right here than the word poetry, because the new word will not be encumbered with any of those associated ideas that tend, in spite of our newly acquired understanding, to lead us from exactitude in its use; and exactitude is essential in the search for truth.

In modern science, it is very often necessary to coin new words for the expression of new ideas, and to name new things and new properties of things. To all figurative language-that is to say, all language whose basic principle is trope-we shall take the liberty of giving the name tropetry; and when figurative language is used in conjunction with what we have named potentry, we shall call it tro-potentry. As rhythm, whose basic principle is time, that is to say, periodicity, is the basic principle of verse, we shall call verse tem-potentry. When we have a mixture of trope and verse and potentry, we shall call it tro-tempotentry, continuing to employ the chemist's method of word-building. When we have something that is simply plain, literal statement, we shall call it literatry, from the Latin word litera, a letter. Literatry is literal statement -non-figurative language, or language where figures have lost their original metaphorical significance.

According to our new terminology, language is divided into six branches with respect to the manner in which thought is exprest through sound-symbols used as the signs of ideas: Potentry, tropetry, literatry, tro-potentry, tem-potentry and tro-tem-potentry. 


\section{APPLICATION OF THE FUNDAMENTAL PRINCIPLES OF COMPOSITION AND RHETORIC-POTENTRY, TROPETRY, LITERATRY, TRO-POTENTRY, TEM- POTENTRY AND TRO-TEM-POTENTRY.}

\section{T ET us readjust our bearings:}

Potentry relates to the impressive use of sounds as distinguished from their symbolic expressive use. It relates to the use of sounds to stimulate and energize, independently of what they stand for as signs of ideas. Language becomes potentry when its impressiveness is supermedial. Not all prose is potentry, but potentry embraces all verse, because all verse is supermedial in impressiveness.

Potentry being a broad term, embracing all the impressive properties of oral sounds as distinguished from the use of sounds as arbitrary symbols, it may be, in consequence, divided into several classes: first, tempotentry, whose basic principle is time-rhythm in verse; second, potentry of emphasis, depending upon the loudness and duration of sounds; third, potentry of tension, depending upon the pitch of the voice, indicative of the tenseness of the emotions; and fourth, potentry of tonecolor, depending upon timbre-accent and the coloring of the sounds with emotional tone-blends. But for the purposes of this book, I employ the term potentry in the broadly inclusive sense, and as the basic principle of verse is rhythm, a time element, I make the term tem-potentry include not only rhythm, but all the other branches of potentry as well when employed in verse.

Verse is a phenomenon of sound. "Verse is a set of specially related sounds," whose purpose is to excite pleasure as nerve and thought stimuli. Hence, all forms 
of verse belong to potentry, regardless of either potentiality or weakness, because all forms of rhythm, rime, alliteration, reiteration and dwell have to do with the use of sounds with respect to periodicity-time. All verse is tem-potentry.

The academicians have so strongly reprobated tautology as something to be sedulously avoided that it has come to be considered an inexcusable blemish in literary productions to repeat one's self. As a matter of fact, repetition is one of the most potential means at our command for impressing thought. Any number of repetitions is permissible as long as there is an apparent need for them, and as long as they do not become too obvious or tiresome. This practise is recognized and justified by the greatest poets and established by the masterpieces of literature. It is true of the Hebrew Scriptures, of the Indian Vedas and the Norse Sagas, and of Homer, Shakespeare and Milton.

Tropetry is a branch of arbitrary symbolism, where arbitrary signs of sensuous ideas, or concrete imagery, are used to express insensuous thought, and is wholly independent of either the tonal impressiveness or imitative character of the sounds employed.

Just as potentry relates to supermedial impressiveness of the sounds used in language, so tropetry relates to supermedial expressiveness by the use of figure.

Literatry is plain, literal, prose statement, the sounds employed being used arbitrarily as the signs of ideas, like the ticks of a telegraphic instrument, or the numerals used in counting. Literatry employs the minimum of stimulative, imitative or impressive use of sounds such as constitute potentry. There is, of course, a residual of tonal impressiveness in literatry, just as there is a residual of figure, but just as the figure has largely become arbitrarily symbolic, so the tonal properties also have largely become arbitrarily symbolic.

Literatry is non-figurative language. Nevertheless, 
since nearly all words had a material origin and were once metaphors, even literatry may contain obsolete figures-dead metaphors-and still be pure literatry.

By long use, many metaphors have entirely lost their original material significance. The metaphoric use of the word heart is so common that it has become literal statement for one to say that he takes anything to heart, or that he has eaten a hearty dinner. The word understand no longer suggests standing under. The word husband no longer suggests the original metaphor, house band. The metaphoric use of the word sweet has been so much abused that it has lost nearly all its sensuous meaning. It no longer occurs to any one that the expression sings sweetly, or sweet song of a bird, is a figure of speech.

Not only do words once sensuous become abstract while still retaining the same sense, but also words frequently acquire by long use very dissimilar meanings, and sometimes meanings quite opposite from the original. This transition is termed desynonymization.

The word miscreant once meant unbeliever. Silly was originally the synonym of happy, fortunate, blessed. Now it contemptuously designates the foolish. Once the reverent named the Savior the "Silly Babe." In the modern signification this were blasphemy.

There is nothing wrong with this expression: Overcome with the heat, and undergoing a severe headache, I went under a shade-tree. But it would be ridiculous, if we used some of the words in their original sense: Come over with the heat, and going under a severe headache, I underwent a shade-tree.

When a figure has become so use-worn and hackneyed as no longer to awaken any awareness of the fact that it is a metaphor, then it has ceased to be a figure of speech, and has become literal. When a metaphor no longer enlists the imagination and requires translation in the mind from the figure to the literal, then it has become literal. 
Words adopted from a foreign tongue, more especially from a dead language, lose much of their original significance, and gradually lose it entirely. For example, the word sincere originally meant without wax. In ancient Rome there were cheats among the furniture manufacturers, who filled up faults and blemishes with wax and painted them over. Hence, it became customary to speak of sound furniture as sincere, without wax.

Tro-potentry. When language is made unusually expressive of the thought by means of trope, and unusually impressive of the thought by means of the potential use of sounds, we have tro-potentry. Tro-potentry is the combination of tropetry and potentry.

Tro-tem-potentry. When tro-potentry takes the form of verse, whose basic principle is time, being essentially rhythmical, we have tro-tem-potentry.

Language is in a state of constant transition, from concrete to abstract, from image to arbitrary symbol, from heterogeneity of imagery to homogeneity of arbitrary symbolism.

The letters of the alphabet and our numeral characters were once pictures, but long use has made them arbitrary signs. The figurative expression of one age becomes the literal of the next. In this way our language, which is now in the main arbitrarily symbolic, has been developed, keeping pace with the growing power of the human mind to receive insensuous impressions without first being prepared for them by sensuous suggestion or illustration.

The terminology of the modern scientist consists almost entirely of arbitrary symbols.

It is kindness to children and the aged to assist them across a crowded thoroughfare; while the strong man would be annoyed by the offer of such assistance, and would resent it. Similarly, the child is aided in his primer by many pictures, while the educated adult does not require them, and would find them a nuisance. The strong man prefers to carry a heavy burden in one load, rather 
than to divide it and bear it piecemeal. Similarly, the strong intellect, accustomed by classical education to the use of arbitrarily symbolic language, generally prefers it to figurative language.

In the realm of modern science, there is so much lying beyond the power of imagery to suggest or express that the scientist has become accustomed to walk only in the field of abstract thought.

All thoughts do not admit of expression in figurative language. Science has penetrated so far into the realm of abstract truth that much insensuous thought now admits of no analogical representation by sensuous things. Then pure literatry alone applies. No figure of speech could express the binomial theorem. When, in physics and philosophy, we pass beyond the frontiers and enter the region of insensuous thought, which can have no analogical representative in sensuous things, then pure literatry alone applies. Hence, the intrusion of imagery is not always an assistance. On the contrary, it may be a needless encumbrance. Nevertheless, the modern classical education tends to adhere too closely to the literal, whereas a leavening of figure would be beneficial and relieve many an essay of its tiresome dryness.

The tendency of academic education is toward literatry, and away from tropetry and potentry, for the reason given: that as terminology becomes time-worn, metaphors lose their figurative sensuous meaning and become insensuous and abstract arbitrary symbols of ideas. As potential impressiveness is a natural concomitant of sounds used in figurative expression of thought, potentry tends also to become obsolete from the atrophy of metaphor.

The "slump in poetry" has been a source of much wonder to modern literary men. The foregoing facts explain this slump. Formerly language was much more figurative; therefore, much more poetical.

It has been my aim in the following examples to give 
as nearly as possible pure specimens of potentry, tropetry, literatry, tro-potentry, tem-potentry, and tro-tem-potentry.

The reader must bear in mind, however, that in these examples, when the use of a metaphor or other figure of speech has become so common and familiar as to cause no surprize by its use, then it is merely an arbitrary symbol of an idea and quite independent of its metaphoric meaning; it is no longer a figure of speech.

\section{SPECIMENS OF PURE POTENTRY.}

The following specimens of potentry are nearly free from live figure, while the language is neither rimed nor blank verse. It is prose.

\section{THE SACKING OF ROME.}

"The plundering of the eternal city by the northern barbarians was the most calamitous event in all the history of the human race."-ANon.

ENGAGEMENT BETWEEN FLEET AND SHORE BATTERIES.

The earth-jarring thunder of the sea-coast gun, the hum of the great steel bolt as it whirs along its way, the crash into the armored side of the battleship, join in one confounding roar, reverberating echoes in the deep foundations of the everlasting hills.-Exм.

FROM WEBSTER'S REPLY TO HAYNE.

"I shall pronounce no encomiums on Massachusetts. There she stands-behold her and judge for yourselves. There is her history; the world knows it by heart. The past at least is secure. There is Boston and Concord and Lexington and Bunker Hill, and there they will remain forever. The bones of her slaughtered citizens fallen in the awful struggle for independence now lie mingled with the soil from Maine to Georgia, and there they will remain forever."-DANIEL WEBSTER. 
NAPOLEON.

I saw him a child, seated on a lofty crag of his island home, drenched by the storm, watching the lightning flash; and pulsing with the thunder peal and the break of ocean on the shore-all sights and sounds harmonious with his lofty soul.-Exм.

FROM THE DUEL BETWEEN THE "MONITOR" AND THE "Merrimac."

"The huge iron pendulum swung. A flash, a thunder roar, and a solid iron shot weighing $a$ hundred and seventy pounds was hurled against the mailed side of the Merrimac.' Never were such bolts hurled from the fabled hands of Jupiter Olympus."-Јона S. C. Аввотт.

FROM THE SPEECH OF SPARTACUS TO THE GLADIATORS.

"Ye call me chief; and ye do well to call HIM chief who, for twelve long years, has met upon the arena every shape of man or beast the broad $\mathrm{em}$ pire of Rome could furnish. If there be three in all your company dare face me on the bloody sands, let them come on! And yet I was not always thus - a hired butcher, a savage chief of still more savage men! My ancestors came from old Sparta, and settled among the vineclad rocks and citron groves of Syrasella.

"Oh, comrades! warriors! Thracians! If we must fight, let us fight for ounselves. If we must slaughter, let us slaughter our oppressors! If we must die, let it be under the clear sky, by the bright waters, in noble, honorable battle."

-E. Kelloga

\section{SPECIMENS OF TRUE TROPETRI}

The following examples are true tropetry. They are replete with trope, but the structure is not rhythmical, being neither rimed nor in blank verse; and the specimens do not possess any qualities of unusual grandeur or sub- 
limity. In other words, they lack that quality which we term potentry.

"Socrates thrust the spear of question through the shield and heart of falsehood."

"His brain took counsel of his heart. To every foe he offered reconciliation's hand."

"The complex, tangled web of thought and dream . . . has never yet been raveled back to simple threads."

-Ingersoll.

"Faint streaks of purple soon blushed along the sky; the whole celestial concave was filled with the inflowing tides of the morning light."

- Edward Everett.

"A breath of will blows eternally through the universe of souls in the direction of the Right and the Necessary."-Emerson.

"If I take the wings of the morning."-BiBLE.

\section{CONCERNING A HEAP OF CLOUDS.}

"Who saw the narrow sunbeams that came out of the south and smote upon their summits until they melted and moldered away in a dust of blue rain? Who saw the dance of the dead clouds when the sunlight left them last night, and the west wind blew them before it like withered leaves?"

-RUskin.

\section{BANQUET TO SPRING.}

Now are all terrestria merging toward the vernal equinox, and the pregnant air is big with unborn laughter; while shelvèd song is waiting in the good old wine with corked-up merriment, to free the fancy and let the soul deeps well to brimming in the eye-dream that gives to Eros freedom of the reason and chains the during future up to the heart's hazard.

Then give the hand to friendship's hand around the board, and drink to the present-to the 
time that bears us freight. Let eons gone, with all their wintered cares, be eons dead, and warm. us at the morning smiling in our face. Let us laugh at the yeurs, and send them laughing on. Be prodigal of gladness as the spring, and carpet all the coming way of summertime with bud and bloom and green of joyousness.

Let the webs of age on the old wine be broken and the boul of amity be filled, and let the glad vine fruit again in poetry, music, song and good fellowship, and eyes let hang on eyes over the. soul's brink until the hours take on their nightshift.-ExM.

\section{SPECIMENS OF LITERATRY.}

The following prose selections are very good specimens of pure literatry-language free from live figure or trope, and without that impressive tonal property which we call potentry :

"With these preliminary explanations, let us go on to consider the true aims and methods of moral education-moral education, strictly so called, we mean; for we do not propose to enter upon the question of religious education as an aid to the education exchisively moral. This we omit as a topic better dealt with separately."

\section{- Herbert Spencer, "Education."}

"It is not to be expected that there should be agreement about the definition of anything until there is agreement about the thing itself. To define, is to select from among all the properties of a thing, those which shall be understood to be designated and declared by its name; and the properties must be well known to us before we can be competent to determine which of them are fittest to be chosen for this purpose. Accordingly, in the case of so complex an aggregation of particulars as are comprehended in anything which can be called a science, the definition we set out with is seldom that which a more ex- 
tensive knowledge of the subject shows to be the most appropriate. Until we know the particulars themselves, we can not fix upon the most correct and compact mode of circumscribing them by a general description.'

-John Stuart Mill, "Logic."

"As we see in existing barbarous tribes, society in its first and lowest form is a homogeneous aggregation of individuals having like powers and like functions: the only marked difference of function being that which accompanies difference of sex. Every man is warrior, hunter, fisherman, tool-maker, builder; every woman performs the same drudgeries; every family is self-sufficing, and, save for purposes of aggression and defense, might as well live apart from the rest."

-Herbert Spencer, “First Principles."

"Nothing surprized the Jesuit missionaries so much as the immense number of languages spoken by the natives of America. But this, far from being a proof of a high state of civilization, rather showed that the various races of America had never submitted, for any length of time, to a powerful political concentration, and that they had never succeeded in founding great national empires."-MAX MüLlen, "Science of Language."

\section{SPECIMENS OF TRO-POTENTRY.}

In the following specimens of tro-potentry the language is neither rimed nor blank verse. It is prose. But it is replete with imagery and with that impressive tonal property which we term potentry.

"Like some wild-flaming, wild-thundering train of Heaven's Artillery, does this mysterious Mankind thunder and flame, in long-drawn, quick-succeeding grandeur, through the unknown Deep. - . Like a God-created, fire-breathing Spirithost, we emerge from the Inane, haste storm- 
fully across the astonished Earth, then plunge again into the Inane. . . . But whence?-Oh Heaven, whither? Sense knows not; Faith knows not; only that it is through Mystery to Mystery, from God and to God."-CARLYLE.

"One life; a little gleam of Time between two Eternities; no second chance to us forevermore." - Carlyle.

"To me, through these thin cobwebs, Death and Eternity sate glaring."

- Carlyle (after seeing a half-dozen notables guffawing at Jeffries' table).

"Our palaces are vast, inhospitable halls. There the bleak winds, there 'Boreas, and Eurus, and Caurus, and Argestes loud,' howling through the vacant lobbies, and clattering the doors of deserted guard-rooms, appal the imagination, and conjure up the grim specters of departed tyrants -the Saxon, the Norman, and the Dane; the stern Eduards and fierce Henrys-who stalk from desolation to desolation, through the dreary vacuity, and melancholy succession of chill and comfortless chambers."-Edmund Burke.

"Which shaketh the earth out of her place, and the pillars thereof tremble;

"Which commandeth the sun, and it riseth not, and sealeth up the stars;

"Which alone spreadeth out the heavens, and treadeth upon the waves of the sea;

"Which maketh Arcturus, Orion, and Pleiades, and the chambers of the south."-B⿵冂卄., Јов Ix.

"The heavens declare the glory of God; and the firmament sheweth his handywork.

"Day unto day uttereth speech, and night unto night sheweth knowledge.

"Let the words of my mouth, and the meditation of my heart, be acceptable in thy sight, $O$ Lord, my strength, and my redeemer.'

-Bible, Psalm xix. 
"Lift up your heads, $O$ ye gates; and be ye lift up, ye everlasting doors; and the King of glory shall come in.

"Lift up your heads, $O$ ye gates; even lift them up, ye everlasting doors; and the King of glory shall come in."

-Bible, Psalm xxiv.

In presenting a picture of the horrors of war, few words are often more expressive than many words. The best effect is often produced by using just words enough to outline the thought, letting the imagination do the rest. Sometimes silence speaks with a loud voice. These points are illustrated in the following two examples of tropotentry:

WAR.

Decks cleared for action-guns shotted-a huge leviathan rolling with the heaving sealiving - tense - waiting - watching - listening. Fleeting fans of fire flaring; long tentacles of light searching, feeling, threading the storm haze and the sea mist between the black sea and the sky dark. A thousand souls there waiting, watching, listening, hearts fast beating.

A speck in the water-fin of a shark, caught by the search-light? No,torpedoes! Awful gun roar, and the sea boils with exploding shell. A burst of spray mounts high around her; the warship shudders, lists to leeward; over, over, bottom upward-down the whirlpool plunges all.

$A$ thousand homes ashore are waitingmothers, wives and sweethearts watching-listening-fearing-hearts fast beating.

This is war!-Exм.

\section{GETTYSBURG.}

Over the stupendous arena, between the vast armies-silence-the murmur of a distant stream, the flutter of a bird along a hedge, the rustle of a leaf-silence. Cannonading thunder then. Three hundred guns in one confounding roar. Three hundred booming thunder guns reply. 


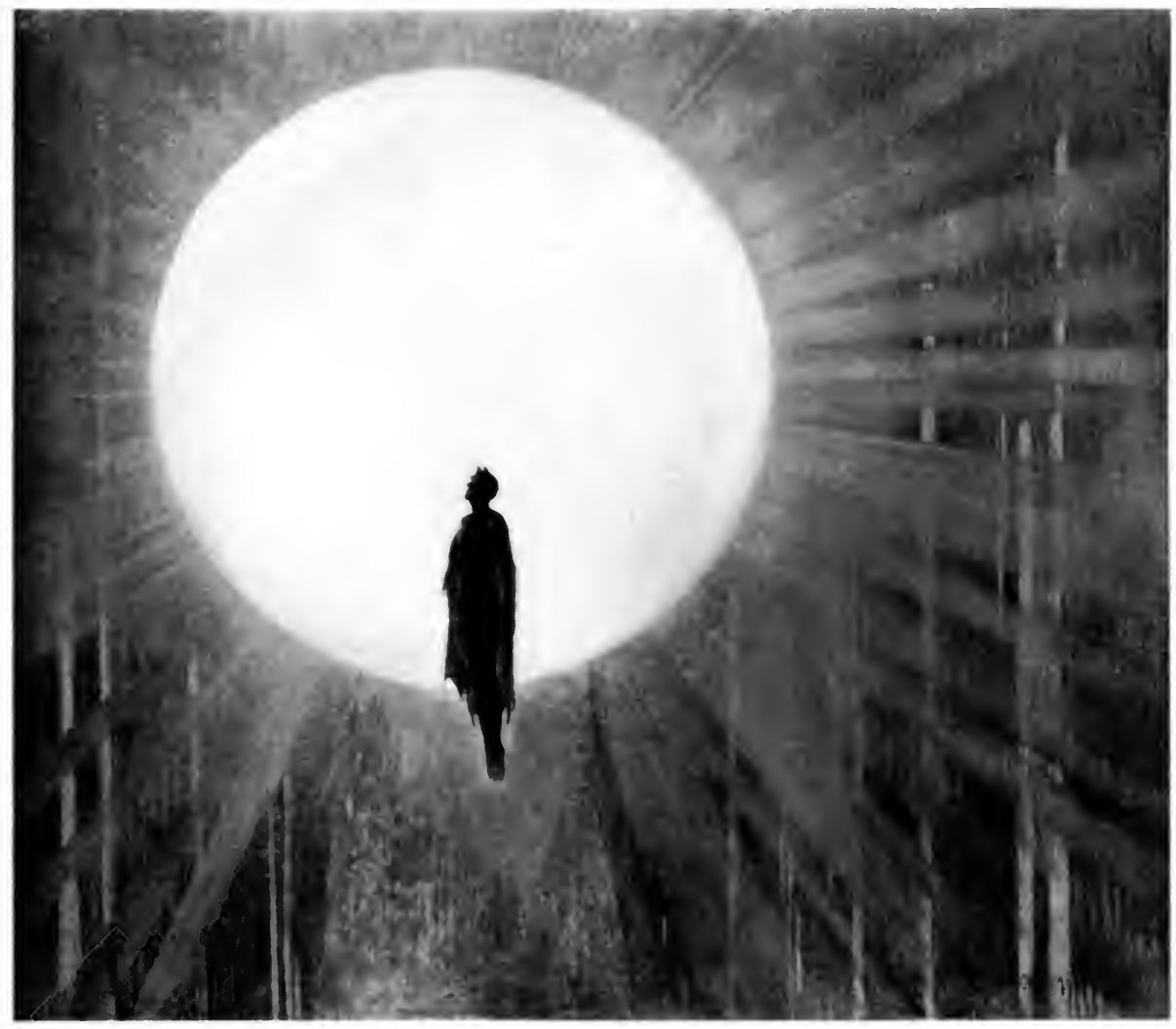

So giant sirius from the drell lurst on Mis Majest!. and halved with salan for a flash the empire of the sky. 


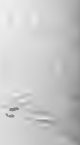

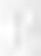

x

4. 
Blasts of fire-bursting shell-storm of iron -death and hell. Shrieks and sighs and groans infernal-loud hurrahs a hundred thousand. Despairing shadows fleeing, hovering on the edge of night. Darkness-victory-silence.-Exм.

\section{COLOSSAL RUSSIA.}

(Extract from magazine article, entitled "The Coming War.")

Owing to her immense size and the rapidity and aggressive character of her growth, Russia commands our chief attention. So vast is her domain, and so diverse and far apart the elements of her vitality, that all the dogs of war of all the world combined would fail to wound her in a mortal part. Armies and armaments hurled against her huge bulk would be broken and destroyed on her very desolation, as angry waves beat impotent upon a rocky shore. The arctic hurricane that sweeps unchecked by any hill, hurtling on a thousand miles of blinding, killing frost, enlists in Russia's cause the artillery of the elements.

To-day that colossus of the North has pushed her way to the farthest East, where the first sun of the morning rises out of the sea, while from her European outlook sunset yet lingers in her western sky. From the confines of India and Arabia's fiery sands on the south, her vast domain stretches to the north, over the end of the earth, till lost in arctic night.

No more can Russian growth be confined within present Russian frontiers than could a lake fed by a thousand living springs, and denied an outlet, be prevented from bursting its bounds to rush in an overwhelming torrent to the sea.

The springs of Russian national life are fed by the same fierce spirits who, under Attila, sprang from the depths of an unknown world, and smote Europe hip and thigh, more than fourteen hundred years ago; and who, seven hundred years later, under Genghis Khan, put a belt of deso- 
lation nearly half-way round the earth, from demolished Pekin to plundered Germany.-Exм.

\section{FROM WEBSTER'S REPLY TO HAYNE.}

"When my eyes shall be turned to behold, for the last time, the sun in heaven, may I not see him shining on the broken and dishonored fragments of a once glorious Union; on states dissevered, discordant, belligerent; on a land rent with civil feuds, or drenched, it may be, in fraternal blood! Let their last feeble and lingering glance rather behold the gorgeous ensign of the Republic, now known and honored throughout the earth, still full high advanced, its arms and trophies streaming in their original luster, not a stripe erased nor polluted, not a single star obscured, bearing for its motto no such miserable interrogatory as, 'What is all this worth?'-nor those other words of delusion and folly, 'Liberty first and Union afterward'; but everywhere, spread all over in characters of living light, blazing on all its ample folds, as they float over the sea and over the land, and in every wind under the whole heavens, that other sentiment, dear to every American heart, 'LIBERTy AND UNION, NOW AND FOREVER, ONE AND INSEPARABLE!',

"Hail, solitary ruins, holy sepulchers and silent walls! you I invoke; to you I address my prayer. While your aspect averts, with secret terror, the vulgar regard, it excites in my heart the charm of delicious sentiments-sublime contemplations. What useful lessons, what affecting and profound reflections you suggest to him who knows how to consult you! When the whole earth, in chains and silence, bowed the neck before its tyrants, you had already proclaimed the truths which they abhor; and confounding the dust of the king with that of the meanest slave, had announced to man the sacred dogma of equality. Within your pale, in solitary adoration of Liberty, I saw her Genius arise from the mansions of the dead; not such as she is painted by 
the impassioned multitude, armed with fire and sword, but under the august aspect of Justice, poising in her hand the sacred balance wherein are weighed the actions of men at the gates of eternity!"-VOLNEx, "Ruins of Empires."

\section{SPECIMENS OF TEM-POTENTRY.}

The following verse selections are excellent specimens of tem-potentry-verse practically free from live figure. It must be borne in mind that verse is a branch of potentry, and that all verse, whether weak or potential, is still potentry. The lines,

\section{"Thirty days hath September, April, June and November,"'}

may not strike one as particularly potential or impressive. Nevertheless, they are unquestionably more impressive than they would be without the rhythm and the rime, as witness :

\section{September has thirty days}

As also have June, November and April.

The effectiveness of verse, however, depends very largely upon its tonal potentiality. One of the best illustrations of this effectiveness is afforded by Macaulay's "Lays of Ancient Rome," which contain very little figure, but are replete with that impressive tonal property which we term potentry.

There is one important thing to be taken into account in all language, whether it be more or less arbitrarily symbolic, or more or less potential, which especially relates to vivid descriptions and the recounting of stirring deeds. This is the pleasurable exercise of faculty in the sweep of the imagination over the field of one's experience for as nearly representative experiences as possible, to frame imaginative subjective sensuous images-sense metaphors -and through them to apprehend and comprehend the meaning. 
"The Three stood calm and silent And looked upon the foes, And a great shout of laughter

From all the vanguard rose: And forth three chiefs came spurring Before that deep array;

To earth they sprang, their swords they drew, And lifted high their shields, and flew

To win the narrow way.

"Stout Lartius hurled down Aunus

Into the stream beneath:

Herminius struck at Seius, And clove him to the teeth:

At Picus brave Horatius

Darted one fiery thrust; And the proud Umbrian's gilded arms

Clashed in the bloody dust.

\section{"Then Ocnus of Falerii}

Rushed on the Roman Three; And Lausulus of Urgo,

The rover of the sea; And Aruns of Volsinium,

Who slew the great wild boar, The great wild boar that had his den Amidst the reeds of Cosa's fen, And wasted field, and slaughtered men, Along Albinia's shore."

-Macaulay, "Lays of Ancient Rome."

"How does the water

Come down at Lodore?'

My little boy asked me

Thus, once on a time;

And moreover he tasked me

To tell him in rime.

Anon at the word,

There first came one daughter,

And then came another,

To second and third 


\section{PRINCIPLES OF COMPOSITION AND RHETORIC}

The request of their brother, And to hear how the water

Comes down at Lodore,

With its rush and its roar, As many a time

They had seen it before.

So I told them in rime, For of rimes I had store; And 'twas in my vocation

For their recreation

That so I should sing;

Because I was Laureate

To them and the King."

-Southey.

"I curl'd and comb'd his comely head, He looked so grand when he was dead.

The wind is blowing in turret and tree. I wrapt his body in the sheet, And laid him at his mother's feet.

$O$ the Earl was fair to see!"

-Tennyson.

"Father of all! in every age,

In every clime adored,

By saint, by savage, and by sage, Jehovah, Jove, or Lord!"

-Pope.

"Say first, of God above, or man below,

What can we reason, but from what we know?

Of man, what see we but his station here,

From which to reason or to which refere"

-Pope.

"Old Grimes is dead, that good old manWe ne'er shall see him more;

He used to wear a long black coat, All buttoned down before."

-Albert G. Greene. 
“Once upon a midnight dreary, while I pondered, weak and weary,

Over many a quaint and curious volume of forgotten lore,

While I nodded, nearly napping, suddenly there came a tapping,

As of some one gently rapping, rapping at my chamber door.

' 'Tis some visitor,' I muttered, 'tapping at my chamber door,

Only this, and nothing more.',

-Poe. 


\section{CHAPTER VII}

\section{THE DYNAMICS OF HUMAN SPEECH}

Tndridual life is formative action and reaction with the environment. It is the acquisition of acquaintance. The environment of the individual constitutes not only everything outside the physical organism, but also everything outside the conscious mind, everything that appeals to and stimulates the conscious mind. Consequently, the different parts of the body and even the subconscious reflex centers of the brain, the seat of subconscious cerebration, indirectly belong to the environment of the real ego.

Whereas, as pointed ont in Chapter I, all five senses of the individual are but branches of the single sense of feeling, and whereas there is nothing to be felt except environment, all that we are is what we are in terms of feeling. All our thoughts and ideas are born of accumulated sense impressions, which we are so constituted as to retain with varying degrees of vividness for varying periods of time, according to their intensity and importance. We can have no thought that is not either directly or indirectly dependent upon some impression received through the senses. Memory is but a record of sensuous experiences, which constitutes a real subjective environment that is constantly appealing to consciousness for attention exactly as does the physical environment. We are able to receive a sense impression of any object or thing in our environment because the thing felt acts as a nerve stimulus. Just as we can have no idea or thought not born of experience, so we can have no sequelae of experience, no directive or determining will, except through motives born of experience. We are true sensory motors, actuated by the stimulus of the environment, which builds us, repairs us, reproduces us, and wears us out.

The relation between the conscious and the subcon- 
scious mind is well set forth by Sully in his "Handbook of Psychology':

"Conscious mind stands in relation to lower centers as the head of an office stands in relation to his subordinates. The mechanical routine of the office is carried on by them. He is called on to interfere only when some unusual action has to be carried out, and reflection and decision are needed. Moreover, just as the principal of an office is able to hand over work to his subordinates when it ceases to be unusual, and becomes methodized and reduced to rules, so the conscious mind is able to withdraw from acts thoroughly familiar."

Just as mutual confidence is engendered between subordinates and a leader, so is mutual confidence engendered between the subconscious mind and the conscious mind.

It is necessary, therefore, that the individual should have the respect of his faculties-that is to say, subconscious respect for his self-consciousness, based upon experience proving that the conscious mind is capable of eminent leadership.

Confidence can be secured only by deserving it. The dominating power of evil habits is due to lack of confidence of the subconscious mind in the fitness of the conscious mind for eminent leadership, whereas the tremendous influence of so-called mental therapy in the cure of disease, in the subordination of habit, appetites and passions, is largely because of the faith of the subconscious mind in the conscious mind. This is the true solution of the phenomena of faith cures. The force of the will depends entirely upon the degree of mastery of the conscious over the subconscious mind.

All sense impressions come into consciousness by way of the subconscious mind, and only the fittest ever actually arrive in consciousness. The remainder, altho felt, are not consciously felt, but often there may be a sort of par- 
tial consciousness of them. In other words, while the consciousness is directed upon a given sense impression, other sense impressions agitating the subconscious mind are felt in the field of consciousness. Such are the dynamies of attention.

Speech is an instrument for conveying ideas of experience from one individual to another by means of symbols of sensuous impressions. All our ideas are either direct or indirect perceptions of sensuous impressions through symbols standing for sensuous impressions. Hence, all thoughts must necessarily arise from sensuous stimuli. Our imagination embraces every sense. There is the imagination of touch, sight, smell, taste and hearing. By the power of association of ideas we are enabled through the imagination to perceive and express symbolically an impression received through one sense in terms of any other sense. Tho perhaps not justifiable by the best use, we may say that we see how a thing tastes, or smells, or feels, or how it sounds. A song is said to be sweet. A beautiful piece of music is said to be delicious. A delightful view of a landscape may be spoken of as a delicious view, the object being to aid thought perception by symbolizing it in terms of the most familiar experience.

We owe all our powers of perception of abstract thoughts and all our understanding of abstract words to their more or less intimate associations with sensuous impressions. The abstract word liberty suggests freedom of evolutions, opportunities for the pleasurable exercise of faculty. We perceive the meaning of the abstract word eternity through our associated sensuous ideas of duration. We are able to perceive the meaning of the abstract word truth only through its relation to sensuous experience. All abstract thoughts and ideas, and all abstract symbols of thoughts and ideas are either directly or indirectly tethered to sensuous experience.

All spoken ideas are conveyed either through symbols 
of sound or symbols of sight, except when a person born deaf, dumb and blind is taught through the sense of feeling. Symbols of sight are confined to gesture, so that the possibilities of visual symbols are very limited, and gestures, except as employed in the language of the deaf and dumb, are mainly imitative of ideas to be conveyed; while the use of oral sounds in onomatopy is narrowly restricted to the conveyance of only such ideas of other sounds as may be imitated by them, or such roughness or smoothness of objects and actions as may be suggested by roughness or smoothness of oral sounds. Such words, altho they play an important and a potential part in language, are, nevertheless, but a leavening of that great mass of words which is used arbitrarily as symbols of ideas and quite independently of any attribute of imitation.

Of far more importance are loudness, duration, pitch and tone-color of oral sounds in the conveyance of ideas by words, phrases, clauses and sentences, because these properties not only enable us to convey ideas, but also serve to indicate the power and importance of the stimulus prompting utterance, the painful or pleasurable nature of it and the intensity of the nervous activity engendered by it. Furthermore, these properties of sound are ever-present concomitants of speech through arbitrary symbols.

A written letter is an arbitrary sign used to symbolize a sound, which in turn is used as the sign of an idea.

There are in the English language about forty different elementary sounds used in making syllables and words. That is to say, there are about forty oral sounds differing from one another fundamentally in tone-color, each of which may have three uses: first, to form the whole or part of a word used arbitrarily as the sign of an idea; second, to reveal the emotional state of the speaker; and third, to act as a stimulus to produce a desired emotional state or mood in the hearer. 
Each of these elementary sounds is a tone-color blend, and may be emotional or non-emotional. In non-emotional literal statement-literatry-the tone-color blends used as arbitrary signs of ideas have no especial emotive significance or stimulative qualities. In potentry, however, the forty tone-color blends used as arbitrary symbols or signs of ideas, which are exprest by the letters of the alphabet, admit of further tone-coloring, to give them emotive significance, without altering in the least their arbitrary symbolic significance. Emotive significance is given to the non-emotive tone-color blends of meaning known as the elementary sounds, by superimposing upon them emotional tone-blends, so that pain, pleasure, love or anger, may be exprest in the voice without altering the fundamental tonal integrity of the blends used as arbitrary signs of ideas. This is generally done by superimposing emotive blends upon the vowel sounds. For example, the vowel $\mathrm{O}$ or the vowel $\mathrm{A}$ may be uttered entirely without feeling, or be uttered so as to indicate pain, pleasure or anger, and in each of these three cases with the same loudness, the same duration and the same pitch.

In music, the scale of the vocal register is divided into octaves, and the octaves into tones, differing sufficiently in pitch to be easily distinguished from one another and coordinated by the ear; still there are other degrees of pitch possible between the tones. Similarly, with the elementary sounds of the English language: there is and can be no hard and fast line of demarcation between these fundamental tone-color blends. The forty elementary sounds of the language may be looked upon as forty divisions of tone-color blending that differ from one another sufficiently to be easily recognized and coordinated by the ear.

As there are but twenty-six letters in the English alphabet with which to symbolize forty elementary sounds, it is necessary that some of the letters be used to symbolize several different elementary sounds. 
The letter A, for instance, is used to express five different elementary sounds :

First, as in fate;

Second, as in far;

Third, as in fault;

Fourth, as in fat;

Fifth, as in the article $a$, when slurringly pronounced.

The ear has become so accustomed to the differentiations of oral sounds into their forty divisions that it does not easily recognize the intermediate tone-color blends, but hears them distinctly as one or another of the socalled independent elementary sounds. For example, if the five sounds of the vowel $A$ be given by continuous utterance, changing gradually from one sound to another, the ear hears each of these divisions distinctly as such without recognition of the intermediary tone-colors.

Any one of the elementary vowel sounds may with some practise be changed into any other elementary sound by a gradual and continual readjustment of the vocal organs in the direction of the final sound while the breath is being expelled with uniform loudness and pitch.

There are two ways in which one elementary sound may differ from another in tone-color blending. The first is in the direction of another elementary sound until it becomes that other, irrespective of any emotive significance. The second way is in the direction of emotive significance, uttered with an additional tone-color blending which will signify whether it is pain, pleasure, love, or anger, that prompts the utterance.

Sidney Lanier, in his "Science of English Verse," treats the subject of tone-color at considerable length, and altho he did not understand its main function in oral sounds, yet he said some very good things. To quote:

"Every vowel sound, every consonant, every combination of letters in a syllable, every shade of pronunciation, is simply a difference of tone- 
color made by the almost instantaneous changes which the muscles of the mouth and throat can effect in the shape of the buccal cavity. It is this facility in the production of tone-colors which gives the human vocal apparatus preëminence as a speech-instrument. No other instrument could be devised which would furnish such a copious variety of elements for a language with such ease and quickness.

"Print and writing are systems of notation for the tone-colors of the human speaking-voice. The sign $A$, for instance, gives us to understand a tone-color produced by a certain adjustment of muscles which we have all learned to make when we see that sign, and which results in a certain shape of the buccal cavity, giving the tone-color indicated. When we see the sign $N$, we understand (tho we have done it so often as to become wholly unconscious of the separate steps of the process unless our attention is specially fixt on them) that we are to take away from the inner end of the nostrils the membrane which divides them from the mouth-cavity and thus add the length of the whole nostril-tube to the length of the mouth-and-throat tube, so producing that hollow and resonant tone-color which we associate with $N . "$

An explorer entering a new territory must study the footprints of previous pioneers and learn where and how far they go in order to determine the merits of his own discoveries. The inventor must study the state of the art in order to determine the value of any invention. Herbert Spencer having penetrated this present field of investigation much farther than any one else has done, we must, therefore, observe what he said and witness how far he went in order to know whether or not we have gone farther than he went. If we succeed in passing his landmarks, we may feel confident that any country discovered beyond the Spencerian confines is our own.

Spencer was the first to point out that there is a 
definite and limited amount of energy at our command during a given period of time for both the expression and the perception of thought, and that whatever energy is expended in the interpretation of words, or in paying attention to catch the speaker's meaning, must be subtracted from the force with which ideas can be received in consciousness. In "The Philosophy of Style," he says:

"The economy of the recipient's mental energy, into which are thus resolvable the several causes of the strength of Saxon English, may equally be traced in the superiority of specific over generic words. That concrete terms produce more vivid impressions than abstract ones, and should, when possible, be used instead, is a current maxim of composition. As Dr. Campbell says, 'The more general the terms are, the picture is the fainter; the more special they are, the brighter.' We should avoid such a sentence as :

"In proportion as the manners, customs, and amusements of a nation are cruel and barbarous, the regulations of their penal code will be severe.

"And in place of it we should write:

"In proportion as men delight in battles, bullfights, and combats of gladiators, will they punish by hanging, burning, and the rack.

"This superiority of specific expressions is clearly due to a saving of the effort required to translate words into thoughts. As we do not think in generals but in particulars-as, whenever any class of things is referred to, we represent it to ourselves by calling to mind individual members of it; it follows that when an abstract word is used, the hearer or reader has to choose from his stock of images, one or more, by which he may figure to himself the genus mentioned. In doing this, some delay must arise-some force be expended; and if, by employing a specific term, an appropriate image can be at once suggested, an economy is achieved, and a more vivid impression produced." 
Again, in speaking of the mental act by which the meaning of a series of words is apprehended, Spencer says, with respect to the proper collocation of substantive and adjective:

"Is it better to place the adjective before the substantive, or the substantive before the adjective? Ought we to say with the French-UN CHEVAL NOIR; or to say as we do-a black horse? Probably, most persons of culture would decide that one order is as good as the other. Alive to the bias produced by habit, they would ascribe to that the preference they feel for our own form of expression. They would expect those educated in the use of the opposite form to have an equal preference for that. And thus they would conclude that neither of these instinctive judgments is of any worth. There is, however, a philosophical ground for deciding in favor of the English custom. If 'a horse black' be the arrangement, immediately on the utterance of the word 'horse' there arises, or tends to arise, in the mind, a picture answering to that word; and as there has been nothing to indicate what kIND of horse, any image of a horse suggests itself. Very likely, houever, the image will be that of a brown horse; brown horses being the most familiar. The result is that when the word 'black' is added, a check is given to the process of thought. Either the picture of a brown horse already present to the imagination has to be supprest, and the picture of a black one summoned in its place; or else, if the picture of a brown horse be yet unformed, the tendency to form it has to be stopt. Whichever is the case, a certain amount of hindrance results. But if, on the other hand, ' $a$ black horse' be the expression used, no such mistake can be made. The word 'black,' indicating an abstract quality, arouses no definite idea. It simply prepares the mind for conceiving some object of that color; and the attention is kept. suspended until that object is known. If, then, by the precedence of the adjective the idea is con- 
veyed without liability to error, whereas the precedence of the substantive is apt to produce a misconception; it follows that the one gives the mind less trouble than the other, and is therefore more forcible."

With respect to the arrangement of the subject and predicate, Spencer shows how the predicate determines the aspect under which the subject is to be conceived, wherefore it should be placed first. Illustrative of the striking effect due to this arrangement, he uses the oftenquoted contrast between, "Great is Diana of the Ephesians," and, "Diana of the Ephesians is great." $\mathrm{He}$ says :

"When the first arrangement is used, the utterance of the word 'great' arouses those vague associations of an impressive nature with which it has been habitually connected; the imagination is prepared to clothe with high attributes whatever follows; and when the words, 'Diana of the Ephesians,' are heard, all the appropriate imagery which can, on the instant, be summoned, is used in the formation of the picture: the mind being thus led directly, and without error, to the intended impression. When, on the contrary, the reverse order is followed, the idea, 'Diana of the Ephesians,' is conceived with no special reference to greatness; and when the words, 'is great,' are added, the conception has to be remodeled: whence arises a loss of mental energy, and a corresponding diminution of effect."

The first part of a sentence should be so constructed as to get the reader or hearer in a proper mood, by making the mind expectant for the main or climacteric idea. The strongest sentence is that in which the main idea is launched, the figure completed, and the climax made at the end of the line or sentence, or in verse at the end of a line-rhythm or set of line-rhythms. All modifiers and qualifiers should be so placed as to arouse expectancy 


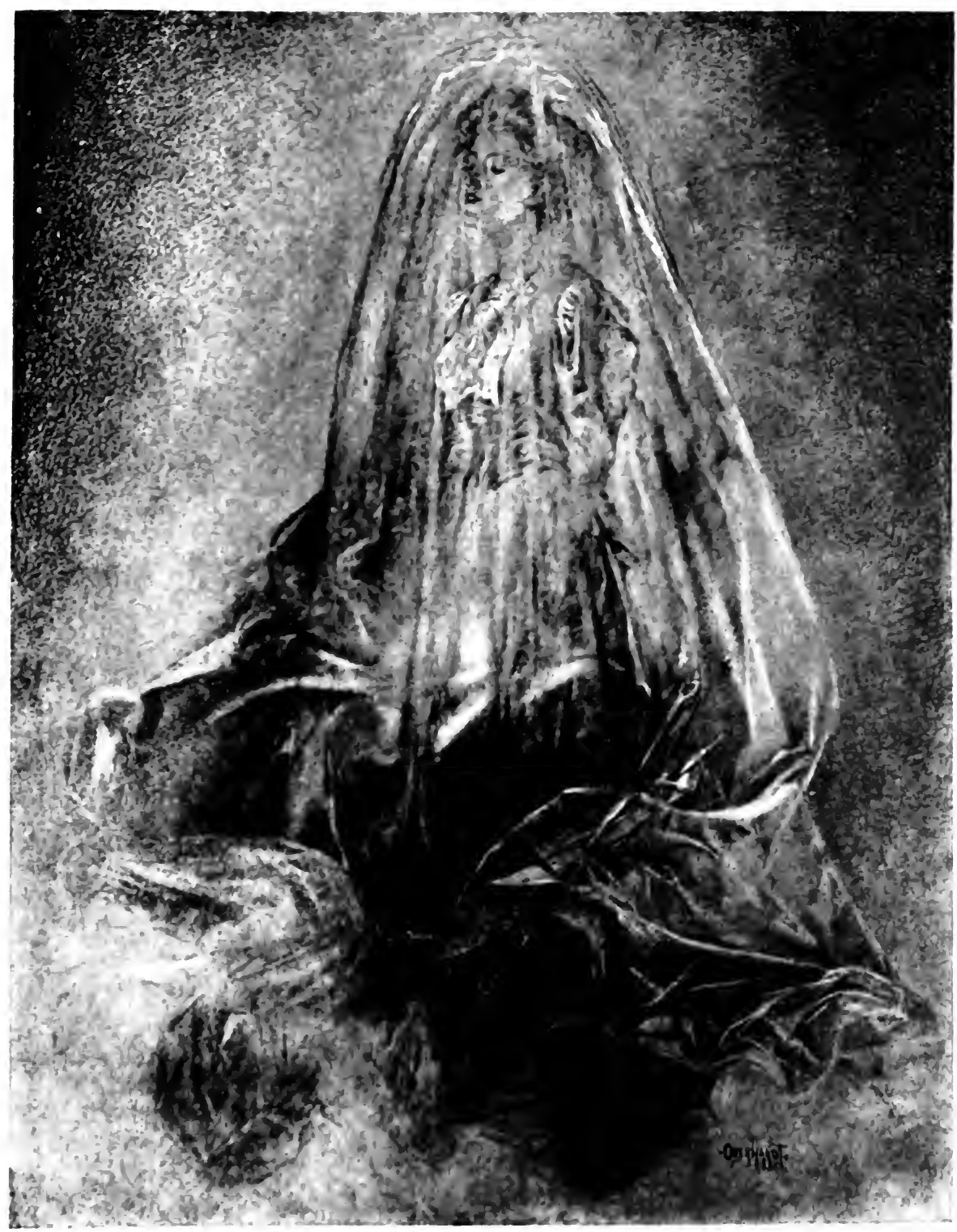

(1"Il" the "rarll is the real.

The wenf is the substance of dreams-

inly the reil is the real.

The face is the subslance of dreams. 

for the reception of the main idea, which comes as a climax. This is the true verse style. When the lines are so constructed that a completed idea, thus modified and qualified, is launched at the end of each line rhythm, and the lines themselves are of uniform length, then we have verse with end-stop lines. When, however, the figure is not completed in a line, but is carried forward into the second line, or even into the third or further, then it is verse with run-on lines.

To give a concrete illustration: Take a boy with a sling holding a stone. He will swing it round his head once to give it momentum. If, however, he wishes to give it still greater momentum, he will swing it round his head twice before launching it on its errand; and he may, perhaps, acquire a still higher velocity by launching it at the end of a third circle about his head. But, if he continues to swing it, he arrives at a point when no greater velocity can be acquired; and this limit is usually at the end of the third swing. Four circles about his head will not give more velocity than can be attained by three circles. Similarly, in verse, sometimes greater force may be given to the idea by launching it at the end of the second or third of run-on lines. If, however, more lines precede the launching of the idea, the effect is necessarily lessened as a rule, instead of increased, due to the limitations of the ability of consciousness to carry the subordinate clauses, with their subordinate figures, and all the attendant modifiers, qualifiers and magnifiers, in a mood of expectancy, to apply them to the final figure or idea.

Spencer quotes the following from Coleridge's "Ancient Mariner," to illustrate the element of dwell and the advantage of placing the expectancy-inducers before the main idea:

$$
\begin{aligned}
& \text { "Alone, alone, all, all alone, } \\
& \text { Alone on a wide, wide sea! } \\
& \text { And never a saint took pity on } \\
& \text { My soul in agony." }
\end{aligned}
$$


And as further illustrating this point, he quotes a passage from "The Battle of Flodden Field":

"The Border slogan rent the sky!

A Home! a Gordon! was the cry;

Loud were the clanging blows:

Advanced-forced back-now low, now high,

The pennon sunk and rose;

As bends the bark's mast in the gale

When rent are rigging, shrouds, and sail,

It wavered 'mid the foes."

In speaking of the direct style, in the construction of sentences where the qualifiers precede the thing qualified, as contrasted with the indirect style, where the dominant thought is approached by a series of approximations, Spencer says :

"Tho, up to a certain point, it is well for the qualifying clauses of a period to precede those qualified; yet, as carrying forward each qualifying clause costs some mental effort, it follows that when the number of them and the time they are carried become great, we reach a limit beyond which more is lost than is gained. Other things equal, the arrangement should be such that no concrete image shall be suggested until the materials out of which it is to be made have been presented."

The direct style presupposes a certain mental capacity in the hearer, and when the hearer has an aptitude for mental grasp commensurate with the occasion, he can receive an idea with more force when presented in the direct way, because he is able, without too much sacrifice, to carry along in his mind all the preliminary qualifiers of the idea. To quote Spencer:

"Just as it may cost a strong man less effort to carry a hundredweight from place to place at once, than by a stone at a time; so, to an active mind it may be easier to bear along all the qualifi- 
cations of an idea and at once rightly form it when named, than to first imperfectly conceive such idea, and then carry back to it, one by one, the details and limitations afterward mentioned. While conversely, as for a boy the only possible mode of transferring a hundredweight, is that of taking it in portions; so, for a weak mind, the only possible mode of forming a compound conception may be that of building it up by carrying separately its several parts.

"That the indirect method-the method of conveying the meaning by a series of approximations-is best fitted for the uncultivated, may indeed be inferred from their habitual use of it. The form of expression adopted by the savage, as in-'Water, give me,' is the simplest type of the approximate arrangement. In pleonasms, which are comparatively prevalent among the uneducated, the same essential structure is seen; as, for instance, in-'The men, they were there.' Again, the old possessive case-'The king, his crown,' conforms to the like order of thought."

The direct style has the advantage over the indirect style that it occupies and holds the attention in the act of carrying along the qualifiers and subordinate phrases and clauses, thereby preventing the mind from wandering to other subjects, and keeping other ideas from intruding themselves upon the consciousness. Not oply is it necessary that a thought should be presented to the mind with force, but also that the mind should be prepared for its reception. With how much keener insight we are able to apprehend a weighty proposition read in the morning than in the middle of the afternoon during the hurry and bustle and preoccupations of business affairs! This is due to the fact that in the morning the mental field has been cleared of preoccupations by sleep, and we are able to apply the undivided mental energy to the perception and recording of a thought without sharing the energy and the attention with a multitude of other perceptions.

The direct style, by arousing expectancy for a coming 
thought, gives the mind time to make room for it and to be prepared for its reception; and, as I have said, by occupying the attention with the qualifiers of the thought to be presented, the consciousness perceives the thought singly with the true sense of its quality.

The construction of our language is such that we can not always frame a sentence to accord exactly with this psychological principle. For example, take the line already quoted, "Great is Diana of the Ephesians." Theoretically, this should be constructed as follows, "Great of the Ephesians is Diana," or, "Of the Ephesians, great is Diana." But the prepositional phrase adjunct, "of the Ephesians," causes the mind to wander from the subject in quest of the implied attribute of the Ephesians, perhaps due mainly to this being an uncommon way of using a prepositional phrase, while we are in the habit of using the adjective great before the substantive qualified by it.

Spencer explains how familiar words have greater force than those with which we are not familiar, and points out the greater force with which the mind perceives the quality of vinegar in the word sour, as compared with the word acid, due to our greater familiarity with the word sour. Similarly, with forms of sentential construction, those with which we are familiar may sometimes be better for the purpose of conveying an idea than others theoretically perfect with which we are not so well acquainted.

On the other hand, when wishing to give a thought some novel shade of meaning, some fine, artistic touch of fancy, familiar words and phrases tie us down too closely to meanings already established in the mind, and do not allow the imagination the desired free play.

Herbert Spencer pointed out that all sensations and emotions, pleasurable or painful, are muscular stimuli. To quote from his article on "The Origin and Function of Music"': 
"Children may often be seen to 'jump for joy.' Even in adults of excitable temperament, an action approaching to it is sometimes witnessed. And dancing has all the world through been regarded as natural to an elevated state of mind. Many of the special emotions show themselves in special muscular actions. The gratification resulting from success raises the head and gives firmness to the gait."

The above instances justify the generalization that every kind of pleasurable mental excitement ends in excitement of the muscles; and that the two preserve a more or less constant ratio to each other.

"But," continues Spencer, "what has all this to do with 'The Origin and Function of Music?',"

And he answers:

"Very much, as we shall presently see. All music is originally vocal. All vocal sounds are produced by the agency of certain muscles. These muscles, in common with those of the body at large, are excited to contraction by pleasurable and painful feelings. And therefore it is that feelings demonstrate themselves in sounds as well as in movements. . . . It is from this cause that in human beings bodily suffering expresses itself not only in contortions, but in shrieks and groans-that in anger, and fear, and grief, the gesticulations are accompanied by shouts and screams-that delightful sensations are followed by exclamations - that we hear screams of joy and shouts of exultation.

"We have here, then, a principle underlying all vocal phenomena; including those of vocal music, and by consequence those of music in general. The muscles that move the chest, larynx, and vocal cords, contracting like other muscles in proportion to the intensity of the feelings; every different contraction of these muscles involving, as it does, a different adjustment of the vocal organs; every different adjustment of the 
vocal organs causing a change in the sound emitted;-it follows that variations of voice are the physiological results of variations of feeling. It follows that each inflection or modulation is the natural outcome of some passing emotion or sensation; and it follows that the explanation of all kinds of vocal expression must be sought in this general relation between mental and muscular excitements. Let us, then, see whether we can not thus account for the chief peculiarities in the utterance of the feelings: grouping these peculiarities under the heads of LOUDNESS, QUALITY OR TIMBRE, PITCH, INTERVALS, and RATE OF VARIATION.

"The force with which the muscles contract is proportionate to the intensity of the feeling experienced. Hence, à priori, loud sounds will be the habitual results of strong feelings. . . While a slight vexation makes a child whimper, a fit of strong passion calls forth a howl that disturbs the neighborhood. . . . Loudness of applause is significant of great approbation; and with uproarious mirth we associate the idea of high enjoyment. : . . The habitual sufferer utters his complaints in a voice raised considerably above the natural key; and agonizing pain vents itself in either shrieks or groans-in very high or very low notes. Beginning at his talking pitch, the cry of the disappointed urchin grows more shrill as it grows louder. The 'Oh' of astonishment or delight, begins several notes below the middle voice, and descends still lower. Anger expresses itself in high tones, or else in 'curses not loud but deep.' Deep tones, too, are always used in uttering strong reproaches. . . . Further, we have groans of disapprobation, groans of horror, groans of remorse. And extreme joy and fear are alike accompanied by shrill outcries.

"Thus we find all the leading vocal phenomena to have a physiological basis. There are so 
many manifestations of the general law that feeling is a stimulus to muscular action-a law conformed to throughout the whole economy, not of man only, but of every sensitive creature-a law, therefore, which lies deep in the nature of animal organization. The expressiveness of these various modifications of voice is therefore innate. Each of us, from babyhood upward, has been spontaneously making them, when under the various sensations and emotions by which they are produced. Having been conscious of each feeling at the same time that we heard ourselves make the consequent sound, we have acquired an established association of ideas between such sound and the feeling which caused it. When the like sound is made by another, we ascribe the like feeling to him; and by a further consequence we not only ascribe to him that feeling, but have a certain degree of it aroused in ourselves: for to become conscious of the feeling which another is experiencing, is to have that feeling awakened in our oun consciousness, which is the same thing as experiencing the feeling. Thus these various modifications of voice become not only a language through which we understand the emotions of others, but also the means of exciting our sympathy with such emotions. . . Why the actions excited by strong feeling should tend to become rhythmical is not obvious; but that they do so there are divers evidences. There is the swaying of the body to and fro under pain or grief, of the leg under impatience or agitation. Dancing, too, is a rhythmical action natural to elevated emotion. That under excitement speech acquires a certain rhythm, we may occasionally perceive in the highest efforts of an orator. In poetry, which is a form of speech used for the better expression of emotional ideas, we have this rhythmical tendency developed. And when we bear in mind that dancing, poetry, and music are connateare originally constituent parts of the same thingit becomes clear that the measured movement common to them all implies a rhythmical action of the whole system, the vocal apparatus in- 
cluded; and that so the rhythm of music is a more subtle and complex result of this relation between mental and muscular excitement.

" "All speech is compounded of two elements, the words and the tones in which they are uttered-the signs of ideas and the signs of feelings. While certain articulations express the thought, certain modulations express the more or less of pain or pleasure which the thought gives. Using the word cadence in an unusually extended sense, as comprehending all variations of voice, we may say that CADENCE IS THE COMMENTARY OF THE EMOTIONS UPON THE PROPOSITIONS OF THE INTELLECT. This duality of spoken language, tho not formally recognized, is recognized in practise by every one; and every one knows that very often more weight attaches to the tones than to the words."

Spencer says that emotions are muscular stimuli, and that strong emotions cause the vocal organs to give utterance to sounds according in pitch, tone, quantity and loudness with the character of the emotions; and that we have come to associate certain sounds with certain emotions, and thereby to use the same sounds voluntarily as words or signs of ideas when expressing our own emotions or imitating the emotions of others, or conveying the ideas to others that corresponding emotions may be provoked in them. But Spencer has not told us what causes rhythm, or why emotional speech naturally tends to rhythm. He admits that he can not tell, or, at any rate, that the answer is not obvious.

Moreover, all oral sounds used in language are differentiated tone-color blends, made up of two kinds-blends of meaning used as arbitrary signs of ideas, independently of any significance as tones, and emotive blends superimposed upon the blends of meaning to indicate and impress feelings in harmony with the thoughts exprest. Spencer, like many others, confounded poetry with 
verse, and was thereby led astray in his rhetorical reasoning.

I hope, in taking up this matter where Spencer dropt it, to explain rhythm, and to give the reason why strong emotions induce rhythmical utterance.

Like the eye, the conscious attention can be directed to but one thing at a time. The attention is constantly flying from one object to another, and the action is so rapid that we imagine we are thinking of several things at the same time. If you lean against the mantel with a book in one hand while talking to a friend standing in front of you, and are especially interested in what you are saying, you do not at that moment notice the color of his eyes, the shape of his mouth, or the sort of clothes he is wearing. Neither do you feel the touch of your fingers upon the book in your hand, nor the pressure of your back against the mantel, nor the boots on your feet, nor the glasses upon your nose; and if your attention be directed to any one of these points of touch, while thinking of it you are oblivious of the touch at any of the other points. If you try to be conscious of all these points of touch at once, you find it impossible. You perceive that the attention merely flits in swift sequence from one to another.

As there are innumerable sense impressions constantly appealing to consciousness and stimulating it to pay them attention, and as only the most potential or the fittest, or the most welcome, are able to reach and survive in consciousness, the mind is obliged continuously to deny attention to innumerable other impressions for every one actually honored by realization. It is necessary, therefore, that consciousness be ever on the alert lest it turn a deaf ear to appeals of vital worth and importance, and for this reason it is constantly diverging from any matter in hand, however important; but it returns often enough and remains long enough not to jeopardize its purposes. 
Herbivorous animals have their eyes in the sides of the head that they may better see an enemy approaching from any direction, while their ears are long and may be rotated to eatch the slightest sound from any quarter, and their scent is keen for the least odor of dangerous carnivora. Watch a wild rabbit feed. At every mouthful of clover, he looks furtively about him, turns his ears and listens and stretches himself up for a better view. A wild bird hopping about the lawn is equally watchful. Similarly does the conscious mind exercise unremitting vigilance, being ever on the alert to the appeals of the environment for the continual readjustment of individual needs with respect to that environment; for life itself, as Spencer has pointed out, is but the constant readjustment of the individual to his environment.

When we look at a very small object we focus the lens of the mind, just as we focus the lens of the eye, and consciousness confines itself to the sense impression received by the eye and to the dimensions of the object, to the exclusion of other objects in the field of vision, in due proportion to the intensity of the attention or interest taken in the thing seen. When we look at a person, we take the whole face in at a single view; but when we direct and confine the attention to a single feature of the face, we largely eliminate consciousness of all save that single feature. When we look at a person surrounded by other persons and objects in a room, we take in the whole scene at a single view, and we receive a general impression of the entire group of objects.

When we look upon a landscape, we see it as a whole. The landscape may contain a grove of trees, a hill, and a valley, in which cattle and sheep are feeding and through which a stream of water is running, while a white-capped mountain looms in the far background. At a single view, we receive a general impression of the whole landscape, with no especial reference to any particular object in it. But if the eye be attracted by some object of extraordinary 
interest, like a house on fire, or a person being attacked by a bull, or a couple of men fighting, then our attention is at once confined to the thing that attracts us, and localized there directly in proportion to the interest we take in it, so as to eliminate all the rest of the landscape from consciousness.

What is true of vision is equally true of all conscious sensations. For example, when the attention is concentrated upon a particular sound, other sounds, altho present, may be entirely inhibited; and when the consciousness is directed through the sense of touch to some particular object, we are unconscious of all else with which we may be in contact at the same time.

Just as, when looking at a single feature of a person's face, we see the whole face in the immediate field of vision, and a large portion of the room in the larger field of vision; so do we, when directing the attention to a given point of touch, also feel the touch of other objects in the field of sensation; and also, as the field of vision grows dimmer, with a ratio possibly as the square of the distance from the direct point of view, so does the intensity of a sensation in the sentient zone decrease in direct proportion with the importance of the touch and the needs for conscious awareness of it.

Therefore, just as loudness and duration of sounds are the measure of their importance, so is the loudness or attractive property or characteristic of an object visualized, and the time during which it holds the attention and the degree in which it inhibits consciousness of other objects are the measures of its importance.

This must be made clear, even at the cost of repetition: Whereas consciousness can be directed to, and absorbed in, but on sense appeal at a time, there is a condition of constant rivalry among the five senses to attract and command the attention of consciousness, so that only the fittest sense impressions attain conscious survival; that is to say, those sense impressions of the most vital con- 
cern and import to the individual and most worthy to be retained in the memory to serve as building materials in the architecture of experience and character. Therefore, the force with which the attention is directed to a particular sense impression, its degree as a stimulus of that attention and the length of its duration together make the measure of importance by which the inhibition from consciousness of other sense impressions is regulated. When a single sense impression is repeated in consciousness, this fact is an especial warranty of importance, by reason of which the impression more easily commands attention for a longer period; while frequently recurrences of it make a veritable battering-ram against the door of consciousness. This accounts for the power of verse-periodicity: rhythm, rime and alliteration, emphasis and dwell.

Rhythm of sounds in language is the recurrence in a systematic series of emphasized periods alternating with unemphasized periods and rests. Now, since all nerve stimuli are also muscular stimuli inducing accordant muscular tension, and since the muscles under tension react spasmodically or rhythmically with a force and frequency proportionate to the intensity of this stimulus, oral utterances under intense nerve and muscular stimuli become rhythmical. 


\section{CHAPTER VIII}

\section{THE PHILOSOPHY OF ENGLISH VERSE}

(TEM-POTENTRY)

V ERSE is a set of specially arranged syllables forming words used as the signs of ideas to express thought, so related to one another with respect to inflection, emphasis, dwell upon syllables and silences as to induce by tonal impressiveness moods or emotions in harmony with the thought exprest.

Having now learned the mechanism, nature and properties of the oral sounds constituting verse-loudness, duration, pitch, tone-color, periodicity, recurrence, rhythm, alliteration and rime-and the fact that they are reactions to various stimuli, subjective or objective, varying according to the intensity of the stimulus and the kind of faculties exercised-let us examine further into the physiological basis of verse, remembering that all mental phenomena are physiological phenomena, and that all metaphysical phenomena are based on physical phenomena.

It is absolutely necessary at the outset that the reader should have firmly fixt in his mind the fact that verse is a phenomenon of sound and not a phenomenon of thought; and that the function of verse is to stimulate and impress thought and not to express thought, the expression of thought depending upon the use of sounds as arbitrary symbols independently of any tonal or emotive significance.

Sidney Lanier, in his book, "The Science of English Verse," made the important pronouncement that verse is merely "a set of specially related sounds." The following, quoted from that work, is his admirable presentation of the subject:

"Perhaps no one will find difficulty in accepting the assertion that when formal poetry, or 
verse,-two terms which will be always used here as convertible,-is repeated aloud, it impresses itself upon the ear as verse only by means of certain relations existing among its component words considered purely as sounds, without reference to their associated ideas. If the least doubt upon this point should be entertained, it may be dispelled by observing that all ideas may be abolished out of a poem without disturbing its effect upon the ear as verse. This may be practically demonstrated by the simple experiment of substituting for the words of a formal poem any other words which preserve the accentuation, alliteration, and rime, but which convey no ideas to the mindwords of some foreign language not understood by the experimenter being the most effective for this purpose. Upon repeating aloud the poem thus treated, it will be found that the verse-structure has not been impaired. If, therefore, the ear accepts as perfect verse a series of words from which ideas are wholly absent-that is to say, a series of sounds-it is clear that what we call 'verse' is a set of specially related sounds, at least in the case of a formal poem repeated aloud.

"But a much more sweeping proposition is true. If we advance from the case of formal poetry repeated aloud to that of formal poetry silently perused by the eye of a reader, a slight examination will show the proposition good that here, as before, verse is still a set of specially related sounds. For, in this instance, the characters of print or writing in which the words are embodied are simply signs of sounds; and altho originally received by the eye, they are handed over to the ear, are interpreted by the auditory sense, and take their final lodgment, not at all as conceptions of sight, but as conceptions of hearing."

The above clear and concise statement by Lanier leads us to believe two things: first, that he was right; and, second, that he himself was convinced he was right. 
Still, in his last chapter, when referring to the book as a whole, he says:

\section{"The matters herein treated are only in the} nature of hints leading to the widest possible views of poetic form, and by no means laws."

And he continues, "For the artist in verse, there is no law."

I have a suspicion, however, aroused by the unqualified presentation of a law by Lanier that he recognized it as such and meant so to proclaim it; and that the remark, "For the artist in verse, there is no law," was offered merely as a sop to the fashionable opinion among the crities and presumed authorities, that poetry is necessarily lawless; for Lanier made the very common mistake of confounding verse with poetry. In bowing himself off the stage in the last chapter, he, like Galileo, recanted without being in the least shaken as to his conviction. Surely, he believed that poetic verse is not lawless; else, why the title: "The Science of English Verse"?

Lanier was an accomplished musician-more, he was a musical genius; but he was great neither as a logician nor as a philosopher. He understood very well the properties of sounds, and their use as artistic material in musical composition; his treatment of sound properties and their relations to music is the clearest and most concise that I have ever seen. But when Lanier got outside the limits of music, he proceeded with less accuracy.

There is an odor of garlie and onions in the gardener's essay on philosophy; the medical student turned preacher becomes a physician to the soul, and the poet's gardening fruits in metaphor. Lanier was both musician and poet. To him, the oral apparatus was above all a musical apparatus, and language a sort of wild melody, where tunes become signs of ideas and symbols of thought.

Musicians, like poets, endeavor to exalt their art far above its rightful place. They believe that by placing 
music upon a pinnacle and themselves standing there with it the eyes of the multitude must be raised. Musicians, not content with the mere emotive significance of music, try to make out that music can talk also.

Lanier, being a student of music, could not break away from the belief that music is capable of expressing thought. Hence, he naturally looked upon tune as the main source of symbols expressive of thought in language, while as a matter of fact, the tunes of the speaking voice serve but slightly and indirectly to symbolize thought, even in the broad sense in which Lanier used the word tune.

Music is based on pitch, while language is based on tone-color blends used as arbitrary symbols of ideas and thoughts.

Lanier truthfully says:

"When the ear exactly coordinates a series of sounds with primary reference to their pitch, the result is a conception of tune."

Again, he truthfully says:

"When the ear exactly coordinates a series of sounds and silences with primary reference to their duration, the result is a conception of rhythm."

And he further truthfully says:

"When the ear exactly coordinates a series of sounds with primary reference to their tone-color, the result is a conception of (in music, fute tone as distinct from violin tone, and the like; in verse, rime as opposed to rime, vowel varied with vowel, phonetic syzygy and the like) in general, tone-color."

In each of these propositions, Lanier is exactly right. But he is exactly wrong in the following quotation, for 

the basic principle of verse is rhythm, and the basic principle of rhythm is time:

"It will presently be found that the soundrelations which constitute music are the same with those which constitute verse, and that the main distinction between music and verse is, when stated with scientific precision, the difference between the scale of tones used in music and the scale of tones used by the human speaking voice."

Lanier's meaning is that the differences in pitch of the tones constitute the main difference between music and verse. This is not true.

The periodical recurrence of any phenomenon constitutes rhythm. There may be rhythm of motion, or even rhythm of historic events, as well as rhythm of sound. Verse rhythm necessarily depends upon the - periodie recurrence of emphasis in certain sounds of a systematic series.

The elements of verse rhythm are known as poetic feet, which depend primarily upon the methodical grouping of accented and unaccented syllables in a systematic series, and, secondarily, upon the periodic recurrence of lines of equal time length, constituting line rhythm or meter. Take the line:

\section{"The bells, the bells, the tolling bells."}

It is at once seen that the rhythm depends upon the greater force with which every second syllable is uttered, and the longer dwell upon the emphasized syllables; and that it does not depend upon the periodic recurrence of syllables distinguished by their pitch. As oral tunes depend upon variations in pitch up and down the scale of the vocal register, and as such variations play but a minor part in syllabic accent or emphasis, upon which 
verse rhythm depends, tune can not, in the nature of things, be the basic principle of verse. Still, Lanier says:

"Tune is, however, quite as essential a constituent of verse as of music; and the disposition to believe otherwise is due only to the complete unconsciousness with which we come to use these tunes after the myriad repetitions of them which occur in all our daily intercourse by words. We will presently find, from numerous proofs and illustrations which are submitted in Part II, on the Tunes of Verse, that our modern speech is made up quite as much of tunes as of words, and that our ability to convey our thoughts depends upon the existence of a great number of curious melodies of speech which have somehow acquired form and significance. These 'tunes' are not mere vague variations of pitch in successive words-which would deserve the name of tune only in the most general sense of that term-but they are perfectly definite and organized melodies of the speaking-voice, composed of exact variations of pitch so well marked as to be instantly recognized by every ear.

"For all purposes of verse, words are unquestionably musical sounds produced by a reed-instrument-the human voice. It must, therefore, be clearly understood by the reader that, in the above distinction between music and verse, what are called musical sounds are only one set out of the possible body of musical sounds; while what are called words are another set; that is, that 'words' (in the sense of the above distinction) means simply one kind of musical sounds, and 'musical sounds' means simply another kind. It is to be regretted that our language does not afford us more precise terms for these purposes."

Lanier is wrong here, for we symbolize thought by the use of the forty different tone-color blends known as 
elementary sounds, while the only function of tune or variations of pitch in language is to impress thought.

Altho loudness, duration, or pitch, may in exceptional cases be used to symbolize thought independently of impressing the thought, still such cases are due to the placing of emphasis or dwell upon a word or phrase to change its meaning, or that of a sentence wherein it occurs, by making the idea conveyed by the emphasized word or phrase dominate the sentence at the expense of other words along with it, sometimes entirely changing the meaning, as, for example: Are you going to town to-day? The question is asked if it be you who are going. If the word "going" be emphasized, the question is, Are you really going? If the word "town" be the one emphasized, then we have the question, Is it to town that you are going? And if the word "to-day" be the one that is emphasized, the question is, Is it to-day that you are going?

Obviously, in each case, it is the importance given to the emphasized word by the increase of loudness, pitch and duration that makes it dominate the interrogatory.

Under strong emotion, a dominating idea, or set of ideas, tends to recur in consciousness coupled or associated with a subordinate or less important idea or ideas, thus constituting idea rhythm, or rhythm of thought, the frequency of recurrence being proportionate to its dominance in consciousness. As every dominating idea, in securing recognition in conscionsness, is brought into strong competition with other and subordinate ideas making a simultaneous appeal, the dominant idea becomes associated with, and modified by, the subordinate ideas, and as the attention quickly diverts from one idea, however dominant, to others, if no particularly important or dominant idea be available among those appealing to consciousness, the attention focuses itself upon a subordinate one.

Consequently, since dominating ideas in consciousness consume an amount of energy proportionate to their importance and the intensity of their realization, conscious- 
ness is obliged, even in justice to the dominant thought, to cast it out and to rest before taking it up again, so that there is a more or less expectant attitude for the return of the dominant thought, which increases the impressiveness of its recurrence. As no two thoughts draw the energy for their realization from exactly the same set of brain cells, the consciousness in its diversion from one idea or thought to another throws one set of brain cells out of use and another set into use.

The nerve energy consumed in mental processes is analogous to electrical energy, even if it be not identical, and the cellular structure of the brain is analogous to a set of primary batteries connected up with the central ganglion, into or out of circuit with which it can be thrown instantly by consciousness. The reason why the undivided attention can be directed for but a few seconds at a time upon any given thought or idea is that the act of consciousness, consuming energy in proportion to its intensity, quickly exhausts the set of brain cells-runs down the nerve batteries, from which the energy is drawn. When this happens, the other sets of brain cells, which in the meantime have been recharging themselves, succeed in forcing some new thought upon consciousness, whereupon they are thrown into circuit and their energy is utilized. Since all physical as well as mental evolutions and functions draw the energy for their activities from various nerve ganglia situated throughout the body, mainly within the head, the law governing mental operations rules the physical as well.

Were it possible to connect up a volt-ammeter in circuit with the nervous system, whereby we could determine the voltage and amperage of the nerve impulse or the nerve fluid, under like conditions, we should find the intensity of the pressure, or the nerve potential, and the quantity, or amperage, of the nerve energy, to vary greatly in different individuals.

In the same individual, we should find the quantity and 
pressure of nerve energy to vary directly with the intensity of the emotions and in direct proportion to the amount of the stimulus exciting the emotions. We should find also that the mental and physical capacities of different individuals vary largely with their capacities for generating powerful nerve currents.

Altho we can not connect a volt-ammeter with the nervous-system and so measure the potential and amperage of the nerve currents, still instruments have been devised by which the effects upon respiration and the circulation of the blood produced by strong emotions may be measured with a considerable degree of accuracy, and criminologists and neurologists make good use of such instruments.

The agitations of the conscious mind produce subconscious effects, which may be measured. Records of respiration and of the radial artery have been made by instruments called the pneumograph and sphygmograph.

We are able to contract the muscles directly in proportion to the amount of nerve current we send into them.

It is impossible to dissociate strong emotions from some great emergency as a cause. Consequently, when the mind is under such stress, the central ganglion throws into circuit a sufficient number of the brain supply cells to meet the emergency. Thus, under great emotion due to strong stimulus, we are sometimes impelled to strike or kick an offending person or thing. We feel a twinge of nerve excitement, a supercharge of nerve force in the limb itching to be used, and it is necessary only that the emotion should be sufficiently strong for the action of striking or kicking to become involuntary. This accounts for many crimes committed in anger, to be repented of afterward.

The emotions are the cerebrations of the lower reflex brain centers and are, therefore, reflex nerve phenomena. Our emotions are spoken of as our feelings. Psychologists 
are divided as to whether the term feeling should be applied to conscious as well as unconscious cerebrations. Pflüger says that the terms feeling and consciousness are synonymous, and that to say we are conscious of a feeling is the same as to say we feel a feeling. But this is obviously a wrong view, for the reason that all our sensations are certainly feelings.

You are aroused from your sleep in the night. You get up and move slowly across the room, feeling your way to avoid obstructions. You touch a table, pass around it. Your hand touches a chair; you lift it from your path. You feel for the electric button and turn on the light. Then you dress yourself, open your bedroom door, pass down a flight of stairs, open the outside door, go down the steps into the street, and cross the street, looking right and left to avoid passing vehicles. If your mind be undisturbed and you are quite at your ease, you may remember the chair, the table, the turning on of the electric button, the passage to the door, the opening of the door, the journey down the stairs and into the street, and across the street, and the dodging of the vehicles. But, if your consciousness be absorbed by some great and intense anxiety, you may be wholly unconscious of any of these evolutions, and may be unable to recall touching a table or chair, or anything that you saw. Nevertheless, you were guided by hand-touch and sight-touch, hand-feeling and sight-feeling.

Consciousness is able to draw upon the mental storehouse in vastly varying degrees in different persons.

The subconscious mind receives and retains in greater or less degrees of vividness all objective and subjective impressions, and very largely reacts to different stimuli independently of conscious direction. In fact, more of these reactions are unconscious than conscious. A person's ability to go with the imagination into the deeper recesses of mentality depends very largely upon his ability to inhibit from consciousness all intrusive stimuli. 
Under such conditions of inhibition any external stimulus suddenly applied comes as a shock, and the mind reacts as suddenly to meet it, turning away from, and often losing beyond recall, perceptions that consciousness was about to lift up out of the depths of the unconscious, just as a person going to sleep or just fallen asleep, if suddenly disturbed, will often kick out or strike under the reflex action of the nerves and muscles. This is an effort of the unconscious, automatic part of us to defend us more quickly than we could be defended if we waited until awake with the full restoration of consciousness.

It is for such reasons that when one is dictating something calling for close application and concentration, any interrogation or suggestion is very disturbing and is likely to break the train of thought, which can be resumed only with great difficulty, if at all. An interrogation about the definition or the spelling of a word, or other question, will come as a shock. The nearer a typist or stenographer comes to being a machine, the better. When a person is tired or nervously exhausted from overwork or from long nervous strain or from disease, objective stimuli, which under normal conditions would be wholly unheeded, become painfully intrusive. Even the fluttering of a newspaper, or the drumming of the fingers upon the table, may cause acute pain. When one in such condition is trying to do any mental work requiring concentration or close application of thought, very small objective disturbances become intensely painful, and hurt as much as would a loud shout in the ears of a normal, healthy person.

Now, as the functioning of the mind with respect to economy must abide by natural laws common to all physical phenomena, the nerve impulse or electrical fluid will be husbanded, and used only in proportion as it is required. Furthermore, being an electrical impulse, it must be governed by the same natural laws as any other electrical impulse. It is not necessary to know exactly in what way the central ganglion becomes charged from the 
nerve-supply cells of the brain, or how it is discharged, or whether it throws into series a given number of supply cells and discharges them directly, to operate a given muscle or set of muscles. To serve our purpose here, it is enough to know that the brain cells are the sources of nerve energy; that the nerve energy is probably a form of electrical energy; and that the brain cells are under the control of the central ganglion, and are discharged at the will of the ganglion for all volitional purposes and all automatic functioning as well.

Knowing this, we know that the nerve impulse will be exerted with increasing strength and exhausted in inereasing quantities as a given muscle or set of muscles is more strongly contracted; and that in the period of relaxation following there will be a correspondingly less amount of nerve energy supplied and consumed. So we have a nerve phenomenon as an accompaniment of a muscular phenomenon which accords with it, both being rhythmical in their action.

The vocal apparatus being under the control of emotional impulses, under high emotion vocal phenomena must necessarily be rhythmical. In other words, under intense emotion utterance will mount and fall, and run up and down the vocal register in accord with the intensity of the emotions and the consequent intensity and rapidity of muscular contraction and relaxation. In the same manner and for the same reason that a man in a fight must relax the muscles of his arm and withdraw the arm after each successive blow in order to give another blow by again contracting the muscles to throw the arm forward, so must his vocal organs or talking apparatus relax after each severe contraction, in order to contract again and give the most impressive word-utterance. There is rhythm in verse, as there is rhythm of blows in a fight.

According to the law of mechanics, supreme effort can be maintained only by making the time brief. When putting forth a series of supreme efforts, intermittent periods 
of relaxation and repose must follow. Supreme efforts must be intermittent or rhythmical. When in utterance we have launched one idea, we must then let go our grasp on it, to fetch forward another, clothe this with its modifiers, magnifiers and predicators, and launch it in turn; and continue in the like fashion.

Such is the philosophy of mental and physical operations, and it explains the tendency to rhythm of both mental and physical activities under strong emotion.

The constitution of verse is based upon the human constitution. Both objective and subjective stimuli induce in us emotive responses, the intensity of which corresponds with the exciting cause or stimulus. Some of our emotive reactions to stimulus are voluntary; others involuntary. Of many we are conscious; of many we are unconscious. Voluntary reactions to stimulus tend to become involuntary in direct proportion to their intensity, and in proportion as they become involuntary from intensity they become spasmodic. Whether voluntary or involuntary, all spasms or orgasms must, in the nature of things, be recurrent, intermittent, rhythmical. When a spasm is not rhythmical, it becomes lockjaw, or catalepsy.

The most natural, and, therefore, the most usual avenue through which the emotions vent themselves is the oral apparatus; and we find that the law controlling emotive human utterance governs as well the psychological reactions to stimulus inducing the utterance, and that, as both high nerve tension and high muscular tension are of necessity intermittent, with corresponding periods of relaxation, the promptings of emotional utterance are therefore rhythmical and tend to make the utterance also rhythmical, the utterance varying from voluntary to involuntary in direct proportion to the intensity of the emotions, and becoming spasmodic and rhythmical in exact accordance with the ebb and flow of the emotions. When the nerve stimulus has produced high nervous tension or stress, with corfesponding muscular tension, then the 
voice becomes strong or weak, high or low, painful or pleasurable, according as the stimulus is strong or weak, important or unimportant, painful or pleasurable.

When we react under any stimulus, whether the reaction be mental or physical, we discharge and consume an amount of nerve force exactly proportionate to the intensity of emotions accompanying the reaction; and each reaction is followed by rests or periods of repose whose completeness and duration are also proportionate to the intensity of the periods of activity with which they alternate. When, therefore, reaction is manifested in utterance, that utterance becomes spasmodic and impulsive, and pulsates with a rhythm in pace with the pulsations of passion.

The nervous organism is so constituted as to utilize its available energies with the greatest economy; and thoughts that are directly related to other thoughts follow them through consciousness with less consumption of energy than do widely divergent thoughts; for the reason that, while the attention of consciousness is being focused upon a given thought, a certain amount of energy is expended in the partial recognition of a relevant thought simultaneously appealing to consciousness, lying within the sensuous field, or field of vision of consciousness. The intrusion of an irrelevant and absolutely independent thought requires mental readjustment and the consumption of the necessary energy for the examination and weighing of the mental intruder, whereas a recurring thought or a relevant thought is received with expectancy as a familiar acquaintance. This explains the effects of rime, alliteration and thought-parallelism.

The most important element in the mechanism of English verse is rhythm, based upon the periodic recurrence, in a systematic series, of emphasized syllables joined to unemphasized syllables. The importance of what is said is indicated by appropriate loudness and duration of utterance upon the periods; the intensity of the nerve stress, 
corresponding with the intensity of the prompting stimulus, is indicated by appropriate pitch; and the symbolic tone-color blends, constituting words used as the signs of ideas, are given an additional tone-coloring to indicate the kind of emotion induced by the prompting stimulus, so that the tones of the voice in utterance harmonize with the thoughts exprest.

The possession of some dominant idea, great purpose, strong affection or aversion, great enthusiasm, or some conception of grandeur, sublimity or beauty, may stimulate the emotions and tend to induce spasmodic or rhythmical utterance. Spasmodic or rhythmical utterance is the chief characteristic of verse utterance. Hence, the beats of verse are in harmony with the beats of the nerve spasms which the nerve potential of passion tends to induce. Poetic frenzy, so-called, has, therefore, no relation whatever to poetry, but is a term indicating a mental condition that may be properly termed high emotional potential.

The emotions are of two kinds, acute and chronic. Strong acute emotion is usually more the result of objective than subjective stimuli, while chronic emotion is generally more the result of subjective than objective stimuli.

Under intense excitement induced by either objective or subjective stimuli, the breathing becomes quick and short, and the voice has an abrupt, bursting quality and is usually high in pitch; the sentences are short, and the dominant idea is generally uttered first, whether it be act or thing.

The rhythmic utterance of acute emotion usually consists of a series of accented and unaccented syllables called poetic feet, the first syllable of each foot being the potential or accented syllable, the second and non-potential being unaccented. This is called trochaic meter; but it would be better to call it trochaic rhythm, because meter relates to line measure, while rhythm relates to beat measure. 
Examples of trochaic rhythm: and,

"Reuben, Reuben, I've been thinking";

\section{"Onward, Christian soldiers."}

Altho the primary rhythm of the voice under intense excitement is generally trochaic, it is often iambic, or is a mixture of iambic and trochaic, as in the following examples:

"Fire! Fire! The ship's on fire! Quick! Let down the boats! Run! Run for your lives. Save himself who can!"

A drowning man will cry, "Help! Help! Throw me a rope."

A dying man, parched with thirst, will gasp, "Water! Water! Give me water."

There is often less dwell upon the periods, and the utterance tends to be rapid.

The bursting quality occurs when the talk is against time, and does not depend upon the importance so much as upon the urgency of the utterance.

In speaking of trochaic inversions, Longinus says that they bear "the very stamp and impress of vehement emotion," and he quotes the words of Dionysius of Phocæa, in Herodotus:

" 'Our fortunes lie on a razor's edge, men of Ionia. ...' Here the natural order would have been: 'Men of Ionia, ... our fortunes lie on a razor's edge.' But the speaker postpones the words 'Men of Ionia.' He starts at once with the danger of the situation, as tho in such imminent peril he had no time at all to address his hearers. Moreover, he inverts the order of ideas. . The result is that what he says seems not to be premeditated but to be prompted by the necessities of the moment." 



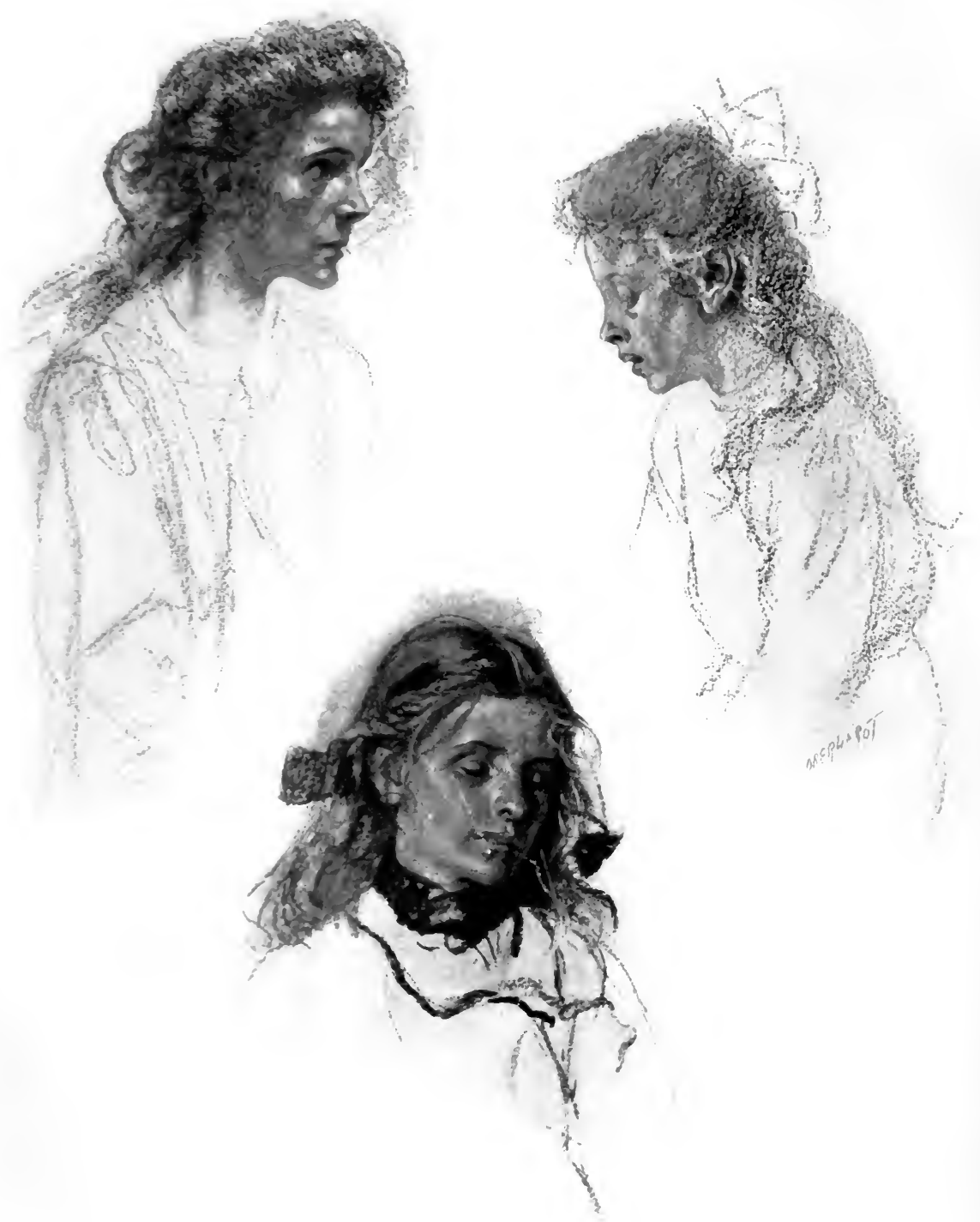




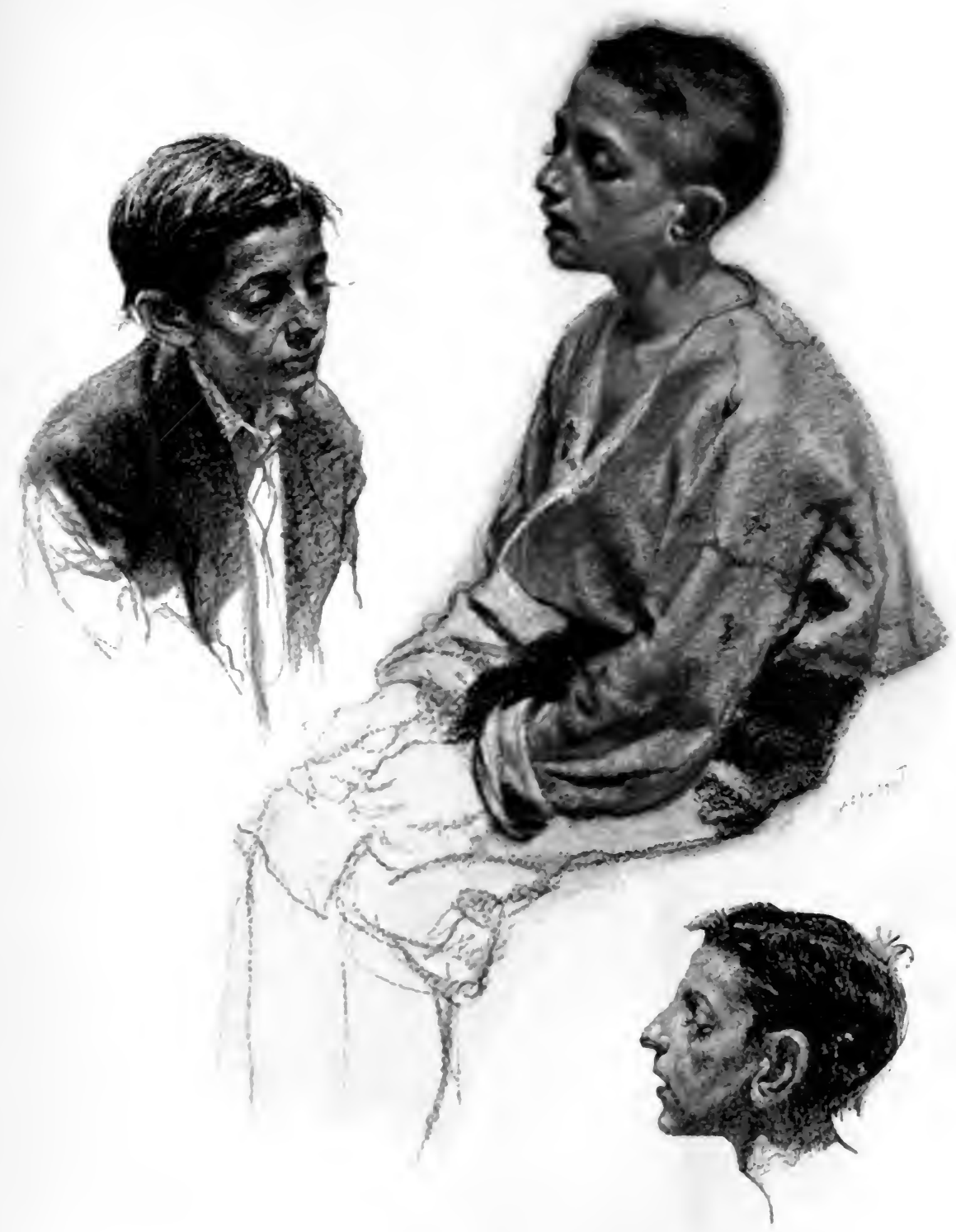

Some Shadows of Toil 

Under less intense emotion, the breathing becomes more regular, deeper and longer drawn, and more breath is available for utterance. Consequently, greater loudness and duration can be given to indicate appropriately its importance. Thus the sentences become longer and the primary rhythm usually consists of a series of double syllables or feet, the first syllable of each foot being an unaccented or non-potential syllable, while the second syllable is the accented or the potential syllable. This is iambic rhythm.

Example:

"The lowing herd winds slowly o'er the lea."

Hodgson says that "the trochee starts forward from impulse, the iambus pauses for reflection."

Meter, that is to say, line-rhythm, is determined by the shortening or lengthening of the breathing in accordance with emotional intensity.

Under intense acute emotion, when the utterance is direct address and an appeal for rapidity of action to meet an urgent need, and when the time is limited, it is not an occasion for the inculcation of weighty thoughts, but for the stimulation of the hearer to emotional activities. Hence, the character of the utterance is in harmony with its needs. In indirect address, however, especially in narrative, where the time element is not an essential, and in appeals to the understanding of the hearer, then the sentences are breathed out longer into more dignified and stately lines or measures, for which the iambus is the most appropriate primary rhythm, and to which the pentameter also is exceedingly well adapted.

The trochee is the rhythm we most naturally adopt in emotional utterance when the stimulus that is the cause of the utterance is still acting directly upon the senses, such as the beauty of a loved object or some immediately impending pleasure or pain; while the iambus is the 
rhythm we naturally adopt when the stimulus has become a chronic mental condition. This distinction between trochaic and iambic rhythms, altho it will not hold always, will be found to apply in the great majority of cases.

The iambic rhythm is better adapted to narrative; the trochaic to direct emotional address and to lyrics. Nevertheless, the use of the trochee in narrative gives an animated quality, and it is especially fitted to barbaric folklore poems like Longfellow's "Hiawatha."

\section{"Oh, the long and dreary winter, Oh, the cold and cruel winter. Ever thicker, thicker, thicker, Froze the ice on lake and river."}

Again, just as a chronic disease has its acute relapses, so may a chronic subjective emotive condition have its acute periods, when the subjective condition will stimulate the nerve centers in the same manner as tho it were really objective, and the nervous and muscular reactions following are the same as those resulting from acute objective stimuli. For this reason intense subjective emotion tends to produce hallucinations in the victim by the translation in consciousness of subjective into objective impressions.

One of the best exemplifications in literature of this mental state is Poe's "Raven." The lover, burdened with a heavy chronic sorrow, with nerves worn to distraction, is brought to a condition in which subjective impressions mingle with objective sense impressions and are confounded with them, and he is quite unable to discriminate between the actual and the imaginary.

The anapest, the dactyl and the spondee are other forms of primary rhythm that are but variations of the iambus and the trochee. The dactyl is merely an inverted anapest; the trochee is but an inverted iambus; and the spondee is an iambus with more than ordinary 
emphasis given to the weaker syllable, which may be done by giving it a longer dwell or by increasing the loudness or by raising the pitch, or by a combination of these.

Example:

\section{"Roll on, thou deep and dark blue ocean, roll."}

The spondee may be read exactly as an iambus; but when read as a spondee, the peculiar emphasis gives solemnity and dignity to the line. Also, like monotone, which it resembles, it is suggestive of supernormality, and is especially applicable to the weird and supernatural.

When Hamlet hears his father's ghost say, in a deep, bass monotone, "I am thy father's ghost," the monotone heightens the effect of the utterance.

The anapest and the iambus are so closely akin that they are often used promiscuously in the same line with good effect:

\section{"I sift the snow on the mountains below, And their great pines groan aghast: And all the night 'tis my pillow white While I sleep in the arms of the blast."} -Shelley.

We naturally adopt the form of utterance that comes easiest, making use of sounds in the middle of the vocal register in preference to sounds pitched in either extreme. We naturally utter literal statement in the middle register; we count in it. It is only when we put feeling into utterance that we pitch the voice either above or below the middle register, except when great loudness and pitch are required to reach distant ears or to make the deaf hear.

The same is true with accent or emphasis of the potential syllables in words. It is easier to give them medial force than either submedial or supermedial force. It requires a stronger exciting stimulus to prompt a strained utterance, whether it be low or loud; so that emphasis and 
the importance of the utterance, altho more usually indicated by loudness, are also indicated by extreme lowness.

When the symbolic significance of utterance is its main or entire object, as in literatry, then the voice is naturally confined to the middle register and is neither loud nor low. There is not very much rise or fall of inflection or of pitch, and there are no marked variations in the duration of different periods. In literatry, the oral sounds are used as symbols of ideas and thoughts often as arbitrarily as the code-flashes of a heliographic message. We can not very well put feeling into the recitation of the multiplication-table. It is difficult to count with fervor.

We must remember that all utterance stands in a proportional relationship to the stimulus producing it, and that there is a natural tendency to make the best possible use of energy, in both thought expression and thought impression. Naturally, then, the contrasts between loudness and lowness of utterance, and lowness and highness of pitch, become very important factors in emphasis.

Not only is utterance emphasized by loudness, duration, and pitch, but by differences in loudness, duration and pitch, and the rapidity of the alternations. It is not only the absolute loudness, the absolute pitch, or the absolute duration, but it is the relative loudness, pitch and duration with respect to other words in the sentence that make language emphatic or impressive.

The iambus being the meter used in less emotional utterance and the trochee the best adapted to intensely emotive utterance, we infer, à priori, that iambic meter requires less effort than trochaic, iambic being the most natural and the most usual. This is easily proven by reciting the lines:

La la, la la, la la, la la,
Lo lo, lo lo, lo lo, lo lo,
Lo la, lo la, lo la, lo la,
Tick tick, tick tick, tick tick, tick tick. 
It is found easier to give these lines iambic than trochaic emphasis; that is to say, it is found easier to put greater force on the second than on the first syllables.

If we listen to the tick of a clock, altho the ticks may be exactly alike, we naturally give them rhythm, with the greater emphasis on every second tick; and the clock appears to say:

Tick tock, tick tock, tick tock, tick tock, instead of :

Tick tick, tick tick, tick tick, tick tick, with equal emphasis on each syllable.

A verse syllable may consist of a single vowel, as $A$, $\mathrm{O}$, or $\mathrm{I}$, or it may be a combination of one or more vowels with a consonant or consonants, as ate, to, at and lisp. Vowel sounds, which are throat tones, consume more breath and require more energy for utterance than do consonant sounds of equal pitch and loudness; but as consonant sounds do not admit of full articulation, except in conjunction with vowel sounds, when we attempt to utter a consonant we either begin or end it in a throat tone-a vowel sound; so that in the independent utterance of consonants, we give both a vowel and a consonant sound, the consonantal part of which consumes less energy than the full utterance of a vowel sound.

The difference between pat, hat, rat, and cat, depends upon the difference in the tone-coloring of the vowel $\mathbf{A}$ by the different consonant sounds. Elementary oral sounds have a tone-color of their own, enabling us to distinguish them, but when used in such close relation with other sounds that they unite in a single sense impression, then their tone-colors become blended.

If a belt made of a ribbon consisting of narrow alternating red and blue stripes running crosswise, be rapidly revolved before the eyes, the sense images of the red and blue stripes blend in the eye, and the belt becomes of a 
uniform violet color. Similarly, in rapid utterance, when syllables follow one another in quick succession, their tone-colors blend in the ear.

There are two ways in which tone-color blends are produced: one by the simultaneous utterance of sounds of different wave mixtures; the other by uttering different sounds in such rapid succession that they blend in consciousness as a single tone.

Here we arrive at what may be termed tone-color accent, or timbre accent.

When a syllable begins with a consonant sound and ends with a vowel sound, like no or the, it has an increasing timbre accent, and when it begins with a vowel and ends with a consonant, as it, at, etc., it has a decreasing timbre accent.

A vowel sound is a continuous tone produced by vibrations of the vocal cords, while consonant sounds are produced by sudden puffs of air, pent and comprest by confinement in the upper mouth and between the lips and teeth, and suddenly released; or by forming a partial vacuum between the tongue and the roof of the mouth or between the lips and tongue and teeth, breaking the vacuum and letting the air suddenly rush in, or forcing the air through constricted passages or orifices between the lips, tongue, teeth and roof of the mouth, forming hissing or whistling sounds.

There is, however, no sharp line of demarcation between consonants and vowels. In addition to the so-called semi-vowels $W$ and $Y$, sometimes $L, N$ and $R$ are used as consonants, sometimes as vowels. Consonantal sounds, however, are mainly employed to modify the tone-coloring of vowel-sounds with which they are blended in utterance.

More breath is consumed in the voicing of vowel sounds than is necessary for consonant sounds, and consequently more energy. Therefore, since the energy used in any utterance is representative of the stimulating cause, while the force is proportional to the importance of the thought 
exprest, it follows that for emphatic expression the broad vowel-sounds are more useful than the consonantal tonecolor blends with weak vowel effects.

Hence, rising inflections by heightened pitch or increased loudness, either independently or combined, naturally fall on broad vowel sounds. Accent, therefore, should, as far as possible, fall on syllables with broad vowel sounds.

Considered dynamically, the quantity of sound produced depends upon both loudness and duration. A lower sound made proportionately longer may consume the energy and produce the impressive effect of a louder sound uttered for a shorter period.

As all sounds, whatever their loudness, pitch and timbre, must have a certain duration, the length of duration, other things being equal, is necessarily the measure of the quantity of energy consumed, the measure of emphasis, and the measure of importance of what is said.

Considered dynamically, the impressiveness of sounds and the expressiveness of thought by sounds used as arbitrary symbols depend upon overcoming the hearer's inertia of apprehension.

Just as it may require quadruple energy to double the speed of a vessel, so it may require quadruple energy of utterance to double the speed of apprehension of a thought. Hence, equal thought may be exprest with equal effectiveness and tonal impressiveness, yet with great conservation of energy, by increasing the duration at the expense of loudness and pitch, rather than by increasing the loudness and pitch at the expense of duration.

Thus, increased time or dwell upon sounds is the most effective expedient of potential expression. Similarly does dwell upon silences or rests serve to enhance the force of the sounds that alternate with the silences. It is as much the depth of the valleys as the height of the hills that makes the hills high.

When accented and unaccented syllables are made to 
alternate in regular order for a breath length or continuously, we have primary rhythm, or foot meter, the sequence of accented and unaccented syllables forming the beats of the rhythm.

Altho vowel sounds consume more energy in their utterance, they are nevertheless easier of utterance than are the consonant sounds. This appears paradoxical; but it must be borne in mind that exercise of faculty is pleasing, and it is common that the lines of greater effort become the lines of least resistance, or, in other words, the lines of choice, because of the pleasure in the exercise of faculty. Moreover, the faculty of speech affords an especial pleasure in its exercise.

Again, as emotions are exprest by variations in the tone-colors of the vowel sounds, and not of the consonant sounds, language replete in vowel sounds is the most indicative of emotion; and when words are chosen as arbitrary symbols, which at the same time by their tonal significance serve to declare the emotions, the language becomes much more impressive than when other words are chosen as arbitrary symbols, which do not admit of equal tonal impressiveness.

In verse, such words are chosen for arbitrary symbols of thought as shall, in addition to their symbolic significance, best serve to attract and stimulate the hearer's attention by their vowel sounds, thus qualifying his mind for perception and inducing moods in harmony with the thoughts exprest. For this reason, the language is divided into rhythmic measures where the accent falls with greater strength on the more potential syllable or syllables of each word, whereby coincidences are formed between the sounds of the words used as arbitrary symbols and the tonal impressiveness of the words.

Verse is based on our physiological constitution. Inevitably, then, the greatest art in verse-construction is making it serve in the best way possible to meet the requirements of our physiological constitution. We are so 
constituted that whatever gives us normal exercise of faculty is pleasure-yielding; and when those faculties most commonly used are given super-common exercise, it has an exhilarating and tonic effect and gives supernormal pleasure.

In verse, we naturally employ for the accented syllables those most pregnant with meaning, so that in emphasizing the syllables we emphasize the sense. In the iambic line:

"The curfew tolls the knell of parting day,"

witness how much more of the sense of the line is conveyed by the syllables:

\section{cur tolls knell par day}

than by the unemphasized syllables:

the few the of ting.

The same is true with the trochaic line:

$$
\text { "Oh, the cold and cruel winter." }
$$

The emphasized syllables,

Oh cold cru win

convey much more of the sense than the unaceented syllables:

\section{the and el ter.}

Often, force is gained by placing the qualifiers before the substantive when these call up stronger associated sense-images of the thing mentioned than does the substantive itself.

For example, the properties of winter, "cold and cruel," call up stronger sense-images than does the word "winter." In addition, there is economy of energy in thus directing the hearer's attention by mention of abstract qualities before naming the thing itself. It is more forcible to say, "Oh, the cold and cruel winter," than, "Oh, the winter, cold and cruel." It is true that our most forcible conception of winter is its cruel cold; but as the season 
has many pleasant days and is not always cold and cruel, and is often associated with many a good time, the word winter is not so forcible as the qualifying words, "cold and cruel."

In the lines:

$$
\begin{gathered}
\text { "Take the song-bird's rarest note, } \\
\text { Bursting from its golden throat," }
\end{gathered}
$$

the word take is the main idea word of the first line, and similarly the word bursting is the main idea word of the second line, but the terminal words of these two lines are so clothed in beautiful associations and are so expressive as to make the terminal effect equal to the initial effect. This is the strongest possible form of trochaic line.

Other things being equal, in trochaic meter we should make the initial effect a little stronger than the terminal: under no circumstances should the conclusion of the line exceed its beginning in forcefulness. But in iambic meter the lines should be climacteric in both emphasis and sense.

Articles, prepositions, conjunctions, and other light and non-potential syllables and words, as well as those not pregnant with meaning, are not well adapted to serve as terminals of lines of verse. This is apparent when such words or syllables are used for riming terminals. Furthermore, words similar in sound used at the beginning of alternate lines of verse largely lose the effect of rime. Let us take, for example, the familiar lines:

$$
\begin{aligned}
& \text { "Little drops of water, } \\
& \text { Little grains of saND, } \\
& \text { Make the mighty ocean, } \\
& \text { And the pleasant LAND." }
\end{aligned}
$$

If we write it thus:

Little drops of water,

SAND in little grains,

Make the mighty ocean,

AND the pleasant earth,

the effect of rime is wholly destroyed. 
Since the introduction of rimed terminal words, rime of idea by thought-parallelism has undeservedly fallen largely into disuse.

When both rime of terminal words and rime of idea in thought-parallels are used together, a very pleasing and powerful effect is produced. It is an evidence of Poe's masterful genius that he availed himself of this method for the potential amplification of rime and rhythmical effects, so much neglected by other modern poets. It is characteristic of all his best verse, and it is a dominant feature in "Ulalume," from which I quote the following stanza:

"Here once, through an alley Titanic,

Of cypress, I roamed with my Soul,

Of cypress, with Psyche, my Soul.

These were the days when my heart was volcanic

As the scoriac rivers that roll,

As the lavas that restlessly roll

Their sulfurous currents down Yaanek

In the ultimate climes of the pole,

That groan as they roll down Mount Yaanek,

In the realms of the boreal pole."

In "Ulalume" there is not much thought. The effect is mainly due to the peculiarly emotive verse-construction. The repetition of the broad riming words, soul, roll, and pole, is particularly impressive. Rime is most effective when falling upon an important or accented syllable or word, and there should not be too many intervening lines or alternate rimes between two riming terminals. The recurring rime or rimes should follow quickly enough to supplement in the mind the tonal impress of the first rime, while it is still ringing in the ears of consciousness.

In the following stanza, the riming words are so far apart that the effect of rime is nearly destroyed:

"So, to this day, when friend meets friend, the word of salute 
Is still 'Rejoice!'-his word which brought rejoicing indeed.

So is Pheidippides happy forever-the noble strong man

Who could race like a god, bear the face of a god, whom a God loved so well;

He saw the land saved he had helped to save, and was suffered to tell

Such tidings, yet never decline, but, gloriously as he began,

So to end gloriously-once to shout, thereafter be mute:

'Athens is saved!'-Pheidippides dies in the shout for his meed."

When a person is suffering a great grief or is absorbed by erotic passion for some loved object, or is dominated by any other strong subjective emotion, thoughtparallels become very frequent, for the reason that the thoughts return at each recurrence of the reflex disturbances with which they are associated.

I know she is dead and her spirit

Is waiting and sighing for me.

She is dead, but I know that her spirit

Is pining and dying for me,

And her grief in my dreams I can hear it,

And her soul-Oh, I seem to be near it-

And her face in my dreaming I see.

In dreaming the face of her spirit

Again as of yore I can see;

The face of her sorrowing spirit

In gladness again I can see.-Exм.

It is not often that two thoughts are of exactly equal importance, deserving of attention for equal periods, and as verse becomes a vehicle for poetic thought, by so much less is it a medium for the expression of emotions, since the pleasure is then derived chiefly from the presentation of insensuous thought by new and surprizing figure. Altho verse-construction, which is a formation of emo- 
tional language, often happily impresses thought, verse with a highly emotional construction is inappropriate for the expression of weighty and dignified poetic ideas. Consequently, meter or line rhythm, alliteration and thoughtparallelisms cease to be essential in proportion as the thought to be exprest by the verse becomes less emotional.

When the lover appeals to his sweetheart, the more passionate his utterance, the more effective. She does not discount his meaning by reflecting that after the passion has subsided he will not be so demonstrative; she does not discount his utterance on the ground that it is not prompted by reason. On the contrary, his plea is made all the more effective from the very fact that it is prompted by such strong emotion as to subordinate reason and bring him to her feet.

With narrative, however, it is otherwise, for when one speaks under high excitement, we discount the utterance, giving it only such weight as is justified by reason, to which standard we are aware the speaker will himself conform later, when his passion has subsided.

For the expression of dignified poetic thought, iambic pentameter better meets the requirements of verse than does any other form in general use; and the run-on line is now largely used in place of the end-stop line. While this is a variation in the right direction, still it does not accomplish enough, for it does not suppress the line rhythm, but merely makes it less obvious. It is a peculiar, even ridiculous phase of such verse-construction that the lines are frequently padded with unimportant, subordinate and irrelevant words to fill out the pentametric measure. This is like padding with sawdust the calves of an athlete for running a race. Even when run-on lines are employed, the versifier imagines that he must still have the pentametric line rhythm, altho he nearly destroys that rhythm by his avoidance of the end-stops and by frequent full pauses marked with periods in the middle of lines. 
I have discovered that the best way to compose the more dignified iambic verse usually written in pentameter, especially when the verse is also a poem, is to eliminate absolutely the pentametric line, ignoring line rhythm entirely, and adhering only to the primary rhythm-the iambic primary rhythm running continuously through the poem-while the lines may be of any length. No one hearing such a poem read can tell whether it be written in pentameter with run-on lines or without the line rhythm, especially if read correctly, with due regard to the expression of thought. In the paraphrase of the following passage from Milton's "Paradise Lost," the padding of the pentametric line-rhythm has been eliminated by writing with a continuous primary rhythm, letting the length of the lines come as it will:

"I laugh, when those who at the spear are bold And venturous, if that fail them, shrink and fear What yet they know must follow, to endure Exile, or ignominy, or bonds, or pain, The sentence of their conqueror. This is now Our doom; which, if we can sustain and bear, Our supreme foe in time may much remit His anger, and perhaps, thus far removed, Not mind us not offending, satisfied

With what is punished; whence these raging fires Will slacken, if His breath stir not their flames.

Our purer essence then will overcome Their noxious vapor; or, inured, not feel; Or, changed at length, and to the place conformed

In temper and in nature, will receive Familiar the fierce heat, and void of pain, This horror will grow mild, this darkness light; Besides, what hope the never-ending flight of future days may bring, what chance, what change

Worth waiting: since our present lot appears For happy, tho but ill; for ill not worst; If we procure not to ourselves more wo. 
Thus Belial, with words clothed in reason's garb, Counseled ignoble ease, and peaceful sloth, Not peace: And after him thus Mammon spake:" -Milton.

\section{PARAPHRASE.}

I laugh, when those who at the spear are bold, But failing, shrink and fear for exile, ignominy, bonds, or pain-

The sentence of their Conqueror.

This now becomes our doom;

Which if ue bear, our Supreme Foe in time may much remit his anger, And perhaps be satisfied;

Wherefore these raging fires will slacken, And our purer essence then will overcome their noxious vapor;

Or, inured, not feel;

Or to the place at length conformed

Will make the heat familiar

And the pain and horror mild,

This darkness light;

Besides, uhat hope the never-ending flight of future days may bring,

What chance, what change worth waiting:

Since our present lot appears but ill;

'Tis not the worst if we procure not to ourselves more wo.

Thus Belial, with words clothed in reason's garb,

Counseled ignoble ease, and peaceful sloth, not peace: And after him thus Mammon spake:-Exм.

But it may be argued that this is not one of the best passages of "Paradise Lost." Very well. If, now, we take one of Milton's best passages, we shall see that it, too, admits of improvement:

"He ceased; and next him, Moloch, sceptered king,

Stood up, the strongest and the fiercest spirit That fought in Heaven, now fiercer by despair. 
His trust was with the Eternal to be deemed Equal in strength, and rather than he less, Cared not to be at all. With that care lost Went all his fear; of God, or Hell, or worse, He recked not; and these words thereafter spake"':

-Milton.

PARAPHRASE.

He ceased. Then Moloch, sceptered king, stood up, The strongest and the fiercest spirit of the warrior host,

In whom despair had fired a fiercer hate.

For him no middle way-omnipotence with God or nothingness.

No fear of God or Hell was fear save for that end. And thus he spake:-Exm.

As verse has an emotional basis, the character of the verse depending upon that of the emotions, so must the effect of verse upon the reader or hearer depend upon his emotional susceptibility; and as the emotional susceptibility of an individual, as well as the character of his emotions, alters with age and experience, so do his susceptibilities and tastes for verse alter in degree and kind.

In childhood, the simplest and most primitive verse, embodying childhood ideas, is the most pleasing; while the poetic leavening of the verse also must be in the simplest and most easily comprehended figure-that of attributing to inanimate objects the properties and attributes of animate things, as in the "Mother Goose" rime :

"Hi diddle, diddle, the cat's in the fiddle,

The cow jumped over the moon;

The little dog laughed to see such craft, And the dish ran away with the spoon."

That a cow should jump over the moon, or that a dish should run away with a spoon, or that a little dog should laugh, are poetic heights for the child-mind. The boy in 
his teens likes the sonorous and potential in verse; and the girl the highly sentimental. The mature man and woman appreciate a greater variety and complexity of verse forms than does the youth in teens. The emotions have been modified and their susceptibility tempered by physiological and anatomical changes and by the complexities of education and experience; while the poetic figure needs to be of a far higher order, and more ingenious and surprizing, to thrill the time-staled taste. But in middle and later manhood and womanhood, verse never has, for the average person, the same absorbing interest that it has in childhood and youth.

The life of the individual is typical of the life of the race. The race also has its infancy, childhood, youthhood and manhood, and will some time have its old age, decrepitude and death. Consequently, what is true of the individual with respect to verse, is true also of the race.

There was a time when all human speech was emotional, for primitive man had no use for language except to voice his emotions, and for the same reasons that man's primitive speech was emotional, it must also have been rhythmical, and must have possest all the original tonal elements and properties from which both verse and music have been constructed.

Originally, all music was vocal, and verse and music were one. The first musical accompaniment was the tread of the dancing foot. Other sounds, made by the hands with sticks or stones to accompany the rhythm of the dance and to accentuate the foot-beats for the assistance of the dancers in keeping time with one another, were the first steps in the production of instrumental music.

When the human mind had developed sufficiently to require a language for transmitting and perpetuating tales of adventure and folk-lore legends, verse was the natural medium, because verse chant was at once speech, song and music, and commanded pleased attention, while the tones and melodies of verse stimulated the reflex 
nerve centers and made them ring up consciousness so that the thoughts and ideas associated with, and conveyed by, the verse measures naturally tended to be reproduced in consciousness with the return of the pleasing measures. This is the reason why thoughts exprest in verse are more easily memorized than when exprest in prose. Before the advent of writing, and even down to the time of the invention of printing, with the subsequent wide distribution of literature, verse was the convenient and universal medium for the transmission and perpetuation of legendary learning.

I quote the following from Blair's Rhetoric:

". . The recital of the achievements of their heroes, and their ancestors, gave birth to what we now call epic poetry; and as not content with simply reciting these, they would infallibly be led, at some of their public meetings, to represent them, by introducing different bards, speaking in the character of their heroes, and answering each other, we find in this the first outlines of tragedy, or dramatic writing.

"None of these kinds of poetry, however, were in the first ages of society properly distinguished or separated, as they are now, from each other. Indeed, not only were the different kinds of poetry then mixt together, but all that we now call letters, or composition of any kind, was then blended in one mass. At first, history, eloquence, and poetry, were all the same."

The ancient bards, in a street-recitation, were capable of stirring their audiences to an emotional frenzy. Now, however, music and song have been divorced from verse, and have gone their separate ways to be greatly developed, complicated and beautified, while verse has, in a measure, fallen into disfavor and disuse.

Modern music and modern song are capable of engendering more intense emotional excitement than is verse, 
and this has rendered us all more or less unappreciative of the simple melodies of verse; while the high state of development to which the art of acting has been brought in modern drama makes the recitation of verse by the novice not only commonplace, but often ridiculous.

Because the tonal potentialities of verse have largely lost their powers of appeal to the blasé consciousness of the modern mind, verse tends to become less and less potential. It is rarely, indeed, that a stanza of modern verse has the old-time ring and vigor.

The almost universal error of assuming that verse and poetry are one, and that poetry is something transcendental, indefinable and incomprehensible, has kept verse out of the field of scientific investigation, thereby robbing poet and versifier alike of introspective and analytical power. Inasmuch as the scientific understanding of any art is its tether to nature, and without such tether any art rapidly differentiates in the direction of artificiality and puerility, modern verse has necessarily degenerated largely into twaddle, while whatever leavening of poetic figure it may have is mostly commonplace and adjectival, and lacks surprize, freshness, invention. The presentday bard goes daffodillying in the flower-garden. A great part of modern verse is based on sentimental mooning and spooning, while ruby lips, limpid eyes, and shimmering hair, flower-beds, sunsets and moonlight, are the bricks and mortar of the poet's building.

All artists necessarily work from models. As the modern verse-maker and the modern poet have by their education been hedged off from getting back to nature, they naturally pattern their work on that of others who have preceded them. There has been no standard of judgment for estimating the poets and the true value of verse and poetry. Current judgment is largely founded upon the say-so of certain authorities who are supposed to know, with whom it is deemed most creditable to agree, despite the fact that these authorities are, by their own 
admissions, densely ignorant on the subject. So it is that the poet of our day naturally employs as his models those of his predecessors who have been the most lauded, and apes a Whitman or a Browning. Here is a reason for the decided "slump" in modern poetry. 


\section{CHAPTER IX}

\section{TROPETRY}

\section{(POETRY)}

LrHo, as I have said, life is formative action and re-
action with the environment, and all that we are is what we are in terms of feeling, still we are what we are because of our ability to interpret, correlate, understand, and retain within the memory sense-impressions, and to call them up again at will as subjective stimuli from the subconsciousness. When you look at objects, as, for example, a book, a cat, an apple, and afterward turn your eyes away, the sense-images retained in your memory are not the actual objects, but are sense-metaphors, which stand for those objects. The subconsciousness thereby constitutes an actual sensuous environment, made up of subjective sensemetaphors which come up into consciousness as substitutes for external sense-impressions, and which, while we are awake, are constantly running through the mind, stimulating and receiving recognition in consciousness.

Our understanding of the nature of any external thing depends entirely upon what experience has taught us through the subjective sense-metaphors, which stand in the memory as symbols and substitutes for direct objective stimuli. Thus it is that the entire understanding, the complete architecture of intellect, is based upon metaphor, upon the ability to see one thing in terms of another, to perceive one experience in terms of another experience.

The great psychologist, Dr. Boris Sidis, in his book, "The Psychology of Suggestion," tells the experience of a young minister in Plantsville, Connecticut, the Reverend Thomas C. Hanna, who fell from a carriage and, striking upon the back of his head, was knocked senseless. When he recovered consciousness, there was total obliteration 
of past experience. All memory was blotted out and he was exactly as a baby would be, born man-grown. His senses, sight, smell, taste, touch and hearing, were unimpaired, but he had no idea of the meaning of anything. $\mathrm{He}$ could see the faces of his anxious relatives around him, but they were without meaning. Dimension, distance, color, light and darkness, hunger, thirst, cold-all were without significance, except insomuch as they aroused the instinct of curiosity or were sources of comfort or discomfort. He swallowed food instinctively with relish, but had to learn to chew; and the satisfaction of his hunger led him to connect the taking of food with its appeasement. He had to learn even that his body and his limbs were a part of him. He was obliged to learn the use of his limbs like a baby, and to talk from the simplest beginnings exactly like an infant, altho he progrest much more rapidly.

Such are the experiences related by Mr. Hanna himself after his complete recovery under the treatment of Dr. Boris Sidis, with the return of his original personality and its old memories.

Obviously, our understanding of objective impressions depends entirely upon our ability to translate them into terms of previously acquired experience. This is the method by which all knowledge is acquired.

No existing thing has for us any significance whatsoever, except analogically through its relationship to other entities and by interpretation of that relationship in terms of experience of previous similar relationships; that is to say, from association by similarity. Thus it is that we learn to see and understand things in terms of their relationships to other things, the less familiar with the more familiar, and the abstract with the concrete. Therefore, when it becomes necessary in language to use a symbol to convey an idea of a thing, we naturally employ as symbol some other thing which it resembles, more familiar than the thing symbolized. This is metaphor. 
Science dissects, analyzes and knows, and has to do with actual relations, while poetry has to do with the seemings of things, and gives understanding through apparent relations.

The analogies of poetry may be as actual as those of science, but they are limited to a single aspect. The poetic expression, "The boy is father to the man," states an actual fact, and gives with few words, in a single view, what science would give somewhat as follows: The reactions of the boy to influences formative of character constitute a rational basis for predicting what his character will be when he becomes a man.

Poetry is intuitive, while science is ratiocinative. Poetry is based on associations by similarity, and is the expression of one of the associates in terms of another, more concrete or familiar; while reason is based on logical deductions from associations by similarity combined with associations by actuality.

We know things through their actual relations to other things. Science is knowledge reduced to a system. It is knowledge of actual relations reduced to a system. All reasoning begins, just as all language begins, with poetry, with the apparent relations of things and their associations by similarity of appearances, until experience deduces the actual from the merely apparent and thereby founds reason on the facts of experience.

The first step in the growth of reason is the drawing of conclusions from associations by similarity based on appearances, and when deductions from appearances have been verified by experience and squared by ascertained knowledge of natural laws, then the deductions become actualities or stand for actualities; and in further reasoning, they are employed in association by similarity of actuality, instead of association by similarity of appearances.

Our experience with wheat flour is that it is a white powder which becomes dongh when mixt with water, and 
may be baked, making bread. One acquainted with flour, but unacquainted with whiting, might compare the actual knowledge of the flour with the apparent resemblance of the whiting to the flour and so try to make bread of whiting.

Observing that a piece of pine wood will burn, one might rightly conclude that a piece of cedar wood will burn, and having proved that it does burn, might also reasonably conclude that to burn is a property common to all wood. This is reasoning from association by similarity of actualities.

When anthracite coal was first discovered in Pennsylvania, a mountaineer, thinking it a form of stone, was surprized when he found by accident that it would burn; and he thereby concluded that other stones also might burn, and that he had discovered the key to the final destruction of the world by fire. This was reasoning from association by similarity of the apparent with the actual.

When an appearance is judged by association with actuality, we reason from association by similarity of the apparent and the actual, and thereby draw deductions from the correspondence between them. Just as in reasoning we necessarily proceed from the simple to the complex, so also do we proceed from the apparent to the actual, from conjecture to knowledge, from fancy to fact.

William James, in his "Psychology," referring doubtless to what Robert G. Ingersoll said of Shakespeare, makes the following statement:

"An often-quoted writer has said that Shakespeare possest more INTELLECTUAL POWER than any one else that ever lived. If by this he meant the power to pass from given premises to right or congruous conclusions, it is no doubt true. The abrupt transitions in Shakespeare's thought astonish the reader by their unexpectedness no less than they delight him by their fitness. Why, for instance, does the death of Othello so stir the spectator's blood and leave him with a sense of 
reconcilement? Shakespeare himself could very

likely not say why; for his invention, tho rational, was not ratiocinative."

Let us analyze Professor James' conclusions. He agrees with Ingersoll that Shakespeare "possest more intellectual power than any one else that ever lived,' for the reason of his "power to pass from given premises to right or congruous conclusions." But Professor James concludes that "Shakespeare himself could very likely not say why; for his invention, tho rational, was not ratiocinative," and that "Shakespeare, whose mind supplied these means, could probably not have told why they were so effective."

Now, Professor James, does it require the very highest quality of intellectual power "to pass from given premises to right or congruous conclusions," or is the kind of intellect that is also ratiocinative, which you say Shakespeare's was not, a higher grade of intellect? If Shakespeare's ability to pass from given premises to right or congruous conclusions was not ratiocinative; that is to say, if it was not a process of reasoning, then it must have been an intuitive process; and as intuition is a simpler and more primitive process of thought than reasoning, being based upon association by similarity in appearances and not upon association by similarity in actualities, or in appearances with actualities, then Shakespeare's intellectual power was of a more primitive kind than the ratiocinative intellect of the scientist and the philosopher, and must have been far inferior, from the viewpoint of rationality, to the intellect of a Herbert Spencer.

Shakespeare was a poet, and exceeded all others in his power "to pass from given premises to right or congruous conclusions" through association by similarity of appearances. It may be true, as Professor James says, that Shakespeare could not have analyzed his own methods and powers, and "could probably not have told why they were so effective." But a Spencer could have explained, and could have told why they were so effective, and for 
that reason the mind of a Spencer possesses more intellectual power than that of a Shakespeare.

Shakespeare was the Herbert Spencer of the poets. He was above all things a poet, and his main power did not lie in merely passing from given premises to right or congruous conclusions, but rather in doing so by means of artistic trope. His main power was in the expression of insensuous thought in sensuous terms by artistic trope.

There are many equally able with Shakespeare to pass from given premises to right or congruous conclusions, but they do not possess the ability to put those right and congruous conclusions into Shakespearian poetry.

I am more generous in my opinion of Shakespeare than is Professor James. Just as I believe that any great man with a ratiocinative mind and a powerful inventive imagination, like Napoleon, or Spencer, or Haeckel, has in him the making of a great poet-as exemplified in Goethe, who was as great a biologist and philosopher as he was poet-so do I believe that Shakespeare had in him the making of a great philosopher and scientist, and had he lived in the nineteenth century, he might have been the peer of Darwin, Huxley, Haeckel and Spencer. Nevertheless, we must admit that nothing Shakespeare did can for a moment compare with what Herbert Spencer did.

There is no difference between intuitive reasoning and ratiocinative reasoning, except in degree, just as there is no difference, except in degree, between the child-mind and the adult mind, between the uneducated mind and the educated mind, between the mind of primitive man and the mind of the modern philosopher. Education, evolution, development, add to mental powers, to their range and complexity, and to that ability which penetrates the abstract and utilizes abstract actualities as elements of reasoning.

The highly developed and highly educated mind, however, transcends that of the uneducated and the savage as much as the savage mind transcends that of the ape. The 
Spencerian type of mind possesses the power of reasoning not only from the simple to the complex, but also of reversing the reasoning and from the complex unraveling the tangled web of thought back to its simplest beginnings and of introspecting and analyzing its processes and purposes.

In the following quotation from Professor James, it appears that, after all, he did not mean to agree with Ingersoll in believing Shakespeare the possessor of the greatest intellect in history, even if Ingersoll "meant the power to pass from given premises to right or congruous conclusions," for he admits that the analytical mind is superior to the intuitional mind, as witness:

". . . Tho it would be absurd in an absolute way to say that a given analytic mind was superior to any intuitional one, yet it is none the less true that the former REPRESENTS the higher stage. Men, taken historically, reason by analogy long before they have learned to reason by $a b$ stract characters. Association by similarity and true reasoning may have identical results. If a philosopher wishes to prove to you why you should do a certain thing, he may do so by using abstract considerations exclusively; a savage will prove the same by reminding you of a similar case in which you notoriously do as he now proposes, and this with no ability to state the pornt in which the cases are similar. In all primitive literature, in all savage oratory, we find persuasion carried on exclusively by parables and similes, and travelers in savage countries readily adopt the native custom. Take, for example, Dr. Livingstone's argument with the negro conjurer. The missionary was trying to dissuade the savage from his fetishistic ways of invoking rain. 'You see,' said he, 'that, after all your operations, sometimes it rains and sometimes it does not, exactly as when you have not operated at all.' 'But,' replied the sorcerer, 'it is just the same with you doctors; you give your remedies, and sometimes 
the patient gets well and sometimes he dies, just as when you do nothing at all.' To that the pious missionary replied: 'The doctor does his duty, after which God performs the cure if it pleases Him.' 'Well,' rejoined the savage, 'it is just so with me. I do what is necessary to procure rain, after which God sends it or withholds it, according to His pleasure.'

"This is the stage in which proverbial philosophy reigns supreme. 'An empty sack can't stand straight,' will stand for the reason why a man with debts may lose his honesty; and ' $a$ bird in the hand is worth two in the bush,' will serve to back up one's exhortations to prudence. Or we answer the question: 'Why is snow white?' by saying, 'For the same reason that soap-suds or whipt eggs are white-in other words, instead of giving the reason for a fact, we give another EXAMPLE of the same fact. This offering a similar instance, instead of a reason, has often been criticized as one of the forms of logical depravity in men. But manifestly it is not a perverse act of thought, but only an incomplete one. Furnishing parallel cases is the necessary first step toward abstracting the reason imbedded in them all.

" . . The primeval man will say, not 'the bread is hard,' but 'the bread is stone'; not 'the face is round,' but 'the face is moon'; not 'the fruit is sweet,' but 'the fruit is sugar-cane.' The first words are thus neither particular nor general, but VAGUELY concrete; just as we speak of an 'oval' face, a 'velvet' skin, or an 'iron' will, without meaning to connote any other attributes of the adjective-noun than those in which it DoEs resemble the noun it is used to qualify. After a while certain of these adjectively used nouns come only to signify the particular quality for whose sake they are oftenest used; the ENTIRE THING which they originally meant receives another name, and they become true abstract and general terms." 
In the following quotation, Professor James again makes a pronouncement in favor of the scientific as opposed to the poetic mind:

"In ethical, psychological, and esthetic matters, to give a clear reason for one's judgment is universally recognized as a mark of rare genius. The helplessness of uneducated people to account for their likes and dislikes is often ludicrous."

The following statement by James is in accord with what I have said in Chapter II: it is not articulate speech that forms the greatest gulf between brute and man, but the ability to form abstract thoughts through concrete metaphors. James says:

"We may, then, we think, consider it proven that the most elementary single difference between the human mind and that of the brute lies in this deficiency on the brute's part to associate ideas by similarity."

\section{Macaulay says in his essay on Milton:}

"He who in an enlightened and literary society, aspires to be a great poet, must first become a little child. He must take to pieces the whole web of his mind. He must unlearn much of that knowledge which has, perhaps, constituted hitherto his chief title of superiority. His very talents will be a hindrance to him."

Macaulay bears testimony to the truth that tropetry is language in its childhood; and that when, by long usage, the metaphors have lost their material significance and become arbitrary symbols-in other words, when language becomes literatry - then just to the extent that it becomes literatry does it cease to be poetry; and just to the extent that the mother-tongue of a person is that of the schools, just to that extent is it literatry, and just to that extent is its author disqualified as a poet. This will be news to 
many persons, and will come as a shock to those who have always believed and held that the poets have been the intellectual heavyweights of the human race.

What Robert G. Ingersoll said, to which Professor James doubtless referred, was:

"William Shakespeare was the greatest genius of our world. He left to us the richest legacy of all the dead. . . . Shakespeare is too great a theme. I feel as tho endeavoring to grasp a globe so large that the hand obtains no hold."

We must remember that Robert G. Ingersoll was himself a poet; and we shall find, whenever we look up the pedigree of highfalutinism about poetry and the poets, that it emanates from the poets themselves. Since Spencer was not himself a poet, his opinion is more candid, and more in keeping with the eternal verities. He says :

“ . . Shakespeare, who, highly appreciated by contemporaries (as witness Ben Jonson's lines), fell afterward into neglect, and then, during the present century, has been continually rising, until now his position is so high that criticism is practically paralyzed and societies occupy themselves with the minutice of his sentences. . . Inspection of the rhythm (of public opinion) may lead us to suspect that the reputation of Shakespeare is at present too high. The judgment of his devoted admirer, Ben Jonson, who, when told that Shakespeare never blotted out a line, remarked that he would have done better to blot a thousand, is probably nearer the mark than the judgment now current, which implies the belief that everything he wrote is good. For to any one unswayed by fashion it is manifest that amid the great mass of that which is supremely excellent, there are many things far from excellent."

Macaulay's dictum-that an educated modern must take apart the whole web of his mind, forget what he has 
learned, and become a little child again in order to write poetry-is not strictly true, but it is partly true. For the modern scholar, it is necessary only to learn what constitutes poetry and the laws governing its composition; and then, if he has the inventive imagination, he can write poetry; but his acquired habit of thinking in abstract symbols and of expressing himself in literatry will be a great hindrance to him, and may prove insurmountable. A modern classical education unquestionably produces atrophy of poetic genius.

Those cryptogrammatic prestidigitators who have been trying to serve us cooked-up Bacon to account for Shakespeare, have used as their strongest argument that the poetry of Shakespeare could have been written only by a highly educated man. As a matter of fact, had Shakespeare received a classical education, probably we should never have heard of him. Robert G. Ingersoll says :

"For the most part, colleges are places where pebbles are polished and diamonds are dimmed. If Shakespeare had graduated at Oxford, he might have been a quibbling attorney, or a hypocritical parson."

Emerson designated language as "fossil poetry," and another writer designated it "a collection of faded metaphors." Certain it is that much of the dry literature of modern times, sans figure, sans wit, sans humor, and sans life, may well be characterized not only as fossil poetry but as the language of fossils.

There is a certain relation between the use of metaphor and the child-play of pretend. When two little boys play horse, one symbolizes the driver, the other the horse. The little girl's doll symbolizes a real baby, and is to her in her play of pretend an actual infant. The same is true with the play of animals. A pair of cats or dogs will rehearse in their play the serious business of cat or dog life in a state of nature. They will take turns in playing 
hunter and hunted, and perform all the evolutions of attack and defense-all play of pretend.

Our love of fiction largely depends upon the play of pretend carried on in the imagination. We see and understand the characters in the story in terms of our own experiences; and just as we can not hear a tune without feeling it; just as we can not listen to potential utterance without being stimulated; just as we can not witness a person gaping without ourselves being stimulated to gape, so we can not read a story without feeling the reflex stimulus induced by the experiences of the characters. And as we are bound sympathetically to share their experiences, we naturally place ourselves metaphorically in the position of the hero or heroine, in order that the experiences may be as pleasant and as congenial as possible; and unless the story ends happily we experience a sense of disappointment-the story leaves a bad mental after-taste.

There is no idea of art more false than this: that stories should occasionally end unhappily because many stories of actual life end miserably. A story may, however, end tragically, even in the death of the hero or heroine, or both, without actually constituting an unhappy ending. In real life, it is often the duty of heroes to die for their country, or for home or loved ones: then death is glorious. And likewise in fiction, as long as a hero dies gloriously, his death may constitute the finale of a story without its being an unhappy ending. Both Longinus and Aristotle have pointed out that it is not the terrible that displeases, but it is the horrible; and Longinus defines the horrible as an admixture of the terrible and the disgusting.

All figures of speech are either directly or indirectly metaphorical. All are based upon analogy and all speech is originally analogical, for, as Max Müller has said, all words once had a material meaning, all were once metaphors.

Metaphors are the pioneer symbols by which we are able to penetrate the regions of the abstract. When by 
long use an abstract thought has become a familiar mental entity, then the symbol loses its material meaning and is no longer a metaphor. It is during this period, when figures of speech retain their nascent material significance, freshness and surprize, that they are poetical. Poetry is language in its youth; and youth being virile, sensuous, emotional, verse-which is artistic, emotional languageforms a natural matrix for poetic figure.

The function of poetry being the expression of insensuous thought in sensuous terms by artistic trope, poetry enables us through the imagination to penetrate the abstract and insensuous by the employment of sensuous symbols; therefore, the excellence of our poetry depends upon the depths of the abstract into which we are enabled to descend, and the heights of the tangible and concrete to which we ascend.

Language is the expression of thoughts about subjects. The subject is that about which we speak, and what we are able to express concerning our subject depends more upon the verb than upon any of the modifiers of the verb, or qualifiers of the subject, or qualifiers of other substantives in the sentence. The subject nominative and the predicate verb are the main parts of every sentence, and all modifiers and qualifiers, whether adjectives, adverbs, prepositional phrases, or what not, altho important, are but qualifiers of the subject and modifiers of the verb. Consequently, the greatest forms of poetic expression must be verbal. Altho the effect may be much heightened by proper use of adjectives and adverbial modifiers, and lines of real beauty may be made up mainly of modifiers and qualifiers, still poetry must always be greatest when it exists in action, or in state of being directly exprest by the verb, when it exists in what is directly predicated of the subject.

A poetic truth is made apparent by the force of striking analogies, while a scientific truth is shown by means of deductions from analogies verified by experience.

Our acquaintance with the environment is made up of 
conceptions of matter, time, space, force and motion. All energy is manifested through motion. Heat, light, electricity, are modes of motion.

Our conceptions of things, then, are conceptions of the values of those things-how much they matter.

Our acquaintance with the environment is that of interactivities, action and reaction between the things with which we are acquainted. As knowledge of things depends absolutely upon the character of their activities, it is a far more important function of language to predicate their activities than to name or to qualify things. Thus, we know a subject by what is predicated of it, and the verbal predicate, or unmodified predicate, is the most important and the most expressive part of the sentence.

Adjectives, which acquaint us with the characteristics or properties of the subject, are less important than the activities of the subject exprest by the verb; and as the nature of the action means more to us than the nature of the subject, adverbs, which modify the verb and tell us when, where and how the action is performed, are more expressive than are adjectives, and for the same reason participial adjectives that participate in the properties of verb and adjective are more expressive than mere qualifying adjectives. The words running horse are more expressive than the words red horse. Adjectives like wicked, wilful, playful, and the like, which indicate qualities dependent upon activities, are more expressive than are adjectives like black, white, red, large, which relate merely to properties; for it concerns us more to know about the active properties of things than about the passive.

Take the following adjectival lines:

"Passionless, pale, cold face, star-sweet on a gloom profound."

" . . The liquid azure bloom of a crescent of sea, The silent sapphire-spangled marriage-ring of the land."

-Tennyson. 
"A train of priestly banners, cross and psalm, The white-veiled rose-crowned maidens holding up Tall tapers, weighty for such wrists, aslant To the blue luminous tremor of the air." -Mrs. Browning.

The adjective sweet is one of the most abused words in the language. It is frequently used ad nauseam in current magazine verse. The following versified emetic by William Carter, which appeared in Frank Leslie's Monthly, February, 1902, is a striking example of how some of the present-day verse-makers run to saccharine idiocy:

"Sweet as the balm of sweetest rose that grows,

Sweet as the sweetest blush of sweetest rose,

Sweet as the stars when maidens call them sweet,

Sweet as the kiss of love when lovers meet,

Sweet as the battle song to victors' ears,

Sweet as the battle lute unswept with tears,

And I remember (listen, and I'll tell),

The dripping of the mill-wheel as it fell,

The dripping of the mill-wheel soft and low."

Witness the greater power of the following lines, in which the poetry consists in magical predication:

Were hanging the night around us fast."

\section{"Hands unseen}

\section{"Struck his mouth}

With one back-handed blow that wrote

In blood men's verdict there."

-Browning.

"And each separate dying ember wrought its ghost upon the floor."-PoE.

"As when far off at sea a fleet descried

Hangs in the clouds."

-Mrltos.

"And there the embattled farmers stood And fired the shot heard round the world." 
"A shout, that tore Hell's concave, and beyond Frighted the reign of Chaos and old Night."

-Milton.

Adjectives serve to define what they qualify, and adverbs define the action exprest in the predicate verb. For that reason, adjectives limit the meaning of substantives exactly to the extent to which they qualify or define them, and adverbs likewise limit the meaning of verbal action exactly to the degree in which they define the action. While definiteness aids the understanding, it circumscribes the imagination. The imagination is the pioneer of understanding; it penetrates beyond the frontiers of exact knowledge and brings back impressions and data of undetermined truths to aid the understanding in their determining. And still further to aid the understanding, it symbolizes the strange and unattained in terms of the attained and the familiar. But altho the function of the imagination is to aid the understanding, still when there is complete understanding, the imagination finds its occupation gone. There is no room for the play of the imagination in the fully defined and the completely understood. For this reason, the use of many adjectives is incompatible with highly imaginative writing.

There are exceptions to this broad rule, however, for all adjectives are not equally definite. Definiteness of meaning is understanding of meaning, and as understanding of meaning depends upon familiarity of use in given applications and associations, it is plain that rare or unfamiliar adjectives frequently suggest much more than they define and so become poetical because they enlist the imagination. They afford pioneer work for the imagination.

Again, sonorous adjectives, those of great tonal and potential impressiveness, are very serviceable in the expression of imaginative thought, from their stimulating effect upon the emotions. What is true of adjectives also holds true of adverbial modifiers. 


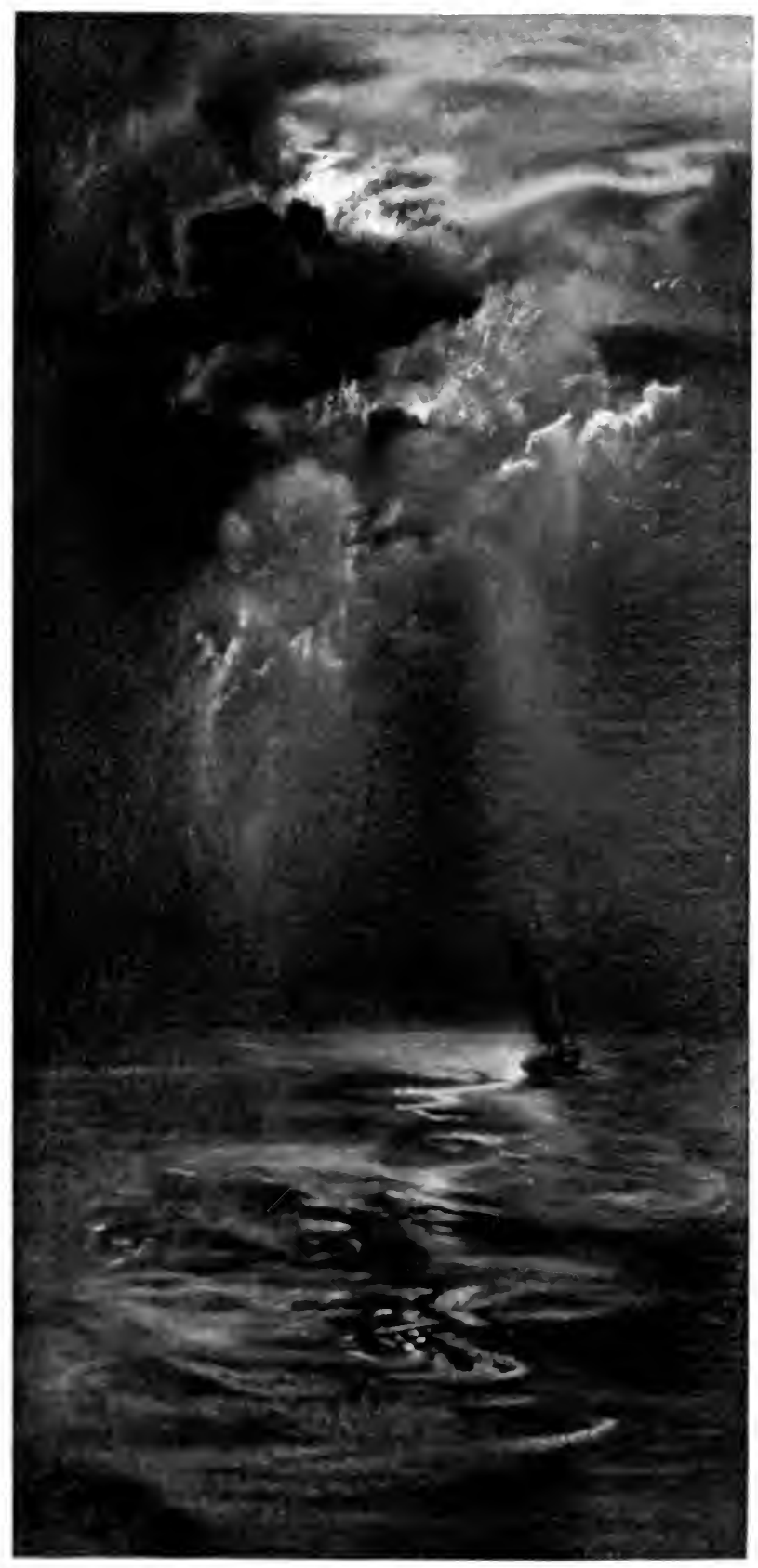

Like the wate of a ship in the monnlighted night-such is louth. 

Again, adjectives with a heritage of dignified usage are serviceable in poetry, and concrete adjectives derived from nouns, when of higher or more noble character than the thing qualified by them, ennoble the thing qualified. For example, noun-adjectives derived from living, thinking and speaking things, when used to qualify things lower on the plane of existence, or inanimate things, ennoble and dignify the things qualified.

Examples:

$$
\begin{aligned}
& \text { "Ponderous and marble jaws." } \\
& \text { "Detested, dark, blood-drinking pit." } \\
& \text { "Loving, black-brow'd night." }
\end{aligned}
$$

-Shakespeare.

Spencer has explained the greater force of familiar words and of those having an exact meaning; and the inference seems to be natural that definiteness of meaning is a desideratum of words used in poetry. But this is not the case, for definiteness of meaning limits the power of expression to the definite meaning of the word, leaving no room for a hidden or subordinate or superior significance dependent upon a new or poetic application. By long use, words acquire familiar meanings, and such meanings become restricted to the applications that use has given them. Furthermore, many words have several meanings, and there sometimes results a confusion that detracts from the force of the required meaning. When, however, a familiar word restricted in its meaning by use is employed in some new application, imposing upon it a novel significance somewhat analogous to the old, then the word to a certain extent becomes a metaphor of the new meaning, and its very familiarity adds to the force of this, exactly as a sensuous term adds force when used as a metaphor for an abstract term.

Words employed in some new sense or application allow the imagination to enlarge their meanings or to give them 
new meanings, and this freedom of meaning is very serviceable to poetry. For this reason, rare words and words that have largely fallen into disuse are frequently very serviceable in poetry, because, their meanings being little known and more or less vague, they allow freedom for new meanings in new applications. Again, there are plebeian words, and words have also their middle class and their nobility, just as persons have, while by use and associations they are sometimes degraded and sometimes ennobled.

Again, with words, as with people, familiarity breeds contempt. Words that have been held aloof from common use, or from vulgar associations, become lavendered by time. All words that stand for high and noble attributes or that call up associated ideas of grandeur are especially serviceable in poetry.

As already pointed out, poetry appeals to the imagination, and the imagination must be enlisted to understand and to appreciate it. Without such enlistment of the imagination, the greatest poetic figures in literature would be mere nonsense, for trope is a turning aside from direct speech to something unfamiliar or abstract in terms of something more familiar or concrete.

Markham, speaking of the Norn Mother, in his poem on Lincoln, says that in order to make a man:

\footnotetext{
"She took the tried clay of the common roadClay warm yet with the genial heat of Earth, Dashed through it all a strain of prophecy, Tempered the heap with thrill of human tears; Then mixt a laughter with the serious stuff."
}

What could be more absurd and nonsensical than these lines taken literally? Yet, by the aid of the imagination, they are the epitome of expressiveness.

Frequently, the chief merit of poetic expression is in what it suggests beyond what it actually expresses. The 
following well-known lines of Coleridge, Keats and Poe are good examples of such suggestive poetry:

"A savage place! as holy and enchanted As e'er beneath a waning moon was haunted By woman wailing for her demon-lover."

-Coleridge.

". . Magic casements, opening on the foam Of perilous seas, in faëry lands forlorn."

-Keats.

"The skies they were ashen and sober;

The leaves they were crispèd and sere-

The leaves they were withering and sere-

It was night in the lonesome October

Of my most immemorial year;

It was hard by the dim lake of Auber,

In the misty mid-region of Weir-

It was down by the dark tarn of Auber,

In the ghoul-haunted woodland of Weir.

"And I said, 'She is warmer than Dian:

She rolls through an ether of sighs-

She revels in a region of sighs:

She has seen that the tears are not dry on

These cheeks, where the worm never dies, And has come past the stars of the Lion

'To point us the path to the skies-

To the Lethean peace of the skies-

Come up, in despite of the Lion,

To shine on us with her bright eyes,

Come up through the lair of the Lion,

With love in her luminous eyes!" " -Poe.

These lines lead us out where reality margins with unreality and merges into mystery at the very verge of sense, to tease us with a grasp at the insensuous. Rossetti pronounced the above quotations from Coleridge and Keats "two pillars of Hercules of human thought." As a matter of fact, there is almost no formulated thought at all exprest in any of the above quotations. The thought is 
insignificant, but the suggestiveness is great as a stimulus of the imagination.

"A Look into the Gulf," by Edwin Markham, is a poem similar in its suggestiveness:

"I looked one night, and there Semiramis, With all her mourning doves about her head, Sat rocking on an ancient road of $\mathrm{Hell}$, Withered and eyeless, chanting to the moon Snatches of song they sang to her of old Upon the lighted roofs of Nineveh. And then her voice rang out with rattling laugh:

'The bugles! they are crying back againBugles that broke the nights of Babylon, And then went crying on through Nineveh.

"Stand back, ye trembling messengers of ill!

Women, let go my hair: I am the Queen, $A$ whirlwind and a blaze of swords to quell Insurgent cities. Let the iron tread

Of armies shake the earth. Look, lofty towers: Assyria goes by upon the wind!' And so she babbles by the ancient road, While cities turned to dust upon the Earth Rise through her whirling brain to live againBabbles all night, and when her voice is dead Her weary lips beat on without a sound."

A poem of this sort is still a great poem, even tho it may not be replete with artistic metaphor in the usual sense in which we understand metaphor or trope. But it is poetry by virtue of the fact that it serves the same function as does trope. The true function of poetry is to express insensuous thought in sensuous terms by artistic trope; in other words, to aid our mental grasp of the insensuous. Therefore, language that aids us in grasping the insensuous by suggestiveness instead of actual metaphor is still true poetry. 
Longfellow's “Excelsior" is perhaps as good an example as any of a poem practically devoid of poetic figure, which, however, taken as a whole, constitutes a trope. It is a symbolic allegory, and, therefore, true poetry.

This property of suggestiveness in certain great poetry, that leaves much to the imagination, has by many been confounded with obscurity of style. Browning's "Sordello" is a good example of obscurity in style. The great vogue of Browning has led many of his numerous admirers to emulate his obscurity of diction. Even a most lucid style, if, like that of Spencer, it be burdened with the weight and heterogeneity of thought, may appear obscure to one of small mental caliber or to one not sufficiently educated to understand the philosophical scientific language. This has led many to believe that obscurity is a necessary concomitant of the expression of great thoughts; while, as a matter of fact, clearness and directness of diction are the actual concomitants of clear thinking.

It must be borne in mind, however, that the expression of thought either by tropetry or literatry, and the impression of thought by potentry, require the exercise of an absolutely different set of faculties from that employed in the thinking of thoughts. Altho we think in language-symbols, still no amount of linguistic genius can make an inventor, a scientist, or a philosopher.

Nevertheless, the expressive and impressive language of the poets has led the great mass of people to the belief that the poets are the greatest thinkers, and that they have a deeper insight into human nature than have other mortals. It has occurred to hardly any one to doubt that Shakespeare was as great a philosopher or was possest of as great an intellect as was Spencer. Who doubts, forsooth, that Shakespeare had a deeper insight into human nature than that possest by the psychologist, William James, or Hugo Münsterberg, or the logician, Mill ? 
W. L. Dawson, author of "The Makers of Modern Poetry," says of Browning:

"Sometimes this sense of the power of mind in Browning is almost oppressive. We long for a little rest in the arduous novitiate he imposes on us. We feel that the vehicle he uses for the exposition of his thought is unequal to the vast strain he imposes on it. The verse moves stiffy beneath the tremendous weight of thought. The forms of poetry seem to cramp and fetter him."

Mr. Dawson's eulogy of Browning reminds me of the eulogy Jim Bennett, down in Maine, once delivered upon a horse he wanted to sell me. The animal was ring-boned and spavined in all four legs, foundered and wind-broken. "Can that thar hoss go?" said he. "Well, I guess. Say, that thar hoss is a reglar racer. Git up, thar, gol durn yer!" But the old horse budged not. Still Jim continued his encomium: "That thar hoss has got the speed in him, all right, only it takes a devil a-drivin' to git it outer him!"

Poetry is felicity of expression, and by just so much as Browning lacked felicity of expression must he necessarily have lacked poetic genius. Even Dawson tells the following about Browning:

"There is a story told of Douglas Jerrold's having 'Sordello' sent him for review at a time when he was in weak health and low spirits. After an hour's fruitless effort, he flung the book aside, crying: 'My brain is failing! I must be mad! I have not understood a word.' His wife then took the book up, and it was agreed that upon the test of her ability to understand it, the question of her husband's sanity must turn. She at length flung it down, saying: 'My dear, don't be alarmed. ,You're not mad, but the man who wrote it is!" ",

Music, starting with the rhythmic vocatives of the primitive savage, the clap of hands or sticks, and the 
beat of the dancing foot, has been scientifically developed to a very high state of complicated excellence. But had the same attitude been maintained toward music that has prevailed in the case of poetry, by which it is set above and beyond law, and defiant of investigation, then we should never have progrest in music beyond the primitive chant and the tom-tom accompaniment.

The coalition of poets, critics, rhetoricians and educators against the scientific investigation and understanding of poetry, which has lasted for two thousand years, in order that the poets might be deified and poetry glorified, has resulted not only in fettering progress in that art with the ball and chain of ignorance, but has greatly hampered advance in other departments of literature. Rhetoric and oratory have been taught mainly by guesswork and example, with little or no knowledge of actual underlying principles.

Think of what a drag upon progress has been the following little statement of Edmund Clarence Stedman. Under the heading, "The Poetic Spirit Not Reducible to Terms," Stedman says:

"Nevertheless, we, too, must begin our answer to the question, What is Poetry? by declaring that the essential spirit of poetry is indefinable."

Stedman has been called the "dean of American letters," and he is one of those with whom it is generally deemed most creditable to agree. Let me whisper to you, reader: Edmund himself was a poet.

In his "Philosophy of Literature," Edgar Allan Poe presumed to tell how he wrote "The Raven," with deliberation and aforethought; but no one has ever believed him, for if "The Raven" were not written in a fine frenzy, certainly no poem ever was so written. If Poe were to be believed, that he produced "The Raven," one of the greatest poems ever written, entirely without any divine 
afflatus, then it would put the badge of charlatanism and false pretense upon the poets for always having claimed divine powers and heaven-sent inspiration.

Poe was a daredevil innovator, a wild sort of genius, miserably poor-exasperatingly poor, and his work was so big as to be far beyond the literary pygmies around him. Poe was unappreciated, misunderstood, underrated. The poverty and the hounding under which he suffered were a national disgrace; his untimely death was a cosmic calamity.

The pathetic, eye-moistening story of poor Chatterton has become a world grief. So young a boy, with so great promise-what a loss to literature! While Chatterton's precocity was a mere indication, the great work of Poe was a monumental demonstration and vindication. Poe, too, was relatively but a boy. What might he have done in a friendly environment?

The author of the "Elegy Written in a Country Churchyard," who was a contemporary of Chatterton, had his attention called to some of the boy-poet's best work. But Chatterton was too near to be appreciated by Gray, and Gray rejected him with cold scorn, when an appreciative word might have saved that genius to literature. Were Gray alive to-day, he would be among those at the mourners' bench, weeping over the tragic fate of the boypoet.

We must stand afar to see a mountain with a realization of its magnitude. Standing close, we see only boulders and sage-brush. Similarly, standing close to some intellectual giant, we see only his frayed trousers and the mud on his boots. We may not be greatly imprest by his work. It may strike us as meritless or mediocre, and so we close our hearts and the purse of our patronage, and turn our backs upon near and present greatness, while we kneel and lowly bow our reverential heads at the shrine of some genius of the past, and irrigate the ground with our tears because he was unappreciated 
by his contemporaries. We are unmindful of the fact that had we, too, been there, he would have looked very small to us, and that even we might have joined the ranks of those who stoned him, or have been among those who turned him away to starve. 


\section{CHAPTER X}

\section{APPLIED TRO-TEM-POTENTRY}

\section{(VERSE-POETRY)}

There are two ways of seeking appreciation: one is to 1 blow one's own horn; the other is to get some one else to blow it. Men are divided into two classes: the egotists, who are their own horn-blowers; and the blushers, who look on coyly, with a shy and retiring pose, while some representative does the horn-blowing.

In ancient Greece and Rome, it was as customary for an author or a hero to proclaim the merits of his wares or his physical prowess as it is to-day for tradesmen to cry up the merits of what they have for sale, or for politicians to proclaim that they possess peculiar qualifications for office and that their cardiacal deeps are big enough for the whole common people.

The Greeks have been called the braggarts of antiquity. But they were no exceptions to the general rule of the times. All the ancients were braggarts. In those old days there were no quick-firing guns, no forts along the frontiers, no coast fortifications, and no battleships. Blood and brawn alone stood between home, loved ones and the fierce barbarian. Human wolves of rapine, murder and slavery howled beyond the wall. Love and life were victory's reward. Death, or worse, was the forfeit for defeat. The transition from the sway and strain, the savage eye, hot panting breath, and fleck of blood and foam of the hand-to-hand conflict, to the embrace of waiting, anxious love, whose life, too, hung on the issue, made the heart volcanic, and grounded self-assertion in the soul of man. No wonder the Greeks were braggarts!

Hyperbolic braggadocio is the natural language of love and patriotism. The modern lover is just as much 
of a braggart and egotist in his way as was the ancient Greek. Love can not be properly profest without hyperbolic egotism. The loved object must be duly appreciated for her exceptional attractions, and this necessarily requires the proclamation of special qualifications in the lover that endow and fit him for her above all other men. Only the great can greatly love.

It is a peculiarity of our natures that we entertain side by side the most incongruous and contradictory emotions, thoughts and convictions, without discovering to ourselves that there is the least incongruity or contradiction. A pompous Englishman once said to a newspaper reporter that no one could flatter him. "Yes," said the reporter, "I have had the great pleasure and distinction of knowing you for some time, and I have particularly observed in you that trait of character-that you have none of the little vanities common to most other men, and that you take everything one may say merely for what it is worth, irrespective of its relevancy to yourself." "Yes," said the Englishman, greatly flattered, "I think that is true."

We all hate deceit, false pretense and prevarication. Nevertheless, we should pronounce a man a braggart who spoke his honest opinions of his own work, even tho his work deserved it to the full. We prefer that he should manage to let its appreciation come to us by some delicate indirection, which will add to his other laurels that of modesty, while we have the pleasure of discovering him to himself, and of enjoying his confusion, just as one enjoys kissing a shy girl for the first time.

Authors and geniuses have learned that they have but to wait until their agents and representatives have beaten up the woods, when there will be plenty of admirers caught in the net of their schemes. Then the quiet author or the budding genius, instead of being a party to the hue and cry, may sit back and enjoy his own crimson confusion at having been discovered. The result is the same, and all concerned are better pleased. 
"The love of praise, howe'er concealed by art, Reigns more or less, and glows in ev'ry heart. The proud, to gain it, toils on toils endure; The modest shun it but to make it sure."

-Young.

We hear much about the psychology and philosophy of Browning, while little is said of the wisdom of Young and Pope. What there is of true psychology or real philosophy in Browning is about as thinly dispersed as are comets in the interstellar spaces; and is so hidden in obscurity that the very effort of the finding renders it precious to the searcher, while in Pope, of whom Young was an imitator, there is such a plenitude of philosophy and psychology and his language is so simple that his wisdom intrudes itself upon us and we depreciate it accordingly.

Our likes and dislikes, and our ideas of the proper and the improper, of the right and the wrong, often depend more upon custom than upon intrinsic merit or demerit. During the Middle Ages the practise by the monks and other religious devotees of crucifying the flesh and humbling the spirit made self-abnegation and meekness the most esteemed of all human traits; while manly selfconfidence, assertiveness and vigorous initiative were traits of character which, next to heresy, were most to be despised.

Our present bias against egotism is very largely a cultivated taste, springing from monkish hypocrisy. While we hate hypocrisy on general principles, still on special occasions and under particular circumstances we require the practise of hypocrisy in others when it happens to meet the requirements of our highly specialized taste.

When smokeless gunpowder was being developed and perfected, I was fortunate enough to invent certain new and useful processes for its manufacture; and in order to prove the value of the inventions, I submitted samples of smokeless powder made by my processes for trial by the Government, because the only way to demonstrate the 
merits of the processes was to test the product. No one ever accused me of being an egotist for having laid the gunpowder samples before the Government with my own hands and having explained their merits with my own tongue. Similarly, having discovered certain new and useful methods for the production of poetry, verse and oratory, and there being no way to test the processes except by the product, just as in the case of the smokeless-powder inventions, I purpose to do with the reader exactly as I did with the Government-to submit product for proving process.

A prominent literary man once said to me: "Mr. Maxim, if, as you claim, poetry admits of scientific analysis, if it be possible to understand and to explain the poet's art, if poetry be amenable to science, then any one capable of analyzing poetry by your scientific method ought also to be able to synthesize poetry by the same method. For example, you, if your holding be true, ought to be able to write poetry. If, as you say, neither a fine frenzy nor any especial inspiration is requisite to the production of poetry, then why could not you rewrite any passage from Milton's 'Paradise Lost' to equal Milton, or paraphrase Hamlet's Soliloquy to equal the original of Shakespeare?',

I told him that, altho I am something of a boxer, and understand the science of the manly art of self-defense pretty well, still, I should not presume that I could whip a John L. Sullivan or a Jim Jeffreys. Nevertheless, I would undertake to rewrite a passage from Milton's "Paradise Lost," and also to paraphrase Hamlet's Soliloquy. Furthermore, as Shakespeare and Milton were obliged to pad the pentametric line-measure in non-lyrical narrative verse, under the mistaken belief that pentameter was essential, I should have the advantage of them, for the reason that I should be unhampered by line-measure, and should not be obliged to pad or to sacrifice to the meter either lucidity or sense. 
Whereas, all thoughts are not of equal importance, it is frequently necessary, in order to maintain the pentametric line-rhythm, to restrict the expression of a thought to a single line, or to employ a run-on line, allowing the sense to be completed in the following line.

The run-on line is a step toward the abandonment of pentameter in non-lyrical iambic verse. Frequently, several lines are employed to predicate a single thought; but this is usually done by padding out with dispensable adjectives and adverbs, modifying phrases and subordinate clauses.

I do not pretend to be a poet, but a scientist, and all the examples in the book written by me (marked Exm. in abbreviation for exemplification), have been designed merely to illustrate the principles I am expounding, and to show that any safe and sane person of education, possest of the requisite inventive imagination, can either write true poetry without any fine frenzy or divine afflatus, and without having had to be born for the especial purpose, or else be able to produce such good imitations of the real thing as to render it difficult to discriminate between the counterfeit and the counterfeited.

We have for so long held the grand old poets in the magnifying limelight of the imagination that we have given ourselves a great handicap, which must be taken into consideration when comparing the work of any latter-day writer with their glorified effusions.

The following is Hamlet's Soliloquy by Shakespeare, followed by a paraphrase written to illustrate the application of the foregoing principles, and especially further to illustrate the effect of continuous primary rhythm without pentametric line rhythm:

\section{HAMLET'S SOLILOQUY.}

"To be, or not to be-that is the question:Whether 'tis nobler in the mind to suffer The slings and arrows of outrageous fortune, 
Or to take arms against a sea of troubles, And by opposing end them?-to die-to sleepNo more; and, by a sleep, to say we end The heart-ache, and the thousand natural shocks That flesh is heir to-'tis a consummation Devoutly to be wish'd. 'To die-to sleep;To sleep! perchance to dream:-ay, there's the rub; For in that sleep of death what dreams may come, When we have shuffled off this mortal coil, Must give us pause. There's the respect That makes calamity of so long life:

For who would bear the whips and scorns of time, The oppressor's wrong, the proud man's contumely,

The pangs of dispriz'd love, the law's delay,

The insolence of office, and the spurns

That patient merit of the unworthy takes,

When he himself might his quietus make

With a bare bodkin? who would fardels bear,

To grunt and sweat under a weary life,

But that the dread of something after death-

The undiscover'd country, from whose bourn

No traveler returns-puzzles the will,

And makes us rather bear those ills we have,

Than fly to others that we know not of?

Thus conscience does make cowards of us all;

And thus the native hue of resolution

Is sicklicd o'er with the pale cast of thought; And enterprises of great pith and moment, With this regard, their current turn awry, And lose the name of action."

-Shakespeare.

paraphrase of hamlet's soliloquy.

How fear doth poise us on the brink of death,

Between contending purposes;

When some outrageous fortune

Steels the leaden temper of the mind,

To seek that last asylum from distress.

To die-to barter with oblivion

The heart-tire and the pain for dreamless sleep,

Were gain indeed, if that were all. 


\section{THE SCIENCE OF POETRY}

But in that sleep of death, there's hazard of the dream-

What dross of deed may cling to us and cumber our repose,

Or rouse such maddening wakefulness,

That could we peer beyond the pale,

The marrow of our mortal bones would freeze, And every separate hair would blanch and stand aghast!

So, with precocious fantasy, prophetic fear

Doth in such horror cast the countenance of death

The harrowed spirit quakes

Upon the verge of action, panic palsies will, And reason flees our pregnant purposes, Compelling suit anew for fortune's grace, Till we give flattered ear again to treacherous hope.

-Exм.

There is one very important desideratum of poetic material-the human import. The mysteries of life, death, immortality, eternity; the problems of justice and duty; the trials of loves and hates, pleasures and pains, rewards and punishments; the grandly terrible, and all that is splendidly magnitudinous, are poetic essentials.

In 1883 occurred the greatest volcanic convulsion in historic time. The island of Krakatoa, in the Straits of Sunda, was blown into the sky with a shock felt through the earth. The awful explosion set up a wave of air that encircled the earth three times. It took two years for all the fine volcanic dust blown out of the volcano to settle from the atmosphere. More mud was discharged from the crater than the Mississippi River carries to the sea in two hundred and fifty years. Thirteen other volcanoes in the great volcanic field were in simultaneous eruption, altogether causing the loss of more than 50,000 lives.

Altho this event was eminently grand and terrible, and the loss of life was enormous, still human import does not depend upon the actual loss of life, or upon the amount 


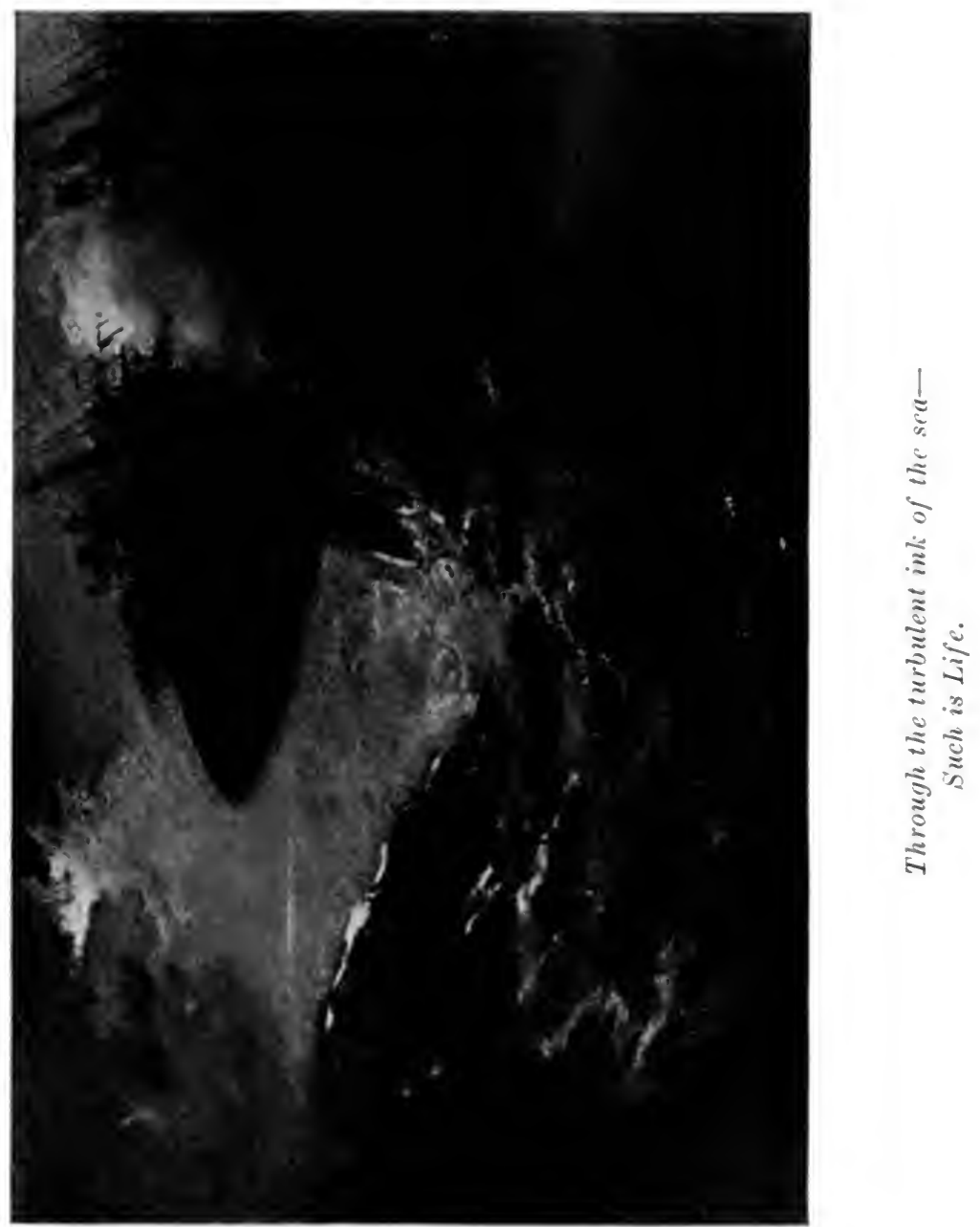


$=$ 
of suffering that may result from a calamity, for the reason that our interest in others, like the warmth of the sun, decreases rapidly with both the actual and the social distance from ourselves. The anxious mother is not so much concerned about a million people starving in India as she is about her baby's croup. Fifty thousand Malays destroyed in the eruption of Krakatoa may be of less concern to us than a fatal automobile accident to a friend and neighbor. An Atlantic liner going down with all on board concerns us much more deeply than the same accident among a strange and unrelated race of people on the other side of the earth.

To us, then, by far the most notable calamity of modern times, from a poetic viewpoint, was the destruction of San Francisco by earthquake, in 1906 . It possest the requisite magnitude and was sufficiently near home, and altho the loss of life was not very great, yet the victims were our own people, and the loss was large enough for the requirements of poetry.

The unexpectedness, suddenness and completeness of the calamity - a city utterly destroyed and its entire population outcast in a day, herded together in the fields, rich and poor alike brought to a common level by inclement fate-rendered it an event replete with human import, spectacular, grandly terrible, sublime. I have, therefore, chosen the San Francisco disaster as a topic for one of the examples of tro-tem-potentry, to illustrate the principles herein enunciated.

Before the birth of science and philosophic understanding of the relations of cause and effect, all natural phenomena were thought to be dominated by spirits, gods and demons of the earth and air. There was the spirit of the winds, the god of the waters, and the god of the great celestial concave. Thunder and lightning were manifestations of the sky god's anger. Famine and pestilence were punishments inflicted for imaginary offenses against the deities. Miracles were possibilities, and magic was 
commonplace. In olden times, before science was, a calamity like the San Francisco disaster would have been accounted the result of the anger of the gods at some human misbehavior, or a consequence of a battle lost by our allies among the warring gods; or the belief would have been that mischievous gods and the spirits of departed enemies from some spite or from sheer caprice, had destroyed the city as Nero fired Rome.

With the advancement of science and the widening of human understanding, miracles have been reduced to poetic figures of speech, and evolution has replaced magic with the play of pretend of the prestidigitator. But the old wonder-world of the past is still realized in poetry, for poetry is based upon things as they appear to be. It is based upon the seemings of things, upon intuitive, and not upon ratiocinative understanding, and has nothing to do with scientific deductions from facts.

I have, therefore, in the following poem, assumed that San Francisco was destroyed for some reason unknown to us, as the result of a conference between the gods and the ghosts of the dead. My object in the poem has been to introduce a large percentage of new and surprizing figures. I have tried to maintain an atmosphere of the weird, mysterious and terrible, in keeping with the character of the calamity, and throughout I have endeavored to make the tonal impressiveness of the lines harmonize with the thought exprest.

Furthermore, I have varied the rhythm somewhat, using both iambic and anapestic primary rhythm in some lines, and in other lines iambic rhythm alone, the purely iambic rhythm being employed in the more potential, solemn and stately parts, and the mixt rhythm in the more fanciful.

A mother, telling her naughty little son that he must be a good boy or the bogy-man will get him, and that there is always a bogy-man watching for an opportunity to punish bad little boys, will use a tone of voice in har- 


\section{APPLIED TRO-TEM-POTENTRY}

mony with the thought exprest; and if she adds, "Listenthere's the bogy-man coming now," she will alter her manner of expression to correspond with the new requirements. Similarly, in the lines:

In glory of gold took toll of the light;

Till witching darkness round her columns thrown,

I change from the mixed rhythm to the uniform rhythm for the same reason.

\section{SAN FRANCISCO FALLEN.}

Where occident day on the great water dies And morning is born to the Orient skies, As the sun-weary hours break ranks with the light

And eyelids are wooed by the narcotic night, While darklings that dwell on the old ocean floors Steal closer and list to the music of shores, Tall splendor built there on an ancient way, Where hell-folk of old came up to the dayOn the decp wound-scar of a molten road

Whence the fiery blood of the earth had flowed; When volcanoes mocked at the solar light, Turning dark on day, setting flame to night. On the primal air wild skies were flung, For the torrid heart of the earth was young.

Then fire and land were at war with the sea, And scourged the dominion of splendor to beA city that reared her towers and spars O'ertopping the clouds in parley with stars; And high in the sunset sheen o'er the night, In glory of gold took toll of the light; Till witching darkness round her columns thrown, Dim hung in mystery of things unknown; Where, maybe, ghosts from far-off other spheres-

Lost tramps of space who wander down the years, And fallen low from some estate sublime, And drifting now, old derelicts of time- 
Had gathered, there to witness human strife, Or be near earth to warm themselves on life. Or had some word gone forth or signal call, Assembling ghosts to see a city fall?

There, maybe, gods communed with souls of men On awful themes beyond all mortal ken, In forum where was closer concord drawn, Hid in the hour's before the purpling dawn.

Or there, maybe, old Chance drew straws with Fate

To cities spare or to annihilate; And dread presagings of the future cast In dark eclipse, till Horror stood aghast, Foreboding dire calamities below, That only Horror and the dark can know. Or Fate, maybe, had set the seal secure, Beyond all power to alter or abjure.

The gods cast their dice and the chance of a fling

Is what life is worth to peon or king. Hope is but builded of fancy and dream, And fits in the flash of a lightning gleam. For man or a world, the life is a spark That ages and dies and goes out in the dark. The earth has her agues, for time is cold, And she is grown shrunken, palsied and old. Now the tread of the heavy ages jars;

She feels her old wounds and aches at old scars. Deep-mantled in dark of a treacherous hour, Earth groaned in the gripe of a demon power; While ashen terror saw the crumbling wall And all the giant-builded city fall;

When domes that pillared up the arch of heaven Came roaring down, in awful thunder riven. And as the high-laid timbers shivering fell, Fate plied the torch and sowed the flames of hell. Then mountainous fire burst night and the sky, And men ran with death in a wild, far cry.

Lean hunger in the shadows ran beside With pestilence, ghost-boned and hollow-eyed; 
And leering lineaments of the tomb

Grew seemingly to skeleton the gloom.

Colossal Horror rose athwart the way, Masked in the murk and holding up the day; Where yester-morn did gladness woo the sight, And all the land lay laughing in the light, Where flowers the earth with gay profusion pearled,

Bright as the star-dust of the spirit world. But envious powers of the under plane

Their Samson strength against the pillars strain,

And the fairest fabric of human power

Ravels to the memory of an hour.

-Eхм.

The way of life is along a narrow ledge, between the infinitely great and the infinitely little. Topless heights tower above and bottomless depths yawn below, and their contemplation gives supernormal exercise of faculty. When any faculty is exercised in an unusual degree, but in less degree than will injure the faculty, the exercise serves as a tonic. We are exhilarated by looking from a great height upon a surrounding landscape, because the faculties brought into play are doing unusual duty. Similarly, anything that gives us a new or deeper view of the mystery of things exhilarates us through the imagination. The keenest delights of the scientist and philosopher arise from the contemplation of stupendous magnitudes or of littleness that transeends understanding, and from trying to fathom the depths of environing mystery where science has not yet penetrated.

Sublimity in poetry, power of oratory, and much of the force of every-day utterance, depend upon the use of potential words and forms of expression, which stimulate perception of magnitudes. Eliminate from Milton's "Paradise Lost" all that stimulates by the contemplation of magnitudes, and it would be without sublimity.

To Herbert Spencer the thought of endless space was 
an obsession. That space is endless is an awful realization. If we could fly out through space with the speed of thought, passing from constellation to constellation, our speed would be limited only by the time requisite to think of one sun after another in the line of flight in order to steer our course between the fiery orbs.

During the past thousand years, Arcturus, traveling at the rate of more than four million miles a day, has moved along the sky less than the apparent diameter of the moon. If, however, we were traveling through space at the speed of thought, Arcturus would rush by us so quickly that it would seem to appear and disappear like a flash of heat-lightning on a storm-cloud at night. I have tried to suggest this speed in "The Flight of Satan."

THE FLIGHT OF SATAN.

Then from the spinning earth himself he hurled forth into space, in swift tangential flight that cut a thousand solar-centered days cored in the dark. Outpacing thought, so swift he plunged on through the night of measureless infinitude, a million suns did stripe with flame his speed upon the dark, as fireflies in a night of June flash past an eagle on the wing. And as old Boreas on some torrid eve piles jetty billows on the sky, and with exploding thunder rends in tongued and sheeted flame, so hot Arcturus, rushing forth, burst the inky void, and as instantly dissolved into the ink behind. As black in deep nocturnal shade at some mysterious hour when groans are heard in underworld and demons haunt the air, an old volcano belches hell into the vault of heaven, and all the mighty concave flares in one great dome of fire, so giant Sirius from the deep burst on His Majesty, and halved with Satan for a flash the empire of the sky. Altho the space from star to star be twice a hundred thousand times the gulf that parts us from our sun, it scarce gave time to bend his course and pass them in his flight; until so far, the 
Milky Way and all our spangled universe became a dim oasis of uncertain glow within the desert void.

Then Satan, in the endless black of space, ere this untrod and undisturbed eternal primal dust and quarry of the worlds frontiering all the realm of then created things, explored old chaos far beyond the troubling touch of time.-Exм.

The above poem is nearly all in straight iambic rhythm, but correct expression in reading compels a variation of the rhythm where the sense demands it, as, for example, the word cored following as the unaccented syllable in the foot, days cored, must, to make sense, be emphasized by greater loudness, pitch and dwell than the word days, and a pause or rest be made between the words. Similarly, the reading sense compels the suppression of accent upon the accented syllable of in the foot is of, in the clause, $b e$ came a dim oasis of uncertain glow.

In the lines:

"So hot Arcturus, rushing forth, burst the inky void, and as instantly dissolved into the ink behind,"

the meter is broken into prose onomatopy that the sounds may better harmonize with the sense, the word burst itself coming in as a burst.

When there is an idea that requires especial emphasis, a good effect is often produced by interrupting smoothly running rhythm by inversions of emphasis, or by some other impediment, thereby forcibly calling attention to that particular idea, just as one encountering unexpected roughness or an obstruction when walking along a smooth way, has his attention forcibly directed to the impediment.

But interceptions should be introduced in verse only sparingly, where the sense demands it, and where the increased pleasure of thought-perception compensates for 
frictional distraction. Browning frequently introduces impediments in his lines, sometimes producing excellent effects, but more often producing effects the opposite of excellent. Without knowledge of the science of poetry and verse, Browning did not understand the reason for the occasional good effects. Therefore, he was unable to avoid inartistic interruption of rhythm. As a result, some of Browning's verse is a veritable hatchel of rhythmic irregularities.

Persons in whom the ocular faculties predominate are called visuals, and those in whom the faculties of hearing predominate are called audils. Many persons have both sets of faculties highly developed, and are, therefore, both audils and visuals. Visuals are strongly stimulated by the spectacular. The fast express with flaring headlight rushing out of the night, madly past and on into the night again, is visually impressive. But to the audil, the scream of the whistle and the roar of the wheels upon the iron rails as the train clatters, crashes and thunders by are far more impressive. To the visual, the mountain height, the long vista through the hills opening upon the sea beyond, landscape and seascape, are sublimely impressive.

When old Boreas piles jetty billows on the sky and with exploding thunder rends in tongued and sheeted flame, the visual is more imprest by the spectacular display, while the audil is more imprest by the thunder crash and roll and roar. Napoleon was deeply affected by the tones of deep-throated bells.

Milton was both visual and audil, highly organized, having the visual and the audil imaginations correspondingly developed. Thus it is that in his sublime lines, he is able to make us in the imagination see, hear and feel as he in his own imagination saw, heard and felt as a spectator of the war in heaven. Milton is the most sublime of the poets. Still, Milton was, as every other poet has been, without scientific knowledge of the laws 


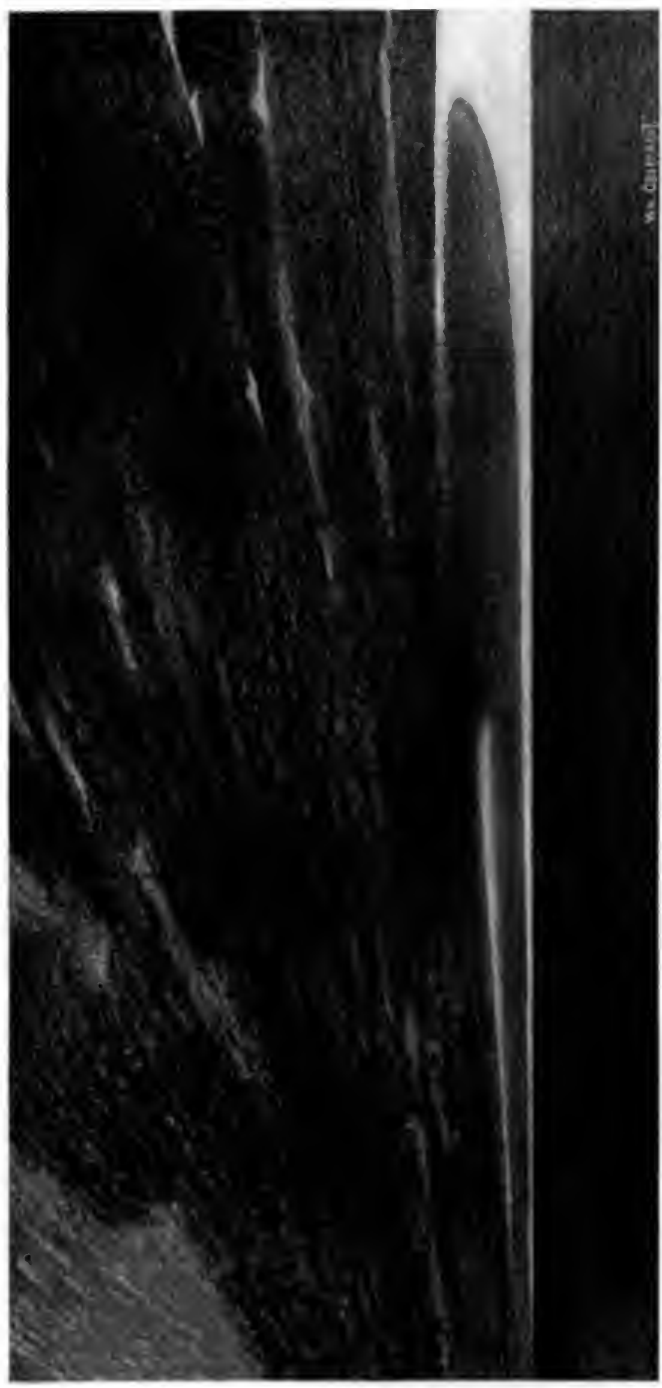

$\frac{\pi}{2}$

$\cong 1$

c

‡

$\stackrel{0}{\approx} \Xi$

$\approx \approx \Sigma$

$\approx \approx$

$\stackrel{0}{\approx}$

$\stackrel{2}{\approx}$

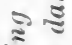

$\stackrel{\Xi}{\approx}$

$\stackrel{5}{5}$

$\approx$ 

that make poetry either great or sublime; and his use of sublimity was an accident of his nature, just as the use of splendid poetic figure by Shakespeare was an accident of his nature. Had either Shakespeare or Milton been possest of an accurate scientific knowledge of the laws underlying their work, they would have better conformed to those laws and would have made fewer mistakes.

The following eulogy on Milton was written as an example of continuous iambic line-rhythm, the poet himself affording a good subject for potential language:

\section{MILTON.}

In the abysmal ocean deeps that dark and awful yawn toward Hell as far as toward the sky the highest mountain peaks extend, life teems; and there, environed by the blackness absolute of the eternal night, the living things have eyes and see by self-created phosphorescent light.

So genius, robbed of other light, still sees by its own inner luminance; and by such light lost Paradise is drawn so true that it no picture seems, but seems as tho 'twere memory of some prenatal life, where we with once transcendent beauty shone, or had with giant strength gigantic deeds achieved.

High up, and made companions of the gods, we soar, and by the side of Michael stand upon the arch and verge of Heaven, to witness there the angelic hosts contend, and Satan see with all his throng "hurled headlong flaming from the ethereal sky, with hideous ruin and combustion, down to bottomless perdition."

Thence we to new created earth are led, and Paradise, where Adam, then before the fall, unshaped to harsh environment, was beautiful as Eve, who on creation's morn awoke, as sunlight him to bless, and with her presence made all Eden glad. With angel guests we visits pay to our first parents in their bower; and when the wicked serpent enters there, we sympathize, and with them flee beyond the flaming sword that bars 
return, to war with heat and war with cold, and war with savage beasts, and with the hurricane and storm and flood, and yet with fellow man to wage a still more savage war.

With painter's touch, the poet's pen has pictured all of life, and set about the Universe the halo of the Infinite. The sun-blush on the face of morn, the glare of torrid noon, the stormpall in the western sky, that veils the dying day as mystery the end of life has veiled, and all in Nature's face to man revealed, e'en to the confines touched by Heaven and Hell, great Milton has so mirrored in his work, we see the whole reflection of the world that he saw in his soul. And he has given tongue to Nature, that she speaks with all the eloquence of the Creator's works; and angels speak from worlds beyond our ken; and wailing souls, lost in the gulf of Hell, commune with angels lost and made companions of their misery; and in poetic voice the great Creator speaks, and sunny gladness gives returning speech from out the depths of all the Universe.-Exм.

While great admiration is due Milton, we must not let that admiration blind us to his faults; and as students of poetry, it behooves us to be sensible of his faults as much as it does to appreciate his virtues. Much of "Paradise Lost" is merely sublime Billingsgate. Let us take, as an example, "Satan's Encounter with Death," and if we are able to read it with mind unbiased by the Miltonic halo, we shall see that certain passages give the impression of common scolding, with all the concomitant crimination and recrimination, brag and vituperation. Milton makes Satan and Death meet like two town bullies and call names, accuse, threaten and lambaste each other with their lingo. Both being immortal, neither is afraid of the other, or of anything else except of what Milton is going to do with them. At the end, when an impossible situation is about to be reached, Milton employs the expedient of a 
"snaky sorceress that sat fast by Hell-gate, and kept the fatal key," who rose up and "with hideous outcry rushed between." It would have been far better to have personified and used old Fate to prevent their coming to blows.

There is, however, a passage in this section of "Paradise Lost" which is one of the greatest in English poetry :

". . . and like a comet burned, That fires the length of Ophiuchus huge

In the arctic sky, and from his horrid hair Shakes pestilence and war."

These lines, combining as they do sublimity with superlative poetic figure, are about the supreme of excellence. I shall first quote Milton's original, and then give a paraphrase or rerendering.

The reader must appreciate the fact that there is a strong current of intellectual bias which he must breast if he desires to judge fairly the work of the old poets. We have been so long accustomed to bow our heads bared to the weather before the shrine of Milton and Shakespeare that it will seem almost an insult to their haloed names to keep our hats on. Witness what Macaulay says of Milton's poetry:

". . . Change the structure of the sentence, substitute one synonym for another, and the whole effect is destroyed. The spell loses its power; and he who should then hope to conjure with it would find himself as much mistaken as Cassim in the Arabian tale, when he stood crying, 'Open Wheat,' 'Open Barley,' to the door which obeyed no sound but 'Open Sesame!' The miserable failure of Dryden, in his attempt to rewrite some parts of the 'Paradise Lost,' is a remarkable instance of this." -Macaulay. 
Nevertheless, here is the passage from Milton, followed by my rerendering:

\section{SATAN'S ENCOUNTER WITH DEATH.}

"Whence, and what art thou, execrable shape! That darest, tho grim and terrible, advance Thy miscreated front athwart my way To yonder gates? Through them I mean to pass, That be assured, without leave asked of thee. Retire, or taste thy folly, and learn by proof, Hell-born, not to contend with spirits of Heaven!

To whom the goblin, full of wrath, replied: Art thou that traitor-angel, art thou he, Who first broke peace in Heaven, and faith, till then

Unbroken; and in proud rebellious arms, Drew after him the third part of Heaven's sons Conjured against the Highest; for which both thou

And they, outcast from God, are here condemned To waste eternal days in wo and pain?

And reckonest thou thyself with Spirits of Heaven,

Hell-doomed, and breathest defiance here and scorn,

Where I reign king, and, to enrage thee more, Thy king and lord? Back to thy punishment, False fugitive, and to thy speed add wings, Lest with a whip of scorpions I pursue

Thy lingering, or with one stroke of this dart Strange horror seize thee, and pangs unfelt before.

So spake the grizzly Terror, and in shape, So speaking and so threatening, grew tenfold More dreadful and deform. On the other side, Incensed with indignation, Satan stood Unterrified, and like a comet burned, That fires the length of Ophiuchus huge In the arctic sky, and from his horrid hair Shakes pestilence and war. Each at the head Leveled his deadly aim; their fatal hands No second stroke intend; and such a frown Each cast at the other, as when two blacle clouds, 
With Heaven's artillery fraught, come rattling on

Over the Caspian, then stand front to front, Hovering a space, till winds the signal blow To join their dark encounter in mid-air:

So frowned the mighty combatants, that Hell

Grew darker at their frown; so matched they stood,

For never but once more was either like

To meet so great a Foe: And now great deeds

Had been achieved, whereof all Hell had rung,

Had not the snaky sorceress that sat

Fast by Hell-gate, and kept the fatal key,

Risen, and with hideous outcry rushed between."

-Milton.

Paraphrase of Milton's "SATAN'S encounter With DEATh."

What carrion dregs and whence hath oozed thine execrable shape,

That dares to swell and reek athwart my way

to yonder gates,

And with pollution's foil to front the purpose of $a$ god,

With whom, offsprung from the omnipotent, Accomplishment is parcel of the will that action hangs upon?

Art thou that emanation of the curse, contaminate

Of leprous ferments venomous,

Which fret the winding blood of life to canker pestilence,

While Hope doth traitorously tease the great abortion on

To make a ghoul's laugh at a grave?

And dost thou, cancerous progen of the curse $I$ brought upon the world,

Seck the impeachment of omnipotent decrees, Wherein, for me, my aspiration's punishment, Hath God ordained an everlasting life,

Who, if 'twere true that time were not so unremitting long,

Had lengthened out eternity to give me measure full 
Among the tortured tenantry of Hell,

Of which thou art an underwhelm?

Go.

Then for response,

The frightful specter wound a hideous laughter out,

And answered thus inflamingly:

Dost thou not know, the humble plant

Doth feed on comfort in the noxious breath that men exhale,

And that in deep iniquity an angel breathing condemnation there

Doth whet up pride of it for proclamation?

And know'st thou not, the deeply base, of rank corruption born,

Pride in their parentage as angels do, And that the slimy progeny of mire do love their home that hates the day?

All things that are, and high as low,

Have somewhere sprung within the purposes of God,

And fair may I, thou miracle of ill, thy damning spurn,

From whom high praise a thousandfold would more condemn.

I, too, am child of all-potential light

That broke the night of chaos into smile, And gave to beauty all the trance of stars.

Nay, do not flaunt too fearfully thy self-made terribles

of mien and might, which vanity is bulging into size,

Where I do hold the gantlet gate of Hell

And am the lord, and where, thy king.

For here shalt thou on crumpled knees do deference,

Or I will now within thy frantic blood Such viperous fermentation set and torrid fevers fan to fire,

Thou shalt within thine own consuming essence burn,

And every naked nerve shall scream, Until thy face doth such contortion wear in habitude, 
The newly damned will bask in furnace heat, And from thy horrid countenance their swimming orbits hide in liquid fire, And grunt for comfort, thankfully, Their torment is so less than thine.

Now vast achievements on their fierce intentions hung

That might have broke the deep foundations up And echoed in the stars,

Had not old Fate inexorable, that governs dark decrees,

With thunderous commanding barred between.-Exм.

When a lover has been brooding over the loss by death, or otherwise, of his Lenore, who has come to fill his heart's world, then subjective memories well up into consciousness in the guise of realities, accompanied by oft-returning thoughts of her which are uttered over and over again, either in the same words or in word-apd ideaparallels. He may be aware that his visions are but hallucinations and that his thinking borders on dreaming, and reason with himself the while. To illustrate this, I have written the following poem, entitled "A Veiled Illusion." The husband sees the wedding veil of the departed wife hanging upon the wall, and gradually the face of the wife appears in the veil, smiling as of old.

\section{A VEILED ILLUSION.}

Only a veil she has worn,

It is but a web of gauze-

Only a touch of the real,

It is but a filmy gauze;

And yet is entangled my heart in that web-

In its mesh is entangled my soul.

A gleam of a fancy is caught in that web,

And smile that entangles my soul.

Only the warp is the real,

The woof is the substance of dreams-

Only the veil is the real,

The face is the substance of dreams; 
And yet all the tangible worth of this life

Is a tissue of only what seemsAnd all of the solider webwork of life

But veils the sweet substance of dreams.

Only a fancy in flight,

Just caught in the web of a wish-

Only a thing of the light-

$A$ ray of the light and $a$ wish;

And yet has the fancy enchanted my sight,

The illusion enraptured my soul-

Enraptured, entranced and enchanted my sight,

Eniranced and enraptured my soul.

-Exм.

In the following poem, the lover is supposed to be seated before an open fire in his den, and while he is "nodding, nearly napping," fancy and memory join hands $\mathrm{s}$ his mind, and he leaves for a while his mortal part to join in the dance of shadows.

THE DANCE OF SHADOWS.

Oh, the mingled joy and terror, When her spirit, flown before,

Hand in hand with firelight shadows,

Danced around me on the floor.

Called, I joined the merry party, Left the mortal sitting there,

Joined the laughing dance of shadows,

Joined the fantoms and the air.

Sorrow then dissolved in gladness,

Joy winged wild and wilder rout;

Unsubstantial wights of being

Swung the round in merry bout.

-Exм.

To-day there is too little of the old, simple, potential verse replete with human import that stimulates the emotions, like Gray's "Elegy," "Hohenlinden," "Bingen on the Rhine," "The Burial of Sir John More," "Charge of 


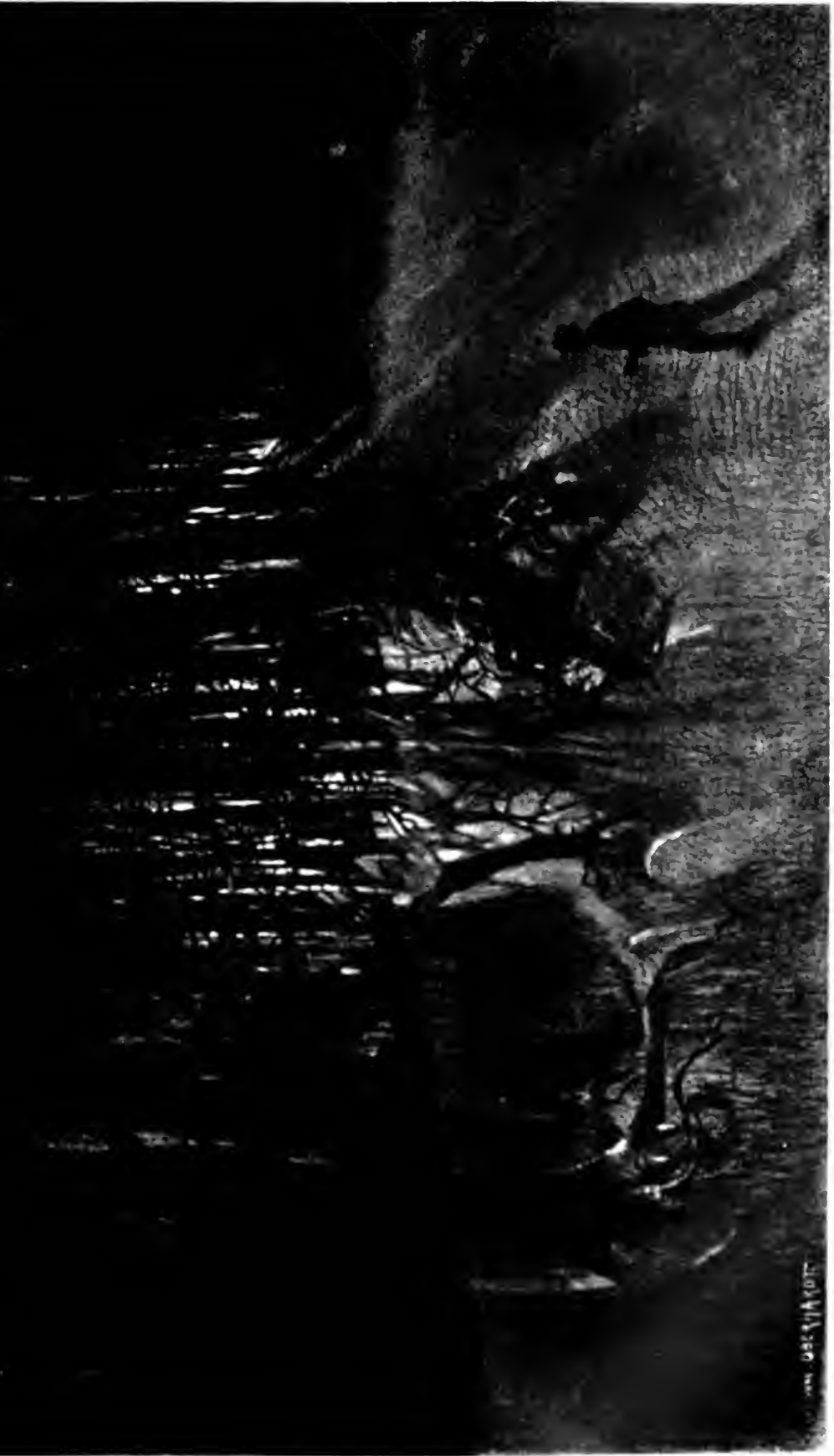



the Light Brigade," "Young Lochinvar," "Lord Ullan's Daughter," "Excelsior." Even tho verse contain but little new and surprizing figure, it must not be forgotten that, while poetry may add greatly to the delight of verse, still it is not indispensable, and we may have excellent verse without it. There is but little poetic figure in Gray's "Elegy," and practically none in "Excelsior." Yet, other things equal, artistic figure both strengthens and embellishes verse.

Among the best examples of the good old potential verse, strong in potentry, but not very rich in poetic figure, are Macaulay's "Lays of Ancient Rome." The following stanza is practically devoid of poetic figure, but it presents to the mind a striking picture, and it is strong in human import. I have paraphrased this stanza to make it figurative, and tho the effect may be slightly more pleasing with the figure, still the verse is so strong in human import that it is very stimulating without the figure.

Now, from the rock Tarpeian, Could the wan burghers spy

The line of blazing villages

Red in the midnight sky. The Fathers of the City,

They sat all night and day, For every hour some horseman came

With tidings of dismay. -Macaulay.

ABove stanza paraphrased.

Now, from the rock Tarpeian, Did paling terror spy Long blazing lines of Roman homes Made torches in the sky. The Fathers of the City

Sat with the night and day, As horsemen of the fearful hours

Told tidings of dismay. 
I contribute the following also:

\section{SHADOWS OF DAWN.}

$A$ whir of dust is sweeping the hill, Between the gray dawn and the huge black mill. There's a drift of rags and of skinny bones, With skeletor feet on the ruthless stones. What specters are these in the witching lightThis ghostly rear-guard of the night, Wearily treading the trail of the dark, Arousing the morn before the lark?

What wights are they, so gaunt and lean, With lagging pace and drowsy mien, Who under the dim lamp's flickering glow Wind into the cavernous mill below? $A$ sortie of ghouls aloose from the tomb, Or a rabble of wraiths begot of the gloom? No-goblins and ghouls such task would shirkIt is only the children going to work!

-Exм.

Verse-parallelisms, where there is rime of thought and idea, rather than rime of sound, such as that largely employed in the Bible, appear to have been the poetic style of remote antiquity. In the course of his explorations near the pyramid of Illahun, from 1888 to 1890, Professor Petrie discovered a number of papyri, upon one of which was written a poem, addrest to Usertesen III by his subjects, which is the oldest known poem, it probably having been written about 3000 B.c.-about 1500 years before Moses. The following is a translation of a few lines of the poem:

"Twice great is the lord of his city; he is, as it were, a cool shelter, letting every man repose unto daylight.

Twice great is the lord of his city; he is, as it were, an asylum; delivering the frightened one from his enemy.

Twice great is the lord of his city; he is, as it were, a verdant shade and cool place in the time of harvest. 
Twice great is the lord of his city; he is, as it were, a corner warm and dry in time of winter.

Twice great is the lord of his city; he is, as it were, a rock barring the blast in the time of tempest."

Note the similarity of the following lines from the Bible:

"O give thanks unto the Lord; for he is good: for his mercy endureth forever.

$O$ give thanks unto the God of gods: for his mercy endureth forever.

$O$ give thanks to the Lord of lords: for his mercy endureth forever.

To him who alone doeth great wonders: for his mercy endureth forever.

To him that by wisdom made the heavens: for his mercy endureth forever.

To him that stretched out the earth above the waters: for his mercy endureth forever.

To him that made great lights: for his mercy endureth forever.

The sun to rule by day: for his mercy endureth forever.

The moon and stars to rule by night: for his mercy endureth forever."

The following poem shows perhaps the way the Bible would have been written in the English of to-day. Altho the verse is without rime of words of similar sound, there is rime of idea, and the parallelism of idea and the repetitions of the same words and the harmony in the potential impressiveness of the words with the thought exprest, give fully as pleasing an effect as tonal rime would give, and the tonal rime is not missed:

DESTINY.

Like the dew-jeweled rose as it glints in the light

Of the rose-diamond glint of the mornAs it smiles with a blush that is born of the light

Of the rose-diamond blush of the mornSuch is Childhood. 
Like the wake of a ship in the moonlighted night-

Like a dim-lighted river that's past-

So our youth flees away from us into the night

Of our memory's dim-lighted past-

Such is Youth.

Like that river that flees from us into the dark, And away, to come back nevermore,

So the bright days of life flee away in the dark, And will never come back any moreSuch is Time.

Like the rush of a ship through the storm and the night-

Like the cleft of its path through the sea-

Like its plunge through the sea and the storm and the night-

Through the turbulent ink of the seaSuch is Life.

Like the enshrouding gloom of the oncoming night, As it hovers down over the sea, All entombing the world in the gulf of the night,

In the darkness and gloom of the seaSuch is Death.

Like a bird as it bursts from the bars of its cage, And mounts with the light of the dawn, So the soul shall be freed from the bars of earth's cage,

And shall mount in the heavenly dawnSuch is Immortality.

-Exм.

Nearly all of the poets have had their try at verseonomatop where the sound and sense are made to harmonize as closely as possible. Poe's "Bells" is probably the most notable example. I contribute the following, not for tonal beauty, such as is possest by "The Bells," but in illustration of onomatopic aptitude in the use of words: 
THE VILLAGE ORCHESTRA.

Lightly touched do the cymbals clink

To the fiddler's long-drawn tone-

The bass drum beats and booms and beats

With its big bass booms alone.

Light and shrill is the fifer's trill

To the cornet's bursting blast-

The trombone pumps and pumps and pumps,

With the bass drum booming fast.

Light are the tings of fiddle-strings,

Then they draw a dying groan.

The big bass viol tums and tums,

And the bass drum booms alone.

Rat-a-tat-tat, rat-a-tat-tat,

And rolls the tenor drum-

Then all roll, rattle, smash and bang,

And the old bass boomings come.

Lightly still do the cymbals clink

To the fiddler's long-drawn tone-

The bass drum beats and booms and beats

With its big bass booms alone.

-Exм.

Folk-lore legends told in verse, plantation melodies and the old songs of endeavor, love and friendship. are filled with human import, and for that reason they are immortal and never grow stale. The old impressive gospel hymns owe their power to human import. The awful peril of the sinner contrasted with the blissful condition of the saved is a strongly emotional theme.

The true theme for a hymn is that of the Christian doctrine of salvation, and the refrain should be a reiteration of the principal suggestive requirements of the hymn: that sinners are rebellious and that Christ can save through faith. The verse-measure should be simple, with strong terminal rimes. 
I wrote the following hymn conformatory to the above themal requirements. It was published in the Christian Herald, February 20, 1901:

\section{HE CAN SAVE THEE.}

Crystal waters of the Jordan Bathed the sinless One, And the voice of God proclaimed Him His belovèd Son.

\section{CHORUS :}

He can save thee, He can save thee,

$O$ rebellious soul.

Still the waters of salvation,

Blessèd waters, roll.

Crystal waters of that fountain

Banish sin and strife.

They are giving, still are giving, Everlasting life.

Blessèd waters of salvation, Free as ambient air,

They can cleanse, exalt, and save thee, Banish thy despair.

By that crystal flood perfected, Freed of every sin,

Then the welcome way will open Wide to let thee in.

When last scenes of earth are fading On the dying eye,

Through the mist will break the vista To the throne on high.

When the tears of love baptize thee For the long good-by, He alone can save and tell thee Thou shalt never die. 
All must part at death's dark river, All must pass it o'er.

He alone can reunite us

On the other shore.

-Exм.

When the rugged old farmer comes in from his work, and has appeased his fierce hunger with a meal of mother's cooking, which he proceeds to disintegrate and assimilate with a shark's digestion, and has humped himself up in the chimney-corner, smoking the pipe of peace and comfort, the good wife cautions the children not to disturb father, because he is in a brown study. But, escaping mother's watchful eye, a little urchin approaches the male parent, and queries, "Papa, what are you doing?" "Oh, I am just thinking," is the answer. But the old man is not thinking at all. $\mathrm{He}$ is just feeling. $\mathrm{He}$ is reflexing. He has unlimbered himself from thought and care, and is enjoying the goings-on of his reflex processes. Thinking would interfere with his enjoyment and retard these operations. Therefore, he has inhibited from consciousness as many of the higher thought-centers as possible consistent with a wakeful state.

There are a large number of persons who, under the stimulus of emotional literature, especially verse, imagine that they are doing a very high grade of thinking; that they are thinking thoughts so lofty and transcendental that their soul-deeps are divinely agitated; while, as a matter of fact, they are merely reflexing under emotional stimulus, just as the old farmer reflexes in the chimney-corner under the stimulus of a good digestion.

In order to illustrate the power of verse to make us reflex and imagine that we are thinking great thoughts, I have written the following verse, entitled, "In the Deep of Things," which, while it is mere nonsense, and entirely without connective thought, contains much suggestion of human import "to you and to me," presumably lovers, who are encountering great harassment, while there 


\section{THE SCIENCE OF POETRY}

is suggestion of remoteness and magnitude to stimulate the imagination. The tonally impressive verse-measures, still further enhanced by repetitions and parallelisms, are very suggestive of the importance of something or other to you and to me.

IN THE DEEP OF THINGS.

In the deep of the bowl where the roarials roll

In the maddening waves of the sea, And the soul with its goal in the boreal pole,

Was the moaning for you and for me;

Was the soul of the pole in its boreal goal, And the moaning. for you and for me.

While the voice of the thunder that speaks down under

With the souls that are never to be, And we dream and we wonder, with hearts torn asunder,

That pulse with the pulse of the sea-

With hearts torn asunder, in dream and in wonder, And that pulse with the pulsing sea.

On the dawn of the day when the stars look our way,

With the raining of tears on the heart,

When our languorous love in the lone lunar ray, And the fates that compel us to part,

In our mad lunar love by that languorous ray, With the fates that compel us apart.

0 my heart, you sublime in the measureless time With a passion born never to die,

Till your soul and my soul shall be merged with the soul

Of the infinite deep of the sky,

Till your sorrowing soul shall be merged with my soul

And the infinite soul of the sky. 
And shadows now teem in the pale lunar beam,

By the languorous lunar ray,

While the fantoms that gleam with the seeming of dream

Float out on their shadowy way,

'Mid the gleamings that seem to be fantoms of dream,

And that float on the shadowy way.

-Exм.

A lover, distracted unto death by the loss of his heart's idol, traverses a heavy wood, through whose lofty arching branches a faint moonlight filters into the under-dark of the early morning hours. To his fevered imagination the forest is alive with demoniacal presences, until, arrived at her grave, they are dispelled by a vision which he embraces as her materialized actuality, come to be his conductor through the mystic maze of the dark pass into the soul-world. This theme was chosen by reason of the opportunities it afforded for striking imagery.

\section{DARKEST BEFORE DAWN}

It was that black and treacherous hour when dread miasmas hang upon the air, Just ere the first vedettes of light appear-

Outriders of the dawn and heraldry of day-

That chase the rabble vapors from the course and van march of the king;

That haunting hour when spirit-mysteries clothe themselves with shadows in the wood, 'And seemings grow to spectral shapes and watchers from the gloom,

I walked alone the dread and whispering night.

The gaunt old elm, weird in the narrow crescent of the dying moon,

Stood out a hungry skeleton;

And e'en the stolid oak did harbor in his sheltering boughs

$A$ brood of muttering goblins. 
On through a vista arched by fantoms and the ghostly trees,

And either side dark-denned and damned, enticing fearsome things,

$I$ rather felt than saw my way,

Groping the gantlet of strange peerings from the shades,

And while the very air attended on expectancy

And held its breath from on the leaves,

Till silence listened for a sound,

And I could hear the tread of misty moonbeams

Stilting through the trees;

And menace whispered from the other world,

As hovering ghosts, from far-off olden days,

Now derelict and drifting on the gulf,

Looked enviously on life,

And chilled the night with their cold bones.

At length I came to where the earth doth merge into eternity -

'A grave-her grave-our tomb.

Then beauty through the curtain dark appeared,

Dispelling all the haunting specters of the night, and all my fears,

And I embraced again my life-again embraced her soul.

To meet me at the verge she came,

To lead me o'er the treacherous way, and home.

-Exм.

Every man is an outgrowth of the combined environing forces of all his ancestry compounded with his own personal experiences. In Paris there has been evolved a new breed of criminals peculiarly adapted to the denizenship of that city's under-world. Singly as cowardly and elusive as a coyote, savage as wolves, and like wolves daring only in packs, emulating in robbery and murder the cunning and cruelty of the Indians from whom they take their name, these human hyenas have of late years become an appalling menace to the life of all classes in the French capital. The blood that is in the veins of the French Apaches has flowed to them mainly from the lowest mob 



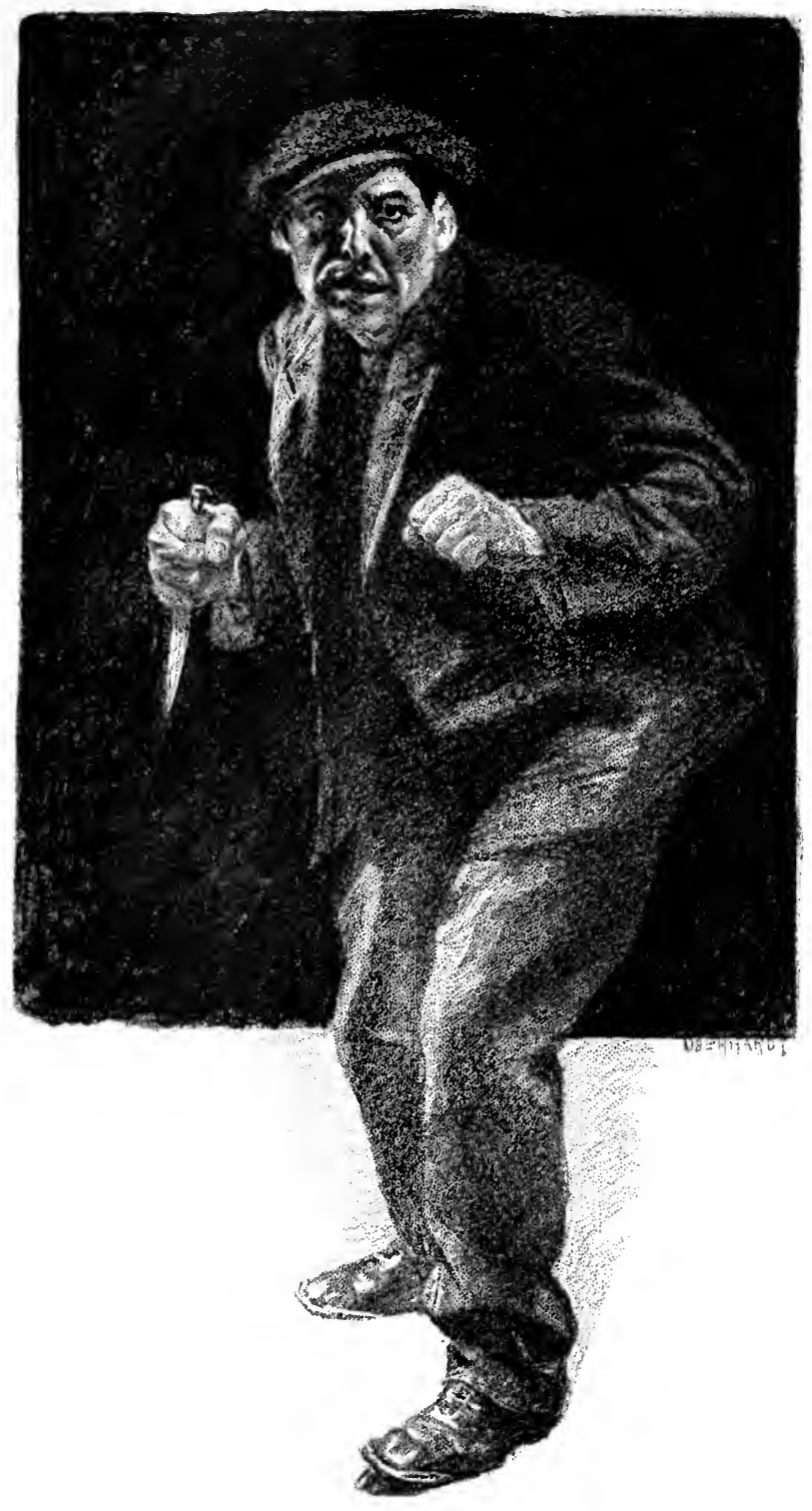

\section{L'A pache}

What legends are there in thy horrid mien Of that dark under-uorld of human dregs, From where the look is up, not down, for Hell. 
type of the French Revolution, from the degraded peon and from the diseased, the vicious, and the criminal of every part of the world.

The French Apache affords a theme for poetic treatment equal to the type portrayed by Millet's famous painting, "The Man with the Hoe," which inspired Edwin Markham to write his great poem bearing that title. But the Apache presents an aspect of human degeneration entirely different from that of the Man with the Hoe. While the Man with the Hoe represents the passive, "stolid and stunned" and "brother-to-the-ox" type of the lowest down-trodden peasantry, the Apache is an actively vicious, alert and cunning creation of oppression, crime and debauchery. While the Man-with-the-Hoe type has been crusht "to the thing he is" by the massive weight of the super-cumbent classes that have borne upon him through long centuries, the Apache has adapted himself to the narrowing spaces into which he has been forced, and has parried wrong with cunning and with retaliating wrong.

I have chosen the Apache as a theme for a few pentametric lines:

\section{L'APACHE.}

Thou monster in the broken mold of man, Blood-cast of vice and welded soul with sin! What legends are there in thy horrid mien Of that dark under-world of human dregs, From where the look is up, not down, for Hell;

Where shame is virtue, virtue is a shame,

Save in the pact that holds to faith with crime?

What old-time wrongs have trailed the aching years-

What ghost-world curses breathed pursuing blight, And wrought their vicious culminate in thee? How long the lineage of fiends was theirs

That thy distempered birth did make a crime;

With price of motherhood a stingy coin,

When loves were centimes on a windy night; And bare-boned hunger lost a meal for lust?

-Exм. 


\section{CHAPTER XI}

\section{APPLIED TRO-POTENTRY}

\section{(ELOCUTION-ELOQUENCE-ORATORY)}

7 सreat conspiracy of the litterateurs that has prevailed since Aristotle's time against the ratiocinative treatment of poetry has not only prevented a rational treatment and scientific understanding of poetry, but has also to a large extent prevented a rational treatment and scientific understanding of the poetic relatives-rhetoric, eloquence and oratory-for without a scientific understanding of poetry, a scientific understanding of these related arts is impossible. Hence, just as in the case of poetry, all critical treatises on the subject of rhetoric, oratory and eloquence are a confusing mixture of ratiocination, intuitive perception and guesswork.

We are in the habit of thinking plain prose to be language in its elemental or simplest form, and verse and poetry and all oratorical embellishments to be deviations from normal language; while, as a matter of fact, the exact converse is true.

The growth of language has been from the simple to the complex; from the material, the concrete, the sensuous, the metaphoric, the onomatopic, the gesticulatory, to the arbitrarily symbolic, the abstract and insensuous, till we have plain prose-literatry.

We become acquainted with objects through their properties and attributes, and man's first words must have symbolized the properties and attributes of substantialities as well as the substantialities themselves. It has been thought that man's first words were all nouns, but such was not the case. As objects are heavy or light, hard or soft, solid or liquid, colored or colorless, transparent or opaque, hot or cold, in motion or at rest, acting or inert, 
animate or inanimate, verbs, adjectives and adverbs must have been evolved simultaneously with nouns.

The qualities of objects gave them their names, and the names or nouns were used in turn to qualify other objects which they resembled. Actions distinguished their subjects and objects, and substantives noted for certain activities were used as verbs to express similar activities of other substantives. Also, many verbs were born of sounds uttered as onomatopes, imitative of sounds produced by objects, and these verbal onomatopes were likewise used to name the objects making the sounds.

Man's primeval vocabulary was very limited and it related almost entirely to concrete, sensuous ideas. For instance, when a dog swam, primitive man might say, "Dog fish"; and instead of saying "Flying fish," he would say, "Fish bird"; and, if the fish flew from one lake to another, he might say, "Fish bird lake, lake," helping out his language with appropriate gestures.

As has already been pointed out, primitive man would say, not, "The bread is hard," but, "The bread is stone"'; not, "The face is round," but, "The face is moon"; not, "The fruit is sweet," but, "The fruit is sugar-cane." Furthermore, he might not employ the verb is, but might say, "Bread stone," or "Stone bread"; "Moon face," "Sugar-cane apple."

Specialization has been a concomitant of the development of language from the simple to the complex and heterogeneous. As the requirements of language have become more and more numerous and divergent, it has developed in diverging branches, each with its corresponding division of labor or usefulness. With primitive peoples, gesture is a far more necessary and constant accompaniment of oral language than with highly civilized peoples.

As we get the greatest amount of pleasure from the exercise of our most powerful faculties, and as our most powerful faculties are those most used or those whose use is the 
most vital, and whereas muscular exercise in the form of gesture and oral exercise in the form of language are necessarily very conducive to pleasure, there was early in the development of human speech a divergence of oral utterance accompanied by gesture away from the strictly utilitarian in the direction of the merely pleasurable.

Music and dancing have diverged from the utilitarian more and more in the direction of amusement. Their original use was mainly for making religious worship interesting and impressive, and they were also instruments of natural selection, for by them the male was able to demonstrate his oral and muscular prowess; the hunter and warrior told in rhythmic chant of past exploits or predicted future ones. Dancing was a part of illustrative gesture.

Poetry, verse and oratory have sprung, like music, from the religious dance, the religious chant, and the proclamation of the lover, the hunter and the warrior. The poet was once music-master, dancing-master, school-master, physician, high priest and historian. But the poet of to-day is only secondarily educator and prophet; he is primarily an entertainer; while music has been so differentiated and highly specialized that we no longer think of it except as an instrument of pleasure.

Oratory maintains a closer relation to the utilitarian than does either music or poetry. Yet, to a large extent, the orator has become an entertainer. His potential periods impress and stimulate us, while his poetic figures delight the imagination. Thus, he succeeds in amusing and entertaining us. In times of great peril, and on other momentous occasions, oratory is still largely utilitarian. But the peril past, we proceed to forge our swords into ploughshares and pruning-hooks; use our war-vessels for ocean-liners, or dress-parade paraphernalia; plant potatoes and corn on the old battle-fields; and utilize our orators as banquet accessories.

Slang, sarcasm, irony, wit and humor are all branches 
of trope, and owe their force either to congruous associations by similarity or to the association of the congruous with the incongruous. The mother, when she says to her little boy who has fallen in the muddy street and soiled his clothes, "Well, you're in a pretty state," or, "You are a beauty," speaks ironically. She turns from the statement of direct truth to a statement the exact opposite in order to emphasize the truth. This is a species of trope. Such familiar expressions as, "Come off your perch, or I'll put a head on you." "Get a move on," "She's a peach," "She's a daisy," are true figure, true trope; but differ from poetic figure in that they are incongruous and inartistic. A funny story to illustrate a point in an argument is a trope.

Mark Twain's cable from Europe to an American friend, that the reports of his death had been greatly exaggerated, was a trope and an excellent specimen of wit. Tropic wit consists in the turning aside from a direct and congruous presentation of a thought to an indirect and incongruous presentation.

Lincoln was asked how long a man's legs ought to be. He answered, "Long enough to reach from his body to the ground." When Lincoln said, in defense of a soldier who had run away in action, that "a man is not to blame for his legs running away with him," he spoke tropically, and both wittily and humorously.

Wit differs from humor in that wit involves invention -creation-and, when combined with humor, wit is often the skill with which the humorous is exprest, while the humorous per se is merely an incongruous eventuation.

The anecdote of Sir Isaac Newton absent-mindedly punching down the cinders in his pipe with the finger of his fiancée, is, if true, merely a humorous tale, but if a fabrication it is a witty fiction.

The story of the absent-minded professor, whose wife sent him to his room to change his necktie before going out to lecture, and who undrest and went to bed, is funny; 
but it is not witty, because it does not involve invention. The remark of the Yankee, however, that his father was so absent-minded that he once put his dog to bed and kicked himself down-stairs, is witty as well as humorous, because it is an evident fiction and involves invention and imagination.

One of the best examples of combined wit and humor with grotesque figure is the remark of Abraham Lincoln upon a windy speech: "Has it not got down as thin as the homeopathic soup that was made by boiling the shadow of a pigeon that had starved to death?"

Henry Ward Beecher, during a speech on behalf of the North, at the time of the Rebellion, was interrupted by some one in the audience crowing loudly like a rooster. Beecher stopt, took out his watch, and remarked, "It is only nine o'clock, and still it must be morning, for the instincts of the lower animals are infallible." This is pure wit.

The compound of wit and humor exercises creative ingenuity in the presentation of striking incongruities between just perceptions and their applications-new and surprizing incongruities of relation. In wit, as in poetry, the degree of excellence is proportionate to the degree in which a thought is exprest with new and surprizing figure.

A thing is humorous when it is merely ludicrous. A crazy man, finding a soldier asleep, stole his sword and chopped the soldier's head off, and then stood by and waited to see what the man would do when he should come to and find his head gone.

A dying costermonger sent his little daughter to the mother to say that he would like a little of that boiled pork afore he died. The mother answered, "Tell yer father he can't 'ave none. It's fer the funeral."

A country Reuben, provided with several sticks of dynamite, set out to dynamite some fish in a stream. Having inserted the detonator in the stick of explosive, with fuse attached, he lighted the fuse and threw it 
toward the stream; but instead of striking in the water, it landed on a stone upon the water's edge. Reuben's little dog, which always accompanied him and which had been taught to fetch and carry, imagined that the stick of dynamite had been thrown for him to bring back; so he instantly pounced upon it and ran toward his master with it, who, in terror, climbed the nearest tree, while the little dog, with the dynamite in his mouth, danced about the tree for his master to come down. The dog-well, the dynamite exploded.

These are examples of humor and not wit, unless the stories are fictitious; then they are witty fabrications. Humor relates to actual occurrences or things that may have been possible and generally more or less to the discomfort of some one, wherein there is a certain incongruity with normal procedure.

While wit employs the humorous, it differs from humor in that it requires imagination and creative ingenuity, while humor does not. As I have said, just as the excellence of poetry depends upon a creative imagination, so does wit depend upon a creative imagination and the surprizing use of trope. Wit and humor are to poetry what caricature is to illustration. Slang, wit and humor are poetry in caricature.

The orators of ancient Greece and Rome never employed any wit and humor in the modern sense. They were often witty in the use of sareasm and irony. Yet they were always supremely serious. Nevertheless, in that physical age, their orations were by comparison a species of entertainment.

In Shakespeare's time, wit and humor in the modern sense had not been developed, and Shakespeare's attempts to be funny are pathetic. The purely humorous had not been dissociated from the gross and vulgar, while the beautiful poetic figure employed by Shakespeare and the other poets of the Elizabethan era probably took the place on the stage of the wit and humor of to-day. 
Poetic figure is a species of wit. While we have refined our wit and humor, largely eliminating the vulgar and the gross, and have idealized poetic figure, we have also lost much of the power of being entertained by poetic figure-artistic poetic wit.

Slang is undignified figure, while poetic figure is artistically dignified slang. Just as witty slang entertains a modern audience, so witty poetic figure entertained an Elizabethan audience.

Oratory is a branch of tro-potentry, for both trope and potentry are the main essentials of oratory. Oratory is suggestive, not reflective language. Oratory appeals to the imagination, arouses the emotions, and with poetic figure compels conviction by striking concrete analogies and contrasts, and not by means of abstract logic and analysis. Altho abstract logic and analysis are often commingled with oratorical phraseology and are often strongly accentuated by oratorical periods, they are never actual essentials of oratory.

Oratory always presupposes super-ordinary occasions, and the more momentous the occasion the more appropriate does oratory become. Like verse, it is essentially emotional language because of its potential character, its tonal impressiveness.

Being emotional language, oratory appeals to the hearer's convictions. It influences him largely through emotional bias. Wit and humor are valuable elements of oratory and are very effective in sarcasm and irony.

Poetic figure is generally esteemed food for the gods alone, requiring a highly cultivated estheticism ingrafted upon some peculiar inherited aptitude in order to be appreciated. As a matter of fact, poetic figure is the only language that savages can understand. It is preëminently the language of the proletariat. The language of the mountaineer, the backwoodsman, the country Reuben, is always replete with figure, witticisms, illustrative anecdotes, parables and allegories-poetry in the rough. 
Abraham Lincoln was a frontier Shakespeare. Those who write down to the common people owe their force mainly to pertinent figures of speech. The language of David Harum is the language of the hills of New England and Central New York, full of figure, touches of nature, human sympathy.

Mark Twain was the Shakespeare of wit and humor. He was humorist, wit, poet, philosopher.

Robert G. Ingersoll was, first, an orator; second, a poet; third, a wit; and fourth, a philosopher. Ingersoll fulfilled many of the conditions necessary to oratory. His orations were in part true prose poems. They were replete with new, surprizing and artistic figure. Often, however, he used a redundance of figure, and sometimes mixt his metaphors.

Again, Ingersoll's language was very potential. Some of his periods were remarkably powerful. $\mathrm{He}$ was a master of irony, sarcasm, satire, wit and ridicule. But there was one dominant characteristic of his utterances, and it was sympathy, the human import, the touch of nature. Ingersoll was, above all, human. No one ever said things in a bigger-hearted way than did he. No one ever made more of the ties and duties of parent, child and citizen. He who can make his opponents appear ridiculous, and can make his audiences laugh at them, secures an easy victory.

Ingersoll employed much sophistry, which he presented so coupled with sentiment as to carry conviction. Many persons who heard him lecture were convinced of certain things that upon cool reflection they discovered to be erroneous. As an example: Ingersoll, in a paralogy on Napoleon, so arouses the paternal and humanitarian instincts that the reader really thinks for the nonce that Ingersoll is right, and that he would rather have been a French peasant and worn wooden shoes than to have been Napoleon-at a time when one-half the peasant's earnings went to the king, one-quarter to the landlord, and 
the balance, except one-fifteenth, to the church, the peasant retaining for himself only the fifteenth of his earnings.

Those were the days that produced such peasants as are portrayed in Millet's "Man with the Hoe," and Ingersoll said he would rather have been such a French peasant, priest-ridden, downtrodden, with wife and daughters dishonored and debauched at the will and fancy of a passing aristocrat on a spree, than to have been the great $\mathrm{Na}$ poleon. Nothing could be more absurd and untrue; nevertheless, most of Ingersoll's hearers actually believed this nonsense, and believed that Ingersoll believed it.

It is a very common mistake to confound emotion with thought, and to confound impressiveness with value and importance of thought. Impressiveness of thought has to do with the emotions and not with facts.

As already pointed out, there are two main divisions of language, the suggestive and the reflective-language that appeals to the critical powers of the mind, and language that suggests and impresses thoughts upon the mind. Oratory utilizes with effect both reflective and suggestive language.

All suggestions of great magnitude in dimension, time, force, ponderability, and suggestions of the remote, the strange, the weird, the mysterious and the terrible, are elements of sublimity, and are, therefore, powerful poetic elements.

Great calamities are always good poetic and oratorical material, while events of the remote past make better poetic material than recent events. "Distance lends enchantment to the view." The remote, the indefinite, the intangible, merge into mystery, and, therefore, stimulate and give play to the imagination.

Sublimity is frequently a great desideratum in oratory. The sublime depends upon the tonic stimulus realized from the contemplation of magnitudes. As the contemplation of magnitudes requires an unusual effort of the mind, the faculties of mental grasp are pleasurably and forcibly. exercised. 
Just as the tones of the voice of a speaker stimulate the hearer and arouse in him moods in harmony with the speaker's emotions, so does loftiness of thought stimulate lofty emotions.

Again, ideas of the great and powerful forces of nature belong to the sublime; and voluminous, potential words are the best symbols for sublime ideas and thoughts.

Some of the greatest orations have been entirely imaginary. The supposed speech of Regulus to the Carthaginians; the speech of Marc Antony over Cæsar's body; the speech of Spartacus to the gladiators-each of these is an excellent example of true oratory. Observe the human import in these potential lines:

\section{REGULUS TO THE CARTHAGINIANS.}

"The moon has scarce yet waned since the proudest of Rome's proud matrons, the mother upon whose breast I slept and whose fair brow so oft had bent over me before the noise of battle had stirred my blood, or the fierce toil of war nerved my sinews, did with fondest memory of bygone hours entreat me to remain. I have seen her, who, when my country called me to the field, did buckle on my harness with trembling hands, while the tears fell thick and fast down the hard corselet scales-I have seen her tear her gray locks and beat her aged breast, as on her knees she begged me not to return to Carthage; and all the assembled senate of Rome, grave and reverend men, proffered the same request. The puny torments which ye have in store to welcome me withal, shall be, to what I have endured, even as the murmur of a summer's brook to the fierce roar of angry surges on a rocky shore."

-E. Kelloga.

SPARTACUS TO THF GIADIATORS.

"Ye stand here now like giants, as ye are! The strength of brass is in your toughened 
sinews, but to-morrow some Roman Adonis, breathing sweet perfume from his curly locks, shall with his lily fingers pat your red brawn, and bet his sesterces upon your blood. Hark! hear ye yon lion roaring in his den? 'Tis three days since he has tasted flesh; but to-morrow he shall break his fast upon yours-and a dainty meal for him ye will be! If ye are beasts, then stand here like fat oxen, waiting for the butcher's knife! If ye are men, follow me! Strike down yon guard, gain the mountain passes, and there do bloody work, as did your sires at old Thermopyla! Is Sparta dead? Is the old Grecian spirit frozen in your veins, that you do crouch and cower like a belabored hound beneath his master's lash? $O$ comrades! warriors! Thracians! If we must fight, let us fight for ourselves! If we must slaughter, let us slaughter our oppressors! If we must die, let it be under the clear sky, by the bright waters, in noble, honorable battle!"-E. KELLOGG.

Shakespeare's masterful rendering of Antony's speech over Cæsar's body is one of the best pieces of oratory ever written, in addition to being good poetry. The occasion was momentous; the stimulus, tremendous; the speaker, one of the master spirits of his age; while colossal Cæsar was the theme. Brutus had spoken. The emotional multitude, unwilling at first, had been convinced by him and were all opposed to Antony and impatient that he should be permitted to speak at all. He was obliged, first, to win their ears that they might hear him; then, by evidence and logic to substantiate his assertions; and lastly, to arouse them to a fury of resentment and thirst for vengeance.

"Good friends, sweet friends, let me not stir you up

To such a sudden flood of mutiny.

They that have done this deed are honorable:

What private griefs they have, alas! I know not, 
That made them do it; they are wise and honorable,

And will, no doubt, with reasons answer you.

I come not, friends, to steal away your hearts:

I am no orator, as Brutus is;

But, as you know me all, a plain, blunt man, That love my friend; and that they know full well

That gave me public leave to speak of him.

For I have neither wit, nor words, nor worth, Action, nor utterance, nor the power of speech, To stir men's blood: I only speak right on;

I tell you that which you yourselves do know; Show you sweet Casar's wounds, poor, poor dumb mouths,

And bid them speak for me: but were I Brutus, And Brutus Antony, there were an Antony Would ruffe up your spirits, and put a tongue In every wound of Casar, that should move The stones of Rome to rise and mutiny."

-Shakespeare.

Altho poetry, potentry and oratory (tro-potentry) of excellent quality have been produced without adequate understanding of the laws that govern them, nevertheless a scientific understanding of those laws, with illustrations of their applications, must be of very great service to the poet and the orator.

I shall, therefore, just as I have done in the cases of tem-potentry (verse), and tro-tem-potentry (verse-poetry), present some examples of tro-potentry (oratory), which I have written in accordance with the principles herein laid down.

A very good specimen of oratory is the paralogy of Robert G. Ingersoll over the tomb of Napoleon. The career of Napoleon gave Ingersoll an admirable opportunity to play upon human sympathy. Nevertheless, a better opportunity is afforded for oratory by lionizing and glorifying a great war hero than by condemning him. The following is Ingersoll's burst of eloquence, and it is unquestionably a superb piece of work: 
AT THE TOMB OF NAPOLEON.

"A little while ago, I stood by the grave of the old Napoleon-a magnificent tomb of gilt and gold, fit almost for a deity dead-and gazed upon the sarcophagus of rare and nameless marble, where rest at last the ashes of that restless man. I leaned over the balustrade and thought about the career of the greatest soldier of the modern world.

"I saw him walking upon the banks of the Seine, contemplating suicide. I saw him at Toulon-I saw him putting down the mob in the streets of Paris-I saw him at the head of the army of Italy -I saw him crossing the bridge of Lodi with the tri-color in his hand-I saw him in Egypt in the shadows of the pyramids-I saw him conquer the Alps and mingle the eagles of France with the eagles of the crags. I saw him at Marengo-at Ulm and Austerlitz. I saw him in Russia, where the infantry of the snow and the cavalry of the wild blast scattered his legions like winter's withered leaves. I saw him at Leipsic in defeat and disaster-driven by a million bayonets back upon Paris-clutched like a wild beast-banished to Elba. I saw him escape and retake an empire by the force of his genius. I saw him upon the frightful field of Waterloo, where Chance and Fate combined to wreck the fortunes of their former king. And I saw him at St. Helena, with his hands crossed behind him, gazing out upon the sad and solemn sea.

"I thought of the orphans and widows he had made-of the tears that had been shed for his glory, and of the only woman who ever loved him, pushed from his heart by the cold hand of ambition. And I said, I would rather have been a French peasant and worn wooden shoes. I would rather have lived in a hut with a vine growing over the door, and the grapes growing purple in the amorous kisses of the Autumn sun. I would rather have been that poor peasant, with my loving wife by my side, knitting as the day died out of the sky-with my children upon my knees 
and their arms about me-I would rather have been that man, and gone down to the tongueless silence of the dreamless dust, than to have been that imperial impersonation of force and murder, known as Napoleon the Great.'

-Robert G. Ingersoll.

The following is my treatment of the same subject, written as an appreciation of Napoleon, and as an illustration of applied tro-potentry:

\section{AT THE TOMB OF NAPOLEON.}

A little while ago, I stood at the tomb of the great Napoleon-that monumental tribute of a nation's gratitude. And I thought of all the mighty deeds that made him master of an empire. In imagination I saw the whole panorama of his strange career.

I saw him a child, seated on a lofty crag of his island home, drenched by the storm, watching the lightning flash, and pulsing with the thunderpeal and break of ocean on the shore-all sights and sounds harmonious with his lofty soul. I saw him at Brienne, studious, stern, stoical, amid the vain and vacillating frivolities around hima sphinx amid the drifting sands. At Toulon next, experimenting with the great game of war.

With arms folded across his breast, I saw him before the French Convention conquer confidence with his eagle eye, and then, with a whirlwind of fire, redeem Paris in an hour.

I beheld him at the head of the ragged, starving legions of liberty, with the tri-color in his hand, at the gates of death, the very mouth of hell, on the Bridge of Lodi.

I saw him again under the shadow of the great pyramids, from whose summits forty centuries looked down upon him, while their deep foundations shook with the thunder of his artillery.

I saw him return from Egypt and snatch prostrate France from the ruins of revolution, 
saw him "cut like Hannibal the white Alps through," and descend like an avalanche upon the Austrian at Marengo, and wrest freedom from the grasp of despotism.

I saw him hurl his conscript legions against the old war veterans of the great Frederick on the field of Jena, and beheld an empire fall bleeding at his feet. I saw him point to the sun of Austerlitz, and the allied hosts melt like mist at noon, and the world bow to his genius. I saw him at the head of half a million men penetrate Russian desolation and conquer the ancient capital of the Czars, to be himself conquered by fire, storm and cold.

Three days, fanned by a hurricane, the conflagration raged, emblazing the whole dark dome of the autumnal sky, until old Moscow was an ember dead, and all her glories gone-in fire gone out upon the ashes of its greed. That consuming flame shone from the Kremlin even to Elba, Waterloo, and St. Helena, and by its light the great Corsican saw fortune's returning pathdown, down, from the highest eminence of military glory to the lowest and most humiliating depths of disaster and defeat. When that light faded his star of fortune, too, went out, and shone no more. Then the retreat, where:

\section{"Hunger and cold, the mightiest powers combined, \\ And never-glutted vengeance trod behind."}

The horrors of the march over that vast arctic sahara out-picture all our mental imagery of Hell, and so border on infinity no human mind can grasp a thousandth part the magnitude of that calamity.

Yet, the spirit of the mighty Emperor has risen from St. Helena into immortality, living in the literature and laws of all the world. The great Napoleon stands alone, the most stupendous man in all the history of the human race. 
Robert G. Ingersoll was a big-hearted, brave, generous, sympathetic man. He was a master of reason, but sympathy mastered him. When his reason and his love pulled in single harness, then they were like Marlowe's "horse that guide the golden eye of heaven and blow the morning from their nostrils."

Witness Ingersoll's scathing denunciation of alcohol

"I believe that alcohol, to a certain degree, demoralizes those who make it, those who sell it, and those who drink it. I believe from the time it issues from the coiled and poisonous worm of the distillery until it empties into the hell of crime, death, and dishonor, it demoralizes everybody that touches it. I do not believe that anybody can contemplate the subject without becoming prejudiced against this liquid crime."

Ingersoll paid this tribute to Henry Ward Beecher:

"As in the leafless woods some tree, aflame with life, stands like a rapt poet in the heedless crowd, so stood this man among his fellow men.

"All there is of leaf and bud, of flower and fruit, of painted insect life, and all the winged and happy children of the air that Summer holds beneath her dome of blue, were known and loved by him. He loved the yellow Autumn fields, the golden stacks, the happy homes of men, the orchard's bending bows, the sumach's flags of flame, the maples with transfigured leaves, the tender yellow of the beech, the wondrous harmonies of brown and gold-the vines where hang the clustered spheres of wit and mirth. He loved the Winter days, the whirl and drift of snow-all forms of frost-the rage and fury of the storm, when in the forest, desolate and stript, the brave old pine towers green and grand-a prophecy of Spring."

In the spring of 1907, when the International Peace Conference was held at Carnegie Hall, New York, some of the radicals advised the destruction of all the old battle- 
flags, soldiers' monuments, and every reminder of war. Several of the most notable participants were invited by the Economic Club of Boston to attend a banquet there for the free hot-airing of their views. I was invited to speak in defense of armaments, as that club, made up of sane, practical, business-headed men of Boston, wished to hear both sides of the question. My talk was very favorably received by the audience. I was the first speaker, and was followed by William T. Stead, who, in the main, much to my surprize and satisfaction, agreed with me, in strong contrast with the other and hyper-sentimental peace-propagandists present.

My speech was afterward published in the Associated Sunday Magazines, under the title, "To Arms for Peace." I shall here make several extracts, to illustrate tropotentry :

Since that remote time when our omnivorous ancestors climbed down from their abodes in trees and fought for place in their environment, and fed on every living thing in earth and sea and sky, the good things of life have been for those who fought for them. Through all the ages man has hewn the living flesh from off the bones of every breathing thing, and won the mastery of all the earth; and the fighting spirit has become a part of the very spirit of life itself, and it now finds expression in business as well as war.

Environed by fierce savage life and savage earth and sky, man was cradled in a world of tempest, rocked by forces that placed the spirit and the nerve in the heart of the Viking who ferried the Atlantic in an open boat, and gave invincibility to the Norseman, the giant arms of whose posterity now circle all the earth.

The worst enemies of the peace movement are those hyper-sentimental friends who demand the abolition of armaments, and who would brand the soldier a criminal and stamp our old war heroes murderers. We do not want posterity to 
hang George Washington in effigy, nor to pull down the statues of General Grant, nor to level the monuments erected to the soldiers fallen in our old wars for freedom. We want posterity to think kindly of the great Lincoln. We want posterity to sing the old songs about Lexington, Concord, and the Sword of Bunker Hill.

Behind any peace tribunal, and behind all laws, must for a long time yet stand the man behind the gun. But for the great bulwarks erected by the sons of Mars along their frontiers, the pretty general peace which the nations now enjoy could not last for a day. To preserve peace it is only necessary to be so prepared for war as to make war evidently unprofitable to an aggressor. Then we may safely absorb ourselves in industry and trade, and love and trust our neighbors-but cut their cards.

The fort is as humanitarian in its nature as the lighthouse, and the sea-coast cannon is as much an implement of mercy as the gun that throws the life-line to a stranded wreck. There never has been invented any life-saving instrument that can compare for a moment with the modern magazine rifle and the quick-firing gun, paradoxical as this may appear.

The debt that civilization owes to gunpowder is one of the greatest that history has to record. In every land and upon every sea gunpowder stands guardian over all the accumulated wealth and progress of the nations. The earth-jarring thunder of the sea-coast gun-the hum of the great steel bolt as it speeds along its way-the crash into the armored ribs of the battleship-are all voices that speak of the highest development in the arts and sciences of an iron age, where chemistry is king. Electricity, steam and gunpowder are the great triumvirs that have been the architects of the modern world." 
EXTRACTS FROM SPEECH BEFORE THE ALDINE ASSOCIATION, APRIL 28, 1908, ON THE INVENTOR

AND THE MEANING OF AERONAUTICAL

\section{ACHIEVEMENTS IN WAR.}

In this age of marvels with which the inventor is constantly surprizing us, it does not do to sleep too late in the morning, else when we awake we may find ourselves laggards in the abject rear. Achievement now runs on so fast that it often outpaces the adjustment of our senses, and tho we pinch ourselves to prove our wakefulness, still the sense of dreaming intrudes itself and harasses conviction.

Many of us here are able to go back far enough in yesterday to view the present through the wide eyes of wonder, while we are so fortified with expectation for the morrow that we look a second time to be assured whether or no that flock of clouds which skirts the sunset may be a fleet of airships climbing up the sky.

The debt we owe the inventor is the difference between all that is ours to enjoy in modern civilized life and the indigence of barbarism. But for the inventor, we should still be denizens of the unbroken forest, clothed in the skins of beasts. Like Antony, the inventor has with his "broadsword quartered the world, and o'er green Neptune's back with ships made cities." He has hewn highways through the granite hills and webworked the earth with the iron rail.

With his instruments of science the inventor has sounded the deeps of the eternal skies. He has discovered whence Orion came, has felt the pulse of Arcturus, and he knows the fortune and the fate of a million worlds. He has seen them quarried out of chaos far beyond the troubling touch of time; and he views their onward drift toward death in the infinite night and cold of immensity. He foresees our own bright sun a paling ember on the hearth of time, and he reads our destiny in the scroll of the milky way by light 
that left its source so long ago that it was already old upon its flight ere Babylon was builded and when the Egyptian pyramids were still unquarried.

The sculptor is an inventor, and in the imagination he sees the living face volatile in the unhewn stone and multitudinous Venus in the formless clay; and on the untouched canvas the painter sees the mirth-riot of the forest nymphs as they push old Pan toward the brimming pool.

It was Benjamin Franklin who discovered the Archimedean lever in the electric switch, and turned on a power that is lifting the world. It was Fulton who taught us how to defy the hurricane and to reduce the ocean to a ferry. It was Morse who made electricity our Mercury, annihilating time and space in the transmission of intelligence-all Americans.

And we have our Alexander Graham Bell, who has brought the world's ear to our desk and makes it listen. Langley brought the sun down to his laboratory to take its temperature-and there is the giant Edison. What a potentiality is the American inventor, who, could he but give the magic word of Joshua and command his inventions to stand still, would halt the world!

An American by the name of Washington was the first soldier, statesman, or vuler, big enough, when he had Liberty in chancery, not to strangle her.

There was one American before whose name more heads have bowed in reverence than ever nodded to a king. He was statesman, philosopher, poet, inventor, and warrior, and tho he fought like a lion, yet he mingled his tears with the blood of his enemies, "with malice toward none, and with charity for all." Lincoln was the first to invent and the first to apply what in his time was a most revolutionary procedure-the tempering of war with mercy. He was the first 
captain big enough in the history of our race to be equally kind to a fallen foe and to a fallen friend.

It does not matter so much whether Americans or Europeans stand ahead in supreme achievement, as it does that we all stand together and join hands across the sea and over the heads of sectional patriots in world-meaning progression that knows no frontiers.

I have noticed that great personal bravery is often a concomitant of great intellectuality, and it is proverbial that inventors are the daredevilest men in the world; and when the flyingmachine inventor casts the earth loose and rounds the ecliptic with the Pleiades, leaves the earthroad and cup-races with Jupiter on the cloudway, or goes tobogganning down the sky slide, as some of you here have already done, then the old soldier's oft-spun yarn of how his company mixt their bones with grape and canister, becomes commonplace.

It will be great sport by and by to out-race and over-ride the thunder-storm, and there in the bright sunlight look down upon the rolling, seething mass of cloud spitting fire like an angry cat. We shall then seem to have Nature at a disadvantage.

Aerial naval tactics will include the use of the thunder-head to mask maneuvers. When the cloud-hung navies war and ride the storm to battle, then conjecture will attend the fall of slaughtered combatants and wreckage from the sky to know if it be Jove or man that thunders there.

-Exm.

On December 28, 1908, one of the most appalling and destructive earthquakes in the history of mankind smote southern Italy and Sicily; Messina and other cities and towns being utterly destroyed, and more than 150,000 
inhabitants killed. Large numbers, not killed outright, were entrapped under the débris in positions of extreme torture for days, until relieved of their misery by death; while those who escaped immediate death or entrapment, terror-stricken, homeless, shelterless, starving, made brutes by misfortune, despair and hunger, herded among the ruins, pale, emaciated, wild-eyed, fighting for crust and bone, with scavenger dogs turned wolves again.

The whole world sprang to Italy's relief. President Roosevelt, without awaiting the approval of Congress, immediately dispatched relief ships loaded with three hundred thousand dollars' worth of provisions; while Congress not only approved the President's action, but also unhesitatingly appropriated five hundred thousand dollars more - eight hundred thousand dollars in all.

Broad human sympathy is mainly a modern trait. In old Roman days, it was not known that there is such a thing as inalienable human rights; and when one people had an opportunity of robbing and enslaving another people, it was thought bad business policy not to rob and enslave them. All foreigners were barbarians, and any sympathy for a foreigner was considered a weakness. An earthquake calamity to a neighboring people was then a cause for thanksgiving.

The Romans, under Julius Cæsar, fell upon and slaughtered two hundred and fifty thousand Germansmen, women and children-in a day, and did this while negotiations for peace were pending. Cæsar saw no use in those Germans. Now we, the posterity of the ancient Teutons, dispense, with a free, glad hand, most generous donations for the relief of the Italian earthquake sufferers, the descendants of Cresar's legions.

Business, commerce, travel, intercommunication, and community of interests in science, art and literature, have taught the different nations and peoples their usefulness to one another; have made the remote near, and the foreigner a neighbor and a friend. 
The great earthquake disaster afforded an opportunity for much tro-potentry by orators all over the world. At a benefit given by the American-Italian General Relief Committee at Madison Square Garden, on the evening of January 7, 1909, for the Italian sufferers, I made the following short speech:

While we walk arm-locked with life, death walks in lock with the other arm. While love and joy and fair fortune fill our cup of good luck to the brim, and we hold the golden beaker high to drink health, happiness and good fellowship, death may on the moment strike down the very arm of health betwixt the lip and cup.

Were men ethereal as the gods are, then the cold, unsympathetic sky were warm enough that hovers wounded Italy to-night. But men are earthen and are mortal, and feel the chill of inclement fate.

Some day-at any moment of any day-we fall by the Great Reaper. Uncertainty hangs menacing, and makes human sympathy earthwide, and the ill-fare of each the sympathy of all.

Death has its compensations. Love draws the thinning circle closer round the fireside. A world affiction like the present binds with a broader and a stronger love all of human kin. A great calamity is no longer a grief confined to a community, a nation, or a people. Calamities like the fall of San Francisco-like the Mont Pelée disaster-like the awful ruining that has swept southern Italy-are now world-griefs.

Modern commerce, modern business, and modern ethics-Christian ethics-are working hand in joined hand over the seas, to unite all nations and peoples in one common brotherhood with common sympathies.

Eternal Italy, mother of the modern world, is bowed with a great affliction, and the world bows its naked head, and America gives her tears to the river of tears.

While we are speaking here, there are in Italy 
our kindred dying of starvation and exposure on the ruin-blackened desolation of their homes. Their voices are faint. We must listen loudly, and then we shall hear their heaven-heard myriad cry: "Help! Help! For God's sake, help!"

-Exм. 


\section{CHAPTER XII}

\section{GREAT POETIC LINES}

Cowd is a rare and a precious metal. A large mass of $G$ ore from the richest mine must be handled and concentrated in order to glean very much pure gold. Similarly, in literature, poetic gold is rare and precious, and a large mass of literary ore must be handled and concentrated in order to glean even a little pure poetic gold. I have placer-mined a mountain of literary sand and débris to find the few poetic gold nuggets given in this chapter.

Even in the writings of the greatest poets, high-watermark poetry is rare. The truly great poetic line is the exception even in Shakespeare.

"By their fruits ye shall know them." There is no way to estimate the greatness of a poet except by his work; and there is no way to estimate his work except by its fitness to meet the requirements for which it is intended. This it can do only by conforming to certain underlying principles of expression grounded in the constitution of the human organism-those principles which I have endeavored to set forth in this book.

Most people estimate the value of the work of great men by squaring it with their opinion of the worker, instead of judging it on its intrinsic merits. For example, they have been taught that Matthew Arnold is a writer whose style is superlatively excellent; that Whitman's "Leaves of Grass" is poetry; and that, as a poet, Robert Browning is peerless. Therefore, when they read Matthew Arnold, or Whitman, or Browning, and think they see things that in the writings of common men would be faults, they lay those faults at the door of their own judgment and lack of understanding concerning the peculiarities and intricacies of literary excellence. 
The following great poetic lines have been selected by me without any regard whatever for the halo of authorship. Since, in the case of many persons, it is absolutely impossible to judge impartially the excellence of a poetic line when the author is known to them, I have represented the authors of the quotations by numbers, and have given their names at the end of the chapter against their respective numbers.

The reader will find it interesting and amusing to let his literary friends and acquaintances select what they esteem some of the best poetic lines from the following collection, and then look up the authors. Unless those literary persons select lines already familiar to them, whose authorship is known to them, they will be as likely to choose lines from the least famous as from the most famous of the poets.

Matthew Arnold recommended intimate acquaintance with great poetic lines to aid in the judgment of poetry. The following is what he says:

"There can be no more useful help for discovering what poetry belongs to the class of the truly excellent, and can therefore do us most good, than to have always in one's mind lines and expressions of the great masters, and to apply them as a touchstone to other poetry."

-Essays in Criticism, 2nd ser., p. 16.

Matthew Arnold has always been considered an eminent literary purist and stylist, and has so long been crowned with a circlet of light that it is interesting to see what Herbert Spencer has to say of the above oft-quoted paragraph:

"My first remark is that the phrase 'useful help' conceals a pleonasm. A help is defined as a thing which aids or assists, and a thing which does that is a useful thing; so that a 'useful help' is a useful useful thing. Instead of 'no more useful help' he should have written 'no better 
help.' We come next to the clause, 'what poetry belongs to the class of the truly excellent.' Why all these words? Whatever belongs to the class of the truly excellent is necessarily truly excellent. Why, then, speak of the class? The phrase should be, 'what poetry is truly excellent.' Then, again, the clause 'to apply them as a touchstone' is, to say the least, awkward. Surely it should be 'to apply them as touchstones.' Once more, what is the use of the final words 'to other poetry'? The first part of the sentence has already implied that 'other poetry' is the thing to be tested. Hence, leaving out intermediate clauses, the statement is that for discovering what poetry is 'truly excellent' certain tests should be applied 'to other poetry!' To convey the intended meaning the sentence should have run: There can be no better helps for discovering what poetry is truly excellent, and can therefore do us most good, than lines and expressions of the great masters kept always in mind and applied as touchstones. Or otherwise: There is no better way of discovering what poetry is truly excellent, and can therefore do us most good, than to keep always in mind lines and expressions of the great masters and apply them as touchstones. Thirteen words are saved and the meaning definitely exprest."

Let us look at Matthew Arnold's statement from still another viewpoint. Herbert Spencer has been good enough to straighten out Arnold's English: let us now examine his philosophy. It is not true that there is no better way of discovering what poetry is truly excellent than to have always in mind lines and expressions of the great masters and to apply them as touchstones, altho this is a very good thing to do. There is another far better way, and it is to study thoroughly the science of poetry and the underlying principles of poetic expression. This method enables one not only to judge poetry correctly for himself without the employment of touchstones, 


\section{GREAT POETIC LINES}

but also to judge the poets by their poetry, and to know who are the great masters and who are not.

Without a knowledge of the science of poetry and the principles that govern it, and consequently without the ability to judge poetry upon its intrinsic merits, how is one to decide who are, and who are not, the really great masters he should emulate, and what are, and what are not, the truly great poetic lines he should employ as touchstones?

Who are the great masters, and who has selected them for us, and for what reasons have they been selected? Obviously, for the merits of their productions. Now, as there has heretofore never been any truly scientific method for the appraisement and judgment of poetry, and as it has been a well-nigh universal assumption of the authorities that poetry transcends comprehension and does not admit of scientific analysis and understanding, there has been no way of knowing with any degree of certainty what poetry is excellent and what is not. As a result, stuff the very opposite of excellent poetry has been selected as "truly excellent," and the author accepted as a great master accordingly and recommended for emulation.

For example, Walt Whitman has been crowned as a great master, not because of the excellence of his poetry, for nearly all he ever wrote comes as near being the antithesis of poetry as could well be produced; but his intentions were good and his sympathies were broad, and his admirers, confounding good intentions with poetry, naturally consider his poetry good. According to W. J. Dawson, author of "The Makers of Modern Poetry," good intentions, anyway, are what constitute excellence in art, for he tells us that art is simply an aspiration. Walt Whitman certainly did aspire to write poetry.

At a county fair down in Maine, when I was a boy, a party of riflemen were shooting at a target, a fat $o x$ being the prize. The range was long and the bull's-eye small. The price was a dollar a shot. Bill Bennett came 
reeling along, so drunk he could see several targets, and he concluded he ought to be able to hit one of them even if he were drunk. He threw down a ten-dollar bill for ten shots. He fired wildly, the attendants steadying him enough to direct his bullets toward that part of the sky and horizon where the target was located. Rolling and pitching like a ship in a storm, his target-practise was as bad as was that of the United States Navy at Santiago; but, to the surprize of all and to the horror of the man who owned the ox, the tenth shot struck the center of the bull's-eye, and drunken Bill won the ox.

Any one who keeps firing away at poetry, however much he may reel and stagger, is likely once in a while to make a poetic bull's-eye and to produce a "truly excellent" line. There are, even in Whitman, occasional excellent lines staggered in by accident.

Many of those who do not accept Whitman as a great master do accept Browning. Robert Browning was a conscientious, religious man, and in his poetry he, like John Milton, oozes creed and moral didactics at every pore. Those who look upon the philosophy of the ecclesiastical moralist as the greatest of all metaphysics naturally esteem Browning as a great metaphysician; and as definitions of poetry have been as elastic and inclusive as the interstellar ether, good intentions, humanitarianism, morality and theology, have by many been mistaken for poetry, whether in plain prose or Whitman rag-time, doggerel jingle, or the sentential maze of Browning. The devotees of Browning admit that that peculiarity of literary style which in others is considered poetry is not requisite in Browning; that his poetry, being so heavily weighted with massive thought, naturally wobbles, squeaks and staggers under the burden, like an old farm-wagon loaded with stone, as witness W. J. Dawson's observation, that Browning's "verse moves stiffly beneath the tremendous weight of thought."

If poetry lies in the thought itself and not in the ex- 
pression of it, then admittedly Browning was a great poet. But as a thing can not both be and not be at the same time, and as a thing can not be both what it is and also its antithesis, poetry can not be both the thought exprest and the expression of the thought; and as we have proven that poetry is a form of thought-expression, we are forced to the position with respect to Browning that he must either stand or fall as a great poet entirely upon the question of felicity of expression, quite independently of the character of the thoughts exprest.

Admittedly, great thoughts, from their concomitant associated ideas, are the best poetic material. Nevertheless, the poetry consists in the manner of expression and not in the character of the thought exprest. The question at issue is, how does Browning compare with other poets in the happy expression of equally great thoughts.

What is true of Whitman and Browning is likewise true of many others.

After one has acquired a scientific understanding of poetry, he will find much pleasure and benefit in the study of the following great poetic lines. They will prove to be touchstones, as Matthew Arnold suggests.

Let the reader bear in mind that poetry is great in proportion as it is great invention; to the extent that it is novel and surprizing, as well as to the extent that it is the expression of insensuous thought in sensuous terms by artistic trope; that sublime thoughts and ideas, human sympathy and human import, add to the impressiveness of poetry; and that potentry, as a concomitant of poetry, by its tonal impressiveness and the power to stimulate and qualify the mind of the hearer for perception, and to induce moods in the mind of the hearer in harmony with the thoughts exprest, adds greatly to its effectiveness. Also, it must be remembered that poetic verbal predication is stronger and more effective than adjectival qualification or adverbial modification; and that the extent to which the insensuous is exprest sensuously-the abstract con- 
cretely-is largely the measure of poetic excellence; and, further, that the imagination must be enlisted in the understanding of poetry; and that without the enlistment of the imagination, as when taken literally, great poetry must make mere nonsense; but with the enlistment of the imagination its excellence is in measure with the inevitability of its phraseology, and with the degree in which it expresses the thought more concisely, lucidly, strikingly and effectively than it could be exprest in any other way. Unless a poetic line or sentence expresses a thought more effectively than it can be exprest in any other way, making it more intimately the reader's own, it is not supreme poetry.

The greatest poetry is always the expression of some magic action, some action true to imagination, but untrue to reality-some action like that of

". the face that launched a thousand ships, And burnt the topless towers of Ilium";

or, some imaginative, symbolic action, like that of Lowell's brute Despair of trampled centuries, which

"Groped for its right with horny, callous hands, And stared around for God with bloodshot eyes."

When something possessing dimensions of extension beyond our comprehension, or lying beyond our powers of concrete, sensuous acquaintance-beyond the sphere of sensuous experience-is symbolized by metaphor in terms of things concrete and sensuous, lying within experience; and when this is done artistically, then we have true poetry.

The artistic use of metaphor depends upon its evident inevitability. As Aristotle said: "The greatest art consists in the art of concealing the fact that it is art." A strained metaphor is one that does not appear inevitable, for the author goes out of his way to bring in a metaphor. A metaphor is inevitable only when it is the most direct way of expressing a thought. As long as the same thought is capable of being exprest in any other way with equal 
directness and force, then the metaphor is not yet inevitable-is not sufficiently artistic.

The true test for the artistic use of metaphor-the true test of poetry-is that it shall be the shortest path along the line of least resistance, upon which the thought shall find its happiest expression, and which necessarily involves a creative act, an act of invention, and an exercise of the imagination for the comprehension of the expression.

In assaying and estimating a poem, it is necessary to keep in mind the fact that it is to be measured both by what it is as a poetic achievement as a whole, and by what it is as a matrix of great lines. A poem may have several supreme lines, and still not be a great poem. On the other hand, a poem may not have a single supreme line, and yet be a great poem. The greatest poem, of course, is that which is great as a whole and is also rich in supreme lines.

It is necessary, while perusing the following great lines of poetry, to remember that tem-potentry (versification) has nothing whatever to do with the appraisement of absolute poetic values, which are to be esteemed entirely for the manner of expression of insensuous thought in sensuous terms by artistic trope.

Furthermore, in our appraisement of absolute poetry, we must not be biased by any appeal to human sympathy, for tho the appeal to the sympathies, like tem-potentry, heightens the impressiveness of what is said, it has nothing whatever to do with tropical expressiveness, and poetry has entirely to do with tropical expressiveness.

While the following great poetic lines have been culled from very wide sources and from a great mass of literature, and while it is probable that the collection embraces by far the larger part of the greatest poetic lines in the English language, still it is not intended to embrace all of the greatest lines.

I have inserted some of my own lines among the great poetic lines of the poets as exemplifications of what any 
educated person with imagination and powers of invention may write by merely proceeding according to scientific method and without any fine frenzy or divine afflatus.

If the reader finds that some of my method-made lines are occasionally mistaken by expert judges for classic specimens of great poetic lines, then will not the value of the method be proven?

In the index to the great lines, those examples of which I am the author are marked Exm., standing for exemplification. 


\section{GREAT POETIC LINES}

1. And all our yesterdays have lighted fools The way to dusty death.

2. Was this the face that launch'd a thousand ships, And burnt the topless towers of Ilium?

3. Through this dread shape the suffering ages look; Time's tragedy is in that aching stoop.

4. Thou, silent form, dost tease us out of thought As doth Eternity.

5.

I was all ear

And took in strains that might create a soul Under the ribs of Death.

6. I, too, am child of all-potential light That broke the night of chaos into smile And gave to beauty all the trance of stars.

7. That grand epic written by the finger of God upon the strata of the Earth.

8.

Enormous shuttles of the dark! That weave the Everlasting Dream.

9. To me, through these thin cobwebs, Death and Eternity sate glaring.

10.

All that we see or seem

Is but a dream within a dream.

11.

Hands unseen

Were hanging the night around us fast.

12. To Whom the unceasing suns belong, And cause is one with consequence,To Whose divine inclusive sense The moan is blended with the song.

13. The red outline of beginning Adam. 


\section{THE SCIENCE OF POETRY}

14.

Stands tiptoe on the misty mountain tops.

Jocund day

15. The horse that guide the golden eye of heaven, And blow the morning from their nostrils.

16. We played all comers at the old Gray Inn, But played the King of Players to our cost. We played Him fair and had no chance to win: The dice of God were loaded and we lost.

17. In the night of death, hope sees a star and listening love can hear the rustle of a wing.

18. What old-time wrongs have trailed the aching yearsWhat ghost-world curses breathed pursuing blight, And wrought their vicious culminate in thee?

19. The Sun's rim dips; the stars rush out: At one stride comes the dark.

20. How sweetly did they float upon the wings Of silence through the empty-vaulted night, At every fall smoothing the raven down Of darkness till it smiled.

21. I heard the trailing garments of the Night Sweep through her marble halls!

I saw her sable skirts all fringed with light From the celestial walls!

22. 'Tis distance lends enchantment to the view, And robes the mountain in its azure hue.

23. But oh! that deep romantic chasm which slanted Down the green hill athwart a cedarn cover! A savage place! as holy and enchanted As e'er beneath a waning moon was haunted By woman wailing for her demon-lover!

24. Backward, flow backward, O tide of the years!

25. Every act is but condition's fruit. 
26.

To live one day of parting love.

27. For within the hollow crown

That rounds the mortal temples of a king,

Keeps Death his court; and there the antick sits,

Scoffing his state, and grinning at his pomp;

Allowing him a breath, a little scene

To monarchize, be fear'd, and kill with looks;

Infusing him with self and vain conceit-

As if this flesh, which walls about our life,

Were brass impregnable; and, humor'd thus,

Comes at the last, and with a little pin

Bores through his castle wall, and-farewell king!

28. The eyes that looked through life and gazed on God.

29. Where occident day on the great water dies And morning is born to the Orient skies, As the sun-weary hours break ranks with the light And eyelids are wooed by the narcotic night-

30. The stars of midnight shall be dear To her; and she shall lean her ear

In many a secret place

Where rivulets dance their wayward round, And beanty born of murmuring sound Shall pass into her face.

31. Take down the horn wherein the thunders sleep, Blow battles into men-call down the fire.

32. Soft eyes looked love to eyes which spake again.

33. Too low they build who build beneath the stars.

34.

And ever against eating cares,

Lap me in soft Lydian airs,

Married to immortal verse;

Such as the meeting soul may pierce,

In notes, with many a winding bout

Of linkèd sweetness long drawn out.

35. Life is a narrow vale between the cold and barren peaks of two eternities. 
36. As, flake by flake, the beetling avalanches

Build up their imminent crags of noiseless snow, Till some chance thrill the loosened ruin launches

And the blind havoc leaps unwarned below, So grew and gathered through the silent years

The madness of a People, wrong by wrong.

There seemed no strength in the dumb toilers' tears,

No strength in suffering; - but the Past was strong:

The brute despair of trampled centuries

Leapt up with one hoarse yell and snapt its bands, Groped for its right with horny, callous hands, And stared around for God with bloodshot eyes.

37.

For none can tell to what red Hell

His sightless soul may stray.

38.

Only the warp is the real,

The woof is the substance of dreams-

Only the veil is the real,

The face is the substance of dreams;

And yet all the tangible worth of this life

Is a tissue of only what seems-

And all of the solider webwork of life

But veils the sweet substance of dreams.

39.

We are such stuff

As dreams are made on, and our little life

Is rounded with a sleep.

40. That fatal and perfidious bark,

Built in the eclipse, and rigg'd with curses dark.

41. Strange wares are handled on the wharves of sleep:

Shadows of shadows pass, and many a light

Flashes a signal-fire across the night;

Barges depart whose voiceless steersmen keep

Their way without a star upon the deep;

And from lost ships, homing with ghostly crews,

Come cries of incommunicable news.

42.

All the night

I listened through the stars for Italy. 
43. From stellate peak to peak is tossed a voice of wonder.

44. $\mathrm{O}$, for a draught of vintage! that hath been Cool'd a long age in the deep-delvèd earth, Tasting of Flora and the country green,

Dance, and Provençal song, and sunburnt mirth!

0 , for a beaker full of the warm South,

Full of the true, the blushful Hippocrene,

With beaded bubbles winking at the brim, And purple-stainèd mouth;

That I might drink, and leave the world unseen, And with thee fade away into the forest dim.

45.

Teach me half the gladness

That thy brain must know;

Such harmonious madness

From my lips would flow,

The world should listen then, as I am listening now.

46.

O Thou my voice inspire

Who touched Isaiah's hallowed lips with fire!

47.

And Music shall untune the sky.

48. Wrapt in the dreamless drapery of eternal peace.

49. Where maybe ghosts from far-off other spheresLost tramps of space who wander down the years, And fallen low from some estate sublime, And drifting now, old dereliets of timeHad gathered, there to witness human strife, Or be near earth to warm themselves on life.

50. On a mountain-peak

Half-sheathed in primal woods and glittering

In spasms of awful sunshine, at that hour

A lion couched, part raised upon his paws,

With his calm, massive face turned full on thine, And his mane listening. When the ended curse Left silence in the world, right suddenly He sprang up rampant, and stood straight and stiff, 
As if the new reality of death

Were dashed against his eyes, and roared so fierce

(Such thick carnivorous passion in his throat

Tearing a passage through the wrath and fear)

And roared so wild, and smote from all the hills

Such fast, keen echoes crumbling down the vales

To distant silence-that the forest beasts,

One after one, did mutter a response

In savage and in sorrowful complaint

Which trailed along the gorges.

51.

Where, moored to solitude, immobile, prone

Before one clothed in change whose name is Time,

Conquered with silence, canopied with night,

Like the vast sleep of mighty motion lies

That postured form of awful vigilance

And dumb and solemn sibyl of the sands,

Mother of mystery, the fabled sphinx,

Facing the infinite with listening eyes.

52. He gave to Misery all he had-a tear.

53. Who loosened and let down this brutal jaw?

Whose was the hand that slanted back this brow?

Whose breath blew out the light within this brain?

54. Full many a glorious morning have I seen

Flatter the mountain-tops with sovereign eye.

55. Then mountainous fire burst night and the sky, And men ran with death in a wild, far cry.

56.

Where slow Eternity anneals The manacles of Time and Form;

Where dim alchemic powers rebuild,

To Law's immutable designs,

The primal, unapparent shrines

With Being's basic mystery filled.

57. And peace went with them one and all, And each calm pillow spread; 
But guilt was my grim chamberlain, That lighted me to bed;

And drew my midnight curtains round, With fingers bloody red!

58. The land lies blasted! All the hills are hearths Of coals! His breath of poison rots the air.

59. From the desert I come to thee,

On a stallion shod with fire; And the winds are left behind

In the speed of my desire.

Under thy window I stand, And the midnight hears my cry:

I love thee, I love but thee

With a love that shall not die

Till the sun grows cold,

And the stars are old,

And the leaves of the Judgment Book unfold!

Look from thy window, and see

My passion and my pain;

I lie on the sands below, And I faint in thy disdain.

Let the night-winds touch thy brow

With the heat of my burning sigh,

And melt thee to hear the vow

Of a love that shall not die

Till the sun grows cold,

And the stars are old,

And the leaves of the Judgment Book unfold!

60.

With God

Accomplishment is parcel of the will That action hangs upon.

61. Methought I heard a voice cry: Sleep no more, Macbeth doth murder sleep; the innocent sleep; Sleep, that knits up the raveled sleeve of care, The death of each day's life, sore labor's bath, Balm of hurt minds, great Nature's second course, Chief nourisher in life's feast. 
62. It flows through old, hush'd Egypt and its sands, Like some grave mighty thought, threading a dream.

63. But Thou canst hear the ocean in one shell, And see the whole world's winter in one leaf.

64. The music, yearning like a God in pain.

65. Love that is first and last of all things made, The light that moving has man's life for shade.

66. Eyes that do mislead the morn.

67. Cycles ferried my cradle, rowing and rowing like cheerful boatmen.

68. On, through a vista

Arched by fantoms and the ghostly trees, And either side dark-denned and damned, enticing fearsome things,

I rather felt than saw my way,

Groping the gantlet of strange peerings from the shades, And while the very air attended on expectancy

And held its breath from on the leaves,

Till Silence listened for a sound,

And I could hear the tread of misty moonbeams stilting through the trees,

And menace whispered from the other world,

As hovering ghosts from far-off olden days,

Now derelict and drifting on the gulf,

Looked enviously on life,

And chilled the night with their cold bones.

At length I came to where the earth doth merge into eternity-a grave!

69. But on us both did haggish age steal on And wore us out of act.

70. Oh, good gigantic smile o' the brown old earth.

71. Rock of Ages, cleft for me, Let me hide myself in Thee! 
72. The past is past. I see the future stretch All dark and barren as a rainy sea.

73. Midnight tremendous, silence, and iron sleep.

74. His coward lips did from their color fly.

75. Is this the Dream He dreamed who shaped the suns And marked their ways upon the ancient deep?

76. On with the dance! let joy be unconfined;

No sleep till morn, when Youth and Pleasure meet To chase the glowing Hours with flying feet.

77. Hope is but builded of fancy and dream, And flits in the flash of a lightning gleam. For man or a world, the life is a spark That ages and dies and goes out in the dark.

78. Dim-paneled in the painted scene of Sleep.

79. That orbèd maiden with white fire laden Whom mortals eall the Moon Glides glimmering o'er my fleece-like floor By the midnight breezes strewn; And wherever the beat of her unseen feet, Which only the angels hear, May have broken the woof of my tent's thin roof, The stars peep behind her and peer. And I laugh to see them whirl and flee

Like a swarm of golden bees, When I widen the rent in my wind-built tentTill the calm rivers, lakes, and seas, Like strips of the sky fallen through me on high, Are each paved with the moon and these.

80. The seeds of the French Revolution were watered by the tears of agony. Blows began to bear interest.

81. $\mathrm{O}$ aching time! $\mathrm{O}$ moments big as years!

82. The Father of waters again goes unvexed to the sea. 
83. Oh, the little more, and how much it is!

And the little less, and what worlds away!

84. For if such holy song

Inwrap our fancy long,

Time will run back, and fetch the age of gold;

And speckled Vanity

Will sicken soon and die,

And leprous Sin will melt from earthly mold;

And Hell itself will pass away,

And leave her dolorous mansions to the peering day.

85. On the primal air wild skies were flung.

86.

\section{I dwelt alone}

In a world of moan,

And my soul was a stagnant tide.

87. How will you ever straighten up this shape;

Touch it again with immortality;

Give back the upward-looking and the light;

Rebuild in it the music and the dream?

88.

$$
\begin{aligned}
& \text { The sea and the sky } \\
& \text { Lay like a load on my weary eye. }
\end{aligned}
$$

89. From the summits of yonder pyramids forty centuries look down upon you.

90. Love took up the glass of Time, and turn'd it in his glowing hands;

Every moment, lightly shaken, ran itself in golden sands.

Love took up the harp of Life, and smote on all the chords with might;

Smote the chord of Self, that, trembling, pass'd in music out of sight.

91. Coming events cast their shadows before them.

92. A shout, that tore Hell's concave, and beyond Frighted the reign of Chaos and old Night. 
93. Heaven from all creatures hides the book of fate.

94. O pardon me, thou bleeding piece of earth, That I am meek and gentle with these butchers!

Thou art the ruins of the noblest man, That ever livèd in the tide of times.

Wo to the hand that shed this costly blood!

Over thy wounds now do I prophesy-

Which, like dumb mouths, do ope their ruby lips, To beg the voice and utterance of my tongueA curse shall light upon the limbs of men; Domestic fury and fierce civil strife

Shall eumber all the parts of Italy;

Blood and destruction shall be so in use, And dreadful objects so familiar,

That mothers shall but smile, when they behold Their infants quarter'd with the hands of war, All pity chok'd with custom of fell deeds; And Cisar's spirit, ranging for revenge, With Até by his side, come hot from hell, Shall in these confines, with a monarch's voice, Cry "Havoe!" and let slip the dogs of war; That this foul deed shall smell above the earth With carrion men, groaning for burial.

95. Our birth is but a sleep and a forgetting: The soul that rises with us, our life's star Hath had elsewhere its setting, And cometh from afar.

.. Trailing elouds of glory do we come From God who is our home.

96. Hid in the hours before the purpling dawn.

97. Life, like a dome of many-colored glass, Stains the white radiance of eternity.

98. She comes like the hush and beauty of the night, And sees too deep for laughter;

Her touch is a vibration and a light

From worlds before and after. 


\section{THE SCIENCE OF POETRY}

99.

My luve is like a red, red rose That's newly sprung in June;

My luve is like the melodie That's sweetly play'd in tune.

100. Men's evil manners live in brass; their virtues we write in water.

101. To die-to barter with oblivion The heart-tire and the pain for dreamless sleep, Were gain indeed, if that were all.

102. Here once the embattled farmers stood, And fired the shot heard round the world.

103. As when the sun, new risen, Looks through the horizontal misty air Shorn of his beams; or from behind the moon, In dim eclipse, disastrous twilight sheds On half the nations.

104. She took the tried clay of the common roadClay warm yet with the genial heat of Earth, Dashed through it all a strain of prophecy; Tempered the heap with touch of mortal tears; Then mixt a laughter with the serious stuff.

105. As when, upon a trancèd summer-night, Those green-rob'd senators of mighty woods, Tall oaks, branch-charmèd by the earnest stars, Dream, and so dream all night without a stir, Save from one gradual solitary gust

Which comes upon the silence, and dies off, As if the ebbing air had but one wave.

106. From where Cortona lifts to heaven Her diadem of towers.

107. Let's talk of graves, of worms, and epitaphs; Make dust our paper, and with rainy eyes Write sorrow on the bosom of the earth. 
108. And each separate dying ember wrought its ghost upon the floor.

109. All the forms that fear can paint upon the shadowy canvas of the dark.

110. She walks in beauty like the night.

111. Now the tread of the heavy ages jars;

Earth feels her old wounds and aches-at old scars.

112. They flash upon that inward eye

Which is the bliss of solitude

And then my heart with pleasure fills,

And dances with the Daffodils.

113. I see a hell of faces surge and whirl.

114. So hath He dreamt. So stands His night,

Wherein the suns abiding range,

Dust of the dynasties of change, And altars of eternal light.

115.

When the host

Is out at once to the despair of night.

116. Let not our looks put on our purposes.

117. Ancestral voices prophesying war!

118. I fled Him, down the nights and down the days; I fled Him, down the arches of the years;

I fled Him, down the labyrinthine ways Of my own mind; and in the mist of tears

I hid from Him, and under running laughter.

119. Mysterious worlds, untraveled by the sun!

Where Time's far-wand'ring tide has never run.

$120 . \quad$ That haunting hour

When spirit mysteries clothe themselves

With shadows in the wood. 
121. The complex, tangled web of human thought and dream has never yet been raveled back to simple threads.

122. Time hath, my lord, a wallet at his back, Wherein he puts alms for oblivion-

A great-sized monster of ingratitudes-

Those scraps are good deeds past; which are devoured

As fast as they are made, forgot as soon

As done; perseverance, dear my lord,

Keeps honor bright; to have done is to hang

Quite out of fashion, like a rusty mail

In monumental mockery. Take the instant way;

For honor travels in a strait so narrow

Where one but goes abreast; keep then the path;

For emulation hath a thousand sons

That one by one pursue; if you give way,

Or hedge aside from the direct forthright,

Like to an entered tide, they all rush by

And leave you hindmost:

Or, like a gallant horse fallen in first rank,

Lie there for pavement to the abject rear,

O'errun and trampled on: then what they do in present,

Tho less than yours in past, must o'ertop yours;

For time is like a fashionable host

That slightly shakes his parting guest by the hand,

And with his arms outstretched as he would fly,

Grasps in the comer: Welcome ever smiles,

And Farewell goes out sighing.

123. And when he fell in whirlwind, he went down

As when a kingly cedar green with boughs

Goes down with a great shout upon the hills,

And leaves a lonesome place against the sky.

124. Hell is paved with good intentions.

125. Your wisdom is consumed in confidence.

126. And the fairest fabric of human power Ravels to the memory of an hour. 
$127 . \quad$ Brazen bells!

What a tale of terror now their turbulency tells!

In the startled ear of night.

128. In passion's storm, the will is wrecked upon the reefs and rocks of crime.

129. My master, God omnipotent, Is mustering in His clouds, on our behalf, Armies of pestilence.

130. Nor can we praise alone In the majestic reticence of stone.

131. And the night shall be fill'd with musie, And the cares that infest the day Shall fold their tents like the Arabs, And as silently steal away.

132. Like a comet burned, That fires the length of Ophiuehus huge In the arctic sky, and from his horrid hair Shakes pestilence and war.

133. When the storm-clouds run fast through the seanty light And the moon beats to windward over the night-

134. There crept

A little noiseless noise among the leaves Born of the very sigh that silence heaves.

135. The flaring pageant and the storied pile May parley with Oblivion awhile.

136. A Greeian queen whose youth and freshness Wrinkles Apollo, and makes stale the morning.

137. While the cock with lively din Scatters the rear of darkness thin. 


\section{THE SCIENCE OF POETRY}

138. $\mathrm{Ah}$, broken is the golden bowl! the spirit flown forever.

Let the bell toll!-a saintly soul floats on the Stygian river.

139. Above the howling senses' ebb and flow.

140. Could we peer beyond the pale, The marrow of our mortal bones would freeze, And every separate hair would blanch and stand aghast.

141. Thy spirit's sister, the lorn nightingale, Mourns not her mate with such melodious pain.

142. And pluck the wings from painted butterflies, To fan the moonbeams from his sleeping eyes.

143.

O Deep whose very silence stuns!

144. And around the dear ruin each wish of my heart Would entwine itself verdantly still.

145. Now are all terrestria merging toward the vernal equinox, and the pregnant air is big with unborn laughter; while shelvèd song is waiting in the good old wine with corked-up merriment, to free the fancy and let the soul-deeps well to brimming in the eye-dream that gives to Eros freedom of the reason and chains the during future up to the heart's hazard.

146. But these are vain to hold Against the slow creep of the patient mold, The noiseless drill of the erasing rust!

147. And think the thoughts that lilies speak in white.

148. IIence, loathèd Melancholy,

Of Cerberus and blackest Midnight born!

In Stygian cave forlorn,

'Mongst horrid shapes, and shrieks, and sights unholy, Find out some uncouth cell,

Where brooding Darkness spreads his jealous wings. 
149. The multitudinous seas incarnadine.

150. Socrates thrust the spear of question through the shield and heart of falsehood.

151.

Music's golden tongue

Flatter'd to tears this aged man and poor.

152.

$$
\text { Put me to present pain, }
$$

Lest this great sea of joys, rushing upon me, O'erbear the shores of my mortality.

153. I walked alone the dread and whispering night-

154. The hidden Norns have woven hope through the murky woof of days.

155. When the first stars were showered upon the night.

156. It is great to do that thing

That ends all other deeds,

Which shackles accident, and bolts up change.

157. The Moving Finger writes; and, having writ,

Moves on: nor all your piety nor wit

Shall lure it back to cancel half a line,

Nor all your tears wash out a word of it.

158. Adown Titanic glooms of chasmed fears.

159.

All the dark

Seems overhung as tho with monstrous wings, And menace loads the gloom.

160. Thou shalt within thine own consuming essence burn And every naked nerve shall scream.

161. High thoughts that run the star-paved roads of Heaven.

162. And Madeline asleep in lap of legends old. 
163. Those who build with thought and dream the temples of the soul.

164. Her bed is India-there she lies a pearl.

165. Cryptic glooms that wall the grave.

166. Thou wast not born for death, immortal Bird! No hungry generations tread thee down;

The voice I hear this passing night was heard In ancient days by emperor and clown:

Perhaps the self-same song that found a path Through the sad heart of Ruth, when, sick for home,

She stood in tears amid the alien corn;

The same that ofttimes hath

Charm'd magic casements, opening on the foam Of perilous seas, in faëry lands forlorn.

167. Clung to the whistling mane of every wind.

168. How fear doth poise us on the brink of death, Between contending purposes.

169. And laid on mortal brows immortal dream.

170. Haste thee, Nymph, and bring with thee Jest, and youthful Jollity, Quips, and Cranks, and wanton Wiles, Nods, and Becks, and wreathèd Smiles, Such as hang on Hebe's cheek, And love to live in dimple sleek; Sport that wrinkled Care derides, And Laughter holding both his sides. Come, and trip it as you go, On the light fantastic toe.

171. When valor preys on reason it eats the sword It fights with. 
172. Ah, sad and strange as in dark summer dawns The earliest pipe of half-awaken'd birds

To dying ears, when unto dying eyes

The casement slowly grows a glimmering square;

So sad, so strange, the days that are no more.

173. Oh, thou art fairer than the evening air, Clad in the beauty of a thousand stars.

174. There's such divinity doth hedge a king.

175. Let eons gone, with all their wintered cares, be eons dead, and warm us at the morning smiling in our face.

176. The sporting of thy howling hurricanes, That run wild races round thy endless tracks

And spin their cyclone tops in giant play.

177. Then felt I like some watcher of the skies, When a new planet swims into his ken; Or like stout Cortez when with eagle eyes He star'd at the Pacific-and all his men Look'd at each other with a wild surmiseSilent, upon a peak in Darien.

178. See the moon Lies stranded on the pallid coast of morn.

179. Conscience is born of love.

180. And my soul from out that shadow that lies floating on the floor, Shall be lifted-nevermore!

181. Some dim derision of mysterious laughter.

182. Here's to the grave, To that last tavern as you leave the town.

183. This sensible warm motion to become a kneaded clod, To lie in cold obstruction and to rot. 
184. I vow some witch hath passed And spat a curse. My dreams were dipt in fear.

185. And eyes let hang on eyes over the soul's brink.

186. Deep as the last road in the gulfs of Hell, And higher than the climb of the first star.

187. The babbling gossip of the air.

188. When all the range is violet smoke And all the valley night

One peak swims like a sculptured isle, An amethyst of light.

It floats a neighbor to the stars.

189. A soul came fumbling at the latch of life.

190. This bank and shoal of time.

191. And loosen the chained silence of the dead.

192. Take thy beak from out my heart, and take thy form from off my door! 


\section{INDEX TO AUTHORS OF GREAT LINES}

1. Shakespeare, William, 261.

2. Marlowe, Christopher, 261.

3. Markham, Edwin, 261.

4. Keats, John, 261.

5. Milton, John, 261.

6. Exm., 261.

7. Spencer, Herbert, 261.

8. Sterling, George, 261.

9. Carlyle, Thomas, 261.

-10. Poe, Edgar Allan, 261.

11. Browning, Robert, 261.

12. Bierce, Ambrose, 261.

13. Beddoes, Thomas Lovell, 261.

14. Shakespeare, 262.

15. Marlowe, 262.

16. Markham, 262.

17. Ingersoll, Robert G., 262.

18. Exm., 262.

19. Coleridge, Samuel T., 262.

20. Milton, 262 .

21. Longfellow, Henry Wadsworth, 262.

22. Campbell, Thomas, 262.

23. Coleridge, 262.

24. Allen, Elizabeth Akers, 262.

25. Ingersoll, 262.

26. Burns, Robert, 263.

27. Shakespeare, 263.

28. Watson, William, 263.

29. Exin., 263.

30. Wordsworth, William, 263.

31. Markham, 263.

32. Byron, George Gordon Noel, 263.

33. Young, Edward, 263.

34. Milton, 263.

35. Ingersoll, 263.

36. Lowell, James Russell, 264.

37. Wilde, Oscar, 264.

38. Exm., 264.

39. Shakespeare, 264.

40. Milton, 264.

41. Markham, 264.

42. Browning, Elizabeth Barrett, 264.

43. Thompson, Francis, 265.

44. Keats, 265.

45. Shelley, Percy Bysshe, 265.

46. Pope, Alexander, 265.

47. Dryden, John, 265.

48. Ingersoll, 265 .

49. Fxm., 265.

50. Browning. Flizabeth B., 265.

51. Van Noppen, Leonard, 266.

52. Gray, Thomas, 266.
53. Markham, 266.

54. Shakespeare, 266.

55. Exm., 266.

56. Sterling, 266.

57. Hood, Thomas, 266.

58. Scheffauer, Herman, 267.

59. Taylor, Bayard, $26 \%$.

60. Exm., 267.

61. Shakespeare, 267.

62. Hunt, Leigh, 268.

63. Markham, 268.

64. Keats, 268.

65. Swinburne, Algernon Charles, 268.

66. Shakespeare, 268.

-67. Whitman, Walt, 268.

68. Exm., 263.

69. Shakespeare, 268.

70. Browning, Robert, 268.

71. Toplady, Augustus Montague, 268.

72. Smith, Alexander, 269.

73. Horne, Richard Hengist, 269.

74. Shak espeare, 269.

75. Markham, 269.

76. Byron, 269.

77. Exm., 269.

78. Lanier, Sidney, 269.

79. Shelley, 269.

80. Ingersoll, 269.

81. Keats, 269.

82. Lincoln, Abraham, 269.

83. Browning, Robert, 270.

84. Milton, 270.

85. Exm., 270.

-66. Poe, 270.

87. Markham, 270.

88. Coleridge, 270.

89. Napoleon, 270.

90. Tennyson, Alfred, 270.

81. Campbell, 270.

92. Milton, 270.

93. Pope, 271.

94. Shakespeare, 271.

95. Wordsworth, 271.

96. Exm., 271.

97. Shelley, 271.

88. Markham, 271.

99. Burns, 272.

100. Shakespeare, 272.

101. Exm., 272.

-102. Emerson, Ralph Waldo, 272.

103. Milton, 272.

104. Mark ham, 272. 


\section{THE SCIENCE OF POETRY}

105. Keats, 272.

106. Macaulay, Thomas Babington, 272.

107. Shakespeare, 272.

-108. Poe, 273.

109. Ingersoll, 273.

110. Byron, 273.

111. Exm., 273.

112. Wordsworth, 273.

113. Markham, 273.

114. Sterling, 273.

115. Browning, Robert, 273.

116. Shakespeare, 273.

117. Coleridge, 273.

118. Thompson, 273.

119. Campbell, 273.

120. Exm., 273.

121. Ingersoll, 274.

122. Shakespeare, 274.

123. Markham, 274.

124. Johnson, Samuel, 274.

125. Shakespeare, 274.

126. Exm., 274.

-127. Poe, 275.

128. Ingersoll, 275.

129. Shakespeare, 275.

130. Markham, 275.

131. Longfellow, 275.

132. Milton, 275.

133. Exm., 275.

134. Keats, 275.

135. Markham, 275.

136. Shakespeare, 275.

137. Milton, 275.

-138. Poe, 276.

139. Swinburne, 276.

140. Exm., 276.

141. Shelley, 276.

142. Shakespeare, 276.

143. Sterling, 276.

144. Moore, Thomas, 276.

145. Exm., 276.

146. Markham, 276.

147. Lanier, 276.

148. Milton, 276.

149. Shakespeare, 277.
150. Ingersoll, 277.

151. Keats, 277.

152. Shakespeare, 277.

153. Exm., 277.

154. Scheffauer, 277.

155. Markham, 277.

156. Shakespeare, 277.

157. Fitzgerald, Edward (Persian of Omar Khayyam), $27 \pi$.

158. Thompson, 277.

159. Sterling, 277.

160. Exm., 277.

161. Markham, 277.

162. Keats, 277.

163. Ingersoll, 278.

164. Shakespeare, 278.

165. Sterling, 278.

166. Keats, 278 .

167. 'Thompson, 278.

168. Exm., 278.

169. Markham, 278.

170. Milton, 278.

171. Shakespeare, 278.

172. Tennyson, 279.

173. Marlowe, 279.

174. Shakespeare, 279.

175. Exm., 279.

176. Jones, Rev. James Clarence, 279.

177. Keats, 279.

178. Smith, 279.

179. Shakespeare, 279.

-180. Poe, 279.

181. Swinburne, 279.

182. Markham, 279.

183. Shak espeare, 279.

184. Sterling, 280.

185. Exm., 280.

186. Markham, 280.

187. Shakespeare, 280.

188. Wilkinson, Florence, 280.

189. Markham, 280.

190. Shakespeare, 280.

191. Markham, 280.

-192. Poe, 280. 


\section{INDEX}

\section{A}

A, sounds of the letter, 116 .

Academic education, tendency of, 97 .

Accent, tone-color, 154 .

Accentuation by contrasts, 27, 28 .

"Achierements, Speech on the Inventor and the Meaning of Aeronautical," Exm., Maxim, 246.

Acid, 124.

Action in poetry, magic, 183, 258. of vocal organs, 125.

Actions, rhythm of, 127.

Adam, 209.

"Address at Benefit Given by the American-Italian Relief Committee," Exm., Maxim, 250.

Adjectival qualifications, 182-185.

Adonis, 238.

Adverbial predication, 182.

"Aeronautical Achievements, Speech on the Inventor and the Mean. ing of," Exm., Maxim, 246.

Ages, the Midule, 196.

A jax, 90.

Alalus, 13, 18, 19, 20, 21.

Alcohol, 243.

"Aldine Association, Extracts from Speech before the," Exm., Maxim, 246.

Allegory, 30, 31 .

"A Look into the Gulf," Mark. ham, 188.

Alphabet, 96.

Alps, 240, 242.

Amelia, 91.

America, 102, 250.

"American-Italian Relief Commit. tee, Address at Benefit Given by the,' Exm., Maxim, 250.

Analogical speech, 13.

Analogy, 30 .

Anapest, 150.

"Ancient Mariner, The," Coleridge, 121.

"Ancient Rome, Lays of," Macaulay, 107, 108, 217.

Paraphrase of, Exm., Maxim, 217.
Ancients, 194.

Animals, herbivorous, 130 .

- speech of, 14.18.

Anthropoid ape, 17 .

Antony, Marc, 43, 237, 238, 239, 246.

A pache, 226, 227.

“Apache, L'," Exm., Maxim, 227.

Ape, anthropoid, 17.

Apparatus, rhythm of vocal, 144.

Appeal of poetic figure, primitive, 234.

Applied tro-tem-potentry, 194.

Appolyon, $\mathbf{x}$.

Appreciation, seeking of, 194.

April, 107.

Arabia, 105.

Arbitrary symbolism, 21, 84.

Areturus, 103, 206.

Argestes, 103.

A ristotle, 45, 46, 47, 72, 75, 228, 258.

Arithmetical problem, xi.

“Arms for Peace, To," Exm., Maxim, 244.

Arnold, Matthew, 252, 253, 254, 257.

“'A rt and Morality,' Ingersoll, 52.

Art, Dawson's definition of, 71 .

Articles, position of, 158.

Articulate speech, 14, 15.

Assaying poetry, 252-259.

Associated Sunday Magazines, the, 244.

Association of ideas, 113.

"Association, Extracts from Speech before the Aldine," Exm., Maxim, 246.

Athens, 160.

Atlantic, 201, 244.

Attention, 77. dynamies of, 112, 113.

"At the Tomb of Napoleon," Exm., Maxim, 241. Ingersoll, 240.

Attila, 105.

Auber, 187.

Audils, 208.

Austerlitz, 240.

"A Veiled Illusion," Fxm., Maxim, 215. 
Babylon, 188, 247.

Bacon, Sir Francis, 42, 71, 179.

"'Banquet to Spring,"' Exm., Maxim, 100.

Basic principles of rhythm, 137.

- of verse, 27.

"Batteries, Engagement between Fleet and Shore,' Exm., Maxim, 98.

“Battle of Flodden Field," 122.

Battle of the Pyramids, 39.

Beecher, Henry Ward, 232, 243.

Belial, 163.

Bell, Alexander Graham, 247.

"'Bells," Poe, 220.

"Benefit Given by the AmericanItalian Relief Committee, Address at," Exm., Maxim, 250.

Bennett, Bill, 255.

- Jim, 190.

Bible, 27, 100, 103, 218, 219.

"'Bingen on the Rhine,"' 216.

Blair, 32, 45, 166.

Blends of tone-color, 128.

Blessed, 95.

Blind, 2.

Bonaparte, Napoleon, 39, 60, 174, $208,235,236,239,240$.

-At the Tomb of," Exm., Maxim, 241. Ingersoll, 240.

Book of Job, 103.

Boreas, 103, 208.

Bosanquet, Bernard, 57.

Boston, 98.

- Economic Club of, 244.

Braggadocio, hyperbolic, 194.

Braggarts, ancient, 194.

Brain, 3.

- use of, 140, 141.

Branches of Language, six, 92.

Bridge of Lodi, 240.

Brienne, 241.

"Brigade, Charge of the Light," Tennyson, 216.

Brittanica, Encyclopedia, 57, 69.

Brown, J., 71.

Browning, 183, 189, 190, 196, 208, $252,256,257$.

Browning, Mrs. 183.

Brute, barrier between man and, 13.

Brutus, 238, 239.

Bunker Hill, 98, 245.
Bunyan, John, $x$.

“'Burial of Sir John More," 216.

Burke, Edmund, 72, 103.

\section{C}

Cacoëthes scribendi, 48.

Cadence, 128.

Cæsar, Julius, 43, 237, 238, 239, 249.

Caliban, 48.

Camilla, 90, 91.

Campbell, T., 70.

- Dr., 118.

Carlyle, Thomas, 40, 70, 103.

Carter, William, 183.

Carthage, 237.

Carthaginians, 237.

Caspian, the, 213.

Cassim, 211.

Caurus, 103.

Cells, use of brain, 140, 141.

Century Dictionary, 14.

Change of taste in verse, 164, 165.

"Charge of the Light Brigade," Tennyson, 216.

Chatterton, 192.

Chief element in verse, rhythm the, $146,147$.

"Churchyard, Elegy Written in a Country," Gray, 192, 216, 217.

Clemens, Samuel L. (Mark Twain), $33,231,235$.

Club of Boston, Economic, 244.

Colburn, Zerah, 23.

Cole, Old King, 33.

Coleridge, 43, 70, 121, 187.

Colors, 6.

"Colossal Russia," Exm., Maxim, 105.

Comanche Indian, 55, 56.

"Coming War,"' Exm., Maxim, 105.

Commandment, Fourth, 60.

"Committee, Address at Benefit Given by the American-Italian Relief," Exm., Maxim, 250.

Composition, application of fundamental principles of, 93.

Concentration, 143.

Concord, 98, 245.

Conference, International Peace, 243.

Conjunctions, position of, 158.

Connecticut, Plantsville, 169.

Consciousness, 1.

Conservation of energy, 36 .

Consonant sounds, 154. 


\section{INDEX}

Contradictory emotions, unconscious, 195.

Contrasts, accentuation by, 27, 29 .

Cortez, 65.

“Country Churchyard, Elegy Writ. ten in a," Gray, 192, 216, 217.

\section{D}

Dactyl, 150.

“'Dance of Shadows,' Exm., Maxim, 216.

Dane, 103.

Darien, 65.

“Darkest before Dawn," Exm., Maxim, 225.

Darwin, xii, 45, 82, 174.

“Daughter, Lord Ullan's," 217.

"Dawn, Darkest before," Exm., Maxim, 225.

“'Dawn, Shadows of," Exm., Maxim, 218.

Dawson, W. J., 71, 74, 190, 255, 256.

Deaf, 2.

Death, 210, 212, 213.

"Death, Satan's Encounter with," Milton, 210, 212.

(Death, Satan's Encounter with), Paraphrase of, Exm., Laxim, 213.

Decline of verse, 166,167 .

- poetry, 167, 168.

"Deep of Things, In the," Exm., Maxim, 224.

Delicious, 113.

“'Destiny," Exm., Maxim, 219.

Dian, 187.

Diana of the Ephesians, 120, 124.

Dionysius of Phocza, 148.

Direct style, 122, 123.

Dog, growling of, 10.

whining of, 10.

Dryden, 211.

"Duel between the Monitor and the Merrimac," Abbott, 99.

Dunton, Theodore Watts, 57, 69, 72.

Duration, 4, 5, 121, 138, 155.

Dwell, 4, 5, 121, 139, 155.

Dynamies of attention, 112, 113.

- speech, 83, 111.

$\boldsymbol{E}$

Eartbquake, Messina, 248.

Economic Club of Boston, 244.
Economy of effort, 78.

- word-symbols in poetry, 36 .

Eden, 209.

Edinburgh, the University, of, 73.

Edison, 247.

"Education," Spencer, 101.

Education, tendency of academic, 97 .

Edward, 103.

Effects, initial, 158.

Effort, rhythm of supreme, 144, 145.

Egotism, 196, 197.

of love, hyperbolic, 194.

Egypt, 39, 240, 241.

Elba, 240, 242.

Electricity, Keely's definition of, 61 .

"Elegy Written in a Country Churchyard," Gray, 192, 216, 217.

Elementary sounds in English, 114.

"Elements of Literary Criticism,", Charles F. Johnson, 55.

Elimination of pentametric line, 162.

Elysium, 43.

Emerson, 70, 100, 179, 183.

Emotional actions, rhythm of, 127 .

- literature, stimulus of, 223.

Emotions, indication and utterance of, 128.

stimulation of, 80 .

- unconscious contradictory, 195.

Emphasis, 137.

"'Empires, Ruins of,' Volney, 107.

"Encounter with Death, Satan's," Milton, 210, 212.

- Paraphrase of, Exm., Maxim, 213.

Encyclopedia Britannica, 57, 69.

Endings, tragic, 180.

Endless space, 206.

End-stop lines in verse, 121.

Energy, conservation of, 36, 75 .

"Engagement between Fleet and Shore Batteries,"' Exm., Maxim, 98.

Enjoyment of poetry, intellectual, 74 .

English and French words compared, 89. order of, 119.

- elementary sounds in, 114. letters, 115. strength of Saxon, 118. verse, philosophy of, 133 .

“'English Verse, Science of,' Lanier, 116, 133. 
Environment, 1.

Ephesians, Diana of the, 120, 124.

Epic poetry, 166.

“'Essays in Criticism,' A rnold, 253.

" Esthetic, History of the," Bosanquet, 57.

Eternity, 113.

"'Eulogy on Milton," Exm., Maxim, 209.

Europe, 105, 231.

Eurus, 103.

Everett, Edward, 100.

“'Evolution of Man, The," Haeckel, 13.

“'Excelsior," Longfellow, 38, 40, $189,217$.

Exercise of faculty, 3.

Exm. (exemplification), Maxim, "Address at a Benefit Given by the American-Italian Relief Committee,"' 250.

"At the Tomb of Napoleon," 241.

"A Veiled Illusion," 215.

"Banquet to Spring," 100.

"Colossal Russia," 105.

“"Darkest before Dawn," 225.

"Destiny," 219.

"Engagement between Fleet and Shore Batteries," 98.

"'Eulogy on Milton," 209.

"Extracts from Speech before the Aldine Association," 246.

"Gettysburg," 104.

"He Can Save Thee," 222.

"In the Deep of Things," 224.

"'L'Apache," 227.

"'Milton," 209.

“"Napoleon," 99.

Paraphrase of "Hamlet's Soliloquy," 199.

"Lays of Ancient Rome," 217.

“Paradise Lost," 163, 164, 213.

"San Francisco Fallen," 203.

"'Shadows of Dawn," 218.

"Speech on the Inventor and the Meaning of Aeronautical Achievements," 246.

" The Coming War,"' 105.

"'The Dance of Shadows," 216.

"'The Flight of Satan," 206.

“'The Village Orchestra,"' 221.
Exm. "'To Arms for Peace," 244. "War," 104.

Expectancy, 120.

- inducers of, 121.

Expression, felicity of, 190.

Expressiveness of words, 77-91.

"Extracts from Speech before the Aldine Association," Exm., Maxim, 246.

\section{$\mathbf{F}$}

Faculties of sense, 1.

Faculty, exercise of, 3.

"Fallen, San Francisco," Exm., Maxim, 203.

Familiar words, 185.

Fantasy, 2.

Fate, 211, 215.

Feelers, 2.

Feeling, 2.

Feet, poetic, 137.

Felicity of expression, 190.

Figure of speech, 29.

"First Principles,"' Spencer, 102.

"Fleet and Shore Batteries, Engage. ment between," Exm., Maxim, 98.

"Flight of Satan," Exm., Maxim, 206.

"Flight, Speed of Sirius',' 206.

"'Flodden Field, Battle of," 122.

Focus of mind, 130.

Fortunate, 95.

Foundation of poetry, 44.

- principles, 1.

Fourth Commandment, the, 60 .

France, 240, 241.

- king of, 33.

Franklin, Benjamin, 247.

Frederick, 242.

French and English uses compared, 119.

- Revolution, 40, 227. words compared with English, 89.

Fulton, 247.

Function, impeded, 3.

"—_ of Music, Origin and," Spen. cer, 124.

Functional response, 1.

Galileo, xii.

Genesis, 28.

G 
Genghis Khan, 105.

Georgia, 98.

Germans, 249.

Germany, 105.

Gesture, 21.

“'Gettysburg," Exm., Maxim, 104.

God, 47, 49, 102, 103, 109, 160, 164, $176,212,213,222,251$.

Goethe, 174.

Goose, Mother, 164.

Gordian Knot, 49.

Gordon, 122.

Grant, General, 245.

"'Grass, Leaves of,"' Whitman, 252.

Gray, 192, 216, 217.

Great Poetic Lines, 252, ot seq.

Greece, 233.

Greeks, 194.

Greene, Albert G., 109.

Grimes, 109.

Growling of dog, 10.

Growth of language, 228.

- reason, 171.

“Gulf, A Look into the,'” Markham, 188.

Gunpowder, smokeless, 196.

\section{H}

Haeckel, Ernst, 13, 45, 46, 82, 174.

Hamerton, 71.

“'Hamlet's Soliloquy,'” Shakespeare, 197, 198.

- Paraphrase of, Exm., Maxim, 199.

“'Handbook of Psyehology,,' Sully, 112.

Hanna, Reverend Thomas C., 169.

Hannibal, 242.

Happiness, causo of, 3.

Happy, 95.

Hart, John, 32.

Harum, David, 235.

“Hayne, Webster's Reply to,"' 98, 106.

Heart, 95.

Heaven, 163, 209, 210, 212, 213.

"'He Can Savo Thee,' Exm., Maxim, 222.

Holen of Troy, 36.

Hell, 164, 209, 210, 212, 213, 214, 227.

Hell.gate, 211.

Henry, 103.

Horbivorous animala, 130.

Horcules, 46, 187.
Heredity, 22.

Herodotus, 148.

" Hiawatha," Longfellow, 150.

"History of the Esthetic,"' Bosan. quet, 57.

Hodgson, 149.

“'Hoe, Man with the," Markham, 35, $39,227$.

- Millet, 227, 236.

“'Hohenlinden," 216.

Holmes, Edmond, 49, 50, 51, 52, 53, 54.

Sherlock, ix.

House band, 95.

Human import in poetry, 200.

Humbling the spirit, 196.

Humor, the philosophy of, 230-234.

Hunt, Leigh, 57, 58, 59, 60, 92.

Husband, 95.

Huxley, 45, 82, 174.

"'Hymn," Exm., Maxim, 222.

Hyperbole, 30, 31.

Hyperbolic braggadocio, 194.

- egotism of love, 194.

\section{I}

Iambic meter, 148.

- pentameter, 161.

Idea-rimes, 27.

- rhythm, 139.

Ideas, association of, 113.

Ilium, 36.

Illahun, 218.

“'Illusion, A Veiled," Exm., Maxim, 215.

Imagination, $\mathbf{2}$.

"Imagination and Fancy," Hunt, 57.

Impeded function, 3.

Impediment in verse and poetry, 208.

Impressiveness of words, $77 \cdot 91$.

India, 105, 201.

Indian, Comanche, 55, 56.

Indication of emotions, 80 .

Inducers, expectaney, 121.

Ingersoll, Robert G., 39, 40, 52, 100, $172,173,175,178,179,235,236$, $239,241,243$.

Inhibition, 142, 143.

Initial effects, 158.

Instinct, 22.

Intellectual enjoyment of poetry, 74

Interceptions, 207.

International Peace Conference, 243. 
"In the Deep of Things," Exm., Maxim, 224.

"Introduction to the Scientific Study of English Poetry,' Liddell, 62.

-Inventor and the Meaning of

"Aeronautical Achievements, Speech on the," Exm., Maxim, 246.

Irony, 30, 31, 230, 234.

"Italian Relief Committee, Address at Benefit Given by the American-," Exm., Maxim, 250.

Italy, 248, 249, 250.

\section{$\mathbf{J}$}

James, Professor William, 2, 77, 172, $173,174,175,177,178,189$.

Jeffreys, Jim, 197.

Jeffries, 103.

Jehovah, 109.

Jena, 242.

Jerrold, Douglas, 190.

Jesuit, 102.

Job, Book of, 103.

Johnson, Charles F., 54, 56.

- Samuel, 72.

Jonson, Ben, 178.

Jordan, 222.

Joshua, 247.

Jove, 109, 248.

June, 107.

\section{$\mathbf{K}$}

Keats, 60, 65, 70, 187.

Keely, John W., 60, 61, 62.

Kellogg, E., 99, 237, 238.

Khan, Genghis, 105.

King Cole, Old, 33.

Kremlin, 242.

Krakatoa, 200, 201.

\section{$\mathbf{I}$}

Lamartine, 71.

Language, barrier between man and brute, 13.

- emotional, 80.

- expressiveness of, 77-91.

- growth of, 228.

- impressiveness of, 77-91.

- six branches of, 92 .

- specialization in, 229.

- suggestive or reflective, 81 .

- the best, 83 .

" Language, Laws of,'” Pincott, 13.

- "Science of," Müller, 13, 102.

two-fold function of, 84,85 .
Lanier, Sidney, 116, 133, 134, 135, 136, 137, 138.

“'L'Apache,', Exm., Maxim, 227.

“'Lays of Ancient Rome,' Macaulay, 107, 108, 217.

- Paraphrase of, Exm., Maxim, 217.

"'Leaves of Grass,", Whitman, 252.

Leipsic, 240.

Letter A, sounds of the, 116.

Letters of the alphabet, the, 96, 115.

Lexington, 98, 245.

Liberty, 113.

Liddell, Mark H., 62, 63.

Life, 1.

"Light Brigade, The Charge of the," Tennyson, 216.

Line, elimination of the pentametric, 162.

Lines, Great Poetic, 252, et seq.

Lincoln, 186, 231, 232, 235, 245, 247.

" Literary Criticism, Elements of," Johnson, 55.

Literatry, 92.

- definition of, 94.

"Literature, Philosophy of," Poe, 191.

Literature, stimulus of emotional, 223.

Livingstone, Doctor, $\mathbf{1 7 5}$.

"Lochinvar, Young," 217.

Locke, 2, 24.

Lodi, the Bridge of, 240, 241.

"Lodore," Southey, 108.

“'Logic,"' Mill, 102.

Longfellow, Henry Wadsworth, 38, $39,40,150,189$.

Longinus, 148.

Long words, impressiveness of, 87 .

"'Look into the Gulf, A,'" Markham, 188.

"Lord Ullan's Daughter," 217.

Love, cause of delights of, 3.

Love, hyperbolic egotism of, 194.

- of praise, 196.

"Love, Silence of," Holmes, 49.

Iowell, 36.

\section{M}

Macaulay, Lord, 107, 108, 177, 178, $211,217$.

Magazines, the Associated Sunday, 244. 
Magie, 43, 44.

- predication in poetry, 183, 258.

Maine, 98, 190.

"'Makers of Modern Poetry, The," Dawson, 71, 190, 255.

Malays, 201.

Mammon, 163.

“'Man, Evolution of,' Haeckel, 13.

Man, primitive, 13, 18, 19, 20.

- speech of, 18, 19, 20. "with the Hoe," Markham, 35, $39,227$. Millet, 227, 236.

Marengo, 240, 242.

Marc Antony, 43, 237, 238, 239, 246.

Markham, Edwin, 35, 36, 39, 48, 186, $188,227$.

Mark Twain (Samuel L. Clemens), $33,231,235$.

Marlowe, 36, 243.

Mars, 245.

Marseillaise, 9, 84.

Massachusetts, 98.

Maxim, Hudson, 197.

Exms. (exemplifications), 98, $99,100,104,105,163,164$, $199,203,206,209,213,215$, $216,217,218,219,221,222$, 224, 225, 227, 241, 244, 246.

Memory, 2, 111.

Mercury, 247.

"Merrimac, Duel betwoen the Monitor and the," Abbott, 99.

Messina, 248.

Metaphor, 24, 25, 26, 29, 30, 32, 169, $170,180$.

Meter, determination of, 149.

— iambic, 148.

- trochaic, 147.

Metonymy, 30.

Michael, 209.

Middle Ages, the, 46, 196.

Milky Way, the, 207.

Mill, John Stuart, 102, 189.

Millet, 227, 236.

Miller, Joaquin, 48.

"Milton," Fixm., Maxim, 209.

Milton, John, 85, 89, 162, 163, 164, $177,183,184,187,205,208,209$, 210, 211, 212, 213, 256.

Mind, focus of, 130.

- subconscious, 112, 141, 142.

Miscreant, 95.

Mississippi River, 200.
"'Modern Poetry, Makers of,' Daw. son, 71, 190, 255.

Modification of predicate, 151.

Moir, George, 72, 73.

Moloch, 163, 164.

"Monitor and the Merrimac, Duel between the," $\Lambda$ bbott, 99 .

Mont Pelée, 250.

Moore, Mrs. Bloomfield, 61.

“'More, Burial of Sir John,"' 216.

Morse, 247.

Moscow, 242.

Moses, 60, 218.

Mother Goose, 164.

Müller, Max, 13, 15, 24, 102, 180.

Multiplication-table, 33, 152.

Münsterberg, Hugo, 189.

Muses, xii.

Musie, 136.

"Origin and Function of," Spencer, 79, 124.

Mystery in poetry, 43, 44 .

\section{$\mathbf{N}$}

“Napoleon," Exm., Maxim, 99.

"At the Tomb of," Maxim, 241.

Ingersoll, 240.

Napoleon Bonaparte, 39, 60, 174, 208, 235, 236, 239, 240, 241, 242.

Narrative, 161.

Neptune, 246.

Nero, 202.

Nerve stimuli, 1.

Nervous organism, the, 2.

New England, 235.

Newton, Sir Isaac, 82, 231.

New York, 243.

Nineveb, 188.

Noise, 3.

Non-potential words, position of, 158 .

Norman, 103.

Norseman, 244.

November, 107.

Numerals, 96.

Old King Cole. 33.

Onomatopy, 21, 29.

Ophiucus, 211, 212.

Oral sounds, 21.

Oratory, origin of, 230 .

— philosophy of, $230 \cdot 250$. 
"Orchestra, The Village," Exm., Maxim, 221.

Organs, action of vocal, 125.

"Origin and Function of Music, The," Spencer, 124.

- of music, 79.

- oratory, 230.

- poetry, 230.

— verse, $27,230$.

Pacific, 65.

Pain, cause of, 3.

Pan, 247.

Paradise, 209.

"Paradise Lost,"' Milton, 88, 162 , 163, 184, 197, 205, 210, 211, 212.

- Paraphrase of, Exm., Maxim, 164, 213. translated into French, 89.

Parallelisms, 27.

- verse, 218.

Paris, 226, 240, 241.

"Peace, To Arms for," Exm., Maxim, 244.

Peace Conference, International, 243. Peculiarities of utterance, 126.

Pekin, 106.

Pelée, Mont, 250.

Pentameter, iambic, 161.

Pentametric line, elimination of, 162.

Perception, energizing of, 79.

Personification, 30.

Petrie, Professor, 218.

Pfliuger, 142.

Pheidippides, 160.

Philosophy of English verse, the, 133.

- humor, the, 230-234.

- "Literature, The," Poe, 191.

__ "Style," Spencer, 32, 46, 72, $75,79,118$.

sublimity, 205.

——wit, 230-234.

Phocaea, 148.

Pierian spring, 48.

Pincott, Frederick, 13, 15.

Pitch, 4, 5, 136.

Place of qualifiers, 157.

Plantsville, Connecticut, 169.

Pleasure, the cause of, 3 .

Pleiades, 103.

Poe, Edgar Allan, 33, 36, 51, 72, 110, 150, 159, 183, 187, 191, 192, 220.
Poetic feet, 137.

Poetic figure, primitive appeal of, 234.

Poetic Lines, Great, 252, et seq.

Poetic principle indefinable, 190.

- spirit not reducible to terms, 191.

Poetry, 26.

- act of visualization, 41 .

- assaying of, 252-259.

— basis of, 35 .

- characteristics of great, 257.

decline of, 167,168 .

defined, 37.

definition of, by author, 67, 74 .

Bacon, 71.

Campbell, 70.

Carlyle, 70.

Coleridge, 70.

Dawson, 71, 190.

Emerson, 70.

Hamerton, 71.

Holmes, E., 51.

- Holmes, O. W., 70.

Hunt, 58.

Johnson, 72.

Keats, 70.

Lamartine, 71.

Moir, 73.

Poe, 72.

-Reynolds, 71.

Shakespeare, 64.

Shelley, 70.

Standard Dictionary, 56.

Stedman, 56.

Trumbull, 70.

Van Noppen, 71.

Watts-Dunton, 57, 69.

Wordsworth, 70.

difference between verse and, 38.

economy of word-symbols in, 36 .

foundation of, 44.

- human import in, 200.

- impediment in, 208.

— indefinable principle of, 191.

— intellectual enjoyment of, 74 .

- making of, the, 41.

- meter not required in, 57.

- most imaginative form of expression, the, 42.

- mystery in, 43, 44.

— not haphazard art, 41.

- origin of, 230. 
Poetry, Poe's interpretation of, 51.

- principle in, the, 51 .

- science of, the, 44 .

- slump in, the, 97.

- spirit of, not reducible to terms, 191.

- suggestiveness in, 186-189.

— tropetry, 169.

- universal property in, $3 \pi$.

- verbal expression in, 181.

what is, 49.

what is not, 45 .

"Poetry, Makers of Modern, The," Dawson, 71, 190, 255.

Pope, 67, 90, 109, 196.

Position of non-potential words, 158.

Potential syllables, 151.

Potentry, 75, 83, 84 .

- definition of, 86, 93.

- specimens of pure, 98,99 .

Praise, love of, 196.

Predication, 181.

- magical, 183, 258.

Prepositions, position of, 158.

Primary rhythm, 149, 156.

Primeval vocabulary, 229.

Primitive appeal of poetic figure, 234.

Primitive man, 13, 18, 19, 20.

Principle of rhythm, basic, 137.

“'Principles, First,"' Spencer, 102.

- of composition and rhetoric, application of, 93.

Problem, xi.

Properties of sound, qualitative and quantitative, 22.

Proverbs iii, 28.

- iv, 28.

- v, 23.

-xvi, 28.

—xiii, 29.

$\longrightarrow$ xii, 29.

- xiv, 29.

Psalm cxiv, 27.

- xix, 103.

- xxiv, 104.

Psyche, 159.

"Psychology," James, 2, 77, 172.

_CHandbook of," Sully, 112. of suggestion, 169.

"Punch, brothers, punch," Twain, 33.

Pyramids, 241, 247.

- battle of, 39.
Q

Qualifiers, place of, $15 \%$.

Qualitative properties of sound, 22.

Quantitative properties of sound, 22.

\section{$\mathbf{R}$}

Rabbit, 130.

“'Raven, The,' Poe, 33, 150, 191.

Reason, growth of, 22, 171.

Reflective language, 81 .

Registers of the voice, 6 .

Regulus, 237.

"Regulus to the Carthaginians," 237.

"Relief Committee, Address at Ben. efit Given by the American. Italian,"' Exm., Maxim, 250.

Repetition, 26.

"Reply to Hayne, Webster's,", 98, 106.

Revolution, the French, 40, 227.

Reynolds, F., 71 .

Rhetorie, application of fundamental principles of, 93. "'Treatise on," Blair, 45, 166.

"'Rhine, Bingen on the," 216.

Rhythm, 27, 126-147. basic principle of, 137 .

chief element in verse, 146, 147. of actions, 127. ideas, 139. sound, 132.

- supreme effort, 144.

- vocal apparatus, 144. primary, 149, 156.

Rime, 158. of Ideas, 27.

Rivalry of senses, 131 .

Rome, 202, 233, 237, 239.

__Lays of Ancient," Macaulay, 107, 108, 217.

Paraphrase of, Exm., Maxim, 217.

"'The Sacking of," 98.

Roosevelt, 249.

Rossetti, 187.

"'Ruins of Empires," Volney, 107.

Run-on lines in verse, 121.

Ruskin, 40, 100.

Russia, 240.

"Russia, Colossal," Exm., Maxim, 105. 


\section{s}

" Sacking of Rome, The," 98.

St. Helena, 240, 242.

San Francisco, 201, 202, 250.

—_Fallen,", Exm., Maxim, 203.

Santiago, 256.

Sarcasm, 230-234.

Satan, 207, 209, 210, 212, 213.

_'Flight of,' Exm., Maxim, 206.

"Satan's Encounter with Death," Milton, 210, 212.

- Paraphrase of, Exm., Maxim, 213.

Saxon, 103, 118.

Science, 171.

—_of English Verse," Lanier, 116, 133.

“'Language,"' Müller, 13, 102. poetry, 44.

"Scientific Study of English Poetry, Introduction to the," Liddell, 62.

Seeking appreciation, 194.

Seine, 240.

Sensations, 1, 2.

Sense-impressions, 112.

Sense-metaphors, 169.

Senses, the, 1.

— faculties of, 1 .

- rivalry of, 131.

September, 107.

"'Shadows of Dawn," Exm., Maxim, 218.

_ "The Dance of," Exm., Maxim, 216.

Shakespeare, William, 35, 36, 42, 43, $63,64,66,67,72,172,173,174$, $175,178,179,185,189,197,198$, 199, 209, 211, 235, 238, 239.

Shelley, 70, 151.

"Shore Batteries, Engagement between Fleet and,' Exm., Maxim, 98.

Sicily, 248.

Sidis, Doctor Boris, 169.

Sidney, Sir Philip, 26.

"Silence of Love," Holmes, 49.

Silly, 95 .

Simile, 30.

Sincere, 96.

Sirius, 206.

- speed of flight of, 206.

Slang, 234.

Slump in poetry, the, 97 .
Smokeless gunpowder, 196.

"Soliloquy, Hamlet's", Paraphrase of, Exm., Maxim, 199.

- Shak espeare, 197, 198.

Sophistry, 45.

“'Sordello,"' Browning, 189, 190.

Sounds, consonant, 153, 154.

- duration of, 4, 5, 6 .

- elementary English, 114.

- of the letter A, 116. oral, 21.

- properties of, 4, 5, 6 .

— qualitative properties of, 22 .

- quantitative properties of, 22. symbolism of, 21 .

- vowel, 153, 154.

Sour, 124.

Southey, 109.

Space, 206.

Sparta, 99, 238.

"Spartacus to the Gladiators, Speech of,' ' Kellogg, 99, 237.

Speech, analogical, 13.

- articulate, 14, 15.

- definition of, 113.

- dynamics of, 83, 111.

- figure in, 29.

— of animals, 14-18.

man, 19, 20.

"Speech before the Aldine Association, Extracts from a," Exm., Maxim, 246.

"of Spartacus to the Gladiators," Kellogg, 99.

Speed of flight of Sirius, 206.

Spencer, Herbert, 8, 27, 32, 45, 46, $47,66,72,73,75,78,79,82,84$, $85,87,88,101,102,117,119,122$, $124,125,128,129,130,173,174$, $185,189,205,253,254$.

Spirit, humbling the, 196.

Spondee, 150.

"'Spring, Banquet to," Exm., Maxim, 100.

Stand under, 95.

Standard Dictionary, 54, 56.

Stead, William T., 244.

Stedman, Edmund Clarence, 56, 191.

Stimulation of emotions, 80 .

Stimuli, 1.

- emotional, 3.

- nerve-, $1,3$.

Stimulus, 2.

— of emotional literature, 223. 


\section{INDEX}

Straits of Sunda, 200.

Strength of Saxon English, 118.

Stress, 4.

Style, direct, 122, 123.

- "Philosophy of,'" Spencer, 32, $46,72,75,79$.

Subconscious mind, the, 112, 141, 142.

Sublimity, philosophy of, 205.

- in oratory, $236,237$.

Subject, the, 181, 182.

Suggestion, psychology of, 169 .

Suggestive language, 81 .

Suggestiveness in poetry, 186-189.

Sullivan, John L., 197.

Sully, 112.

Sunda, Straits of, 200.

Supreme effort, rhythm of, 144, 145.

Sweet, 95, 113, 183.

Syllables, potential, 151.

Symbolism, 21, 25, 32, 80.

- of sounds, 21.

Synecdoche, 30.

$\mathbf{T}$

Tabula rasa of Locke, 2 .

Taste in verse, change of, 164, 165.

Tem-potentry, 92.

- definition of, 93, 133.

Tennyson, Lord, 109, 182.

Tenseness, 10.

Terminal words, 158, 159.

Teutons, 249.

Texas, University of, 62.

"The Dance of Shadows," Exm., Maxim, 216.

"The Flight of Satan," Exm., Maxim, 206.

Thermopylae, 238.

"The Village Orchestra," Exm., Maxim, 221.

"Things, In the Deep of," Exm., Maxim, 224.

Thought, expression of, $77 \cdot 91$.

- impression of, 77.91 .

- rhythm, 139.

Thracians, 99.

Timbre, 4, 6, 8.

- accent, 154.

- blends, 128.

Time, 137.

- in verse, 27.

"To Arms for Peace," Exm., Maxim, 244.
"Tomb of Napoleon, At the," Exm., Maxim, 241.

Tomb of Napoleon, 240.

Tone-color, 4, 6, 8 . accent, 154. -blends, 128.

Toulon, 240.

Tragic endings, 180.

"'Treatise on Rhetoric,' Blair, 45.

Trochaic inversions, 148. meter, 147.

Trochee, 149.

Trope, 24, 25, 26, 29.

- divisions of, 30,32 .

Tropetry, 92, 169.

- definition of, 94 .

- specimens of true, $99,100$.

Tro-potentry, 92.

— applied, 228.

- definition of, 96.

- specimens of, 102.

Tro-tem-potentry, 92.

— applied, 194.

- author's examples, 198. definition of, 96 .

Troy, Helen of, 36 .

Trumbull, J. R., 70.

Truth, 113.

Tune, 138.

Twain, Mark (Samuel L. Clemens), 33, 231, 235.

Tyndall, 45, 82.

U

“"Ulalume," Poe, 159.

“'Ullan's Daughter, Lord,” 217.

Ulm, 240.

Unbeliever, 95.

Unconscious contradictory emotions, 195.

Understand, 95.

Union, 106. ..

Universal property in true poetry, 37.

University of Edinburgh, 73. Texas, 62.

Use of brain-cells, 140, 141.

Usertesen III, 218.

Utterance and the emotions, 128.

- peculiarities of, 126.

Van Noppen, 71.

"Veiled Illusion," Fixm., Maxim, 215. 


\section{THE SCIENCE OF POETRY}

Venus, 247.

Verbal predication, 181, 182, 257, 258.

Verse, a phenomenon of sound, 133.

- basic principle of, 27. change of taste in, 164, 165.

- chief element in, 146, 147.

- decline of, 166,167 .

- definitions of, 133.

- difference between poetry and, 38.

end-stop lines in, 121.

functions of, 133 .

impediment in, 208.

origin of, $27,230$.

-parallelism, 218.

- Philosophy of English, 133.

" Science of English," Lanier, 116, 133, 135.

Vibration, 7 .

Viking, 244.

"Village Orchestra," Exm., Maxim, 221.

Visuals, 208.

Vocabulary, primeval, 229.

Vocal apparatus, rhythm of, 144.

- organs, action of, 125.

Voice, registers of, 6 .

Volney, 107.

Voltaire, 39, 47, 54.

Vowel sounds, 154. w

"War," Exm., Maxim, 104. "Coming," Exm., Maxim, 105.

Washington, George, 245, 247.

Waterloo, 240, 242.

Watts-Dunton, Theodore, 57, 69, 70, 72.

Wax, without, 96.

“Webster's Reply to Hayne,", 98, 106.

Weir, 187.

Whining of dog, 10.

Whitman, Walt, 252, 255, 256, 257.

Wit, philosophy of, 230-234.

Words, familiar, 185.

- impressiveness of long, 87.

- in new sense, 185.

- position of non-potential, 158. rare, 186.

terminal, 158, 159.

Wordsworth, 36.

Word-symbols, emotional, 80. poetic economy of, 36 .

\section{$\mathbf{Y}$}

Yaanek, 159.

Yankee, 232.

Young, 196.

"'Young Lochinvar," 217. 




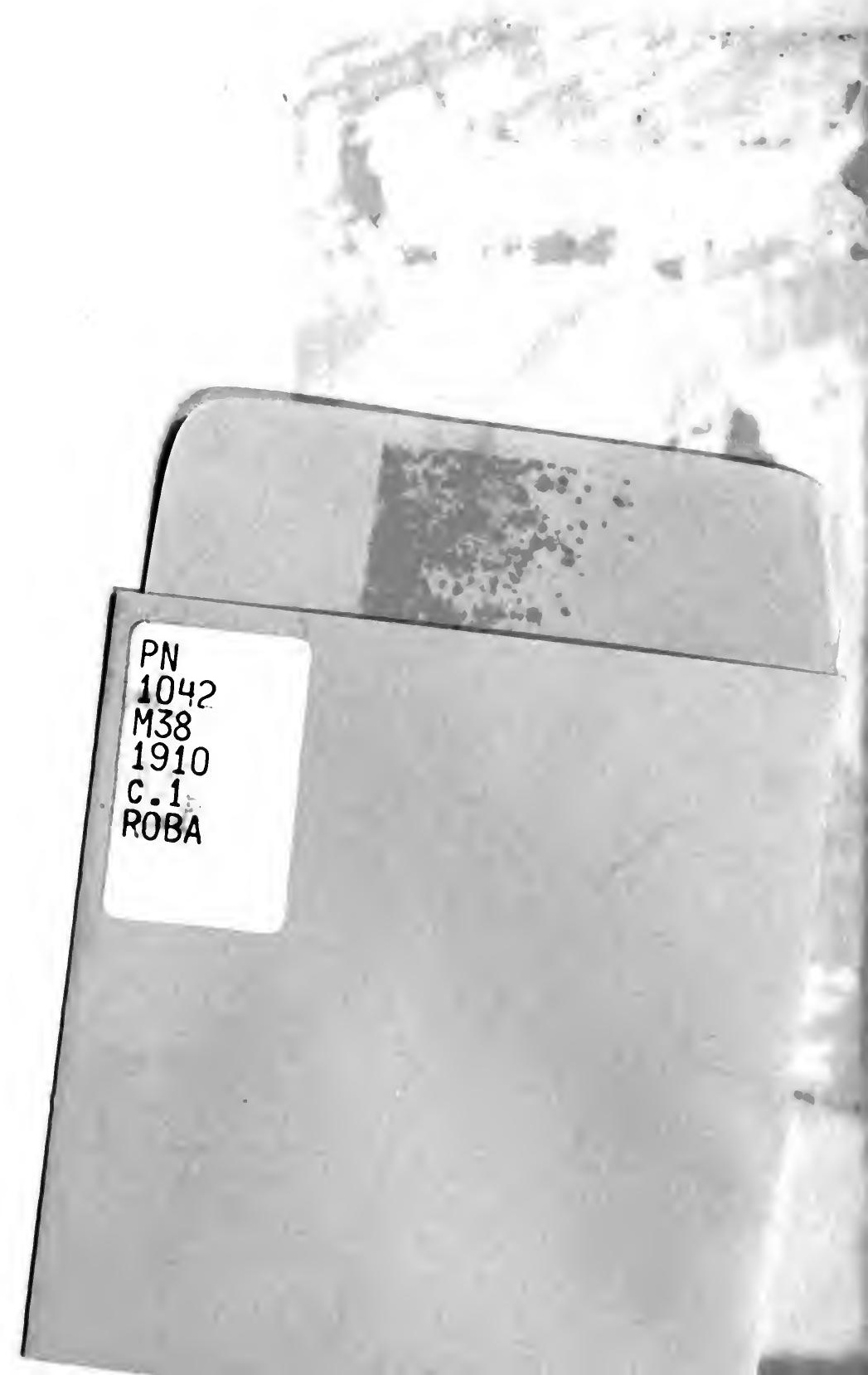


